\title{
Energy Management Strategy of PV Grid-Connected Household Nano-Grid System
}

by

Yiyuan Ding, B.ASc.

A thesis submitted to the Faculty of Graduate and Postdoctoral Affairs in partial fulfillment of the requirements for the degree of

Master of Applied Science

in

Electrical and Computer Engineering

Ottawa-Carleton Institute for Electrical and Computer Engineering Department of Electronics

Carleton University

Ottawa, Ontario, Canada

May, 2018

(C) 2018, Yiyuan Ding 


\begin{abstract}
This thesis investigates the long-term optimal scheduling algorithm proposed for the energy storage system, to better organize charging/discharging action of battery for the economic operation in a PV grid-connected household nano-grid system. To fulfill this goal, the household nano-grid is modeled, including PV module, energy storage system, $\mathrm{DC} / \mathrm{AC}$ inverter and their corresponding controllers. Battery is used to execute the optimal power command scheduled by long-term optimal scheduling algorithm. The optimal power scheduling algorithm is based on the rolling optimization method, which can realize the minimum operational cost of the PV nano-grid system. Moreover, a smoothing function is introduced to alleviate the power fluctuation of the exchanging power between PV nanogrid system and the main power grid caused by PV and residential loads. The validity of the proposed energy management strategy in upper Energy Management System (EMS) has been examined using simulations in MATLAB/Simpower.
\end{abstract}




\section{Acknowledgements}

I would first like to express my sincere gratitude to my Professor Xiaoyu Wang for his suggestion, instruction and guidance of my Master study and research. His invaluable guidance, constant encouragement inspires me a lot when I was troubled with difficulties. Without his continuous support and care, it would have not been possible to complete this thesis.

I would also show my warm thank to the colleagues in my research group: Zhijun Wang, Shichao Liu, Anda Zhang, Jian Xiong, Dawei Zhu, Yanwei Wang and Mingchao Zhao. I am very appreciated for their timely motivation and unfailing help during my study and research.

I would like to thank Anna Lee, Blazenka Power, Sylvie Beekmans, Scott Bruce, and Stephen MacLaurin from the Department of Electronics for their help during my research.

Finally, I would like to thank my parents for their unselfish support and love. They not only assisted me finically but also supported me spiritually. 


\section{Table of Contents}

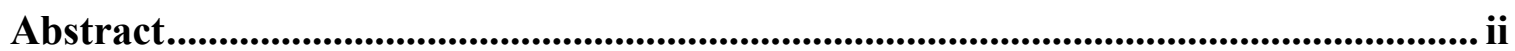

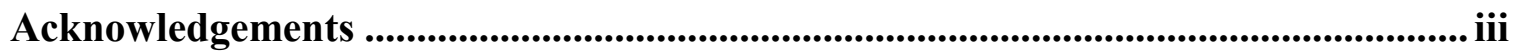

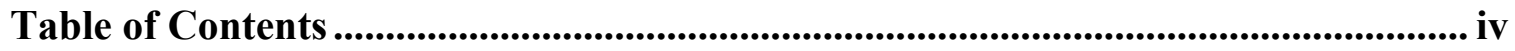

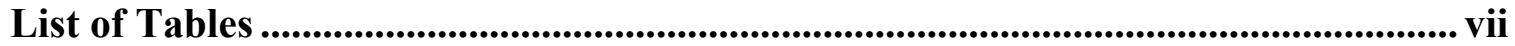

List of Illustrations.......................................................................................... viii

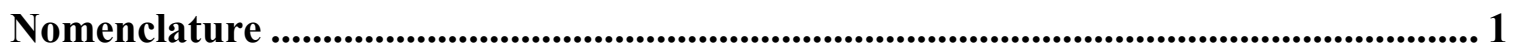

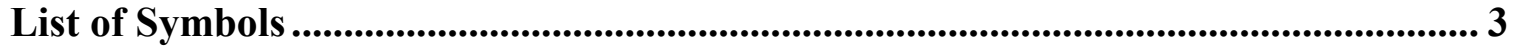

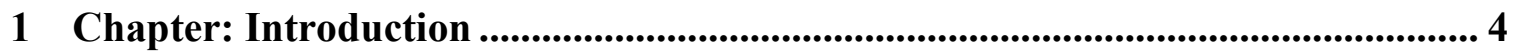

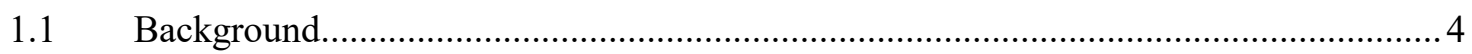

1.2 Literature Review of Grid-Connected Household Nano-Grid Management ..................5

1.2.1 Development of Grid-Connected Household Nano-Grid System ............................. 5

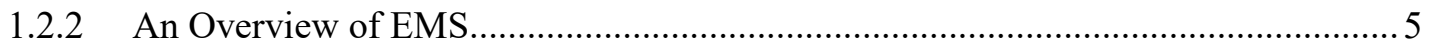

1.3 PV Grid-Connected Household Nano-Grid System .................................................. 7

1.3.1 Characteristic of Grid-Connected Household Nano-Grid System ............................ 7

1.3.2 The Structure and EMS of PV Grid-Connected Household Nano-Grid System........ 8

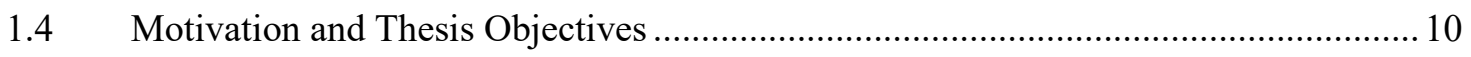

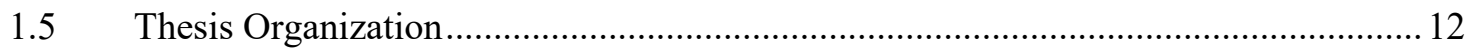

\section{Chapter: Literature Review of EMS in Grid-Connected Household Nano-Grid}

System ............................................................................................................................................ 14

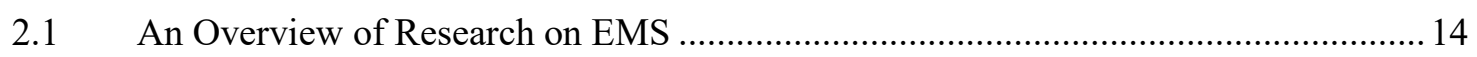

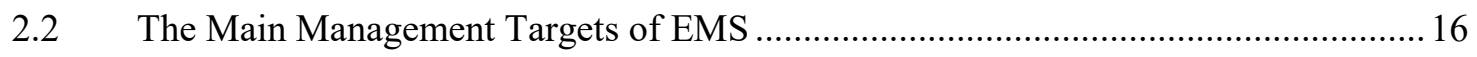

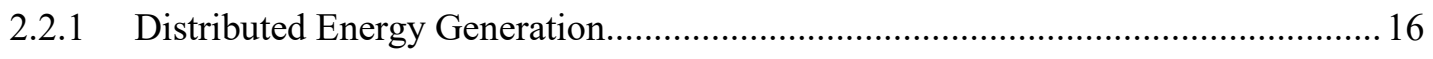

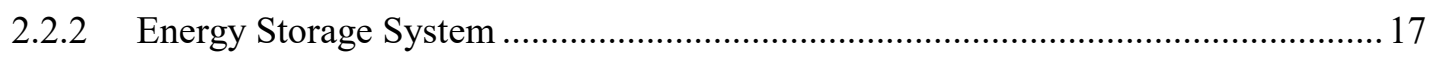




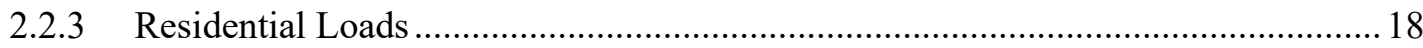

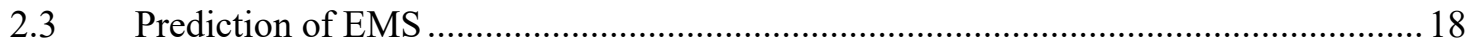

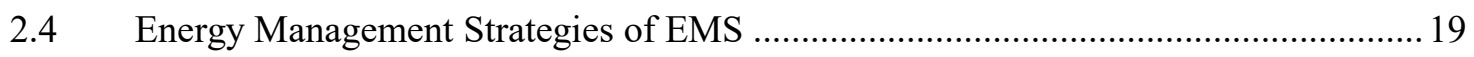

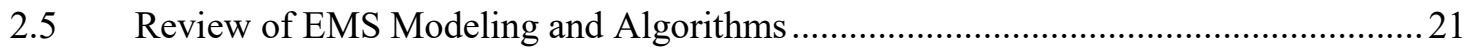

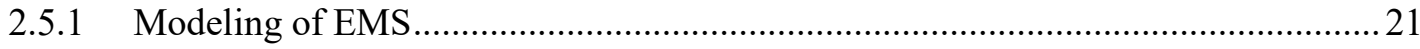

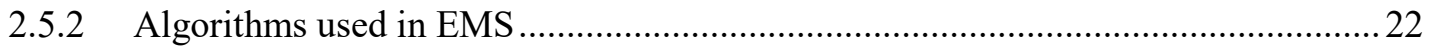

2.6 Challenges of Grid-Connected Household Nano-Grid System ..................................24

\section{Chapter: Model and Analysis of PV Grid-Connected Household Nano-Grid}

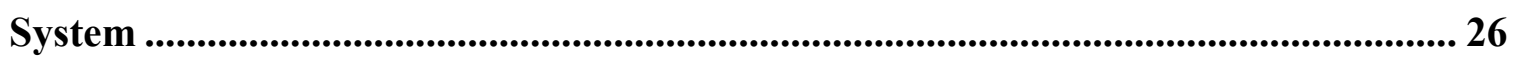

3.1 Structure of the PV Grid-Connected Household Nano-Grid System ..........................26

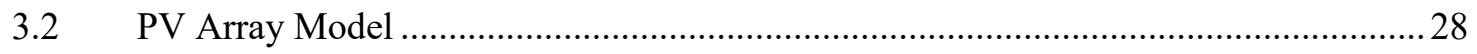

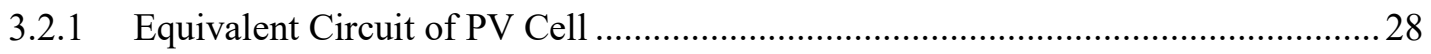

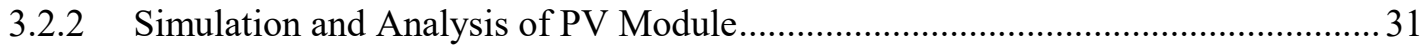

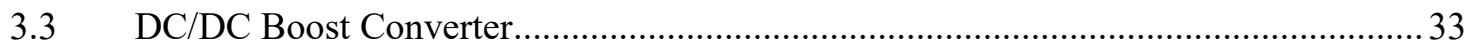

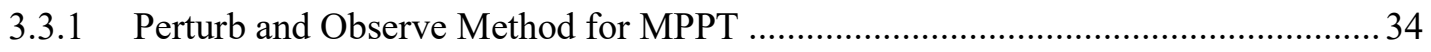

3.3.2 Simulation of MPPT Technique Applied in PV System ...........................................36

3.4 Energy Storage System and Related Control Strategies .......................................... 39

3.4.1 Characteristic of Bi-directional DC/DC Converters of Energy Storage System...... 40

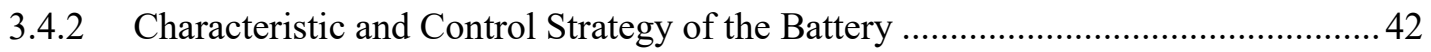

3.4.3 Characteristic and Control Strategy of the Supercapacitor .................................... 47

3.4.4 Control Strategy for Hybrid Energy Storage System .......................................... 48

3.5 Single Phase Full-Bridge DC/AC Inverter and its Control Strategy .......................... 49

3.5.1 Topology of Single Phase Full-Bridge DC/AC Inverter ........................................50

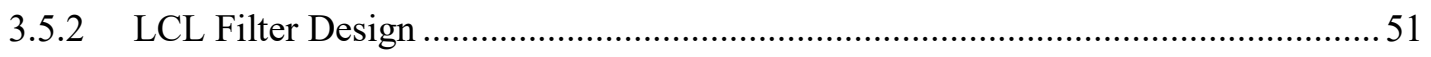

3.5.3 Control Strategy of Single Phase Full-Bridge DC/AC Inverter ...............................53

3.5.4 Simulation of Single Phase Full-Bridge DC/AC Inverter Control and Its Analysis 54 
3.7 Summary.

\section{Chapter: Energy Management Strategy of EMS in PV Grid-Connected}

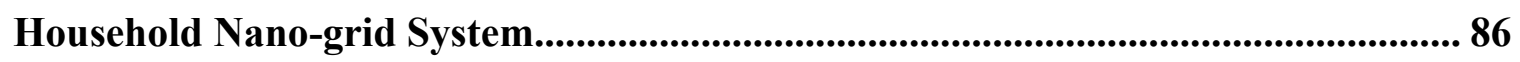

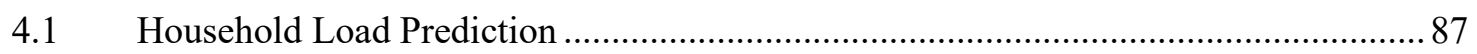

4.2 Long-Term Optimal Scheduling for Energy Storage System in PV Grid-Connected

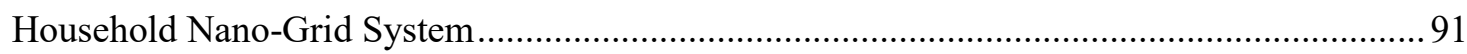

4.3 Smoothing the Power Fluctuation of the Main Grid Caused by PV and Loads ......... 101

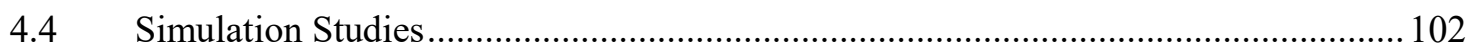

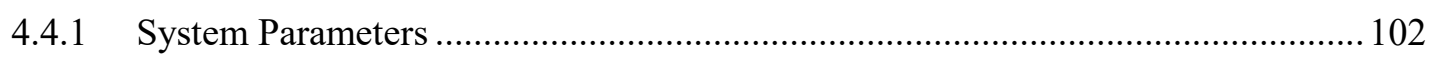

4.4.2 Comparison of Simulation Results by Using Load Historical Data and Load

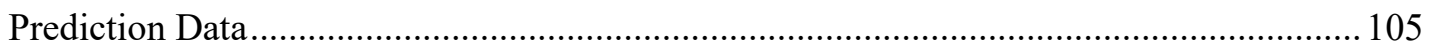

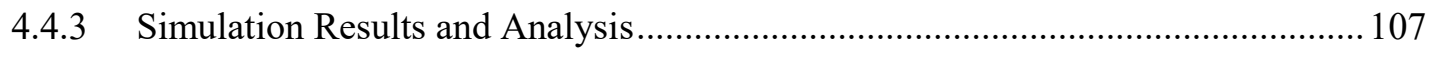

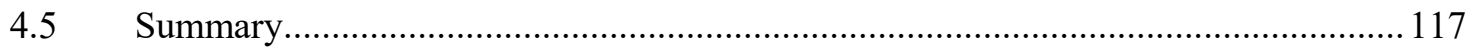

5 Chapter: Conclusions and Future Work ........................................................ 118

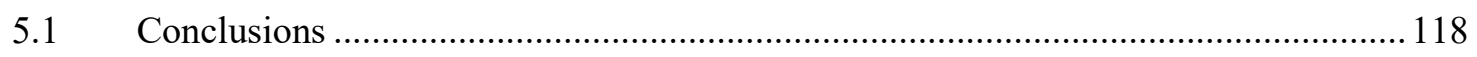

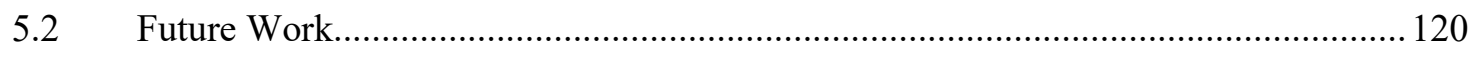

References.................................................................................................................................. 12 


\section{List of Tables}

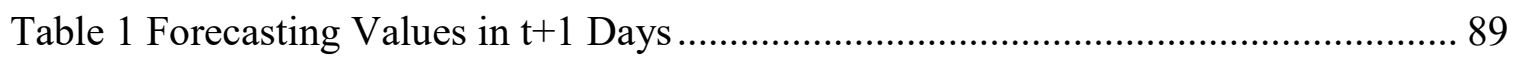

Table 2 PV Nano-Grid System Operation Parameters ........................................... 103

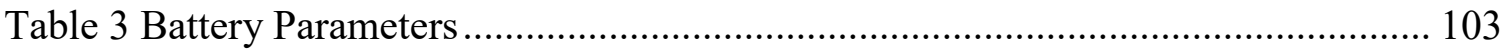

Table 4 ToU Electricity Pricing for Winter Period (November 1 to April 30) Weekdays

Table 5 Electricity Price of Selling Electricity to Main Power Grid ............................. 104 


\section{List of Illustrations}

Figure 1.1 Appliance Annual Energy Use (kWh) compared to data in 2009 RECS ......... 8

Figure 1.2 The structure of a nano-grid system .................................................. 9

Figure 2.1 Flow chart of double layer coordinated control ........................................ 20

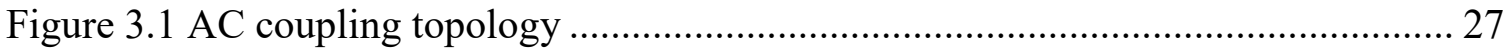

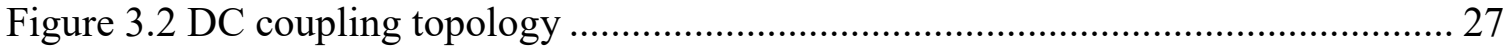

Figure 3.3 Overall structure of PV grid-connected household nano-grid system............ 28

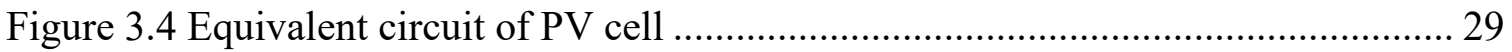

Figure $3.5 \mathrm{PV}$ characteristic curve with irradiance variation ..................................... 32

Figure 3.6 PV characteristic curve with temperature variation ................................... 32

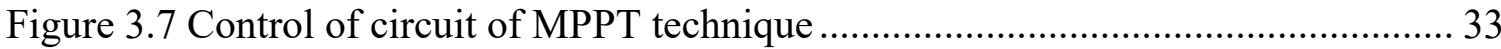

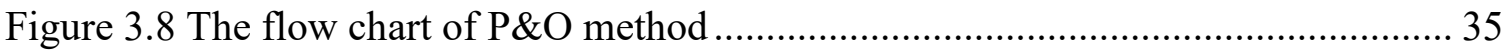

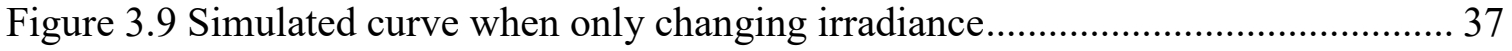

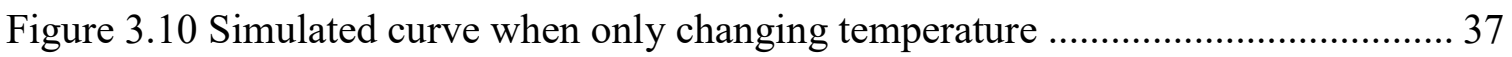

Figure 3.11 Simulated curve when changing irradiance and temperature ...................... 38

Figure 3.12 Basic structure of hybrid storage system.............................................. 40

Figure 3.13 Topology of energy storage system................................................ 41

Figure 3.14 Switch signal of $S_{3}, S_{4}$ and inductor $L_{2}$ current waveform under PWM

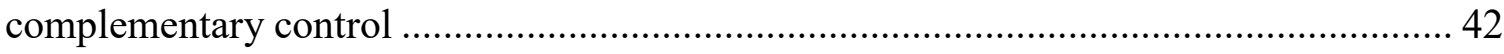

Figure 3.15 Flow chart of operation modes selection and limiting protection at different

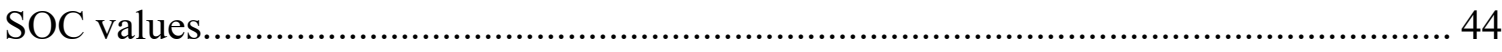

Figure 3.16 Control strategy of battery charging/discharging ................................... 46 


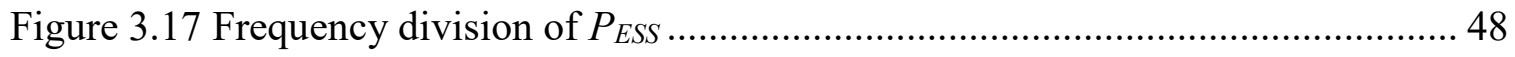

Figure 3.18 Topology of a single phase full-bridge inverter and LCL filter ................... 51

Figure 3.19 Control strategy of single phase full-bridge inverter for grid-connection..... 54

Figure 3.20 Main power grid voltage and grid connected current................................. 55

Figure 3.21 Main power grid voltage and grid-connected current(enlarged) ................... 56

Figure 3.22 Current going into main power grid ..................................................... 57

Figure 3.23 FFT Analysis of the current going into main power grid ............................. 57

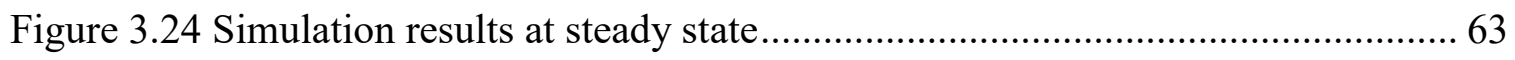

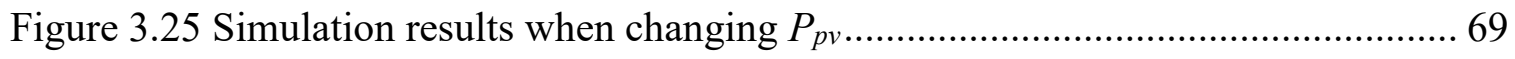

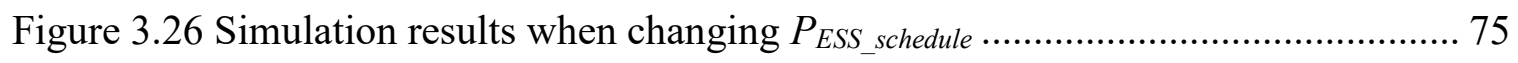

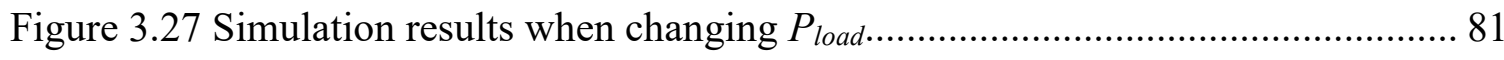

Figure 4.1 Schematic diagram of upper energy management strategy ………………..... 86

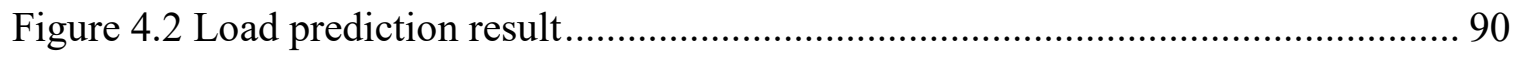

Figure 4.3 Rolling optimization method.................................................................... 92

Figure 4.4 Flow chart of long-term optimal scheduling utilizing rolling optimization in 24

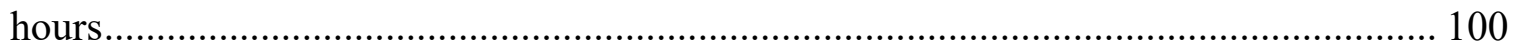

Figure 4.5 Smoothing power fluctuation of PV and loads.......................................... 102

Figure 4.6 Overall system structure .......................................................................... 103

Figure 4.7 Simulation comparison between using load prediction data and load historical

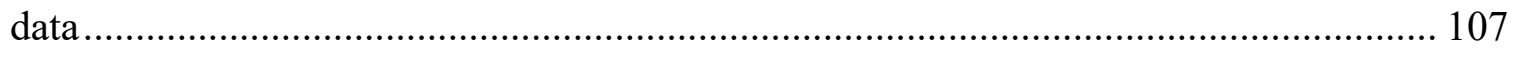

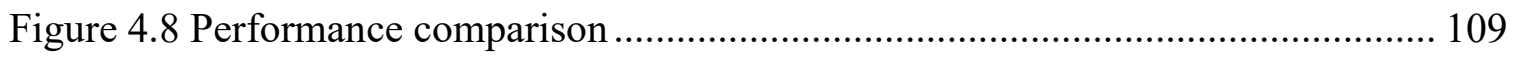

Figure 4.9 EMS simulation results of different seasons ............................................... 111

Figure 4.10 EMS simulation results of four typical weathers ...................................... 115 


\section{Nomenclature}

\begin{tabular}{ll} 
Nomenclature & Definition \\
PV & Photovoltaic \\
RECS & Residential Energy Consumption Survey \\
SOC & State of Charge \\
ToU & Time-of-Use \\
MPPT & Maximum Power Point Tracking \\
CERTS & Electric Reliability Technology Solution \\
PQMS & Power Quality Management System \\
TCP & Transmission Control Protocol \\
IP & Internet Protocol \\
NTUA & National Technical University of Athens \\
MAS & Multi-Agent System \\
GSM & Global System for Mobile \\
NEDO & New Energy and Industrial Technology Development Organization \\
PEV & Plug-in Electric Vehicle \\
PHEV & Plug-in Hybrid Electric Vehicle \\
V2G & Vehicle to Grid \\
NILM & Nonintrusive Load Monitoring \\
NSGA-II & Nondominated Sorting Genetic Algorithm-II \\
FOS-ELM & Fuzziness-based Online Sequential Extreme Learning Machine \\
PAR & Peak-to-Average Radio \\
\hline
\end{tabular}




$\begin{array}{ll}\text { FLC } & \text { Fuzzy Logic Control } \\ \text { MILP } & \text { Mixed Integer Linear Programming } \\ \text { DP } & \text { Dynamic Programming } \\ \text { GA } & \text { Genetic Algorithm } \\ \text { LO } & \text { Lyapunov Optimization } \\ \text { MPC } & \text { Model Predictive Control } \\ \text { NN } & \text { Neutral Network } \\ \text { MLPNN } & \text { Multilayer Perceptron Neural Network } \\ \text { P\&O } & \text { Perturb \& Observe } \\ \text { THD } & \text { Total Harmonic Distortion } \\ \text { PLL } & \text { Phase Locked Loop } \\ \text { FTT } & \text { Fast Fourier Transform } \\ \text { NREL } & \text { National Renewable Energy Laboratory } \\ \text { AI } & \text { Artificial Intelligence }\end{array}$




\section{List of Symbols}

$\begin{array}{ll}\text { Symbols } & \text { Definition } \\ P_{p v} & \text { PV module power output } \\ P_{l o a d} & \text { Power consumption of residential loads } \\ P_{E S S} & \text { Power sum of optimal power command and power fluctuation } \\ P_{E S S_{-} s c h e d u l e} & \text { Optimal power command scheduled from upper EMS } \\ P_{g r i d} & \text { Exchanging power between PV nano-grid and main power grid } \\ P_{E S S_{f} f l u c t u a t i o n} & \text { Power fluctuation caused by PV and loads in minutes level } \\ P_{e c} & \text { Battery charging power } \\ P_{e d} & \text { Battery discharging power } \\ P_{g i} & \text { Exchanging power from main power grid to PV nano-grid } \\ P_{g o} & \text { Exchanging power from PV nano-grid to main power grid } \\ S_{e} & \text { State of energy storage system } \\ S_{g} & \text { State of PV nano-grid system } \\ k_{c} & \text { Battery charging price per kWh } \\ k_{d} & \text { Battery discharging price per kWh } \\ k_{i} & \text { Buying electricity price per kWh from main power grid } \\ k_{o} & \text { Selling electricity price per kWh to main power grid } \\ \eta_{c} & \text { Battery charging efficiency } \\ \eta_{d} & \end{array}$




\section{Chapter: Introduction}

\subsection{Background}

In the past decade, there has been an increasing research effort of distributed generation energy conducted [1]. However, due to the stochastic and intermittent nature of distributed renewable resources, the high penetration of renewable generation energy has a negative influence on stability and reliability of power grids [2]. The concept of micro-grid, consisting of distributed renewable resources, distributed storage units and loads, has been proposed to enhance the stability and reliability of power grids and make conventional power grids suitable for distributed renewable generations. The similar concept can also be extended to residences and small building, which is termed as Nano-grids [3].

Depending on different voltage levels of distribution system and grid-connected manners, microgrids have three scale-levels: high-voltage distribution substation level, mediumvoltage feeder level, and low-voltage microgrids [4]. Nano-grids is a low voltage microgrid at household-user end. A household nano-grid system is comprised of renewable energy resources such as Photovoltaic (PV) and wind, an interface to a local utility grid, energy storage units, and customer loads [3]. Bi-directional power flow and real-time interactive information flow can be achieved by nano-grids, providing significant convenience for the balance between suppliers and customers [5]. As it is noticed, the intermittent nature of distributed renewable resources has an adverse impact on the reliable operation of nanogrid systems. Therefore, energy storage systems should be used to cooperate with distributed renewable generations, being able to store energy surplus and be discharged when energy deficit happens or electricity price is high offered by main power grid [6]. 
Energy Management System (EMS) can improve some concerns of customers such as power quality, comfort level and electricity consumption cost. With the application of energy storage systems, an EMS has been recognized as an efficient approach to realize power interacting with distributed renewable resources, energy storage systems and main grid. Without the EMS, it is difficult for nano-grids to operate harmoniously with main grid in a stable and reliable state.

\subsection{Literature Review of Grid-Connected Household Nano-Grid Management}

\subsubsection{Development of Grid-Connected Household Nano-Grid System}

A grid-connected household nano-grid system is becoming a key role to meet the high demand of energy consumption and reduce fossil fuel consumption. In South Australia, household grid-connected nano-grid systems based on solar PV have been deployed with a significant growth. There are $25 \%$ households which installed solar PV and there are about $65 \%$ people living in some suburbs using solar PV [7]. Solar PV counts for $11 \%$ (663MW) of the total capacity and $7 \%(857 \mathrm{GWh})$ of the annual generation [7]. In Bangladesh, the number of households using nano-grids based on solar home system has been growing at a dramatic rate in past few years [8]. Today, there are more than 50000 solar home systems installed every month [9]. And it is recognized as one of the most successful solar programs in the world [8].

\subsubsection{An Overview of EMS}

1) Consideration of Serval Factors before EMS Making Decisions

An EMS should consider serval factors before making decisions. Firstly, if the electricity 
price of main power grid changes, the demand for customer load should be reconsidered [10]. In addition, charging/discharging power of energy storage units should be modified as a way to reduce the cost of electricity consumption [11]. Furthermore, with the adequate distributed renewable resources, the utilization ratio of these renewable resources should be improved [12]. Moreover, due to the intermittency of distributed energy resources, it is necessary to alleviate the power fluctuation between household grid-connected nano-grids and distribution network.

\section{2) Data Prediction of EMS}

In the EMS, there are roughly three groups of data. The first group is data interacting between customer and grid-connected household nano-grids such as the demand for electricity and parameters of controllable loads [13]. The second data group is the information that is interactive between grid-connected household nano-grids and main power grid such as real-time electricity price. The third group of data is the power output of distributed renewable energy. The first and third group of data are difficult to predict. However, it is relatively easier to predict the data of power output of distributed renewable energy provided that the specific weather condition can be known.

\section{3) Time Resolution of EMS}

Time resolutions of EMS can be from day-ahead level to minute's level. For investors, it is crucial to utilize a technique with lower cost on the control system of grid-connected household nano-grids. This objective can be achieved by applying "plug and play" technique that is based on power electronic technology. For instance, an EMS is integrated 
as the algorithm module of the monitoring system in a grid-connected household nanogrids. Computer or embedded terminal systems are usually taken as the operating systems. Therefore, considering the restraints of the hardware, the complexity of EMS should be limited [14].

\subsection{PV Grid-Connected Household Nano-Grid System}

\subsubsection{Characteristic of Grid-Connected Household Nano-Grid System}

In a grid-connected household nano-grid system, how residential households use electrical appliances is of great importance for a comprehensive understanding on electrical energy consumption. Residential electrical appliances are loads which are relatively low power demand in comparison with loads in grid-connected buildings/industry microgrid system. Large appliances are responsible for approximately $30 \%$ of all electricity consumption in the US for residential households [15]. There are four large appliances most commonly used in the US including refrigerators, clothes washer, clothes dryers, and dishwasher [16]. Because of the high penetration of these four large appliances, the four large appliances have been considered as main customer loads when cooperating with grid-connected household nano-grid system. Figure 1.1 shows the annual energy use of four large appliances compared to data shown in the Residential Energy Consumption Survey (RECS) (2009) [17]. 


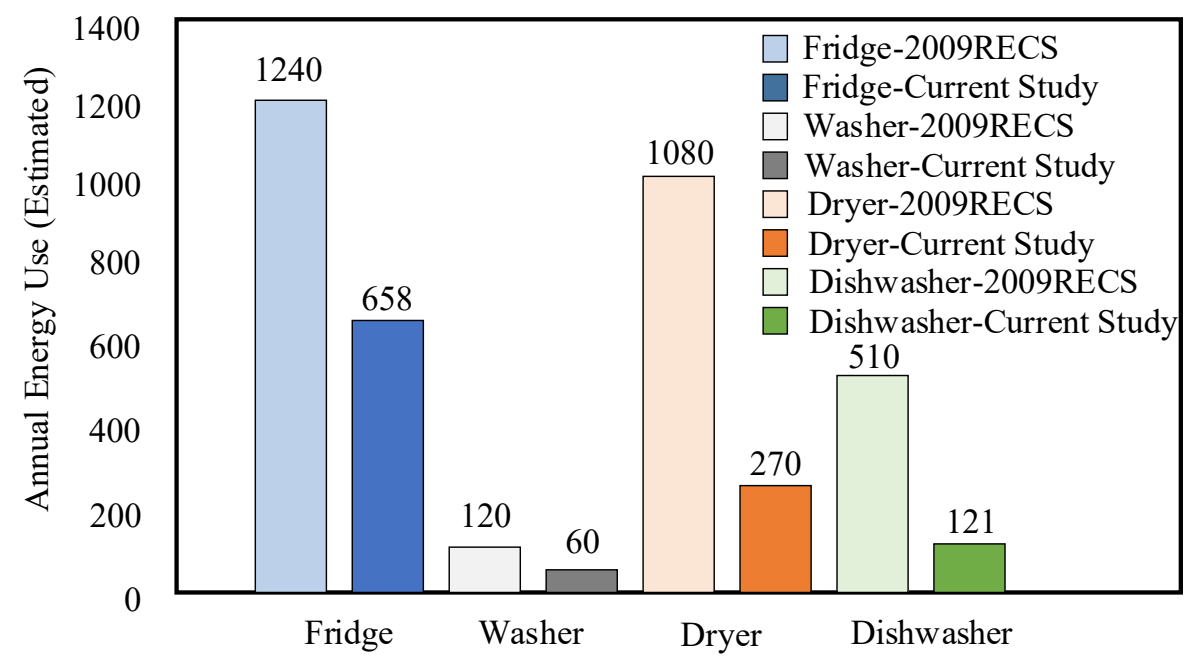

Figure 1.1 Appliance Annual Energy Use (kWh) compared to data in 2009 RECS

From Figure 1.1, it is found that the energy use of refrigerators and clothes dryers have been increasing dramatically, playing a dominated role in electrical energy consumption.

\subsubsection{The Structure and EMS of PV Grid-Connected Household Nano-Grid}

\section{System}

Nano-grid systems, which are basic building blocks of micro-grids, generally are smallscale grid-connected household systems. A PV grid-connected household nano-grid system consists of PV module, energy storage units, EMS and loads. A simple structure of PV grid-connected household nano-grid system is shown as Figure 1.2 [18]. 


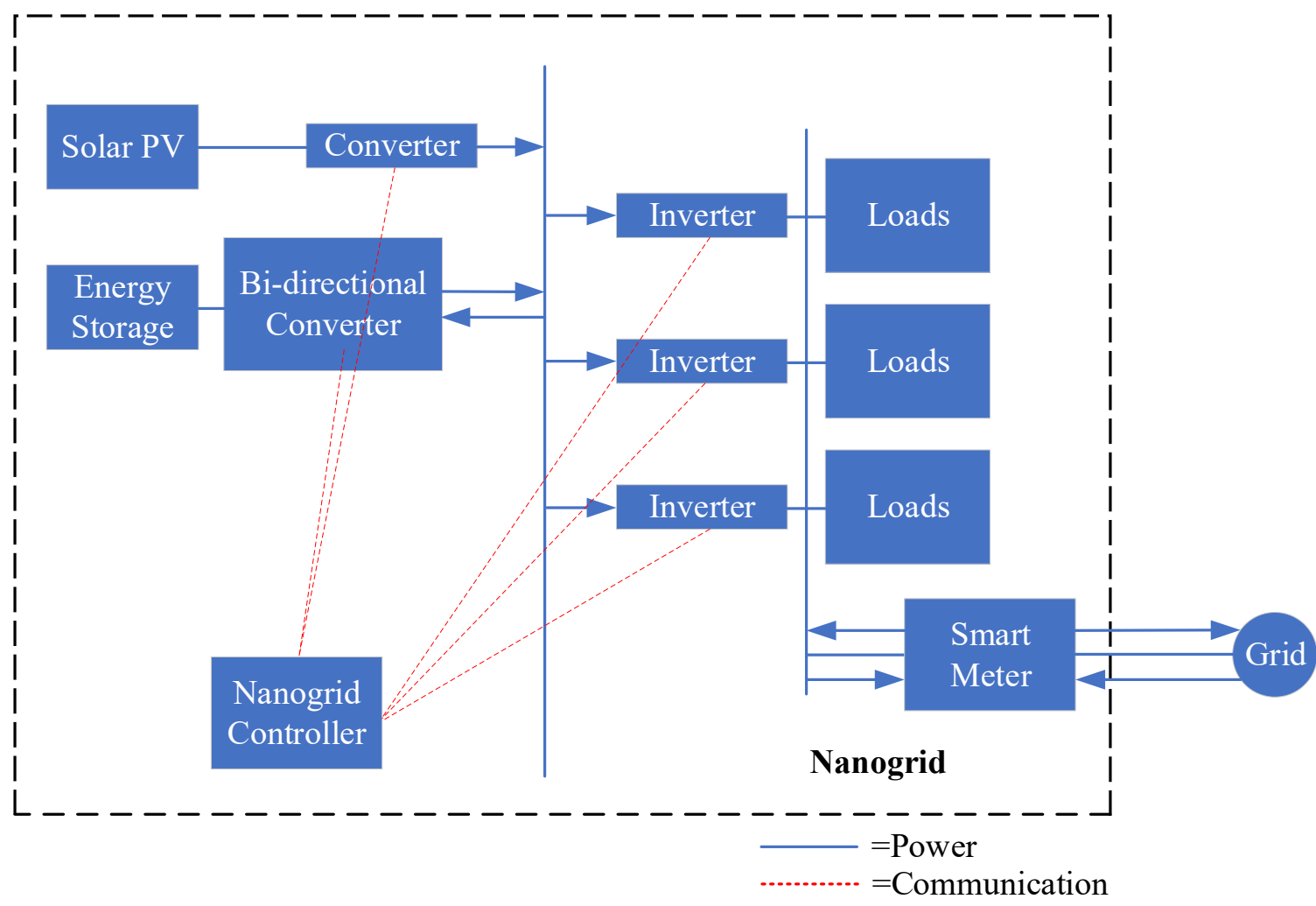

Figure 1.2 The structure of a nano-grid system

A PV grid-connected household nano-grid system has its small-scale generation and loads. $\mathrm{PV}$, which is inexpensive and environmental-friendly, is a logical solution to use distributed energy resources for residential nano-grid systems. However, due to its intermittent nature, energy storage units need to be in conjunction with PV generation to ensure the stable operation of power grids. Batteries are widely used for energy storage units due to its functionality and low price. The reason to use batteries as energy storage units is that batteries have the ability of relieving power fluctuation from PV generation. Batteries discharge power when PV generation cannot release enough power, while batteries can be charged when PV generation have power surplus. 
EMS can manage the power interacted with PV generation, energy storage units, residential loads and main power grid by monitoring the electricity-generating capacity of PV generation, the power consumption of residential load, main grid price and batteries' state of charge (SOC). EMS will store energy surplus that could be discharged upon energy deficit or high electricity price offered by main power grid [6]. On the other hand, if the demand of electricity cannot be satisfied or electricity price is low, EMS can buy electricity from main power grid. It can determine to buy electricity from main power grid or sell electricity to main power grid. Therefore, minimizing the operational cost of a PV gridconnected household nano-grid system is achieved and the comfort of living also needs to be satisfied by implementing EMS.

\subsection{Motivation and Thesis Objectives}

In this thesis, considering the stochastic nature of household electricity demand, the intermittency of PV generation and real-time electricity price, the EMS of a PV gridconnected household nano-grid system is proposed to achieve the minimum operational cost. Energy management strategy of the EMS realizes the power coordination among PV module, residential loads, energy storage system and the main power grid. This thesis designs an optimal scheduling methodology for the energy storage system in the PV gridconnected household nano-grid system. Furthermore, a smoothing function is added into the optimal scheduling algorithm to relieve the fluctuation of the exchanging power between the household nano-grid system and main grid, caused by the intermittency of the PV power and residential loads. The specific goals of this research are listed below: 
1) The PV grid-connected household system has been modeled in MATLAB/Simpower, including PV module, PV DC/DC boost converter, single phase fullbridge DC/AC inverter, battery, supercapacitor and bi-directional DC/DC buck/boost converters in energy storage module, as well as their controllers.

2) An optimal scheduling scheme is designed for the energy storage system, based on the rolling optimization, considering multiple variables and constraints. By modeling battery SOC, PV power output, power consumption of residential loads, Time-of-Use (ToU) electricity price and multiple constraints, the minimum operational cost is chosen as the objective, to realize the optimal battery charging/discharging in the PV nano-grid system. Furthermore, with the utilization of the smoothing function, the fluctuation of the exchanging power between the household nano-grid system and main grid can be relieved.

3) The optimal scheduling scheme of the energy storage system and the smoothing function have been investigated through simulations of the PV grid-connected nano-grid, based on historical load data.

In this thesis, the novelty of the proposed energy management strategy, which is focusing on PV nano-grid system, not only designs a long-term optimal scheduling to achieve the minimum operational cost for customers to realize economic operation of PV nano-grid system but also a smoothing function to smooth fluctuation on the exchange of power between PV nano-grid and main power grid to ensure the reliable operation for the main power grid. 


\subsection{Thesis Organization}

The reminders of the thesis are organized as follows:

Chapter 2 provides a detailed literature review in terms of EMS of grid-connected household nano-grid systems.

Chapter 3 shows models and related control strategies of each unit in the PV grid-connected household nano-grid system. For PV generation, Maximum Power Point Tracking (MPPT) technique has been utilized. Then, for the energy storage system, the constant power control strategy is used. Furthermore, for single phase full-bridge DC/AC inverter, the constant voltage control is utilized, which realizes the grid-connection and voltage stability of DC bus bar. In MATLAB/Simpower, the PV grid-connected household nano-grid system is modeled and simulated. Simulation results at various operating conditions can prove the correctness of the listed control strategies.

Chapter 4 introduces the long-term optimal scheduling algorithm and a power fluctuation smoothing function for the power fluctuation in the PV grid-connected household nanogrid. Various simulations are conducted to prove the proposed methodology in MATLAB/Simpower. The simulation results show that the smoothing function can reduce the fluctuation of the exchanging power between the nano-grid and the main grid. In addition, typical day's data in four seasons are used to analyze the performance of the optimal scheduling algorithm. Based on the simulation studies, it is known that the smallest operational cost of the nano-grid is achieved in spring, while the largest operation cost is 
in winter. In the end, the nano-grid under four typical weather conditions in summer are investigated including sunny, cloud moving, sunny to cloudy, and rainy to cloudy. The results show that the smallest operation cost of the nano-grid is made in the sunny day, while the largest operational cost is made under a rainy to cloudy weather condition.

Chapter 5 concludes the thesis and points out the future work. 


\section{Chapter: Literature Review of EMS in Grid-Connected Household}

\section{Nano-Grid System}

EMS is implemented in grid-connected household nano-grid system to achieve the optimization of power scheduling and dispatch by ensuring the efficient operation of nanogrid systems. EMS has the functionality of optimizing power dispatch, real-time monitoring [19] [20]. In [21] [22], EMS contains two functions. The first function can guarantee the power quality of residential load as well as the power balance among distributed energy resources, energy storage systems, residential loads and main power grid. The second function can optimize the power dispatch of charging/discharging power of the energy storage system and exchange of power on the tie line as a way to minimize the operational costs and improve the energy utilization of distributed energy resources.

\subsection{An Overview of Research on EMS}

Smart grids have been emerging in recent twenty years [23]. Nano-grids have similar EMS with micro-grid, are smaller and technologically simper microgrid, typically serving a single building [24]. There are many famous experimental microgrids and microgrid testbeds built and equipped with relevant EMS all over the world in the past decade [25]. A few distinguished microgrid projects are summarized as follows.

In America, Consortium for Electric Reliability Technology Solution (CERTS) built a demonstration microgrid at a full-scale test bed built near Columbus, $\mathrm{OH}$ and it was operated by American Electric Power [26]. This test bed is comprised of battery, combustion gas turbine, controllable loads and some sensitive loads. CERTS Microgrid 
Laboratory Test Bed project shows the feasibility of integrating small energy sources into a microgrid, which includes the autonomous sources with plug-and-play functionality. The main technique of EMS in the CERTS microgrid is the method for realizing automatic and seamless transitions between grid-connected and islanded modes of operation. In addition, CERTS microgrid concept attains stable behaviors at critical operations points.

In Germany, Am Steinweg microgrid is controlled by an EMS called Power flow and Power Quality Management System (PQMS) [27]. PQMS, which consists of centralized process unit and couple controllable interface boxes, has the functionality of distribution network management, distributed energy generation and demand-side management. Data monitoring system can communicate with centralized processor unit utilizing Transmission Control Protocol/Internet Protocol (TCP/IP) through controllable interface boxes. Furthermore, the laboratory-scale microgrid system built by National Technical University of Athens (NTUA), is comprised of PV arrays, wind turbine, a battery energy storage and controllable loads [28]. MAS (Multi-Agent System) based on Java Agent Development Framework (Jade) 3.0 platform is deployed as EMS of this microgrid. Jade is a Java-based tool for developing MAS systems. Moreover, Bronsbergen resort microgrid project funded by European Union deploys centralized control method [29]. Power on every feeder in this microgrid is transmitted from the monitoring system to the central controller that can communicate with dispatching center by Global System for Mobile (GSM) Communications. The central controller is also responsible for the seamless transition between grid-connected and island modes. 
In Japan, Microgrid built by New Energy and Industrial Technology Development Organization (NEDO) in Hachinohe has been put into operation since October 2005 [30]. This microgrid is $6.6 \mathrm{kV}$ radial distribution network connecting three $170 \mathrm{~kW}$ gas engine, $1130 \mathrm{~kW}$ PV generation, $120 \mathrm{~kW}$ wind turbine and one $100 \mathrm{~kW}$ battery. Centralized control method is applied as EMS for this microgrid. With the deployment of fiber optical communication, central controller can achieve power dispatch for distributed energy generations and energy storage system.

With the review of EMS in different microgrid projects, an EMS generally includes generation-side management and demand-side management. Generation-side management focuses on distributed energy generation, energy storage system and distribution network while demand-side management emphasizes on hierarchical loads. In terms of the structure of EMS, America is inclined to utilize autonomous control. Centralized control has been more recognized in Japan. In Europe, centralized control and agent-based control are mainly used. However, centralized control is still the mainstream method for EMS now. Varieties of optimal algorithms are developed in top layer to schedule the power output of generation units so that controllers in bottom layer can receive the command sent from top layer to control power output of generation units.

\subsection{The Main Management Targets of EMS}

\subsubsection{Distributed Energy Generation}

Distributed energy generations can be classified as adjustable units and nonadjustable units [31]. Solar and wind, which are nonadjustable units, are mostly dependent on the 
environmental circumstance. Because of the nature of intermittency and fluctuation, their power output can be predicted but with some errors. However, fuel units such as diesel generators, fuel cells and micro turbines are adjustable units.

\subsubsection{Energy Storage System}

Energy storage systems, which mostly consists of batteries and supercapacitors, have been widely used in grid-connected household nano-grid systems. Batteries, which is utilized to alleviate power fluctuation of grid-connected household nano-grid system in steady state, has the characteristic of large capacity and energy density, while supercapacitors which can manage the power fluctuation of nano-grid system in transient state, take advantage of large power density and fast response. Energy storage system that is instructed by EMS has the ability to smooth out the power fluctuations of distributed energy generation and residential load to prevent the power fluctuation on the tie-line. The power output and operating method of energy storage system are obtained from the power command generated by the EMS of nano-grid system, determining energy storage system's charging/discharging mode. The utilization of energy storage system is capable of removing the intermittency of solar PV and has the potential to shave the peak loads [32]. However, to achieve the full benefits of energy storage system, an EMS, which is a forecasting and scheduling algorithm, should be utilized [33]. Thus, the EMS plays a significant role in smoothing the power fluctuation in grid-connected household nano-grid system and optimizing power dispatch of energy storage system. 


\subsubsection{Residential Loads}

Residential loads of grid-connected household nano-grid system can be categorized into essential loads and controllable loads. Essential loads are the loads that operates under steady and reliable power supply while controllable loads can be available for load shedding under emergency condition. Considering saving electricity consumption, optimal load usage could be realized by applying demand-side management at normal operating condition [34]. For example, in the condition of not affecting customer electricity utilization, electricity consumption can be saved by adjusting Heating Ventilation and Air Conditioning [35]. Therefore, demand-side management is a significant part of EMS in grid-connected household nano-grid system. However, some loads can be controllable. With the popularity of electric vehicles, the concept of Plug-in Electric Vehicle (PEV) and Plug-in Hybrid Electric Vehicle (PHEV) have been widely used in Micro-grid/Nano-grid systems [36]. PEV and PHEV can be charged from main power grid anytime. Also, with the realization of $\mathrm{V} 2 \mathrm{G}$ (Vehicle to Grid) technique, PEV and PHEV can be the power supply for main power grid. Therefore, PEV and PHEV have the capability of being controllable loads or power supply at the same time. Nevertheless, the complexity of EMS of grid-connected household nano-grid system will be undoubtedly rising up due to the involvement of PEVs and PHEVs.

\subsection{Prediction of EMS}

Prediction for related data is required to schedule the optimal power allocation of gridconnected household nano-grid system. The data that needs to be predicted is classified in three categories. The first category is the data that is interactive between nano-grid system 
and customers such as power demand of customers, parameters of controllable loads and comfort level of electricity usage [13] [37]. The second category is the data interacted between nano-grid system and main power grid such as real-time electricity price or ToU electricity price. The third category is the power output of distributed energy generation. For first and third categories, the prediction is not very accurate. The data of distribution energy generation can be predicted with a high accuracy with the utilization of a high precision weather forecast. However, it will lead to the increase of operational cost. In [38], a household EMS based on a Nonintrusive Load Monitoring (NILM) technique with an automated Nondominated Sorting Genetic Algorithm-II (NSGA-II) home power scheduling mechanism is proposed. Operation periods of different loads can be predicted based on an analysis of the NILM technique with historical data. With the utilization of NSGA-II, the scheduling usage of electrical appliance can be optimized day-ahead based on operation period of different loads to save electricity bills of customers. In [39], a PV power prediction based on the Fuzziness-based Online Sequential Extreme Learning Machine (FOS-ELM) algorithm is proposed, which is capable of replacing outdated data with new data constantly. Historical weather data and historical PV power data are utilized to predict the PV power in the next period of time in this PV prediction method. In [40], an EMS integrated with real-time electricity pricing model and genetic algorithm is proposed to effectively reduce electricity expense and Peak-to-Average Ratio (PAR).

\subsection{Energy Management Strategies of EMS}

The solutions of energy management strategy for grid-connected household nano-grids can be demonstrated as different approaches in order to realize the economic operation and 
power allocation of different modules in grid-connected household nano-grid system. Traditionally, it can be summarized as two different techniques: double layer coordinated control approach and three-layer coordinated control approach.

In [41], a double layer coordinated control approach is proposed, which can be divided into two layers including schedule layer and dispatch layer. The schedule layer shows an economic operation scheme by using forecasting data. Moreover, the dispatch layer takes power of controllable units into consideration based on real-time data. Therefore, both economic optimization and technical concerns are considered. The coordinated control of two layers can eliminate the errors between forecasting data and real time data. The flow chart of double layer coordination approach is illustrated in Figure 2.1 [41].

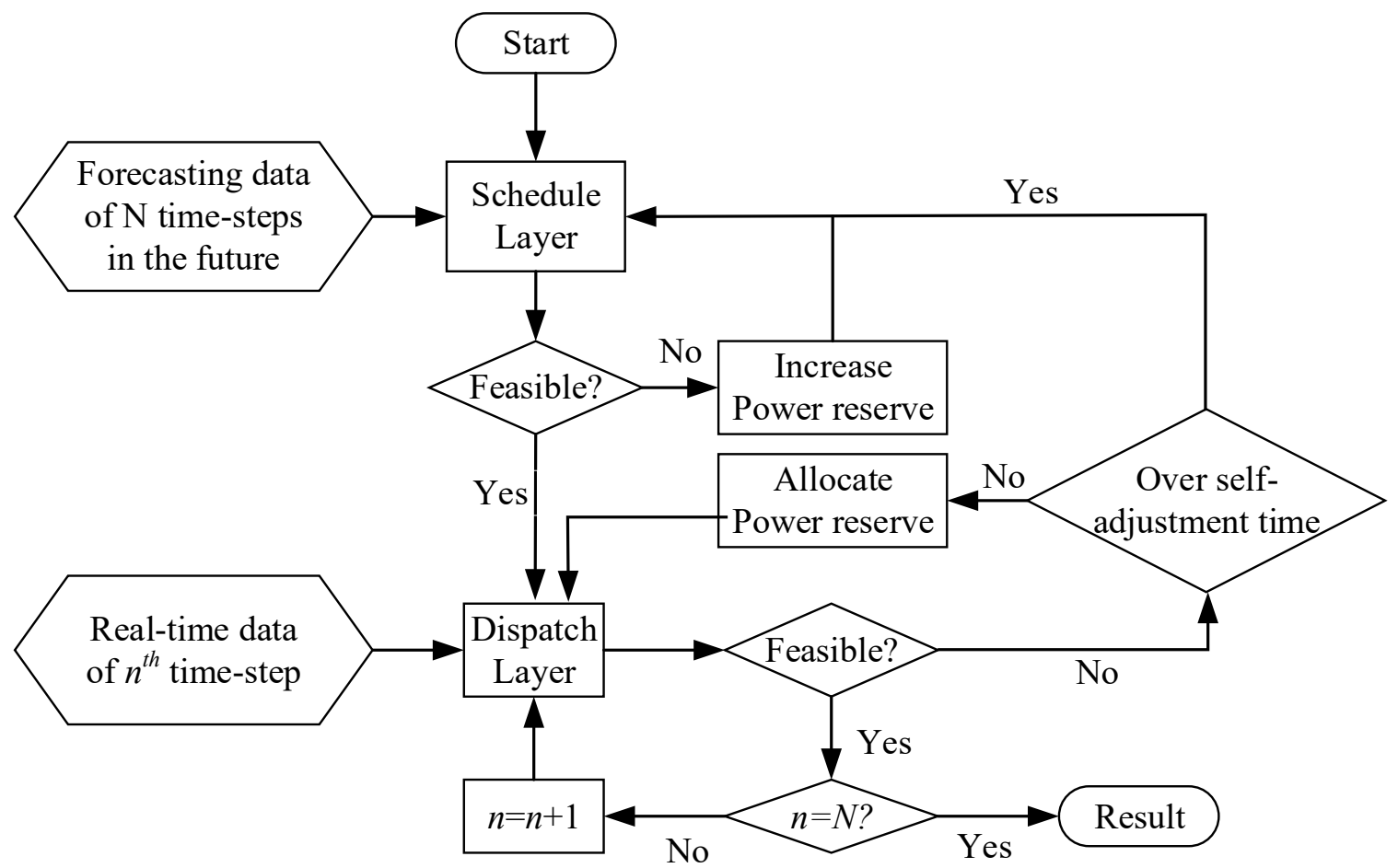

Figure 2.1 Flow chart of double layer coordinated control

In [42], a three-layer coordinated control approach is proposed. There are three different 
layers in this technique, including day-ahead layer, adjustment layer and real-time layer. The day-ahead layer based on look-ahead multi-step optimization technique can make available prediction of future operation conditions for controllable units. In the adjustment layer, by using updated wind/solar/load data at dispatch time, economic dispatch model could be determined at the dispatch time. In addition, the exchanging power between nanogrid and main power grid could be estimated. The real-time layer is used to keep the exchanging power between nano-grid and main power grid constant.

\subsection{Review of EMS Modeling and Algorithms}

\subsubsection{Modeling of EMS}

With the consideration of satisfying demand of residential loads and various constraints of EMS, the main objective of EMS in a grid-connected household nano-grid system is overall long-term cost minimization, which can be integrated with some other objectives such as minimizing peak demand, greenhouse gas emissions and possibility of power outage. When pricing schemes execute penalties for peak demand, minimizing peak demand is necessary [7]. In addition, minimizing fuel usage becomes significant if there are taxes on excessive gas emissions [7]. In [43], the balance of customer comfort level and minimizing operational cost are both taken as objectives, which leads to an EMS based on mixed integer non-linear programming with multi-objectives. Therefore, due to the existence of multiple objectives, the optimization function of EMS can be either single-objective or multi-objectives [44] [45]. 


\subsubsection{Algorithms used in EMS}

A multi-objective optimization can be converted to a single-objective optimization to realize optimal power scheduling using a weighting factor [46]. Follows are algorithms for single-objective optimization.

The widely used algorithms for solving model of EMS with single-objective optimization mainly are Fuzzy Logic Control (FLC), Mixed Integer Linear Programming (MILP), Dynamic Programming (DP), Genetic Algorithm (GA), Lyapunov Optimization (LO), Model Predictive Control (MPC), Neutral Network (NN) and some others. MILP technique has ability of transferring power optimization into mixed integer programming by changing nonlinear functions into linear functions in models. MILP takes integer variables into consideration of the optimization model. By introducing integer variables, MILP can be applied to optimize the minimum operational cost for large power generators including its stop-start cost in the power system. Furthermore, the minimum operation power output of power generators can be expressed, which benefits for the generators lifespan. Compared with MILP, FLC has a faster computational time but a relatively increasing cost [7]. In [47], DP can be implemented to solve the model of EMS when the electricity pricing is dynamic. In [48], GA, which is inspired by nature selection, is utilized to adjust and train Multilayer Perceptron Neural Network (MLPNN) controllers. LO also has been used in solving the model of EMS. One LO effectiveness is not requiring future values or statistic of the stochastic processes. The main functionality of $\mathrm{NN}$ is used to predict and control in EMS. NN is capable of learning complex models which are difficult to determine. In [44], $\mathrm{NN}$ is used to forecast solar generation, wind generation and load demand in a microgrid. 
However, the drawback of NN algorithm is that they need to be trained. In [49], modified MPC is used to coordinate the power allocation between charging/discharging power of energy storage system and the exchanging power on tie-line. MPC is basically a rolling process that solves the EMS optimization model repetitively with the updating forecasted data. It is recognized that MPC is a feasible method to a number of control problems with uncertainty [50].

Compared with modeling and algorithms of different energy management strategies listed before, the proposed energy management strategy in this thesis concentrates on PV nanogrid system which is serving for a single household user. Most of energy management strategies listed in literature review are serving for microgrids such as industrial parks or residential areas. Furthermore, the introduced smoothing function can smooth the power fluctuation on the exchange of power between PV nano-grid and main power grid to maintain the reliable operation of main power grid, which makes up the weakness of energy management strategies shown in literature review.

For the double layer energy management strategy proposed in [41], the energy management strategy including two layers, which is scheduling layer and dispatch layer, to achieve the economic operation of a microgrid system. Compared with the proposed energy management strategy in [41], the energy management strategy in this thesis reduces the complexity of the EMS by only considering one single scheduling layer. In this thesis, the energy management strategy is focusing on PV grid-connected household nano-grid system for a single household user instead of a microgrid system. Due to the small-scale 
of the PV nano-grid system, there is no need to divide into two layers like the proposed energy management strategy in [41]. The functionality of the dispatch layer is inner contained, which is dispatching the optimal power command by optimal battery charging/discharging to realize the minimum operational cost of PV nano-grid system.

The proposed energy management strategy in [44] and [48] utilizes the nonlinear optimization method such as GA or NN. However, in this thesis, the optimization model of the long-term optimal scheduling can be solved linearly by introducing integer variables, which realizes the linearization of the optimization model. Therefore, the more optimized and accurate optimization results can be achieved by using MILP which is considered in this thesis [51]. For the energy management strategy using FLC algorithm in [7], it is shown that FLC algorithm, while having a faster computational time, leads to more operational cost compared with using MILP algorithm. Therefore, more economic benefit is achieved by applying MILP algorithm in energy management strategy in thesis compared with using FLC algorithm.

\subsection{Challenges of Grid-Connected Household Nano-Grid System}

EMS of grid-connected household nano-grid system mainly deploys centralized control. However, with the development of decentralized control, decentralized control can realize plug and play of distributed energy resources, which improves the flexibility of electricity usage. Thus, more attention will be drawn on decentralized control in the future. The main challenges of decentralized control now are concentrated on its system structure and energy management strategy. The main challenges are listed as follows: 
1) PV generation has the nature of intermittency, fluctuation and difficulty on prediction due to the environmental influences such as temperature and irradiance. With the increasing controllable loads such as Plug in Electric Vehicles, grid-connected household nano-grid systems have the nature of uncertainty. Therefore, EMS is required to consider uncertain factors.

2) The safety of customer information is also a serious problem that needs to be solved. With the popularity of grid-connected household nano-grid systems, a lot of information reflecting household electricity usage are generated, involving in customer privacy. Therefore, safety protection should be integrated into EMS.

3) The reliable and compatible communication network is the basis of realizing EMS. Problems such as time-delay and time-out can lead to the failure of the execution of energy management strategy. Furthermore, there is no standardized criterion now, which should be considered to standardize in the future. 


\section{Chapter: Model and Analysis of PV Grid-Connected Household}

\section{Nano-Grid System}

In this chapter, a PV grid-connected household nano-grid system is modeled and investigated, including PV units, energy storage system, and house loads. Each unit is examined by simulations. The whole nano-grid system is also investigated under difference operating conditions.

\subsection{Structure of the PV Grid-Connected Household Nano-Grid System}

The investigated PV grid-connected household nano-grid system is comprised of PV arrays, DC/DC boost converter, energy storage system including both battery and supercapacitor, DC/AC inverter and residential loads. In terms of the PV and energy storage system grid-connection with power-electronic inverters, there have been mainly two different configurations shown in Figure 3.1 and Figure 3.2. As shown in Figure 3.1, one configuration is to integrate the $\mathrm{PV}$ generation to $\mathrm{AC}$ bus bar through a $\mathrm{DC} / \mathrm{AC}$ inverter while the energy storage system is connected to the same AC bus bar through a bidirectional DC/AC inverter. Then, the $\mathrm{AC}$ bus bar is connected to residential loads and distribution network. The other topology is to connect the distributed PV generation to a DC bus bar with a DC/DC boost converter while energy storage system is connected to the same DC bus bar through a bi-directional DC/DC buck/boost converter. Then, a DC-AC inverter is connected to convert the DC voltage to AC voltage and provide power supply for residential loads. Both of the two topologies can achieve the bi-directional power flow of energy storage system and the improvement of PV generation utilization. However, the DC coupling topology has a simpler structure compared with AC coupling topology [52]. 
Thus, the DC coupling topology (shown in Figure 3.2) is used in this thesis. The overall structure of PV grid-connected household nano-grid system is illustrated in Figure 3.3. Each unit is introduced in the following sections.

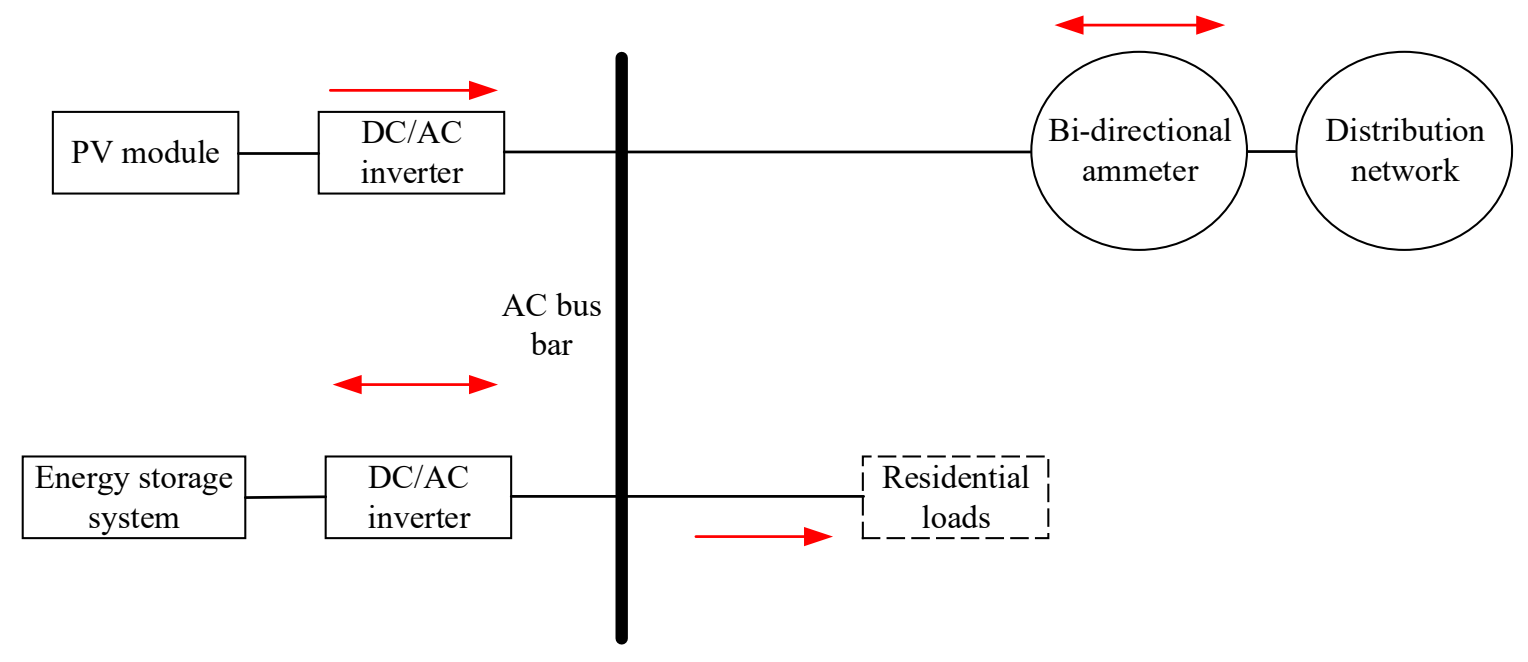

Figure 3.1 AC coupling topology

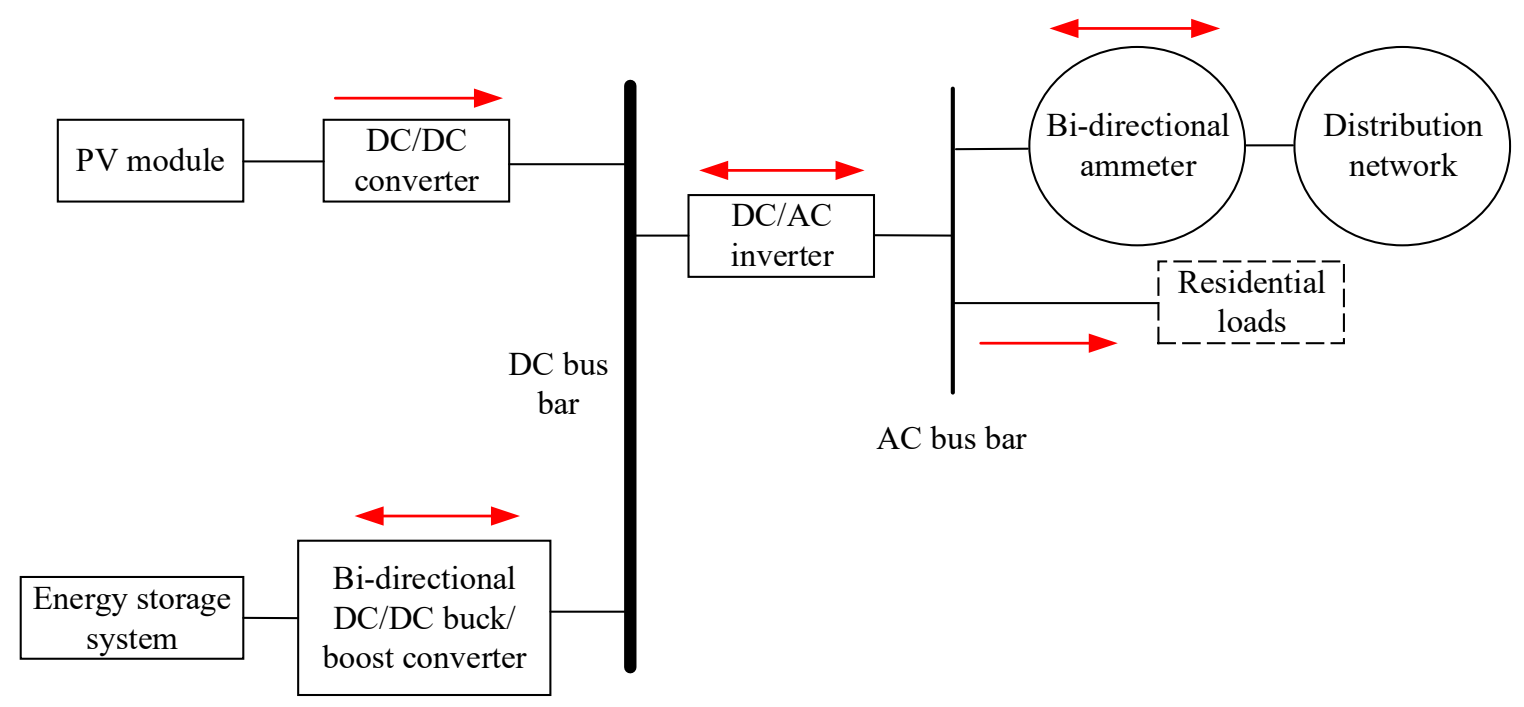

Figure 3.2 DC coupling topology 


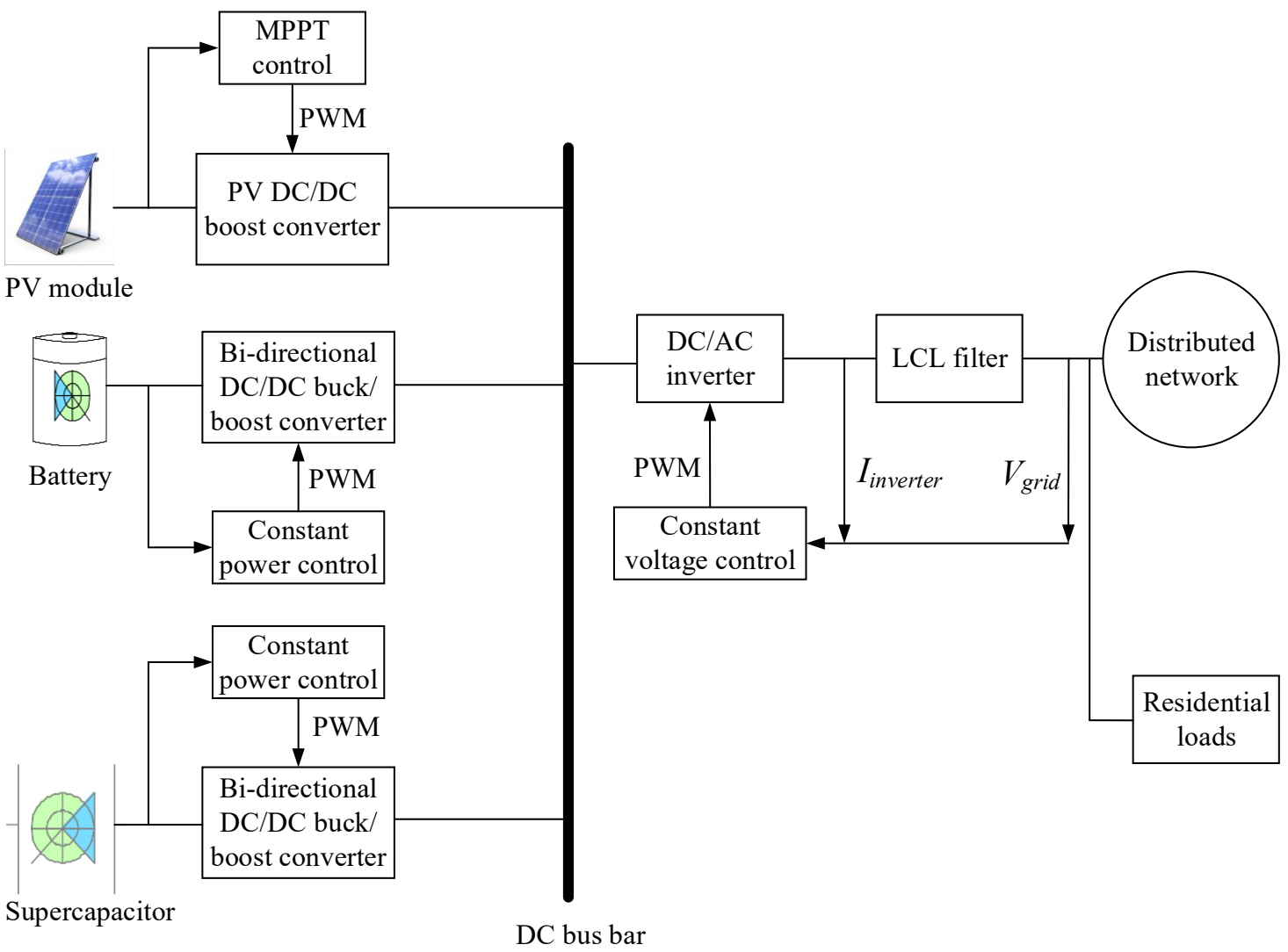

Figure 3.3 Overall structure of PV grid-connected household nano-grid system

\subsection{PV Array Model}

In this section, the PV array model is obtained and simulated in MATLAB/Simpower environment.

\subsubsection{Equivalent Circuit of PV Cell}

As PV cell is a DC device, junction capacitors and other distributed capacitors are neglected. The equivalent circuit Figure 3.4 (a) of PV cell is comprised of a DC current source, a diode, a shunt resistor $R_{s h}$, and a serial resistor $R_{s}$. While $R_{s}$ is usually small (from $10^{-3}$ to several ohms), $R_{s h}$ is usually large (usually being more than 1 kilo ohms). $R_{s h}$ is generally about $10^{-6}$ times compared with $R_{S} . R_{S}$ and $R_{s h}$ can be neglected to simply the 
equivalent circuit, which is shown Figure 3.4 (b).

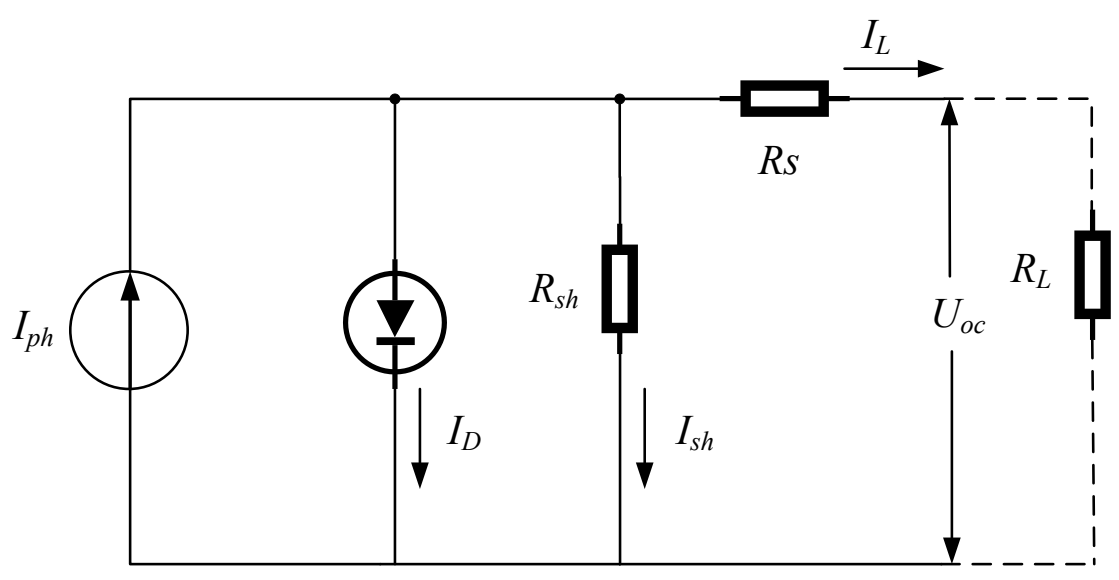

Figure 3.4(a) Equivalent circuit

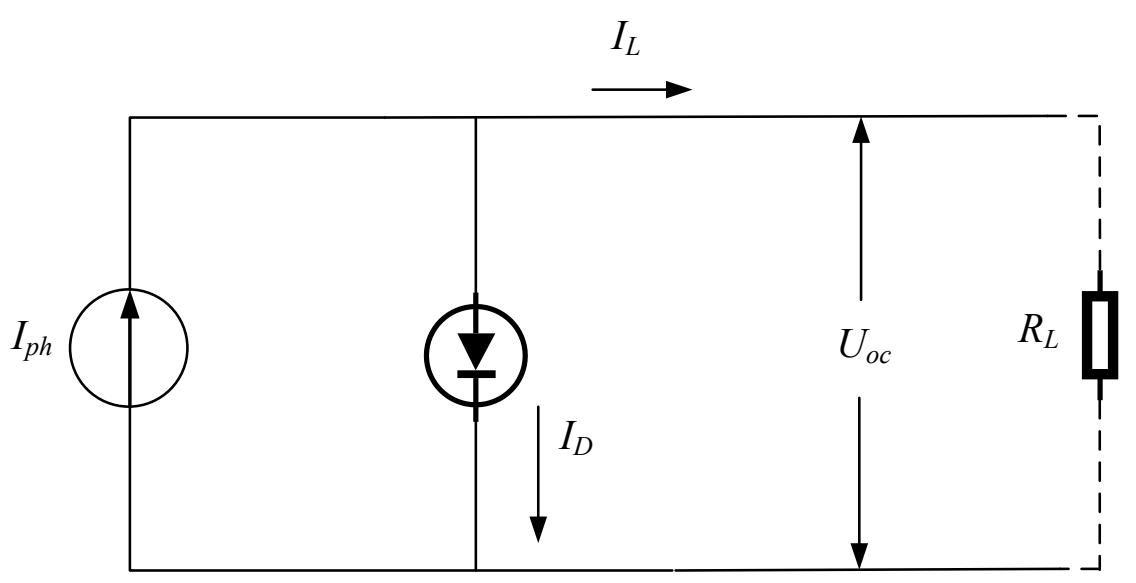

Figure 3.4(b) Simplified equivalent circuit

Figure 3.4 Equivalent circuit of PV cell

In the equivalent circuit shown in Figure 3.4 (a), according to KCL, we can get:

$$
I_{L}=I_{p h}-I_{D}-I_{s h}
$$

Here $I_{p h}$ represents the light-generated current in the cell, which is expressed as:

$$
I_{p h}=\left(I_{s c}+K_{t} \Delta T\right) \frac{s}{S_{n}}=\left[I_{s c}+K_{t}\left(T-T_{n}\right)\right] \frac{s}{1000}
$$


In (3.2), $I_{s c}$ is short circuit current of PV cell, $K_{t}$ is short current temperature coefficient, $T$ is temperature, $T_{n}$ is reference temperature $(298 \mathrm{~K}), S$ is irradiance. $S_{n}$ is reference irradiance $\left(1000 \mathrm{~W} / \mathrm{m}^{2}\right)$.

In Figure 3.4(a), the photogenerated current $I_{L}$ is governed by the voltage across the diode:

$$
U_{D}=U_{o c}+R_{S} I_{L}
$$

In (3.3), $U_{D}$ is the voltage across diode. $U_{o c}$ is the open circuit voltage. $R_{S}$ is series resistance. $I_{L}$ is the photogenerated current.

Based on the Shockley equation, diode current $I_{D}$ is:

$$
I_{D}=I_{0}\left[\exp \left(\frac{q U_{D}}{A K T}\right)-1\right]=I_{0}\left\{\exp \left[\frac{q\left(U_{o c}+R_{S} I_{L}\right)}{A K T}\right]-1\right\}
$$

In (3.4), $I_{0}$ is the reverse saturation current. $q$ is the elementary charge, which is $1.6 \times 10^{-19}$. $K$ is Boltzmann constant, which is $1.38 \times 10^{-23} . A$ is diode ideal constant.

Shunt current $I_{s h}$ is expressed as:

$$
I_{s h}=\frac{U_{D}}{R_{s h}}=\frac{U_{o c}+R_{S} I_{L}}{R_{s h}}
$$

Now, we embed equations (3.2), (3.3), (3.4), (3.5) into (3.1), and the current is:

$I_{L}=I_{p h}-I_{D}-I_{s h}=\left[I_{s c}+K_{t}\left(T-T_{n}\right)\right] \frac{s}{1000}-I_{0}\left\{\exp \left[\frac{q\left(U_{o c}+R_{S} I_{L}\right)}{A K T}\right]-1\right\}-\frac{U_{o c}+R_{S} I_{L}}{R_{s h}}$

Ideally, we can assume $R_{s} \rightarrow 0, R_{s h} \rightarrow \infty$, then we can express photogenerated current $I_{L}$ and PV cell power output $P_{L}$ in Figure 3.4 (b) as below: 


$$
\begin{gathered}
I_{L} \approx I_{p h}-I_{D}=\left[I_{s c}+K_{t}\left(T-T_{n}\right)\right] \frac{s}{1000}-I_{0}\left[\exp \left(\frac{q U_{L}}{A K T}\right)-1\right] \\
P_{L}=U_{L} I_{L}=U_{L} I_{p h}-U_{L} I_{0}\left[\exp \left(\frac{q U_{L}}{A K T}\right)-1\right]
\end{gathered}
$$

\subsubsection{Simulation and Analysis of PV Module}

Due to the insufficient power output of a single PV cell, a PV module which combines a number of PV cells either in parallel or in series is usually used to support high power output. Assuming every single PV cell has same characteristic, the characteristic equation of PV module is expressed as:

$$
I_{z}=N_{p} I_{p h}-N_{p} I_{D}=N_{p} I_{p h}-N_{p} I_{0}\left[\exp \left(\frac{q U_{z}}{N_{S} A K T}\right)-1\right]
$$

where, $N_{p}$ and $N_{s}$ represent the number of parallel PV cells and the number of series PV cells respectively. $I_{z}$ represents the current output of PV module and $U_{z}$ represents voltage output of PV module.

The PV module is simulated at the different irradiances and temperatures. Parameters are set as maximum voltage output of PV module $V_{m}=300 \mathrm{~V}$, maximum current output of PV module $I_{m}=24 \mathrm{~A}$, open circuit voltage of PV module $V_{o c}=350 \mathrm{~V}$, short circuit current of PV module $I_{s c}=40 \mathrm{~A}$. By simulating with a variety of irradiances $S$ and temperatures $T$, the relationship between current output and power output of PV module can be found.

When the temperature is fixed at $25^{\circ} \mathrm{C}$, the $\mathrm{I}-\mathrm{V}$ and $\mathrm{P}-\mathrm{V}$ characteristic curves are plotted with irradiances $=800 \mathrm{~W} / \mathrm{m}^{2}, 1000 \mathrm{~W} / \mathrm{m}^{2}$ and $1200 \mathrm{~W} / \mathrm{m}^{2}$ respectively, as shown in Figure 3.5. When the irradiance is fixed at $1000 \mathrm{~W} / \mathrm{m}^{2}$, the $\mathrm{I}-\mathrm{V}$ and $\mathrm{P}-\mathrm{V}$ characteristic curves of 
the PV module are plotted as temperature $=0{ }^{\circ} \mathrm{C}, 25^{\circ} \mathrm{C}, 50^{\circ} \mathrm{C}$ respectively, as shown in Figure 3.6.
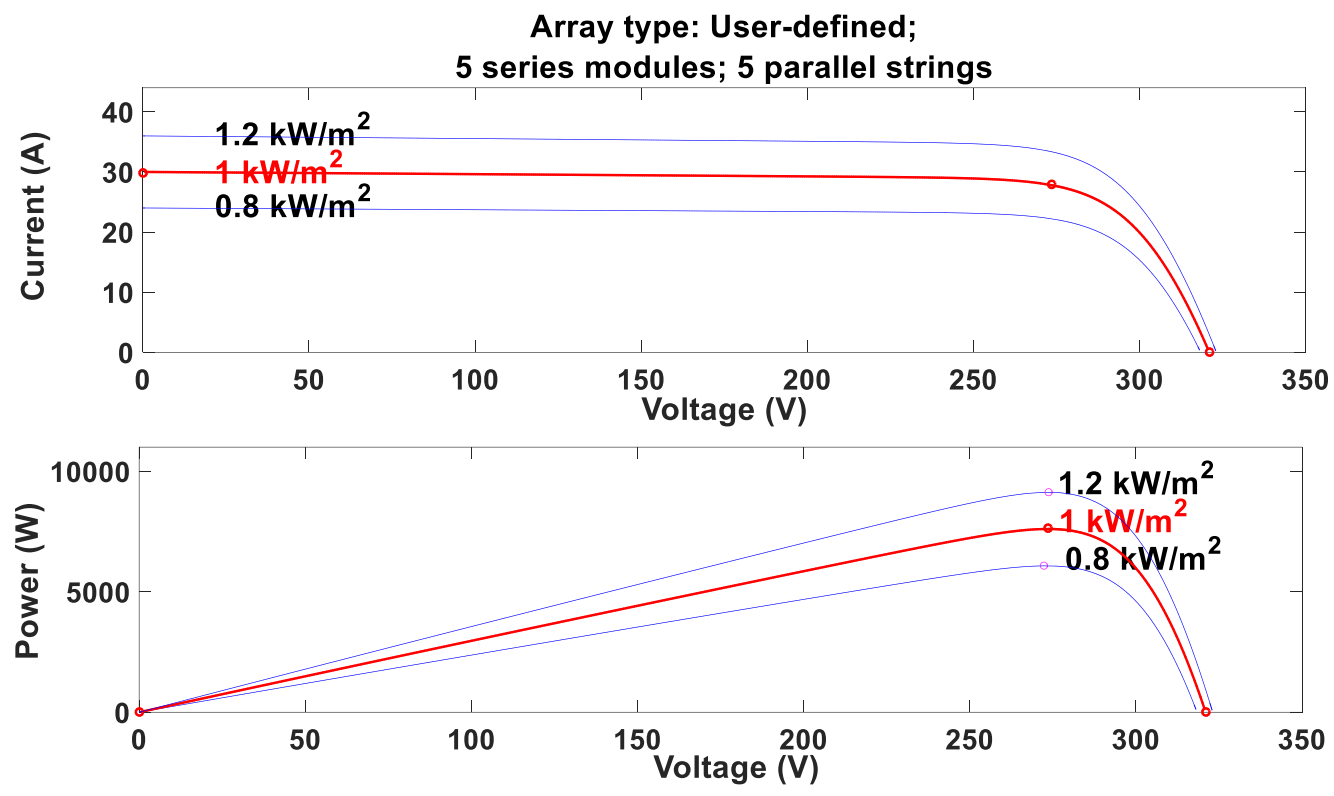

Figure 3.5 PV characteristic curve with irradiance variation

Based on the simulation result of Figure 3.5, it demonstrates that PV maximum power output increases with the increasing irradiance when temperature is fixed.

Array type: User-defined;

5 series modules; 5 parallel strings
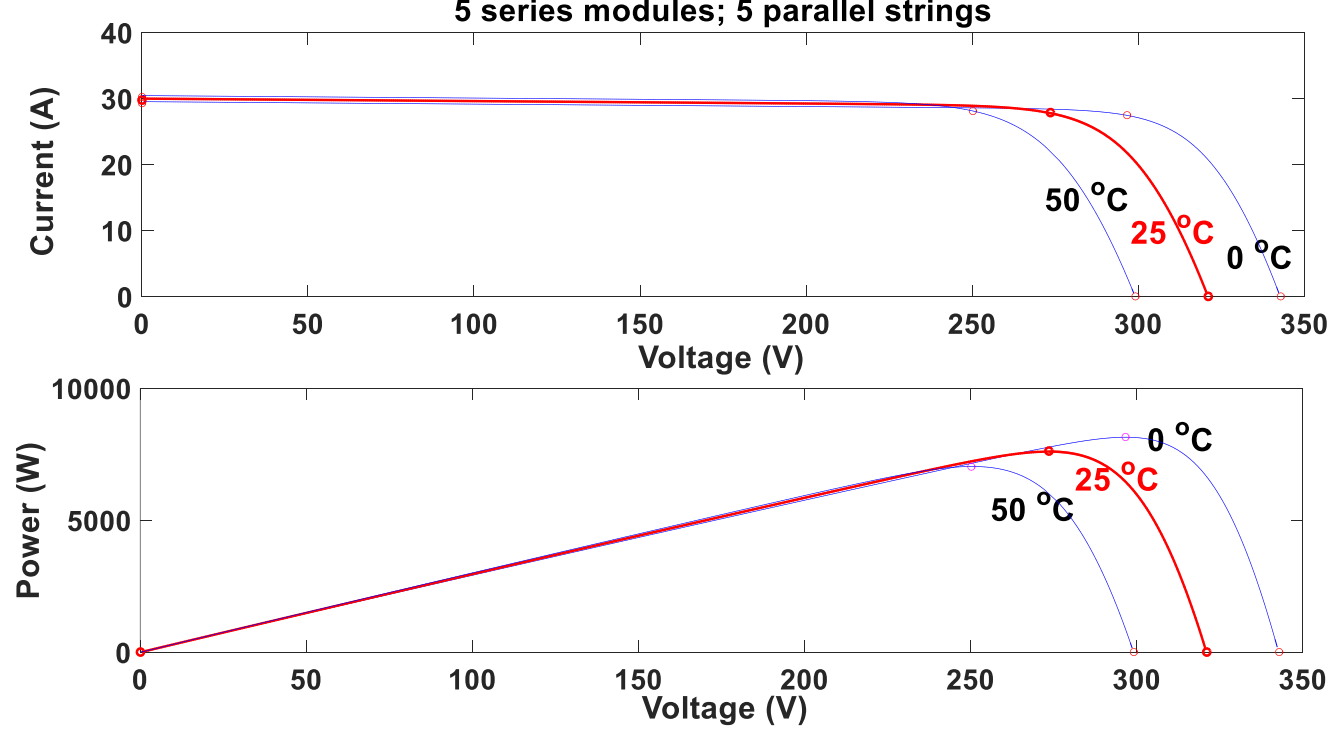

Figure 3.6 PV characteristic curve with temperature variation 
Based on the simulation results of Figure 3.6, it demonstrates that PV maximum power output decreases with the increasing temperature when irradiance is fixed.

\subsection{DC/DC Boost Converter}

A DC/DC boost converter is implemented between PV module and DC/AC inverter, as shown in Figure 3.7. The circuit out of PV module can be taken as load. By using Perturb and Observe $(\mathrm{P} \& \mathrm{O})$ method, the duty cycle of DC/DC boost converter can be controlled. The voltage and current output of DC/DC boost converter can be changed, which can realize the impedance matching. Therefore, when the internal resistance is equal to the impedance of the equivalent circuit out of PV module $\left(R_{i}=R_{L}\right)$, PV module can work at maximum power point.

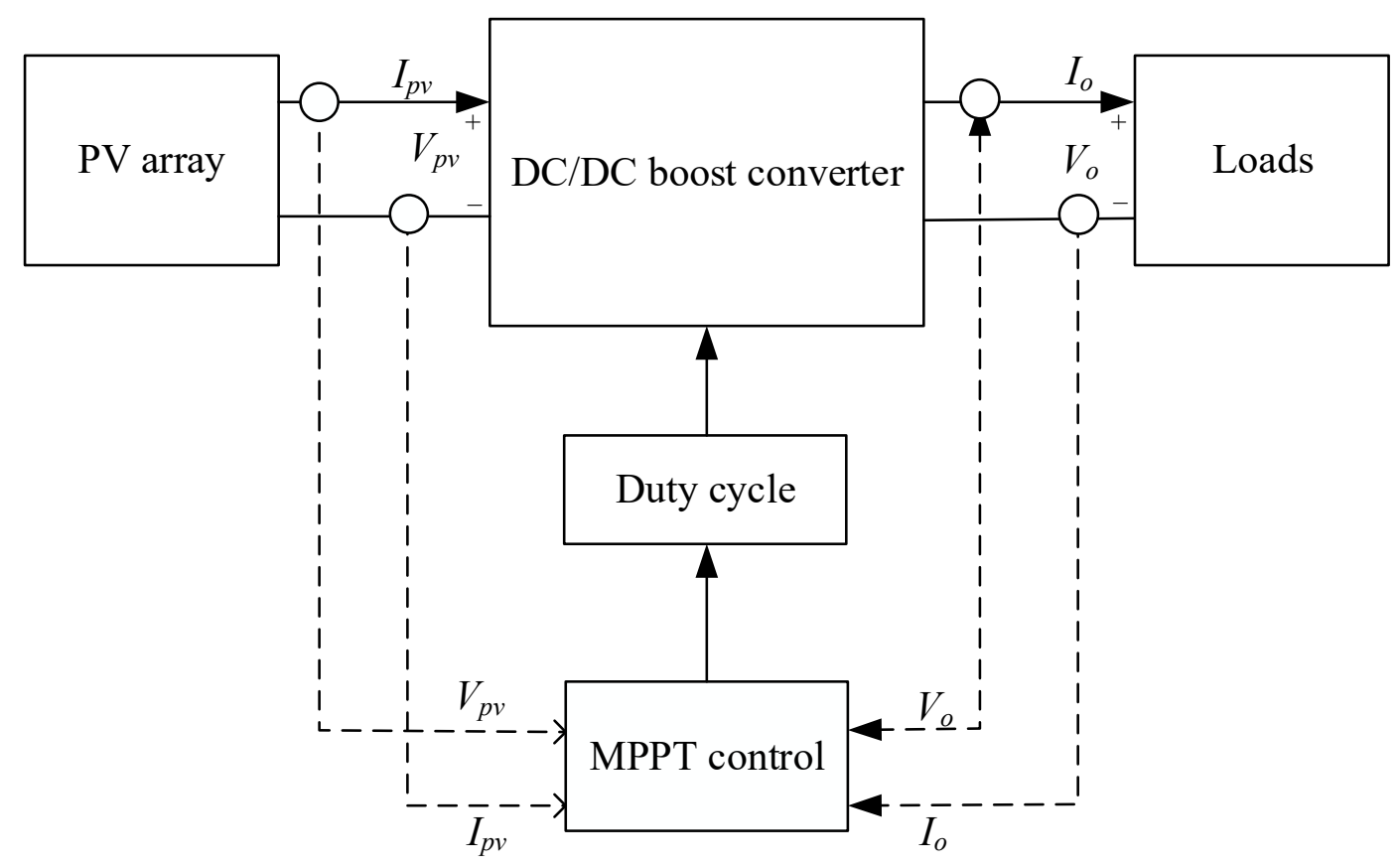

Figure 3.7 Control of circuit of MPPT technique 


\subsubsection{Perturb and Observe Method for MPPT}

The output characteristic of PV module is influenced by the change of irradiance and temperature. When irradiance and temperature change, PV module will not work at maximum power point. Even when temperature and irradiance are kept unchanged, the difference of load will lead to different output characteristic of the PV module. Therefore, MPPT technique is used to ensure PV module generating maximum power at any time and improve the solar energy utilization.

There are many different MPPT techniques applied to PV system, such as constant voltage tracking method, P\&O method and incremental conductance, etc. For these MPPT techniques, real-time measurement of voltage and current output of PV module should be conducted. The shift of maximum power point can be observed by measuring voltage and current output of PV module. These techniques can be used to track the maximum power point of PV module for any environmental condition. Among these MPPT methods, in this thesis, the $\mathrm{P} \& \mathrm{O}$ method is used due to the consideration of simple structure and feasibility of the technique.

The principle of $\mathrm{P} \& \mathrm{O}$ method for tracking maximum power point is that when the voltage output and power output of PV module fluctuate, the fluctuating direction of the voltage output of PV module next time can be determined. If power output of PV module increases, the fluctuating direction of voltage output in the next step will be in the same direction as its previous step. If the power output of PV module decreases, the fluctuating direction of voltage output in the following step will be in the opposite direction as its previous one. 
By repeating in the above process, the operation point will finally move towards maximum power point. Meanwhile, the fluctuating voltage and power output of the PV module are the input parameters in this method, to guarantee the power output of PV module in steady state. Figure 3.8 shows the flowchart of the P\&O method.

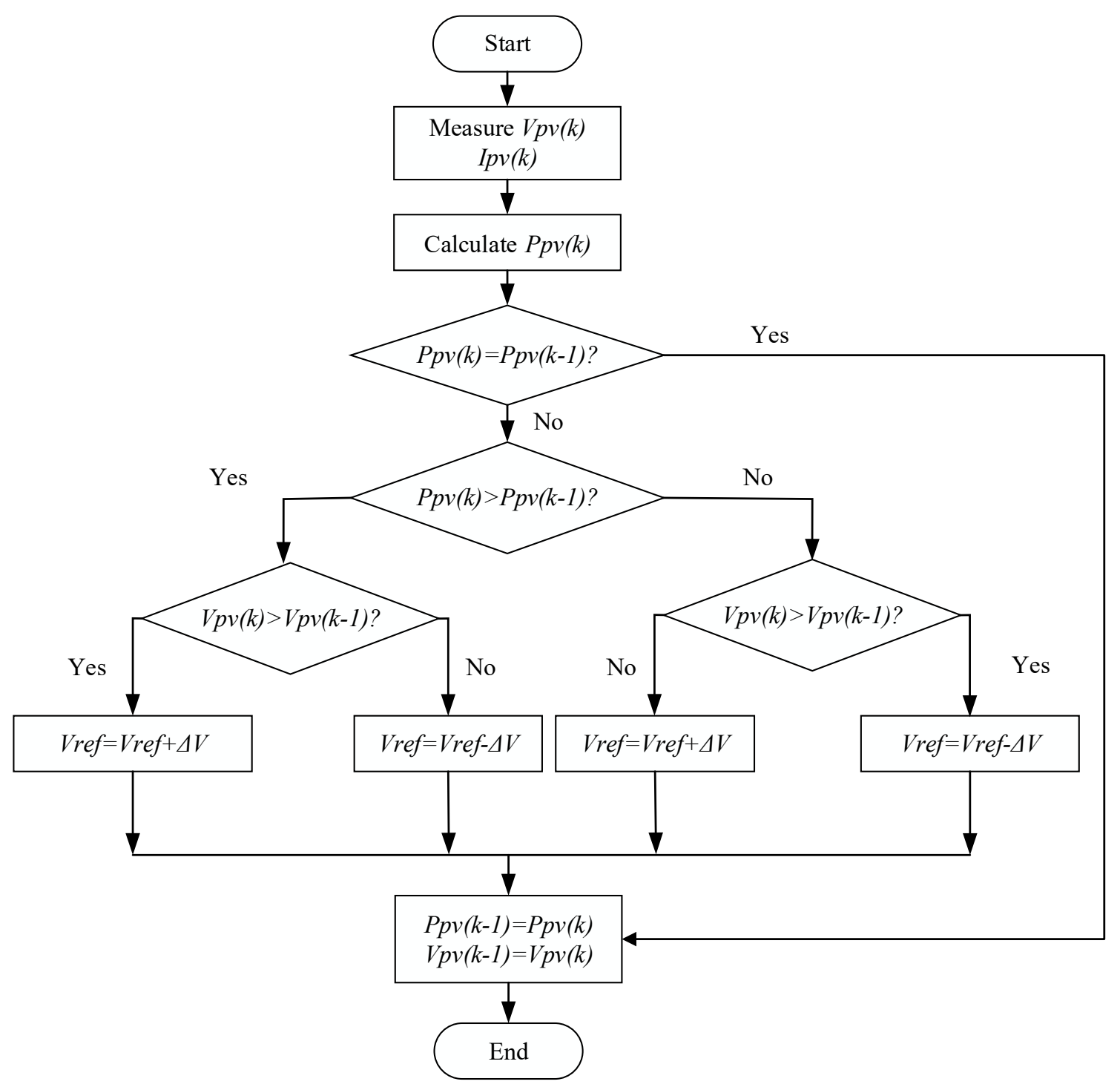

Figure 3.8 The flow chart of P\&O method 


\subsubsection{Simulation of MPPT Technique Applied in PV System}

With the utilization of MPPT technique based on P\&O method, PV maximum power output can be achieved at different temperatures and irradiances. In this Simulink model, $\mathrm{PV}$ maximum power generation is $8.4 \mathrm{KW}\left(\right.$ Irradiance $=1000 \mathrm{~W} / \mathrm{m}^{2}$; Temperature $\left.=25^{\circ} \mathrm{C}\right)$. Short circuit current $I_{s c}=40 \mathrm{~A}$. Open circuit voltage $V_{o c}=350 \mathrm{~V}$. Maximum current $I_{\max }$ $=24 \mathrm{~A}$. Maximum voltage $U_{\max }=300 \mathrm{~V}$.

By changing the irradiance and temperature on PV module, maximum power output of PV module can be tracked, which can reflect the dynamic response and steady state characteristic of the PV system. In Figure 3.9, PV system is simulated that irradiance is set as irradiance $=1000 \mathrm{~W} / \mathrm{m}^{2}, 800 \mathrm{~W} / \mathrm{m}^{2}, 400 \mathrm{~W} / \mathrm{m}^{2}$ at time $=0 \mathrm{~s}, 1 \mathrm{~s}, 1.8 \mathrm{~s}$. In Figure $3.10, \mathrm{PV}$ system is simulated that temperature is set as temperature $=25^{\circ} \mathrm{C}, 50^{\circ} \mathrm{C}, 70^{\circ} \mathrm{C}$ at time $=0 \mathrm{~s}$, 1s, 1.8s. In Figure 3.11, PV system is simulated that irradiance and temperature are changing together according to time point above.

From Figure 3.9 Figure 3.11, PV maximum power generation can be achieved at different irradiance and temperature. In Figure 3.9, Irradiance changes while temperature is kept unchanged. PV maximum power generation decreases when irradiance decreases. When irradiance goes from $1000 \mathrm{~W} / \mathrm{m}^{2}$ to $800 \mathrm{~W} / \mathrm{m}^{2}$ at $1 \mathrm{~s}$, from $800 \mathrm{~W} / \mathrm{m}^{2}$ to $400 \mathrm{~W} / \mathrm{m}^{2}$ at $1.8 \mathrm{~s}$, the transient response is fast, which is only $0.1 \mathrm{~s}$. In Figure 3.10, Temperature changes while irradiance is kept unchanged. PV maximum power generation decreases when temperature increases. When temperature goes from $25^{\circ} \mathrm{C}$ to $50^{\circ} \mathrm{C}$ at $1 \mathrm{~s}$, from $50^{\circ} \mathrm{C}$ to $70^{\circ} \mathrm{C}$ at $1.8 \mathrm{~s}$, the transient response is fast, which is only $0.1 \mathrm{~s}$. 


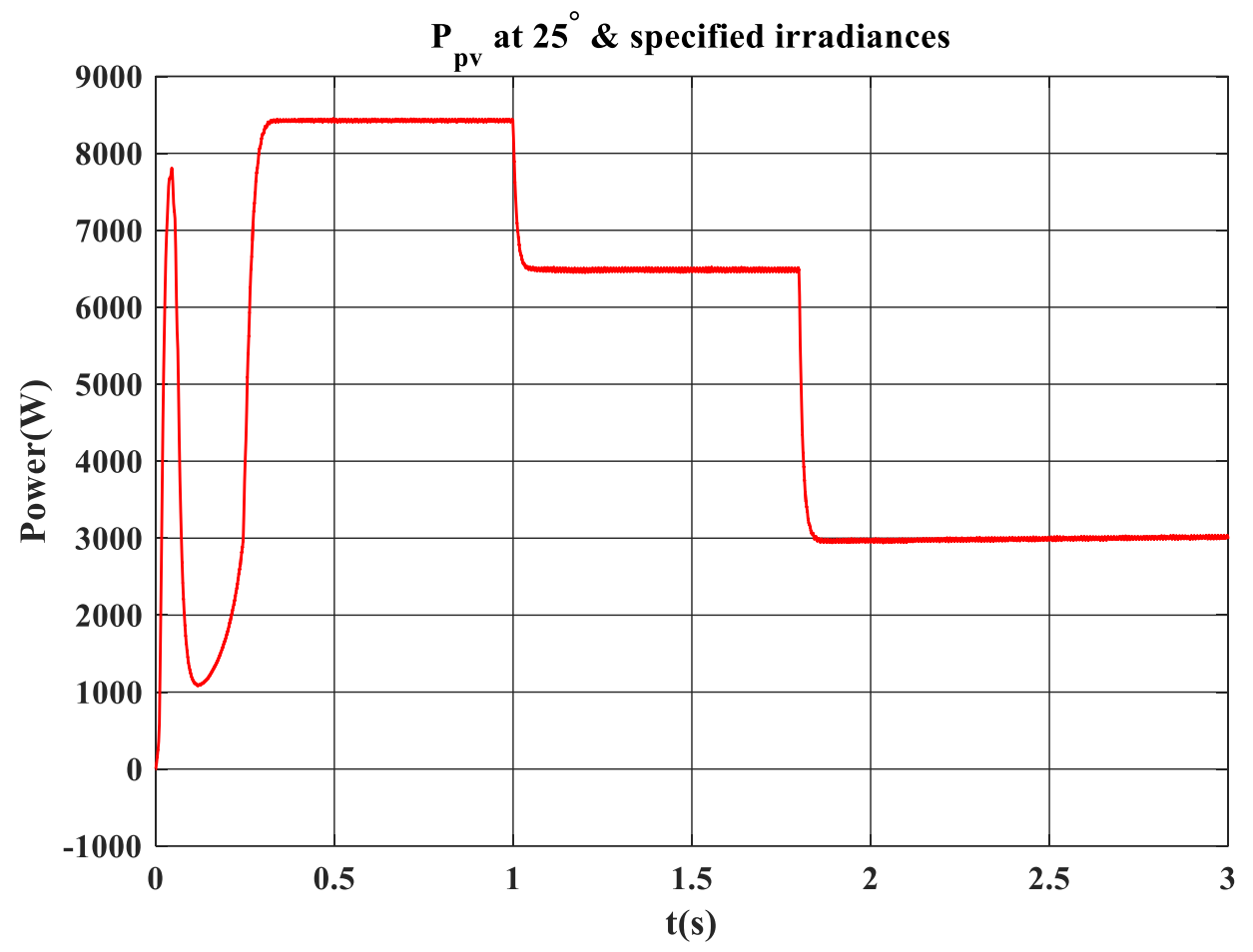

Figure 3.9 Simulated curve when only changing irradiance

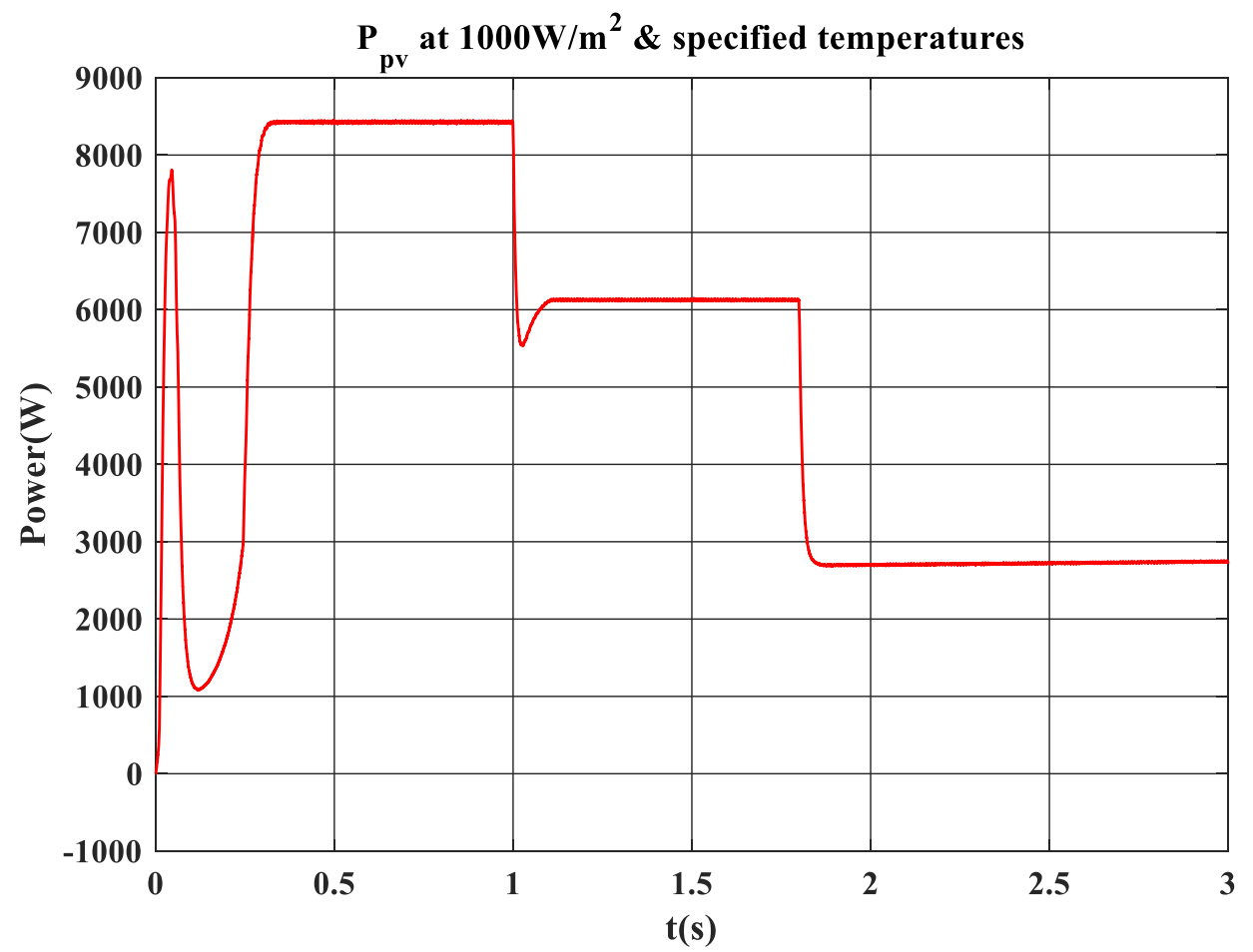

Figure 3.10 Simulated curve when only changing temperature 
In Figure 3.11, temperature and irradiance both change. PV maximum power generation decreases with decreasing irradiance and increasing temperature. When irradiance and temperature change from $1000 \mathrm{~W} / \mathrm{m}^{2}, 25^{\circ} \mathrm{C}$ to $800 \mathrm{~W} / \mathrm{m}^{2}, 50^{\circ} \mathrm{C}$ at $1 \mathrm{~s}$, from $800 \mathrm{~W} / \mathrm{m}^{2}, 50^{\circ} \mathrm{C}$ to $400 \mathrm{~W} / \mathrm{m}^{2}, 70^{\circ} \mathrm{C}$ at $1.8 \mathrm{~s}$, the transient response is fast, which is only $0.1 \mathrm{~s}$.

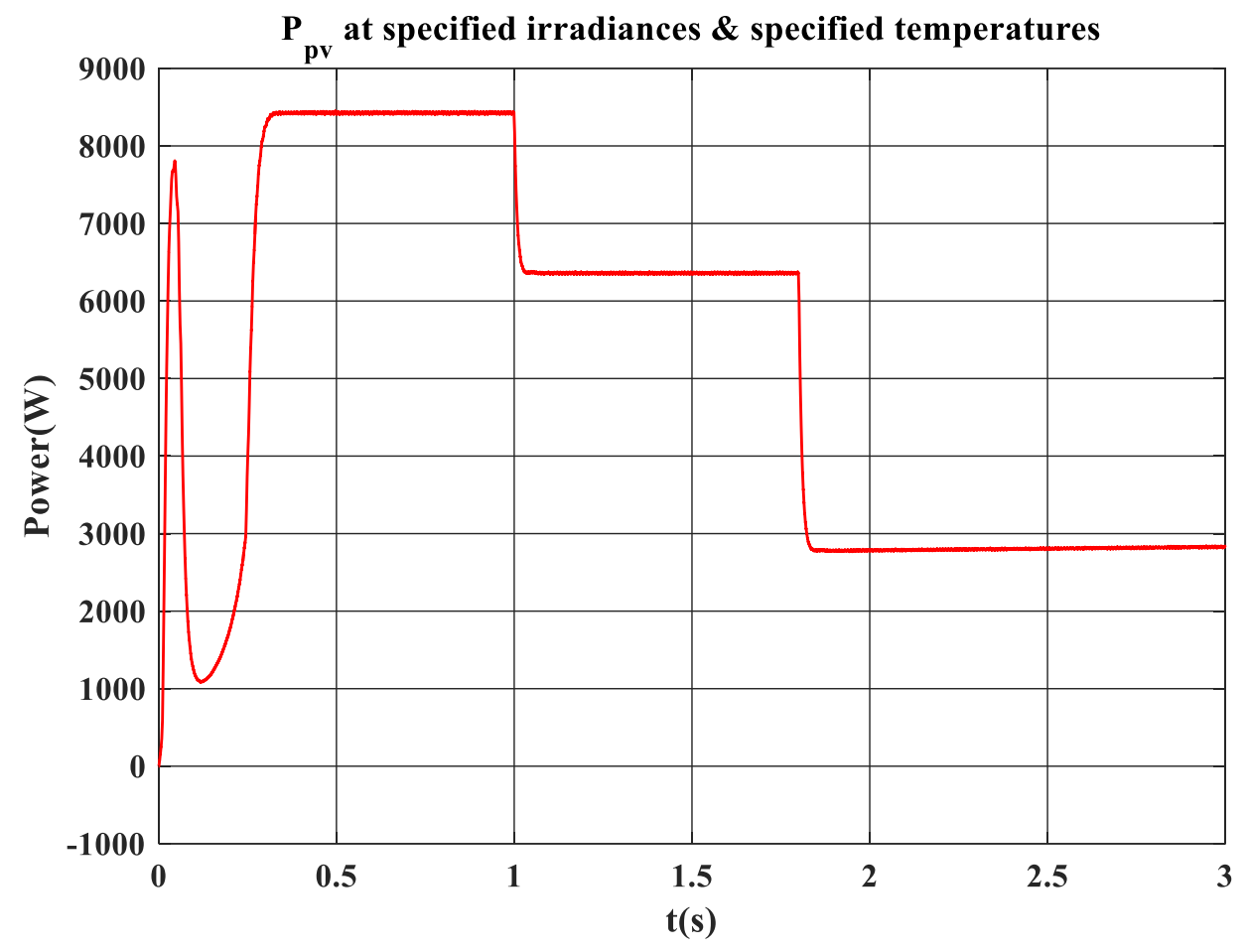

Figure 3.11 Simulated curve when changing irradiance and temperature

Based on Simulation results above, PV maximum power generation can change with the irradiance and temperature. PV maximum power generation can be achieved at different irradiance and temperature with the utilization of $\mathrm{P} \& \mathrm{O}$ MPPT technique, which shows good steady state and transient state performance. 


\subsection{Energy Storage System and Related Control Strategies}

Power fluctuation of PV grid-connected household nano-grid system is caused by uncertainty of PV power generation and power demand of residential loads. Energy storage system deploys constant power control as a way to alleviate the power fluctuation of PV grid-connected household nano-grid system. However, the rapid changing charging/discharging current has an impact on the lifespan of battery in energy storage system. The battery will be damaged due to the rapid and frequent charging/discharging during power fluctuation. In order to prevent the damage of the battery, supercapacitor is used to realize rapid and frequent charging/discharging, which can effectively alleviate high frequency component of power fluctuation in PV nano-grid system. Even though supercapacitors do not have the power capacity as batteries, supercapacitors can endure the rapid and frequent charging/discharging current without damaging itself due to its high power density. Therefore, the hybrid use of battery and supercapacitor can be complementary. With reasonable coordination between battery and supercapacitor, this hybrid energy storage system can alleviate power fluctuations of PV nano-grid system with the deployment of constant power control. The basic structure of hybrid storage system is shown in Figure 3.12. 
DC side of PV grid-connected household nano-grid system

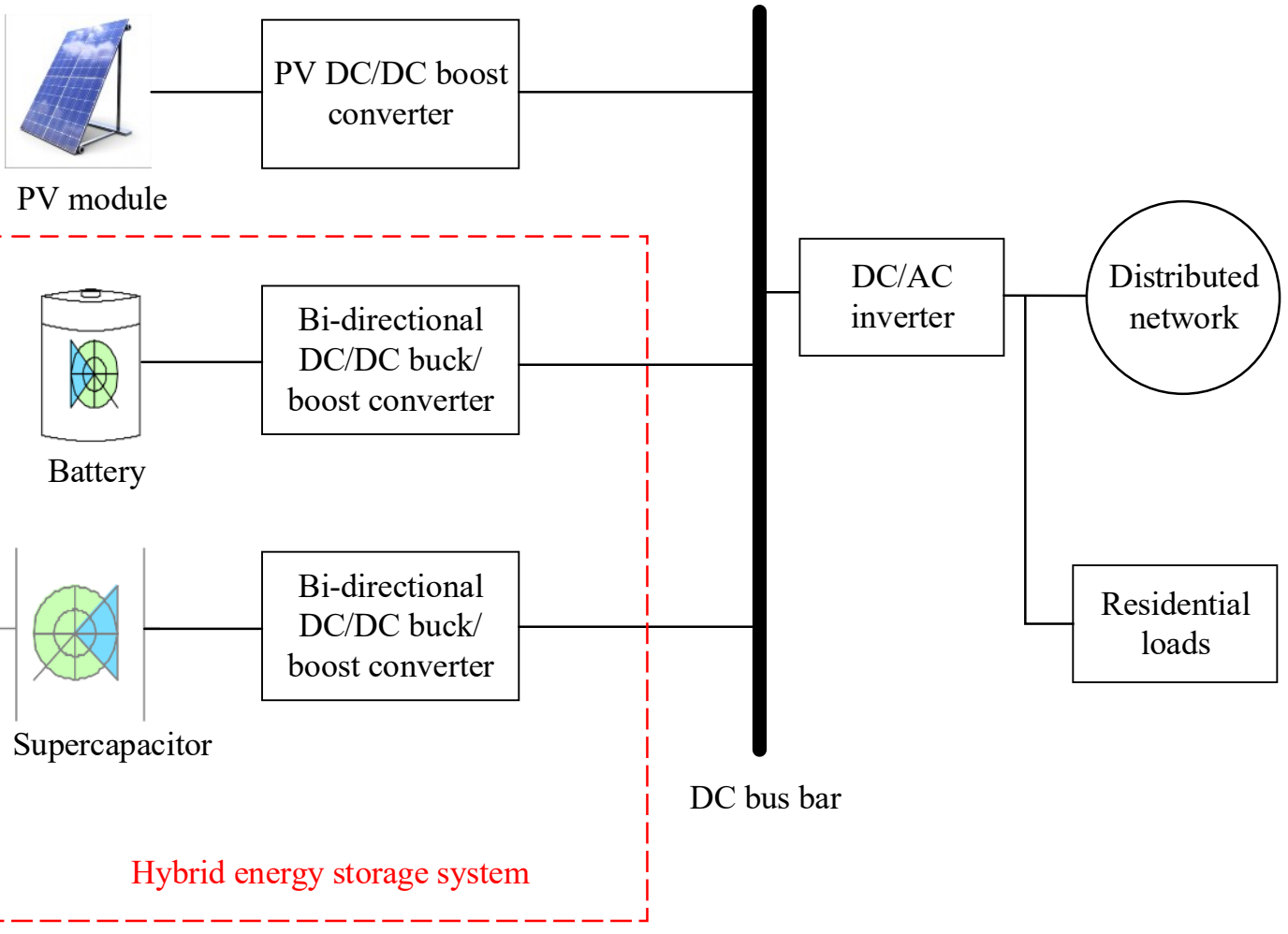

Figure 3.12 Basic structure of hybrid storage system

\subsubsection{Characteristic of Bi-directional DC/DC Converters of Energy Storage}

\section{System}

\section{1) Topology of Bi-directional DC/DC Buck/Boost Converters}

In energy storage systems, batteries and supercapacitors are connected to DC bus bar through bi-directional DC/DC buck/boost converter respectively, which is shown in Figure 3.13. In order to minimize the voltage ripple of battery voltage output, $C_{b}$ is used as filtering capacitor, which is parallel with battery. $C_{d c}$, which has a large capacitance, is used to alleviate voltage ripple. $R_{L}$ is the equivalent resistor at DC bus bar side. Due to the large capacitance of supercapacitor, the voltage of DC bus bar can be assumed unchanged in one cycle. Supercapacitor can be equivalent to be an ideal voltage source $V_{s c}$ in series 


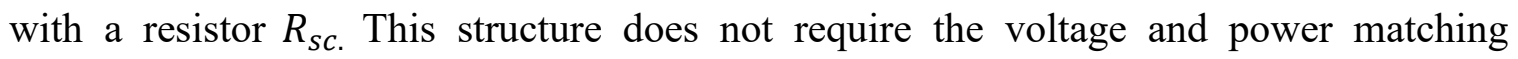
relationship between battery and supercapacitor. These two bi-directional DC/DC buck/boost converters, which are responsible for battery and supercapacitor, are controlled separately. Therefore, control of battery and supercapacitor are independent.

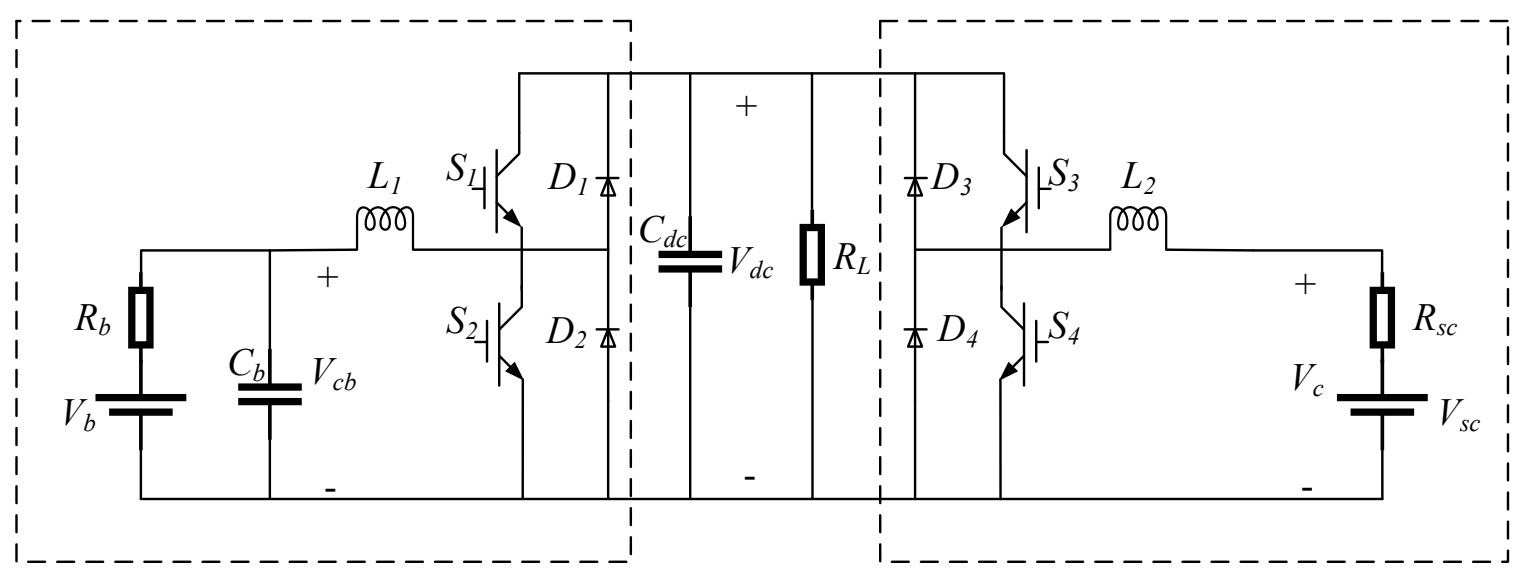

Figure 3.13 Topology of energy storage system

\section{2) Operation Modes of Bi-directional DC/DC Buck/Boost Converters}

PWM complementary control is used to control the operation modes of bi-directional DC/DC buck/boost converters in energy storage system. For PWM complementary control, two switches operate complementarily at the same time. In energy storage system, with the utilization of PWM complementary control, intermittent current of battery will not emerge. Battery is charged at buck operation mode while battery discharges at boost operation mode. Therefore, bi-directional DC/DC buck/boost converter connecting with battery works at PWM complementary control. Supercapacitor has a high power density, which is required to charge at buck operation mode or discharge at boost operation mode frequently. Therefore, bi-directional DC/DC buck/boost converter connecting with supercapacitor also 
works at PWM complementary control.

PWM complementary control of bi-directional DC/DC buck/boost converter connecting with supercapacitor is shown as example in Figure 3.14. Switch signal of $S_{3}$ and $S_{4}$ are shown as $u_{g 3}$ and $u_{g 4}$. In one cycle, current of inductor $L_{2}$ could be positive or negative. By changing duty cycle, the average current of inductor $L_{2}$ could be changed. When current of inductor $L_{2}$ is positive, supercapacitor discharges power to DC bus bar. When current of inductor $L_{2}$ is negative, supercapacitor is charged by DC bus bar.

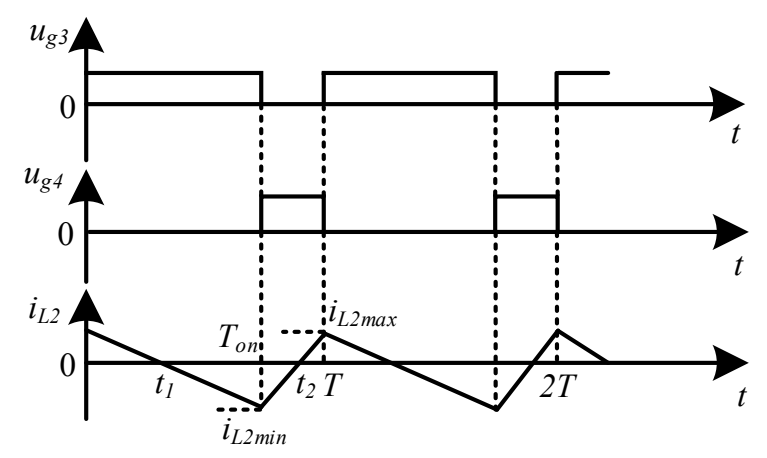

Figure 3.14 Switch signal of $S_{3}, S_{4}$ and inductor $L_{2}$ current waveform under PWM complementary control

\subsubsection{Characteristic and Control Strategy of the Battery}

1) Characteristic of Battery Charging and Discharging

The battery using for PV grid-connected household nano-grid system is required to have the nature of high energy density and reliability. Lithium-Ion battery, which has reliable charging and discharging performance, has many advantages such as high nominal voltage, large specific energy, long lifespan, non-pollution and no memory effect etc. Therefore, Lithium-Ion battery is used in energy storage system. It is important to use a reasonable 
control strategy of Lithium-Ion battery to ensure its lifespan. The SOC is an important parameter presenting battery charging and discharging. SOC of Lithium-Ion battery is the criterion of deciding the charging or discharging. The realization of control strategy of Lithium-Ion battery is also based on SOC state, which can guarantee reliable performance of Lithium-Ion battery SOC, which is the ratio of remaining capacity and total capacity, reflects remaining capacity of battery. SOC is defined in equation 3.10.

$$
S O C=\frac{Q_{c}}{Q_{r}} * 100 \%
$$

In (3.10):

$Q_{c}:$ remain capacity of Lithium-Ion battery $\left(\mathrm{A}^{*} \mathrm{~h}\right)$

$Q_{r}:$ total capacity of Lithium-Ion battery $\left(\mathrm{A}^{*} \mathrm{~h}\right)$

Equation (3.11) represents the prediction of SOC of Lithium-Ion battery:

$$
S O C=S O C_{0}-\frac{1}{Q_{n}} \int_{0}^{t} \eta i d t
$$

In (3.11):

SOC: Predicted value of present SOC

$S O C_{0}$ : Initial SOC value

$Q_{n}:$ Total battery capacity $\left(\mathrm{A}^{*} \mathrm{~h}\right)$

$\eta$ : Coulombic efficiency of Lithium-Ion battery

$i$ : Working current of Lithium-Ion battery

Coulombic efficiency of Lithium-Ion battery $\eta$ can represent the charge-discharge rate and temperature-affecting coefficient. The error of working current of Lithium-Ion battery $i$ 
has influence on coulombic efficiency of Lithium-Ion battery $\eta$.

\section{2) Control Strategy of Lithium-Ion Battery Charging and Discharging}

When the battery is charging/discharging, its SOC is measured in real time to know the operation mode of the battery. In order to prevent the excessive charging/discharging, limiting protection is implemented. Figure 3.15 shows the operation mode selection and limiting protection design for the charging/discharging of the battery at different SOC values.

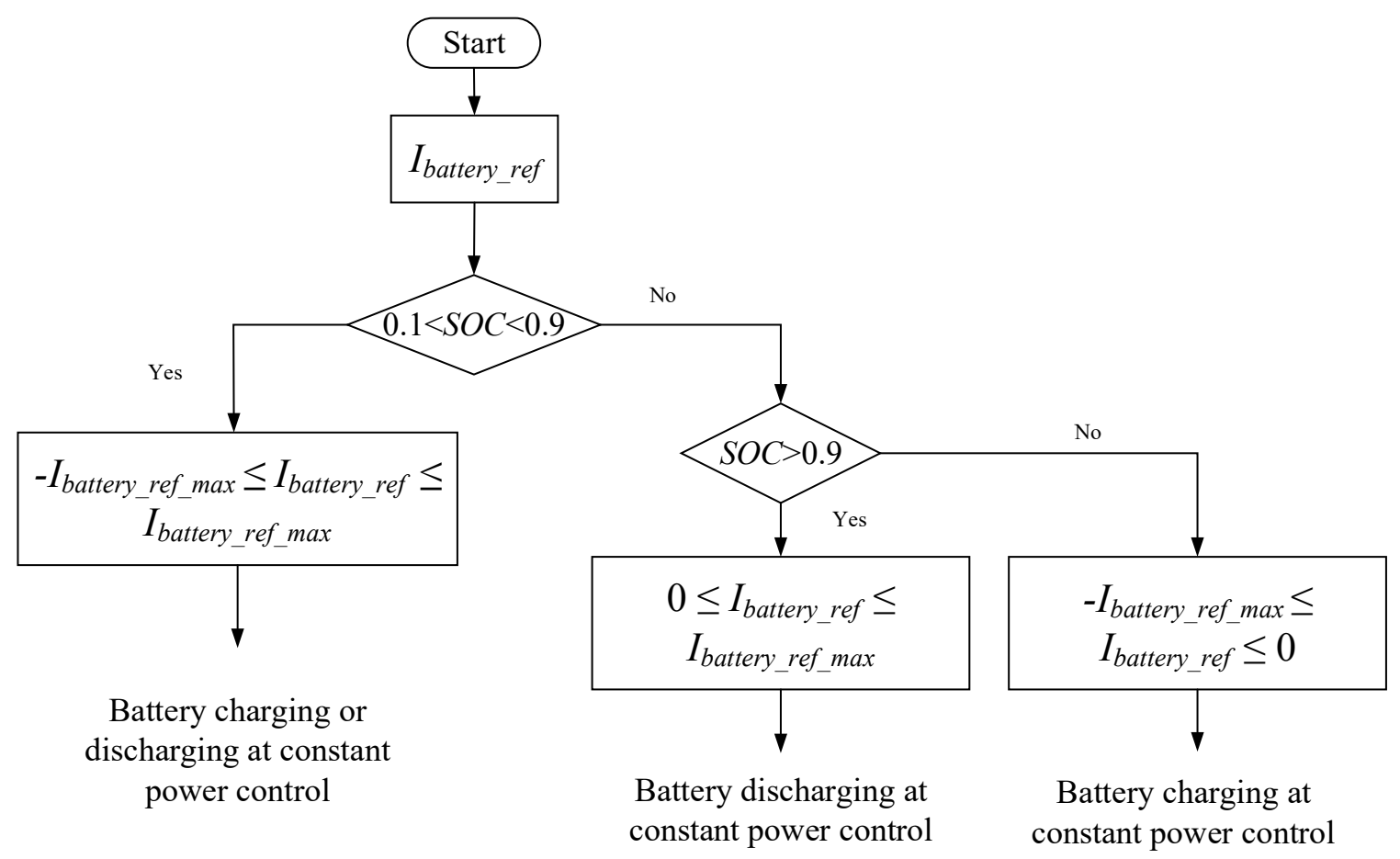

Figure 3.15 Flow chart of operation modes selection and limiting protection at different SOC values

The energy storage system receives optimized power command $P_{E S S_{s} s c h e d u l e}$ sent from upper EMS. In addition, the real-time fluctuation of PV power output and residential loads 
should be considered. Correspondingly, the sum of the difference between $P_{\text {load }}$ and $P_{p v}$ and the optimized power command $P_{\text {ESS_schedule }}$ sent from EMS is taken as the input into energy storage system. Then, the frequency division will be conducted on this sum named by $P_{E S S}$ in order to get its low frequency component. The low frequency component of $P_{E S S}$, which is called $P_{\text {battery_ref }}$, will be managed by battery, which can prevent the frequent battery charging/discharging. With $P_{\text {battery_ref }}$ is taken as the input, reference output current of battery $I_{\text {battery_ref }}$ can be known. By measuring the real-time SOC of battery, the charging/discharging can be determined. There are three scenarios listed as follows:

(1) $0.1<$ SOC $<0.9$ : Battery can work at charging/discharging mode normally. A limiting protection is required to avoid the battery charging/discharging. The limited range is set as $-I_{\text {battery_ref_max }} \leq I_{\text {battery_ref }} \leq I_{\text {batte_ref_max }}\left(I_{\text {battery_ref_max }} \geq 0\right)$. $I_{\text {batte_ref_max }}$ is the upper limit and $-I_{\text {batte_ref_max }}$ is the lower limit. Battery is discharging when $I_{\text {battery_ref }} \geq 0$. Battery is charging when $I_{\text {battery_ref }} \leq 0$.

(2) $\mathrm{SOC} \geq 0.9$ : When $\mathrm{SOC} \geq 0.9$, SOC value of battery exceeds the safe operation range. Battery is only permitted to work at discharging mode. A limiting protection is required to implement. The limited range is set as $0 \leq I_{\text {battery_ref }} \leq I_{\text {battery_ref_max }}$ $\left(I_{\text {battery_ref_max }} \geq 0\right)$.

(3) $\mathrm{SOC} \leq 0.1$ : When $\mathrm{SOC} \leq 0.1, \mathrm{SOC}$ value of battery is below the safe operation range. Battery is only permitted to work at charging mode. A limiting protection is required 
to implement. The limited range is set as $-I_{\text {battery_ref_max }} \leq I_{\text {batter_ref }} \leq 0$ $\left(I_{\text {battery_ref_max }} \geq 0\right)$.

As the PV household nano-grid system is grid-connected, main power grid can provide steady AC voltage and frequency. The single-phase DC/AC inverter connecting with main power gird deploys constant voltage control, which is capable of ensuring the voltage stability of DC bus bar. Because energy storage system is used to receive optimal power command from EMS, constant power control should be applied to energy storage system. When the exchanging power between PV nano-grid system and main power grid fluctuates due to the uncertain power output of PV generation and residential loads, the energy storage system can alleviate this power fluctuation. By alleviating the power fluctuation of PV nano-grid system, energy storage system can also stabilize the DC bus bar voltage. As a result, battery utilization can be largely improved and power balance in PV nano-grid system can be maintained by deploying constant power control for energy storage system.

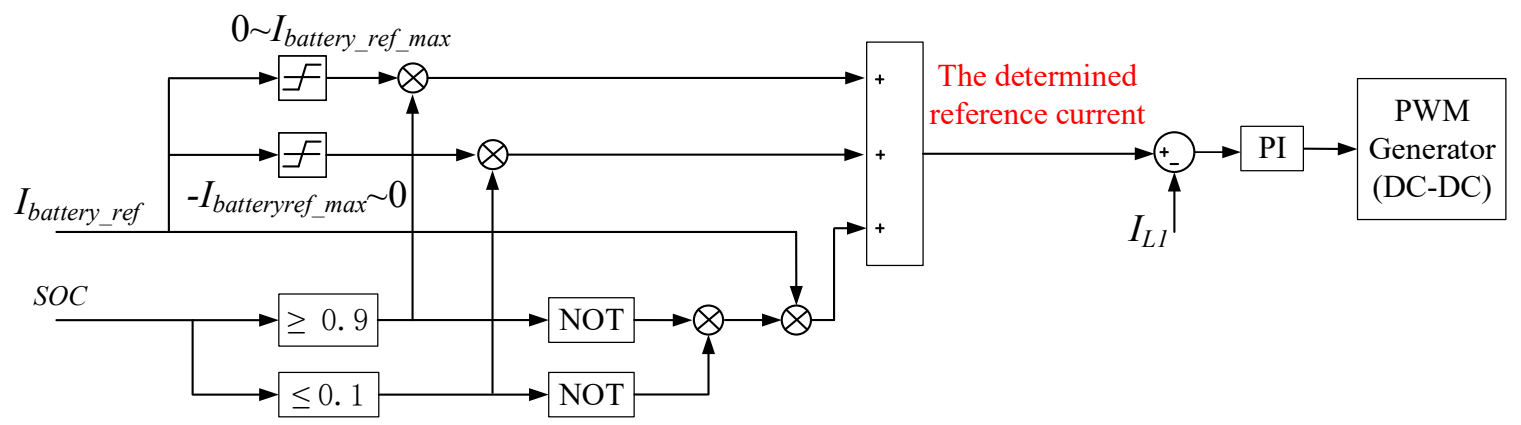

Figure 3.16 Control strategy of battery charging/discharging

Figure 3.16 shows the constant power control of battery. Battery charging/discharging reference current $I_{\text {battery_ref }}$ goes into the operation mode selection block. It selects the 
operation mode for battery based on the battery SOC value and passes through the limiting protection. Then, the reference current of the battery charging/discharging can be determined. With the utilization of single current loop, the real-time output current of battery $I_{L 1}$ tracks the determined reference current of the battery charging/discharging. By using PI controller, $I_{L 1}$ can track the determined reference current of the battery charging/discharging precisely. Duty cycle of the bi-directional DC/DC buck/boost converter in battery module can be controlled. Therefore, constant power control of battery can be realized.

\subsubsection{Characteristic and Control Strategy of the Supercapacitor}

Due to its low energy density and high power density, a supercapacitor has the ability of satisfying instantaneous large power demand of residential loads and charging/discharging without reducing lifespan, effectively compensating the disadvantages of battery. To deal with the rapid power fluctuation of power pulsed loads and PV generation, the supercapacitor can realize power compensation instantaneously. When power demand of residential loads suddenly increases, DC bus bar voltage will go down. At this time, the supercapacitor can respond quickly to discharge power to DC bus bar so that DC bus bar voltage goes up to the reference value. The discharging of the supercapacitor will be finished until DC bus bar voltage recovers. Then, the supercapacitor will be charged by the PV nano-grid system. Constant power control is also deployed to control the bi-directional DC/DC buck/boost converter in the supercapacitor module. 


\subsubsection{Control Strategy for Hybrid Energy Storage System}

Control strategy of coordinating hybrid energy storage system is described as follow: Due to the power fluctuation of PV power generation and power demand of residential loads, hybrid energy storage system is applied to smooth this power fluctuation. The difference value of real time power of residential load $P_{\text {load }}$ and PV power generation $P_{p v}$ is the power fluctuation of $\mathrm{PV}$ nano-grid system, named by $\Delta P=P_{\text {load }}-P_{p v} . \Delta P$ is added with optimized power command $P_{E S S_{-} \text {schedule }}$ that is scheduled by EMS from upper layer. Then frequency division is conducted on this sum, called by $P_{E S S}$. By utilizing the low pass filter in frequency division, low frequency component of $P_{E S S}$, named by $P_{\text {battery_ref }}$, is absorbed by battery while high frequency component of $P_{E S S}$, named by $P_{S c_{-} r e f}$, is absorbed by supercapacitor. The detailed process is shown in Figure 3.17.

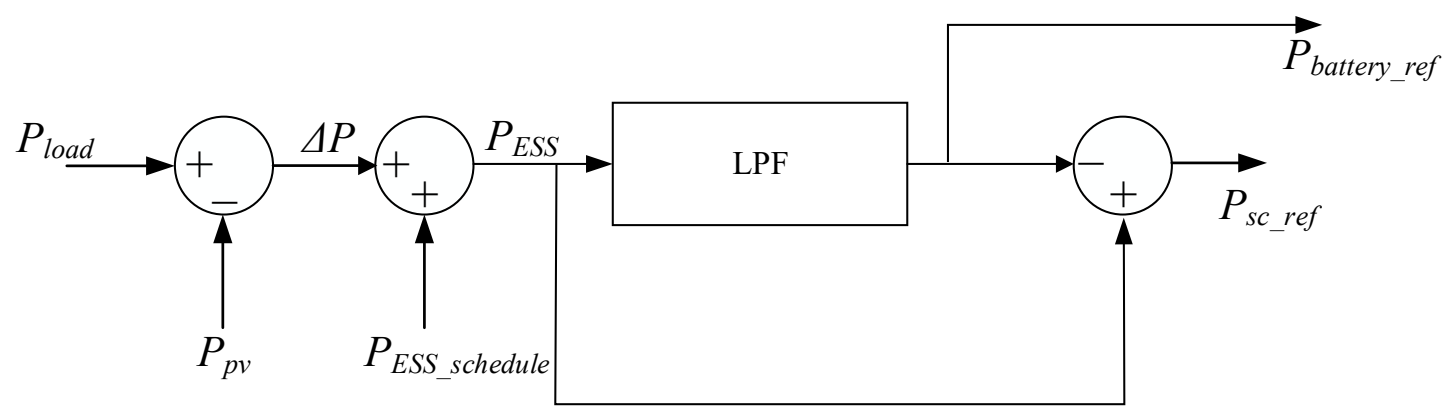

Figure 3.17 Frequency division of $\boldsymbol{P}_{E S S}$

In Figure 3.17, optimized power command $P_{\text {ESS_schedule }}$ from EMS is added with real time power fluctuation $\triangle P$. This sum, which is $P_{E S S}$, is sent into low pass filter. The power passing through low pass filter, which is $P_{\text {battery_ref }}$, is sent into control module of battery. This power is main portion of $P_{E S S}$, which fluctuates mildly in real time. However, the filtered high frequency component of $P_{E S S}$, which is $P_{S c_{-} r e f}$, is sent into control module of 
supercapacitor. This power is not very large but fluctuates rapidly in real time. When $P_{E S S}$ $>0$, battery can be taken as execution unit of scheduled power command $P_{E S S \_s c h e d u l e}$ and alleviate the low frequency component of power fluctuation $\Delta P$ by discharging. When $P_{E S S}<0$, battery can be taken as execution unit of scheduled power command $P_{E S S_{-} s c h e d u l e}$ and alleviate the low frequency component of power fluctuation $\Delta P$ by charging. Supercapacitor can realize the alleviation of power sum $P_{E S S}$ in transient state, which is high frequency, by rapid and frequent charging/discharging. Due to the limiting protection

in constant power control, excessive charging/discharging is prevented for the battery and supercapacitor in energy storage module. With the hybrid use of battery and supercapacitor, battery is not required to charge or discharge very frequently, which increases the battery lifespan.

\subsection{Single Phase Full-Bridge DC/AC Inverter and its Control Strategy}

For the PV grid-connected household nano-grid system, a single phase full-bridge DC/AC inverter is utilized for the grid connection. Based on IEEE 929, current going into main power grid is required to have a high current quality [53]. IEEE 929 requires that Total Harmonic Distortion (THD) of the current going into main power grid is smaller than 5\% and 3rd order $\sim 9$ rd order harmonic wave of the current going into main power grid is required to be smaller than $4 \% .11$ rd order 15 rd order harmonic wave of the current going into main power grid is required to be smaller than $2 \%$.

For the grid connection, the PV nano-grid system needs to invert DC current to be AC current having the same frequency and phase with main power grid. Main power grid can 
be considered as an infinite huge $\mathrm{AC}$ voltage source. If $\mathrm{DC} / \mathrm{AC}$ inverter deploys current controlled grid-connection mode, the output of DC/AC inverter can be considered as a controllable current source. Therefore, the PV grid-connected household nano-grid system and main power grid can be seen as a $\mathrm{AC}$ current source in parallel with a $\mathrm{AC}$ voltage source. The output voltage of DC/AC inverter is constrained to be the voltage of main power grid. With the utilization of a Phase Locked Loop (PLL), the output current of $\mathrm{DC} / \mathrm{AC}$ inverter is regulated to have same frequency and phase with $\mathrm{AC}$ voltage of main power grid, which guarantees grid-connection under unit power factor. At current controlled grid-connection mode, the grid-connected DC/AC inverter presents the characteristic of high impedance. The influence of disturbance of main power grid on output current of DC/AC inverter can be largely reduced. Thus, the quality of DC/AC inverter current output can be improved.

\subsubsection{Topology of Single Phase Full-Bridge DC/AC Inverter}

The single phase full-bridge $\mathrm{DC} / \mathrm{AC}$ inverter is used to modulate current, which regulates the output current of DC/AC inverter to have the same frequency and phase with $\mathrm{AC}$ voltage of main power grid. Figure 3.18 shows the topology of single phase full-bridge inverter, which is comprised of $C_{d c}$, four IGBT, and LCL filtering circuit. 


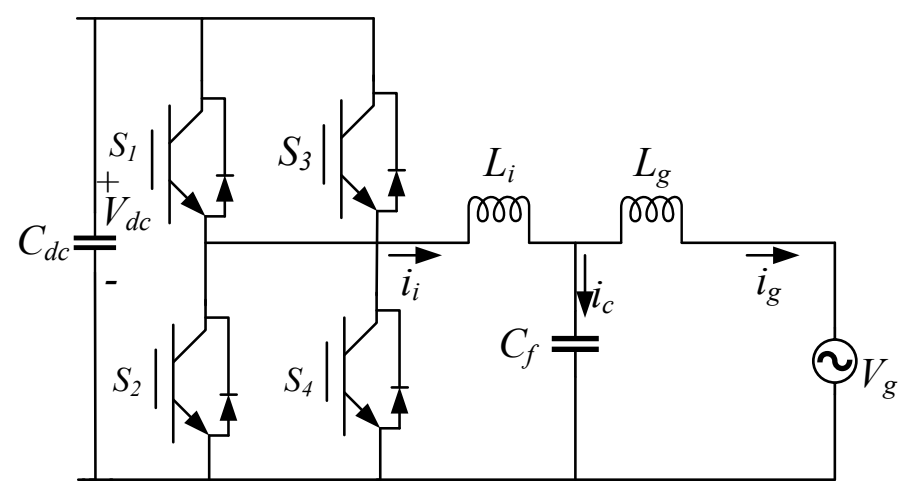

Figure 3.18 Topology of a single phase full-bridge inverter and LCL filter

In Figure 3.18, four IGBT controlled by inverter control system work as alternate conducting. The diodes in parallel with IGBT realize the bi-directional power flow. The capacitor $C_{d c}$, which is localized on the DC side of DC/AC inverter, can be used to realize the power decoupling from DC side of nano-grid system to AC side of nano-grid system. When PV nano-grid system works in steady state, power in DC side almost keeps unchanged while instantaneous power output of DC/AC inverter in AC side changes with time. In order to transfer steady power in DC side to AC power output of DC/AC inverter in AC side, a power decoupling process should be implemented for this inverting. Therefore, $C_{d c}$, which has a large capacity, is set up in DC/AC inverter to achieve the power decoupling between DC power and AC power.

\subsubsection{LCL Filter Design}

LCL filter is used to eliminate the harmonic waves of DC/AC inverter current output and realize the control for magnitude and phase of grid-connected AC current. Furthermore, LCL filter can isolate DC/AC inverter output and main power grid, which effectively protect the switches of DC/AC inverter and prevent the fault in main power grid side 
influencing DC/AC inverter. Therefore, grid-connected system can have damping characteristic due to the use of LCL filter, which is effective for control system of DC/AC inverter. The main LCL filters can be categorized as three types: L filter, LC filter, LCL filter. For L filter, large value inductor is used to effectively filter the harmonic waves, which increase the size and voltage loss of the filter. For LC filter, it is rarely used in gridconnected DC/AC inverter. Therefore, LCL filter, which has satisfactory dynamic performance, is utilized to filter the harmonic waves of grid-connected current. The detailed design of single phase full-bridge DC/AC inverter is shown as follows.

DC bus bar voltage $V_{d c}=500 \mathrm{~V}$; RMS value of DC/AC inverter voltage output $E_{m}=240 \mathrm{~V}$; Rated power output $=10 \mathrm{~kW}$; Grid-connected frequency $f_{N}=60 \mathrm{~Hz}$; Switch frequency $f_{S}=$ $2 \mathrm{kHz}$. Design procedures of LCL filter parameters are shown below:

(1) Based on the ripple current of inductor $L_{1}$, inductor $L_{1}$ can be determined.

$$
L_{1} \geq \frac{\left(2 V_{d c}-3 E_{m}\right) \times E_{m}}{2 V_{d c} \times \Delta i_{\max } \times f_{s}}
$$

In equation (3.11), $\Delta i_{\max }$ is the ripple value of inductor $L_{1}$ peak current value. $\Delta i_{\max }$ is set as $20 \%$. Therefore, according to equation (3.11), $L_{1}>2.1 \mathrm{mH}$. $L_{1}$ is taken as $3 \mathrm{mH}$ here.

(2) For $X_{L 1}$ and $X_{L 2}$, they are satisfied as $\frac{X_{L 1}}{X_{L 2}}=3 \sim 7$. Therefore, $L_{2}$ is taken as $1 \mathrm{mH}$ here.

(3) In order to let capacitor absorbing high frequency component, capacitive reactance of $C_{f}$ is set as $X_{c}\left(f_{s}\right)=(0.1 \sim 0.2) X_{L 2}\left(f_{s}\right)$. Based on experience, $C_{f}$ is taken as $50 \mu \mathrm{F}$. 
According to the above parameters, we can get $X_{c}(2 \mathrm{kHz})=1.6 \Omega ; X_{L 2}(2 \mathrm{kHz})=12.56 \Omega$; $\frac{X_{C}(2 K H z)}{X_{L 2}(2 K H z)}=0.12$. Therefore, $C_{f}=50 \mu \mathrm{F}$ is reasonable.

(4) Resonant frequency $f_{r e s}$ should be 10 times larger than the fundamental frequency of main power grid and smaller than $0.5 f_{s}$. Based on $L_{1}=3 \mathrm{mH}, L_{2}=1 \mathrm{mH}, C_{f}=50 \mu \mathrm{F}$, resonant frequency $f_{s}$ can be known:

$$
f_{\text {res }}=\frac{1}{2 \pi} \sqrt{\frac{L_{1}+L_{2}}{L_{1} \times L_{2} \times C_{f}}}=822 \mathrm{~Hz}
$$

Then, $10 f_{N} \leq f_{\text {res }} \leq 0.5 f_{s}$ is required. Therefore, $f_{\text {res }}=822 \mathrm{~Hz}$ is reasonable.

Based on the design of LCL filter above, parameters of LCL filter can be determined. For LCL filter, $L_{1}=3 \mathrm{mH} ; L_{2}=1 \mathrm{mH} ; C_{f}=50 \mu \mathrm{F}$.

\subsubsection{Control Strategy of Single Phase Full-Bridge DC/AC Inverter}

The use of DC/AC inverter realizes the grid-connection of PV system. The aim of using inverter is to achieve the output current of inverter which has the same frequency and phase with AC voltage of main power grid. At the same time, the harmonic waves of gridconnected current should be reduced with the deployment of LCL filter. Therefore, the influence of disturbance from these harmonic waves could be largely reduced. Figure 3.19 shows the constant voltage control as control strategy of the single phase full-bridge inverter, which is a double loop control. 


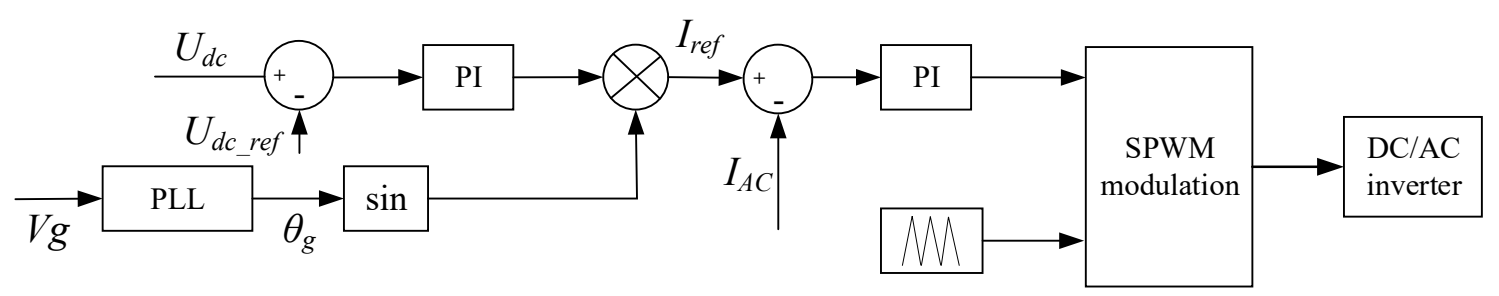

Figure 3.19 Control strategy of single phase full-bridge inverter for grid-connection

In order to realize the power balance of input power and output power of DC/AC inverter, DC bus bar voltage should be stabilized, which deploys outer voltage loop. Therefore, real time DC bus bar voltage $U_{d c}$ is used to track the reference voltage of DC bus bar $U_{d c \_r e f}$. The error voltage is sent into PI controller to output the magnitude of reference gridconnected current $I_{r e f}$. At the same time, because the phase of AC voltage of main power grid needs to be known. AC voltage of main power grid, which is achieved by sampling, is sent into PLL. Thus, the phase of main power grid voltage $\theta_{g}$ could be known. Then, by multiplying the magnitude of grid-connected current and $\sin \theta_{g}$, the reference current output of DC/AC inverter $I_{r e f}$ is achieved. Then, real time current output of DC/AC inverter $I_{A C}$ is used to track reference current output of DC/AC inverter $I_{r e f}$, which is inner current loop. At the end, by using SPWM modulation, PWM signal can control the single phase full-bridge inverter and realize the control of grid connection.

\subsubsection{Simulation of Single Phase Full-Bridge DC/AC Inverter Control and Its} Analysis

Grid connection plays a significant role in PV grid-connected household nano-grid system, which ensures normal operation of PV nano-grid system. Therefore, grid-current and main power grid voltage are simulated to show the validity of grid connection. Power output of 
residential loads $P_{\text {load }}$ changes in the simulation as a way to prove the robustness of inverter control.

For this simulation, $P_{\text {load }}$ is set as $0 \mathrm{~kW}, 4.8 \mathrm{~kW}, 6.3 \mathrm{~kW}$ at $\mathrm{t}=0 \mathrm{~s}, \mathrm{t}=1.5 \mathrm{~s}, \mathrm{t}=2.5 \mathrm{~s} . P_{p v}=$ $8.4 \mathrm{~kW}$ at $1000 \mathrm{~W} / \mathrm{m}^{2}, 25^{\circ} \mathrm{C} . P_{\text {ESS_schedule }}=3 \mathrm{~kW}$. Grid-connected current $I_{\text {grid_connected }}$ and main power grid voltage $V_{\text {grid }}$ are simulated, which is shown in Figure 3.20 and Figure 3.21. Figure 3.21 shows the enlarged simulation result of $I_{\text {grid_connected }}$ and $V_{\text {grid. }}$

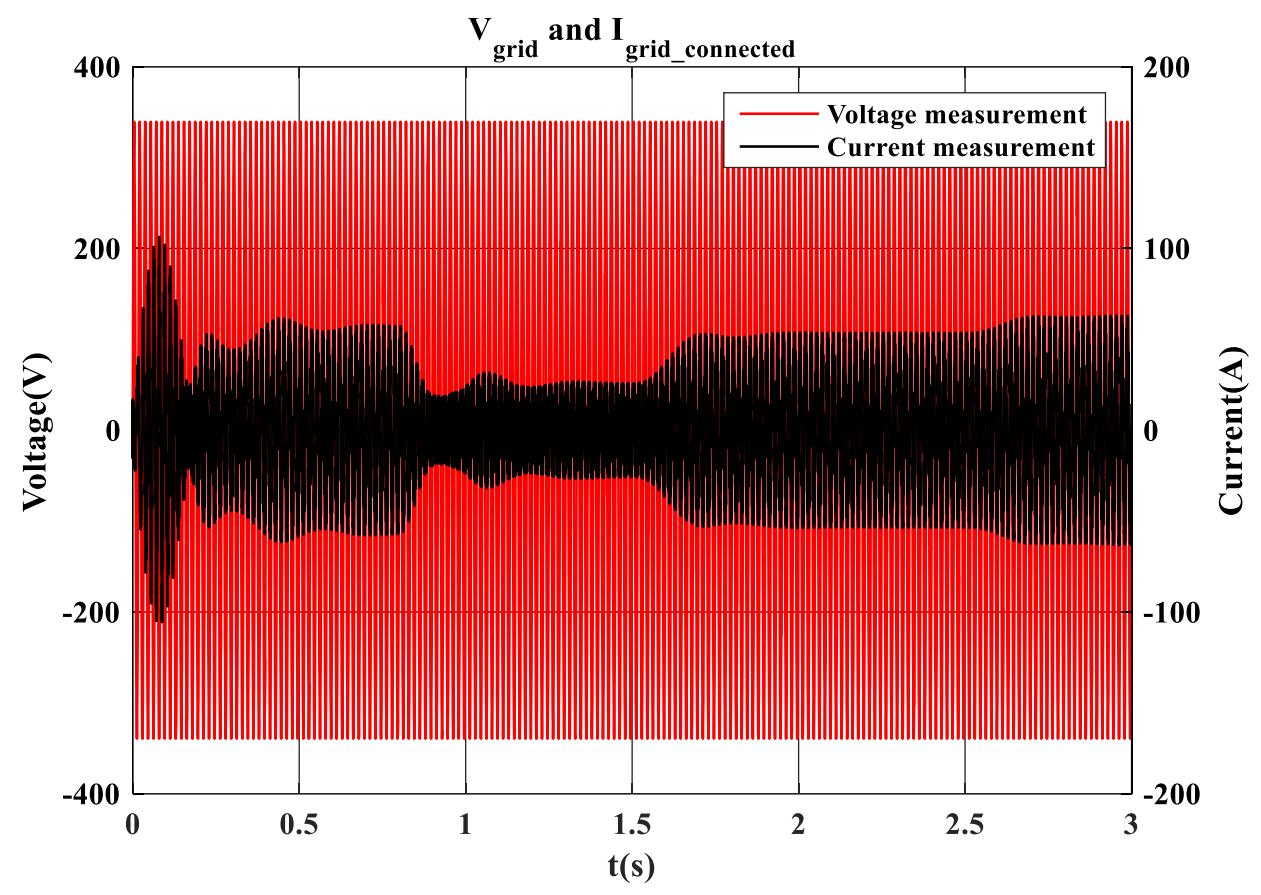

Figure 3.20 Main power grid voltage and grid connected current 


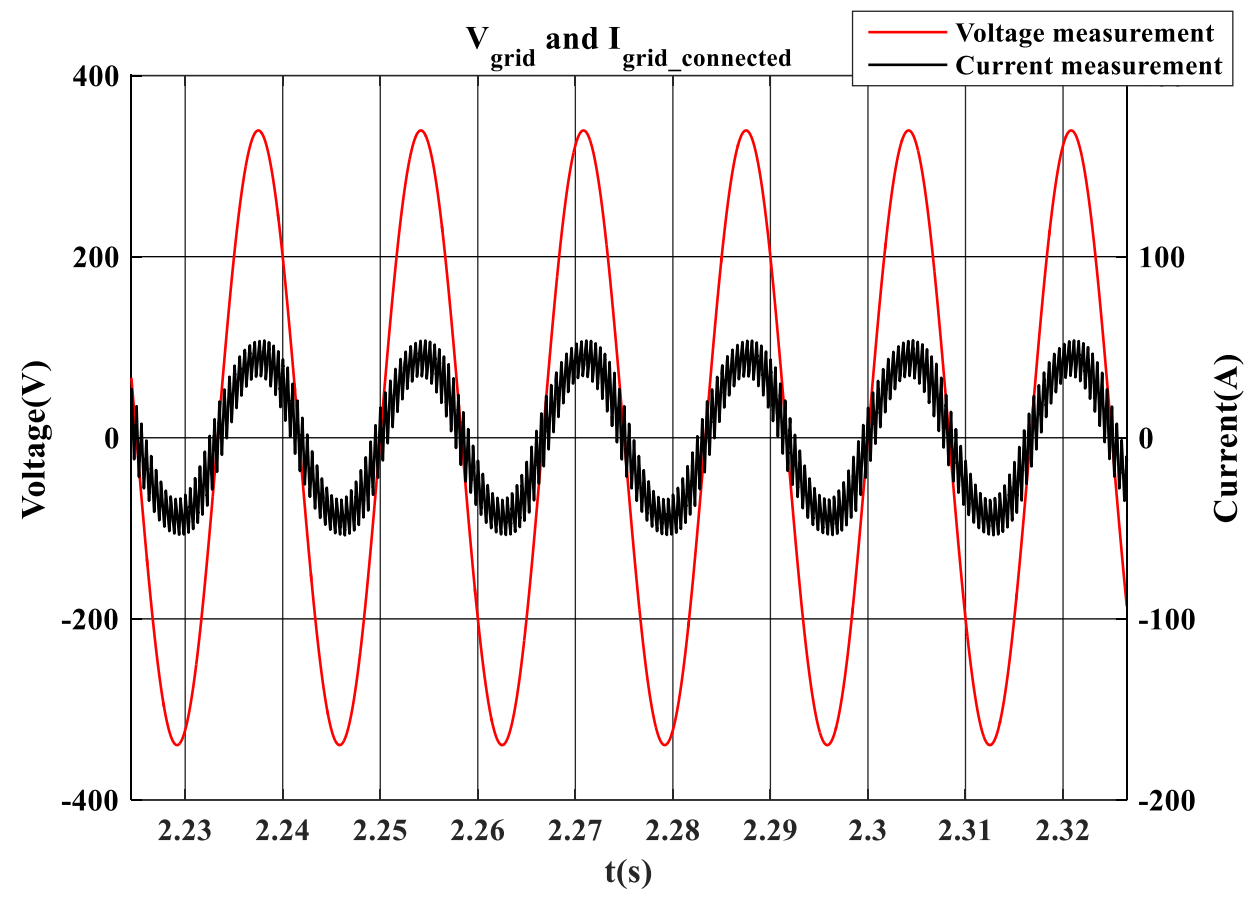

Figure 3.21 Main power grid voltage and grid-connected current(enlarged)

From Figure 3.20 and 3.21, main power grid voltage and grid connected current are in the same phase and same frequency, which proves the correctness of inverter control.

From the Figure 3.22, the current going into main power grid is simulated. Most of harmonic waves are filtered by LCL filter. Fast Fourier Transform(FFT) analysis is shown in Figure 3.23 to prove the reliability of LCL filter. 


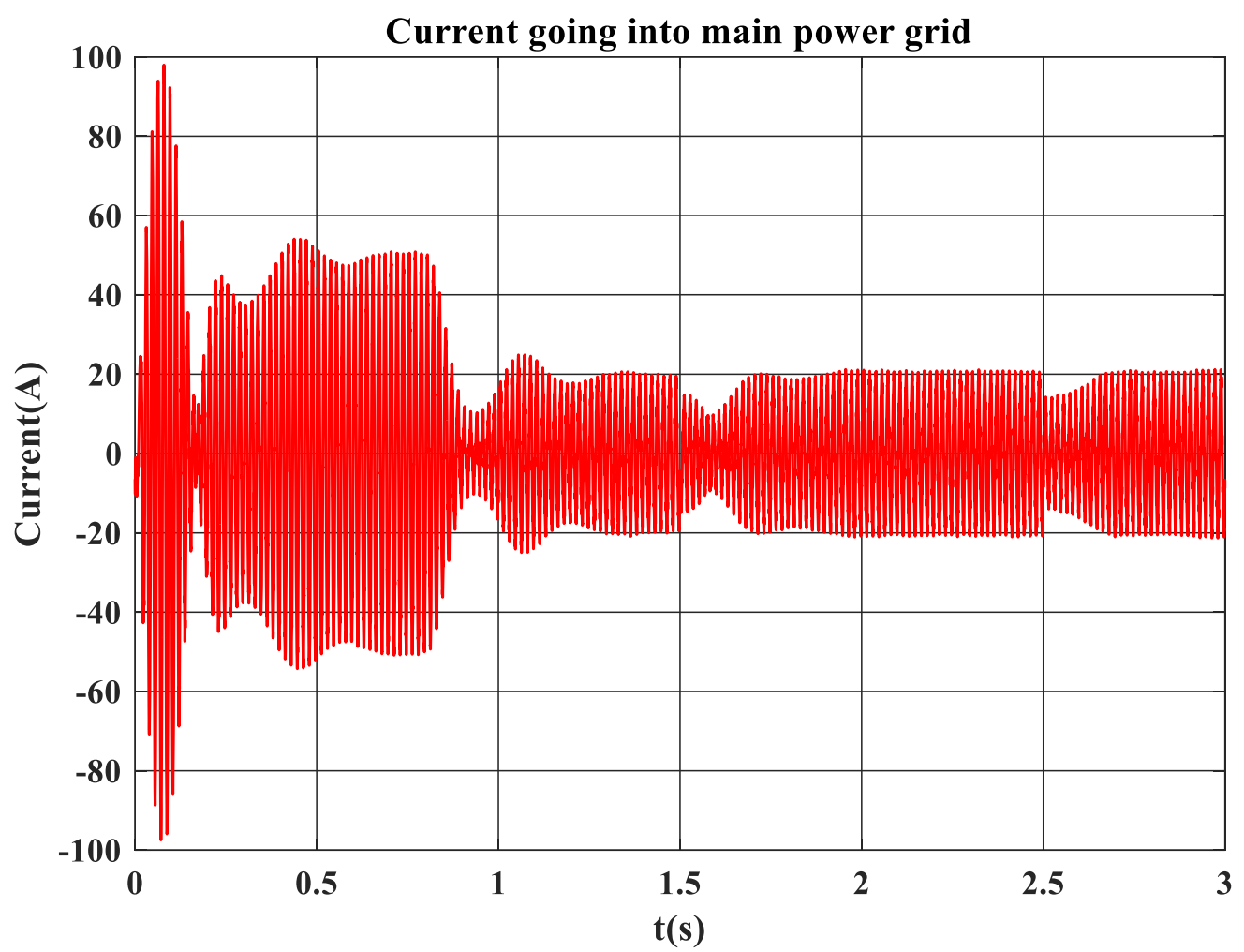

Figure 3.22 Current going into main power grid

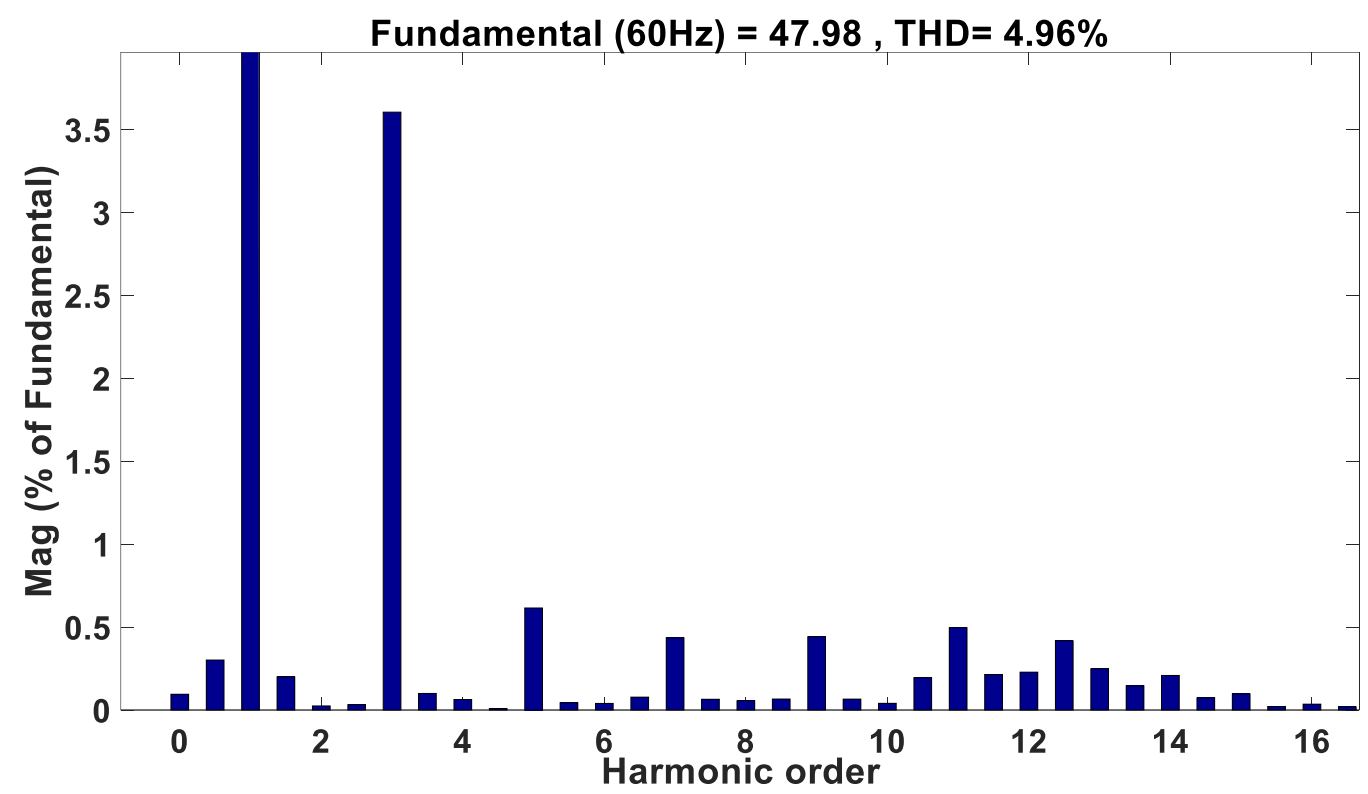

Figure 3.23 FFT Analysis of the current going into main power grid 
In Figure3.23, it can be seen that THD of the current going into main power grid is $4.96 \%$, which is smaller than $5 \%$. 3rd order $\sim 9$ rd order harmonic wave of the current going into main power grid is smaller than $4 \%$. 11 rd order 15 rd order harmonic wave of the current going into main power grid is smaller than $2 \%$. Therefore, the feasibility of this LCL filter has been proven.

\subsection{Simulation Analysis of PV Grid-Connected Household Nano-Grid System}

The PV grid-connected household nano-grid system is modeled in MATLAB/Simpower and simulated for $3 \mathrm{~s} . \Delta P$ is the power fluctuation of $\mathrm{PV}$ and residential loads. The following four conditions are demonstrated: Steady state, $P_{p v}$ changes, $P_{E S S \_s c h e d u l e}$ changes, power consumption of residential loads $P_{\text {load }}$ changes. Power maximum power generation, power consumption of residential loads, DC bus bar voltage, power scheduled by EMS $P_{E S S_{-} s c h e d u l e}$, power sum of scheduled power command from EMS and power fluctuation $P_{E S S}$, low frequency power of $P_{E S S}$ managed by battery $P_{\text {battery_ref }}$, high frequency power of $P_{E S S}$ managed by supercapacitor $P_{S C_{-} \text {ref }}$, battery charging/discharging current $I_{\text {battery }}$ and supercapacitor charging/discharging current $I_{s c}$ are displayed to prove the feasibility and correctness of this model. The hybrid energy storage system is comprised of battery and supercapacitor. Battery and supercapacitor parameters are set as follows: For the battery, nominal voltage is $120 \mathrm{~V}$. Rated capacity is $6.5 \mathrm{~A} * \mathrm{~h}$. Initial SOC is $50 \%$. For the supercapacitor, capacitance is $60 \mathrm{~F}$. Capacitor initial voltage is $100 \mathrm{~V}$.

1) At Steady State

$P_{E S S_{-} s c h e d u l e}, P_{p v}$ and $P_{\text {load }}$ are kept unchanged. $P_{E S S_{-} \text {schedule }}$ is set as $2 \mathrm{~kW} . P_{p v}=8.4 \mathrm{~kW}$ 
at $25^{\circ} \mathrm{C}, 1000 \mathrm{~W} / \mathrm{m}^{2} . P_{\text {load }}=4 \mathrm{~kW}$. Therefore, we should get:

$$
\begin{aligned}
& \Delta P=P_{\text {load }}-P_{p v}=4 \mathrm{~kW}-8.4 \mathrm{~kW}=-4.4 \mathrm{~kW} ; \\
& P_{E S S}=\left(P_{\text {load }}-P_{p v}\right)+P_{E S S_{\text {_schedule }}}=-4.4 \mathrm{~kW}+2 \mathrm{~kW}=-2.4 \mathrm{~kW} ;
\end{aligned}
$$

Simulation results are shown below:

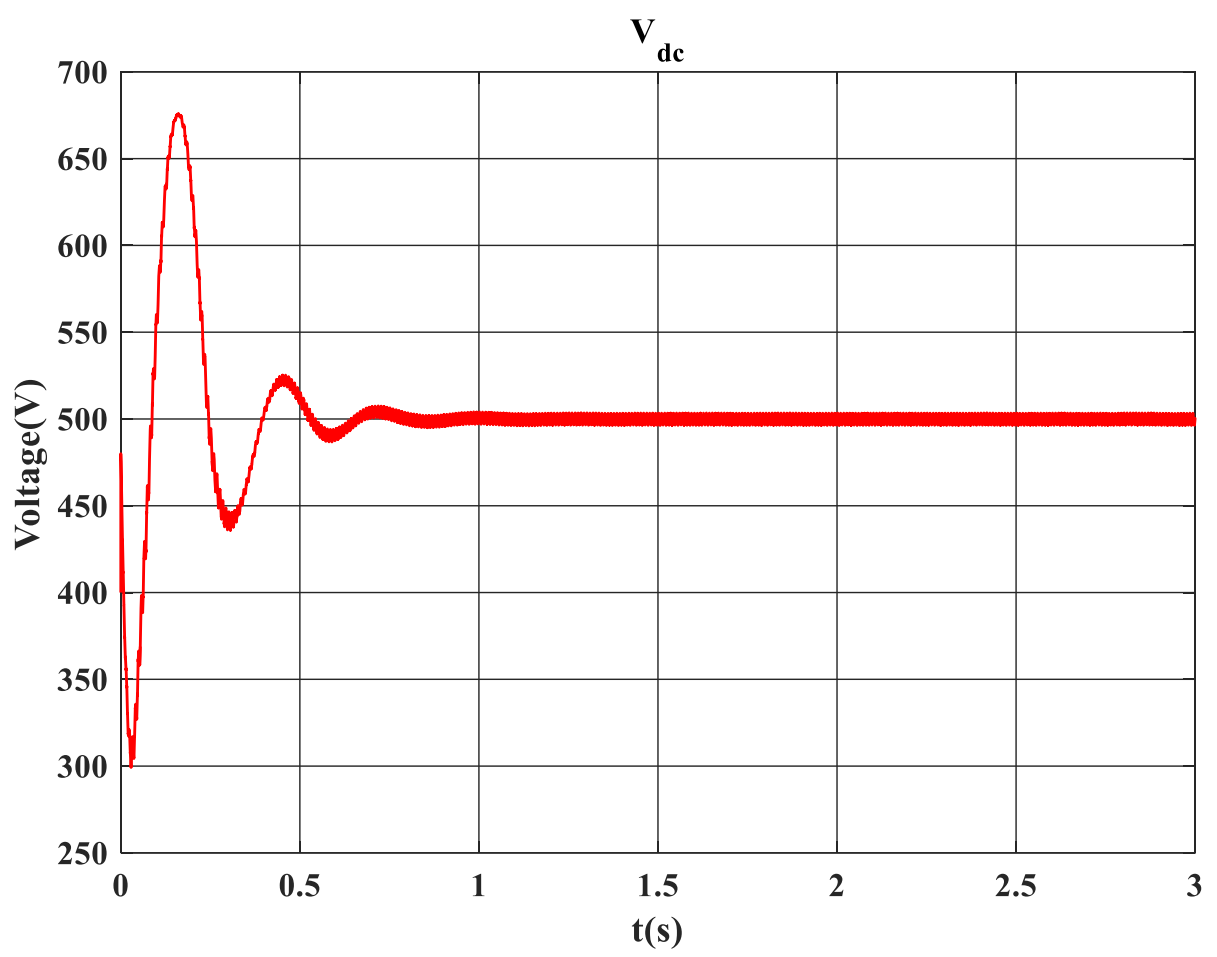

Figure 3.24(a) DC bus bar voltage 


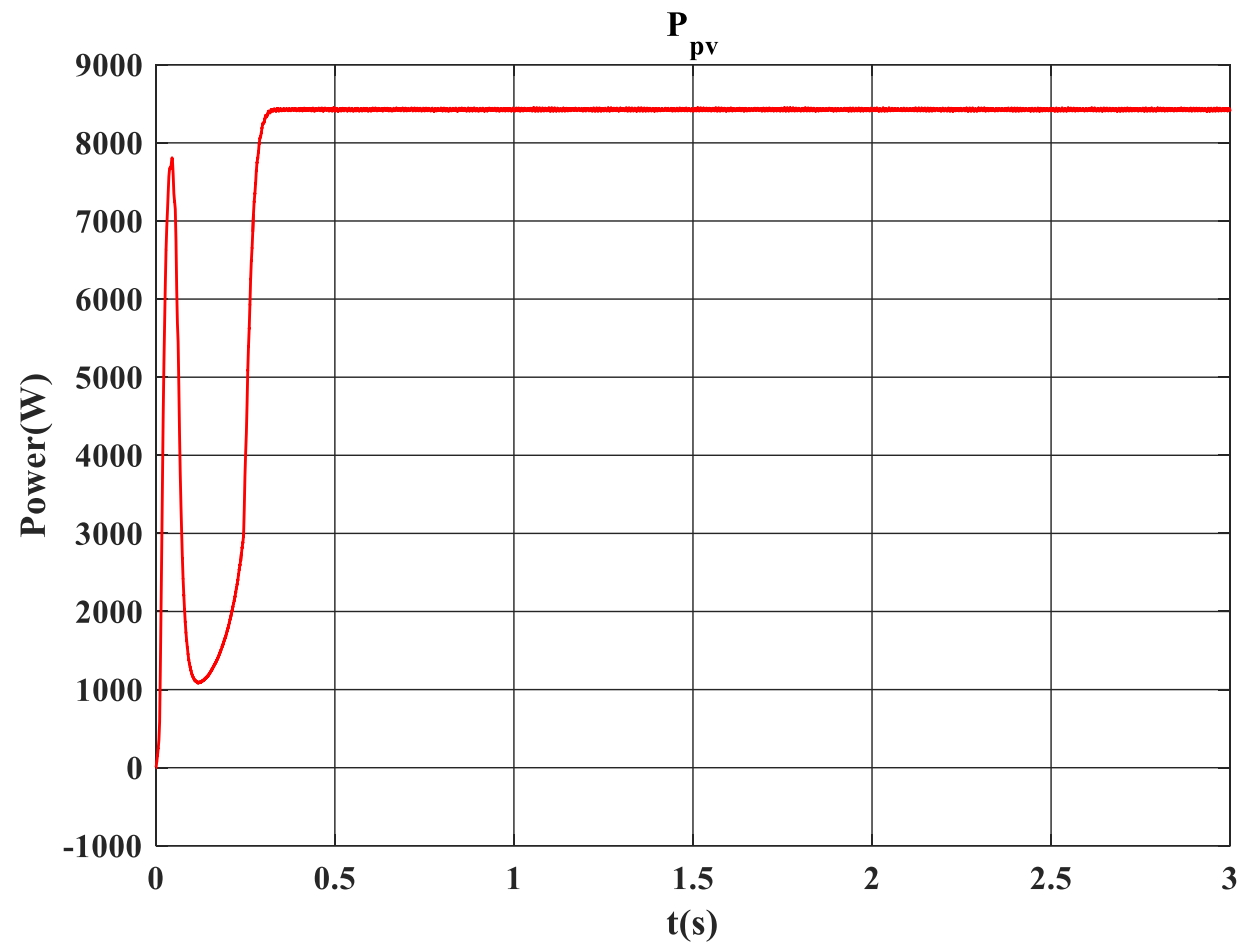

Figure 3.24(b) PV power output

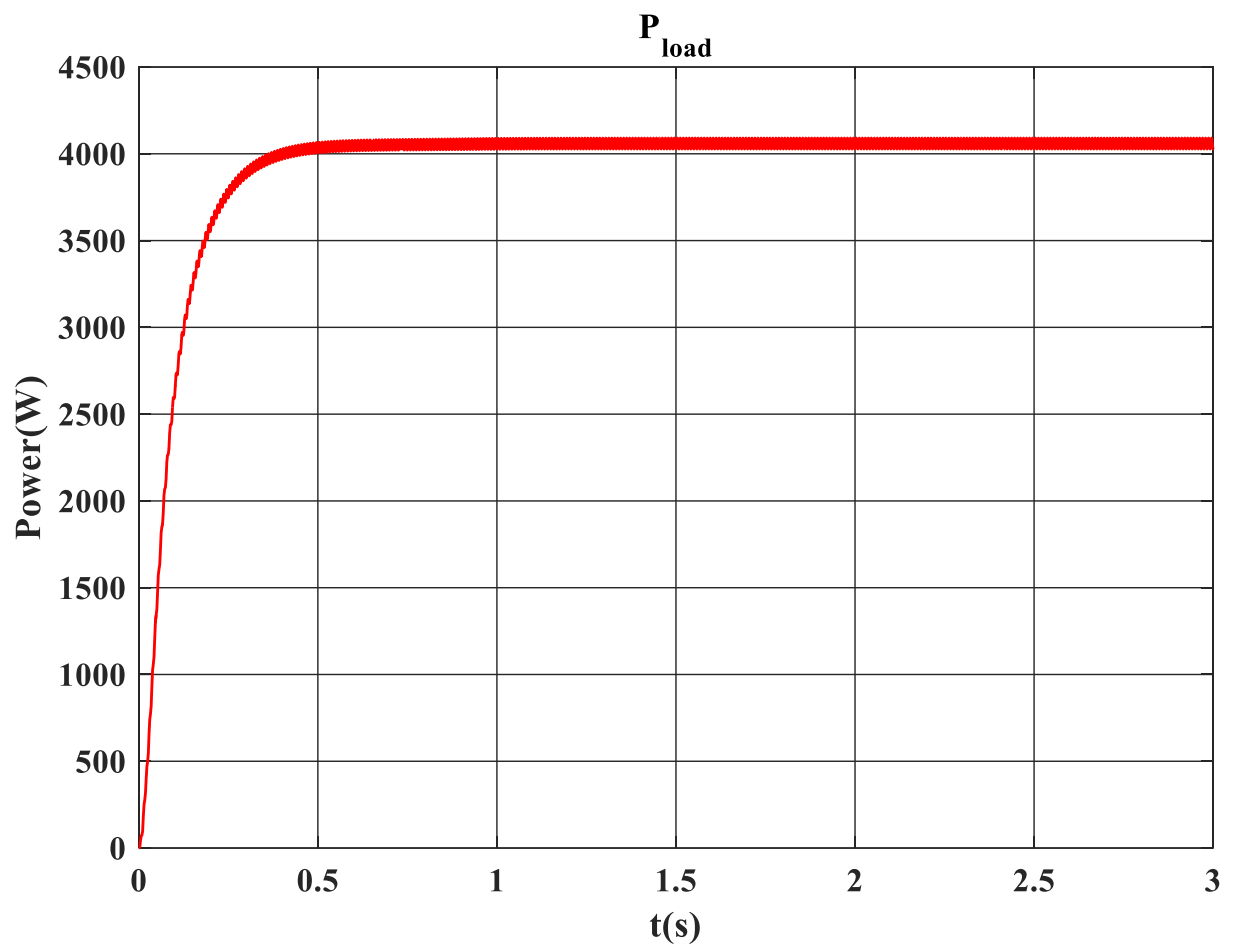

Figure 3.24(c) Power consumption of loads 


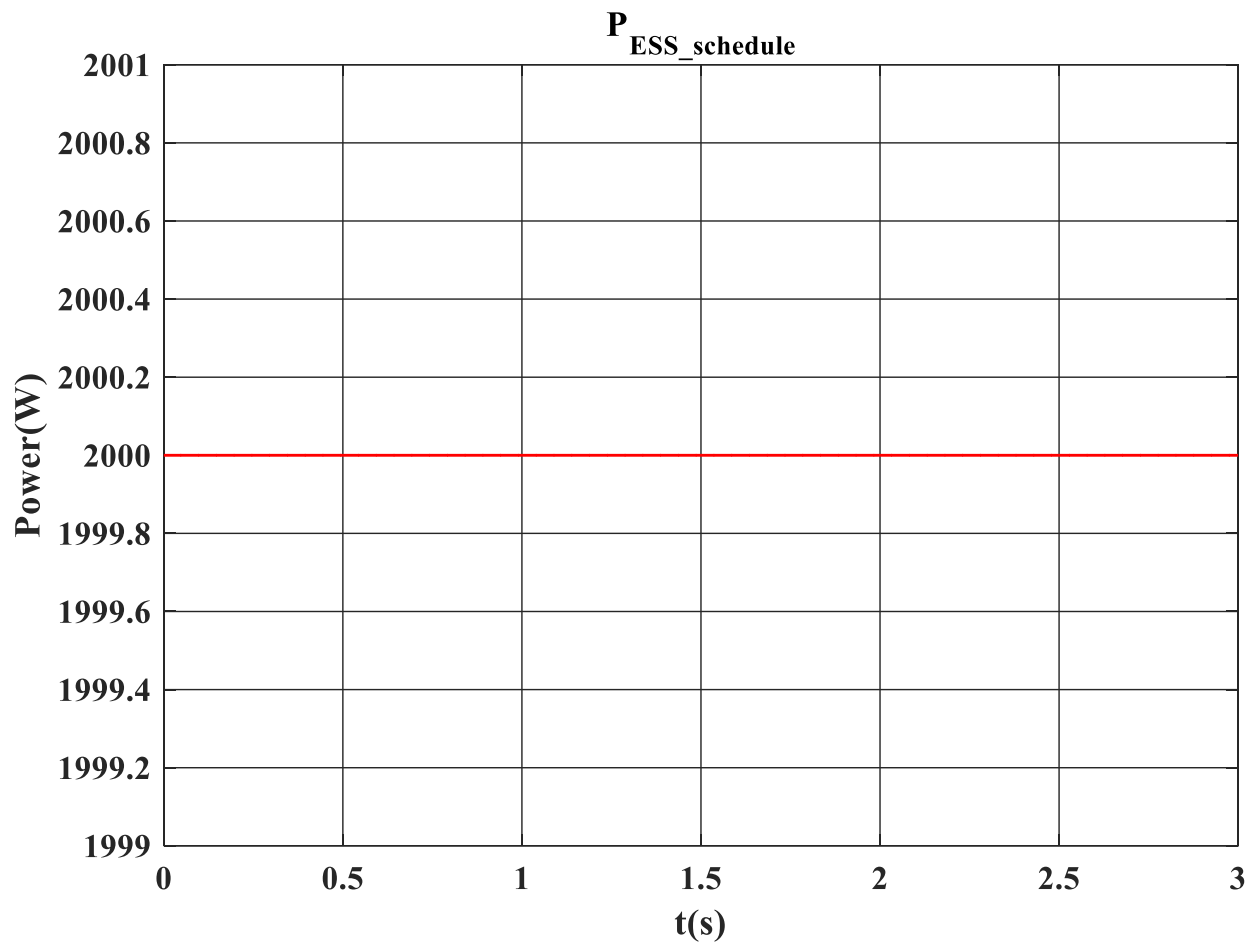

Figure 3.24(d) Optimal scheduled power command

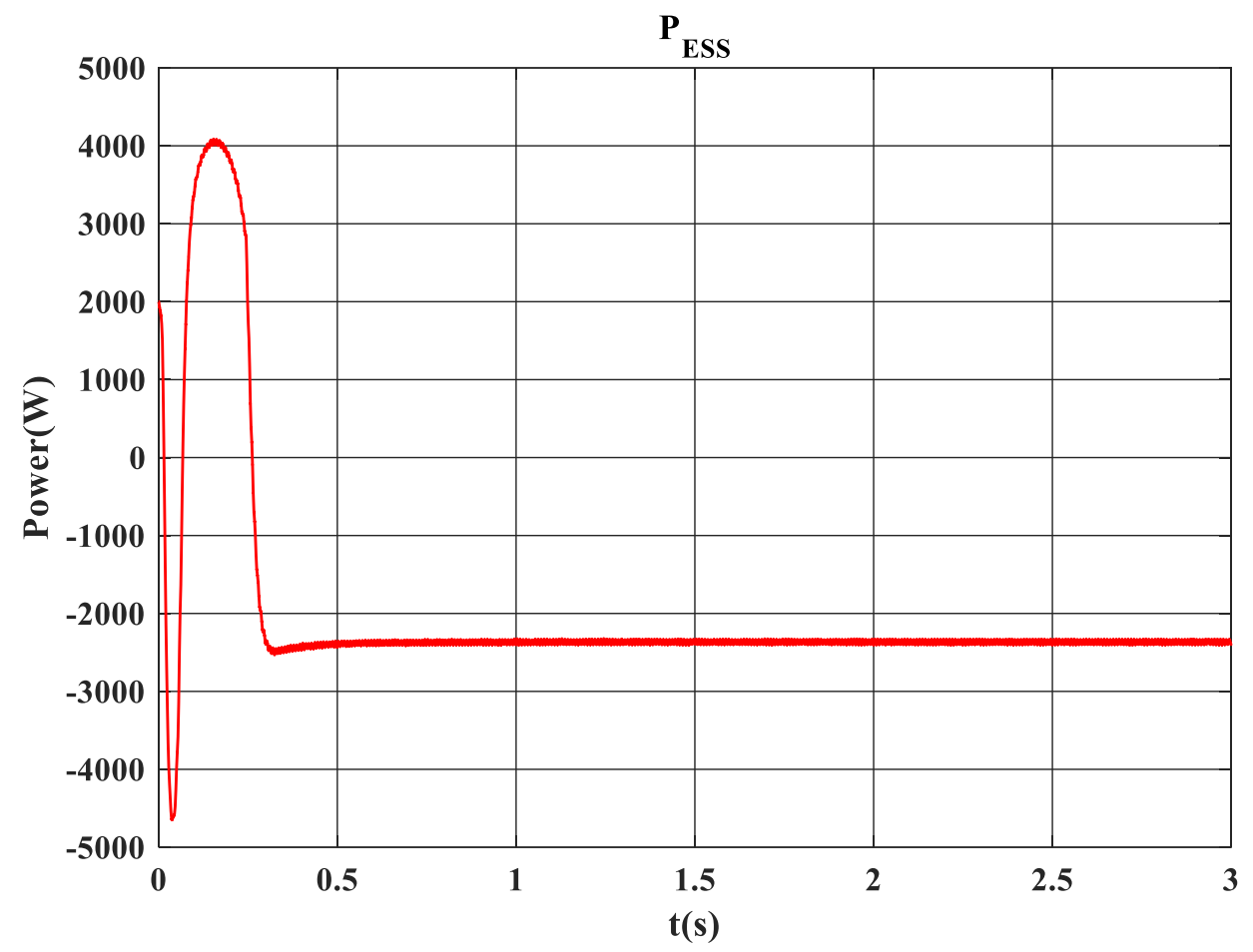

Figure 3.24(e) Power sum of scheduled power command and power fluctuation 


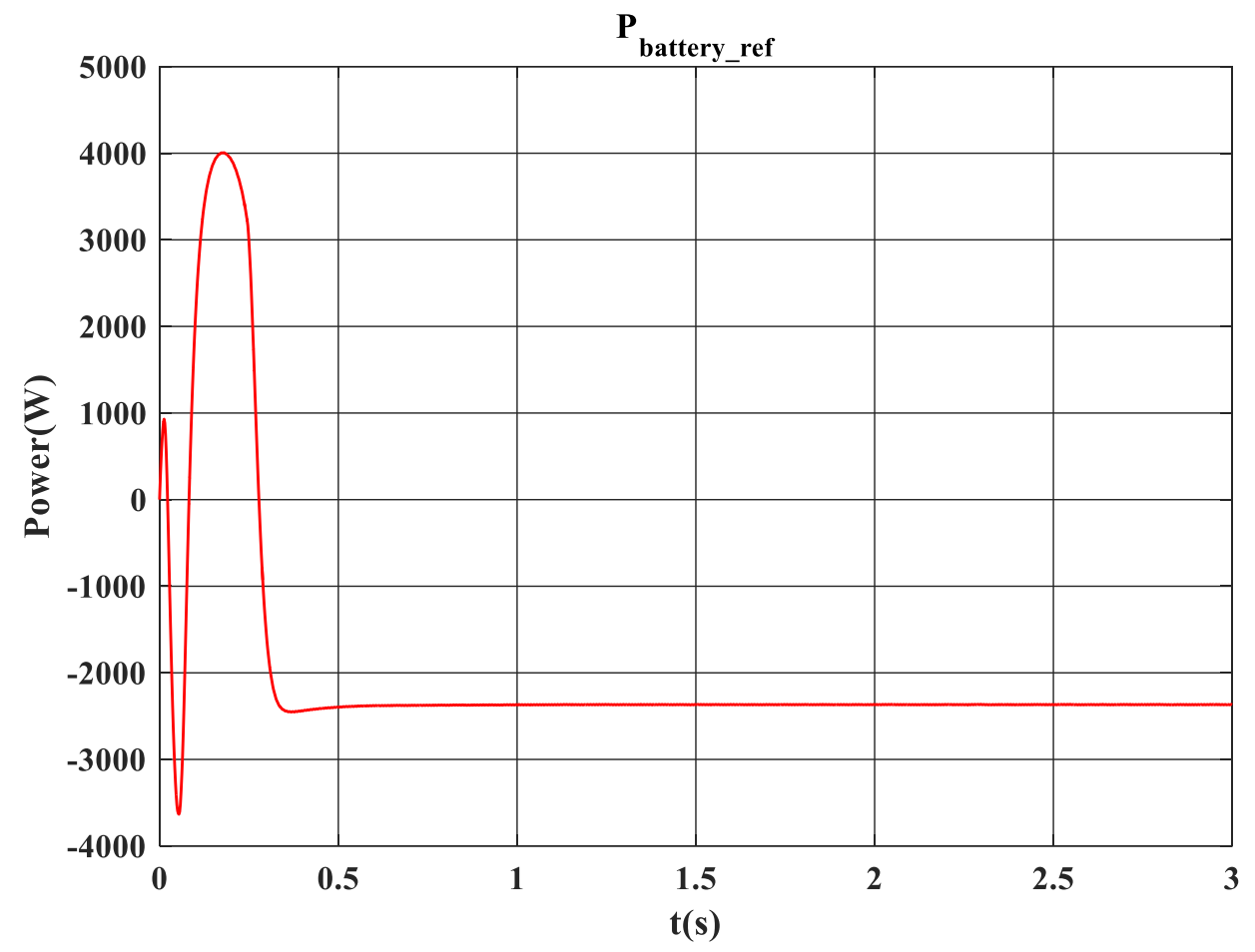

Figure 3.24(f) Low frequency power component of the power sum managed by battery

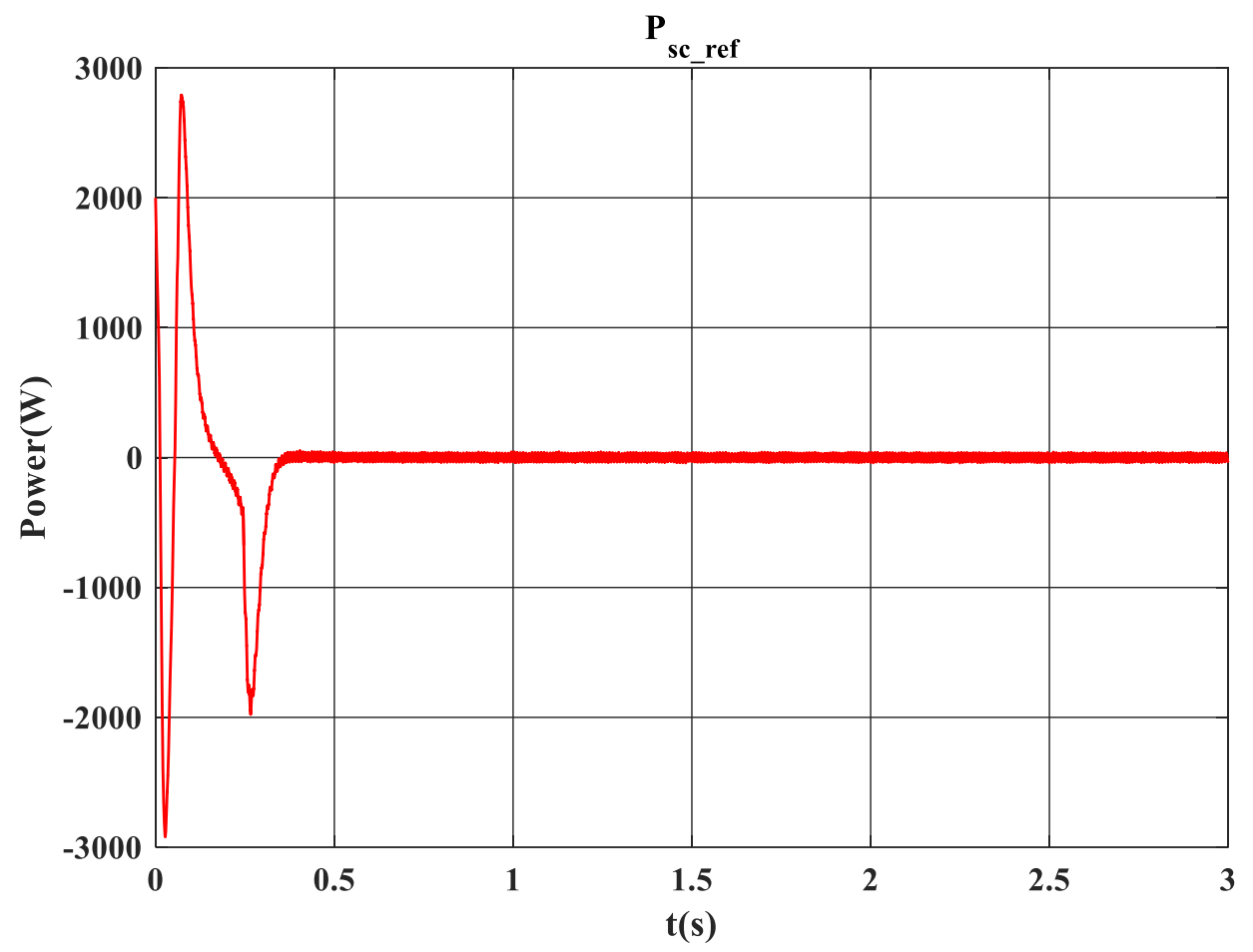

Figure 3.24(g) High frequency power component of the power sum managed by supercapacitor 


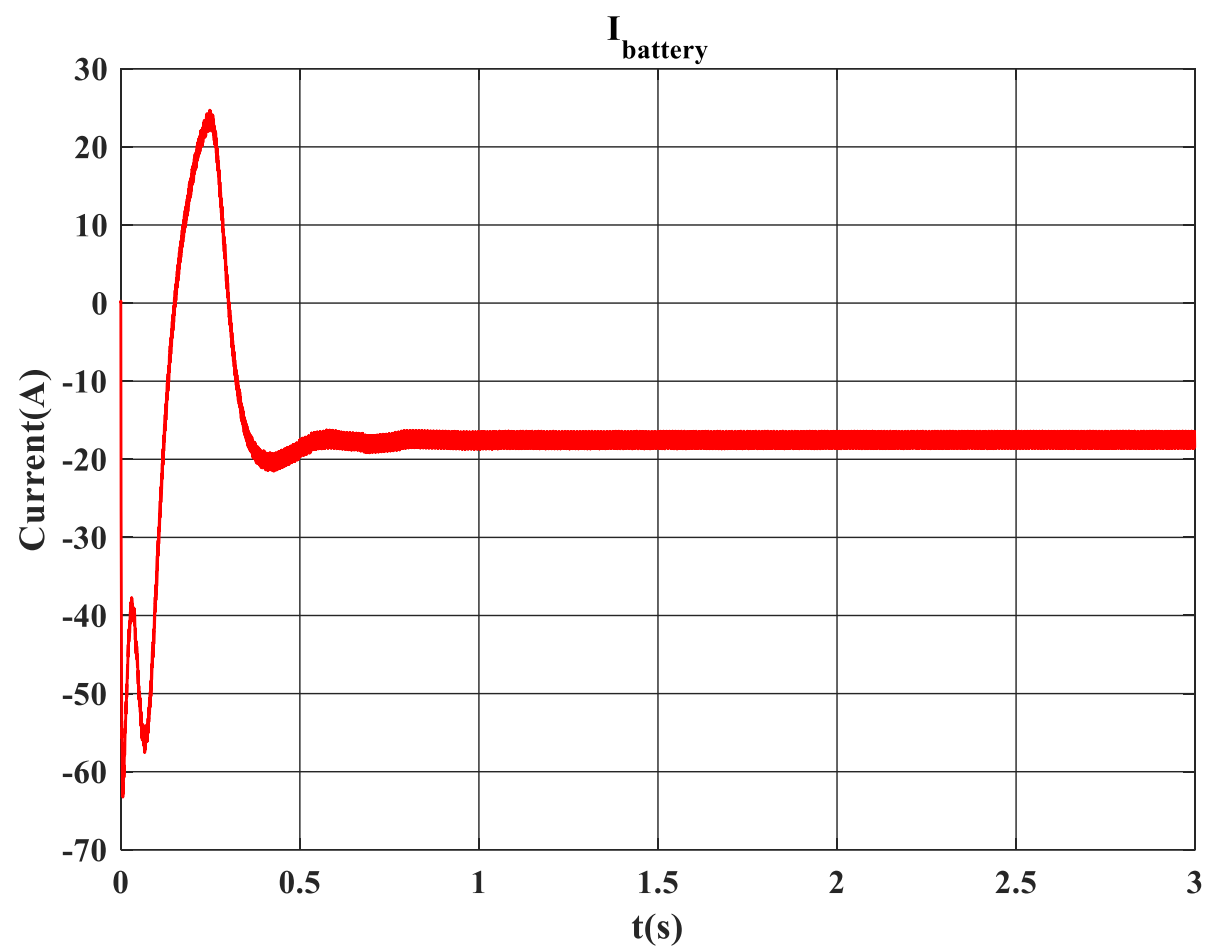

Figure 3.24(h) Battery charging/discharging current

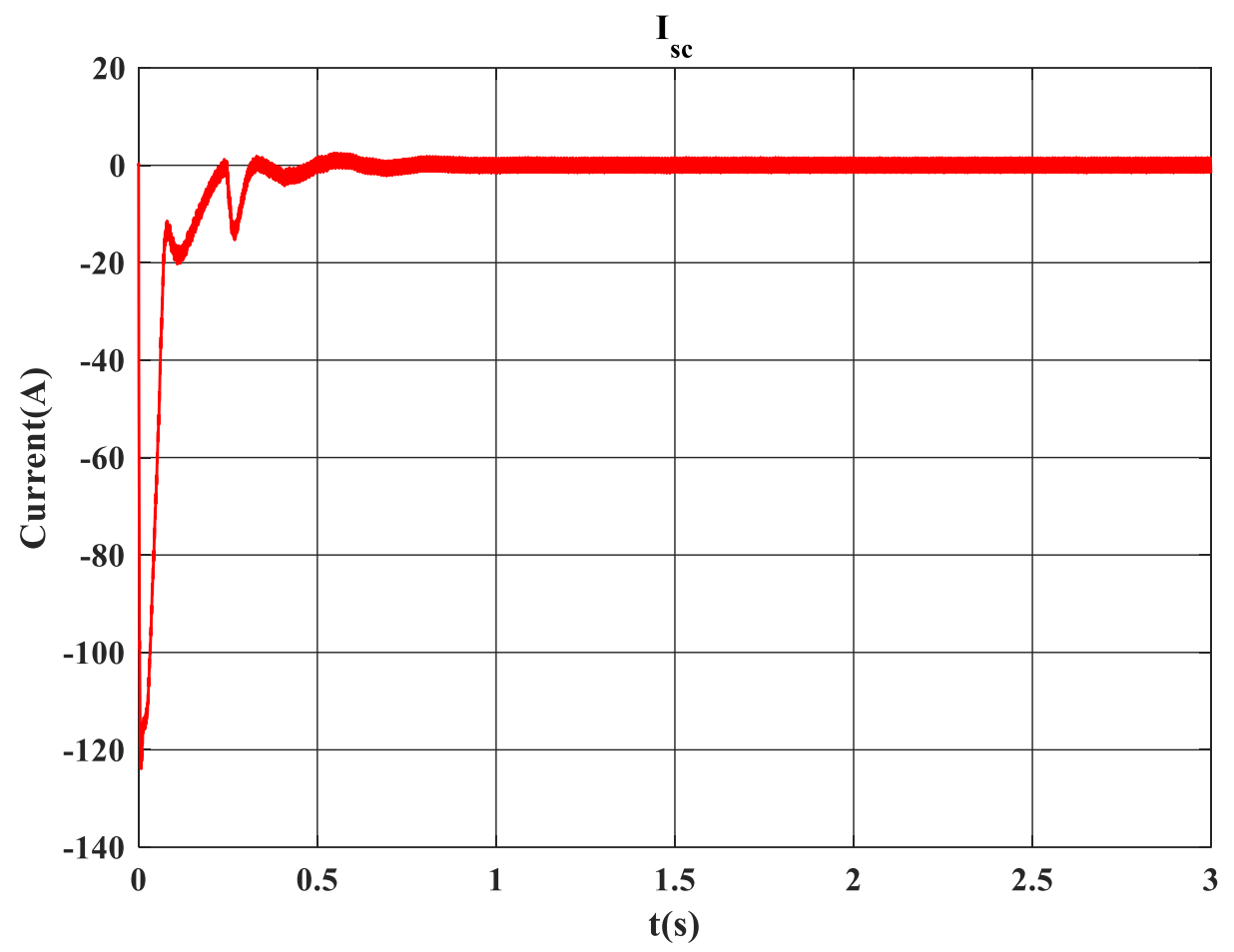

Figure 3.24(i) Supercapacitor charging/discharging current

Figure 3.24 Simulation results at steady state 
From simulation analysis in Figure 3.24, Simulation results match the assumed condition. DC bus bar voltage is stabilized around $500 \mathrm{~V}$ at steady state. The low frequency component of $P_{E S S}$ is managed by battery while the high frequency component of $P_{E S S}$ is managed by supercapacitor. The battery is charging at constant current in this condition. The supercapacitor is charging/discharging frequently in order to alleviate the high frequency component of power fluctuation.

\section{2) $\quad P_{p v}$ Changes}

Irradiance and temperature is set at $1000 \mathrm{~W} / \mathrm{m}^{2}, 25^{\circ} \mathrm{C} ; 800 \mathrm{~W} / \mathrm{m}^{2}, 50^{\circ} \mathrm{C} ; 400 \mathrm{~W} / \mathrm{m}^{2}, 75^{\circ} \mathrm{C}$ at $\mathrm{t}=0 \mathrm{~s}, 1 \mathrm{~s}, 2 \mathrm{~s} . P_{E S S_{-} s c h e d u l e}$ and $P_{\text {load }}$ are kept unchanged. $P_{E S S_{-} s c h e d u l e}=3 \mathrm{~kW}, P_{\text {load }}=$ 4kW. Therefore, we should get:

$$
\begin{aligned}
& \text { At } \mathrm{t}=0 \sim 1 \mathrm{~s}: \\
& P_{p v}=8.4 \mathrm{~kW} ; \\
& \Delta P=P_{\text {load }}-P_{p v}=4 \mathrm{~kW}-8.4 \mathrm{~kW}=-4.4 \mathrm{~kW} ; \\
& P_{E S S}=\left(P_{\text {load }}-P_{p v}\right)+P_{E S S_{-} s c h e d u l e}=-4.4 \mathrm{~kW}+3 \mathrm{~kW}=-1.4 \mathrm{~kW} ; \\
& \text { At } \mathrm{t}=1 \sim 2 \mathrm{~s}: \\
& P_{p v}=6.3 \mathrm{~kW} ; \\
& \Delta P=P_{\text {load }}-P_{p v}=4 \mathrm{~kW}-6.3 \mathrm{~kW}=-2.3 \mathrm{~kW} ; \\
& P_{E S S}=\left(P_{\text {load }}-P_{p v}\right)+P_{E S S_{-} \text {schedule }}=-2.3 \mathrm{~kW}+3 \mathrm{~kW}=-0.7 \mathrm{~kW} ;
\end{aligned}
$$

At $\mathrm{t}=2 \sim 3 \mathrm{~s}:$ 


$$
\begin{aligned}
& P_{p v}=2.7 \mathrm{~kW} \\
& \Delta P=P_{\text {load }}-P_{p v}=4 \mathrm{~kW}-2.7 \mathrm{~kW}=1.3 \mathrm{~kW} ; \\
& P_{E S S}=\left(P_{\text {load }}-P_{p v}\right)+P_{\text {ESS_schedule }}=1.3 \mathrm{~kW}+3 \mathrm{~kW}=4.3 \mathrm{~kW} ;
\end{aligned}
$$

Simulation results are shown below:

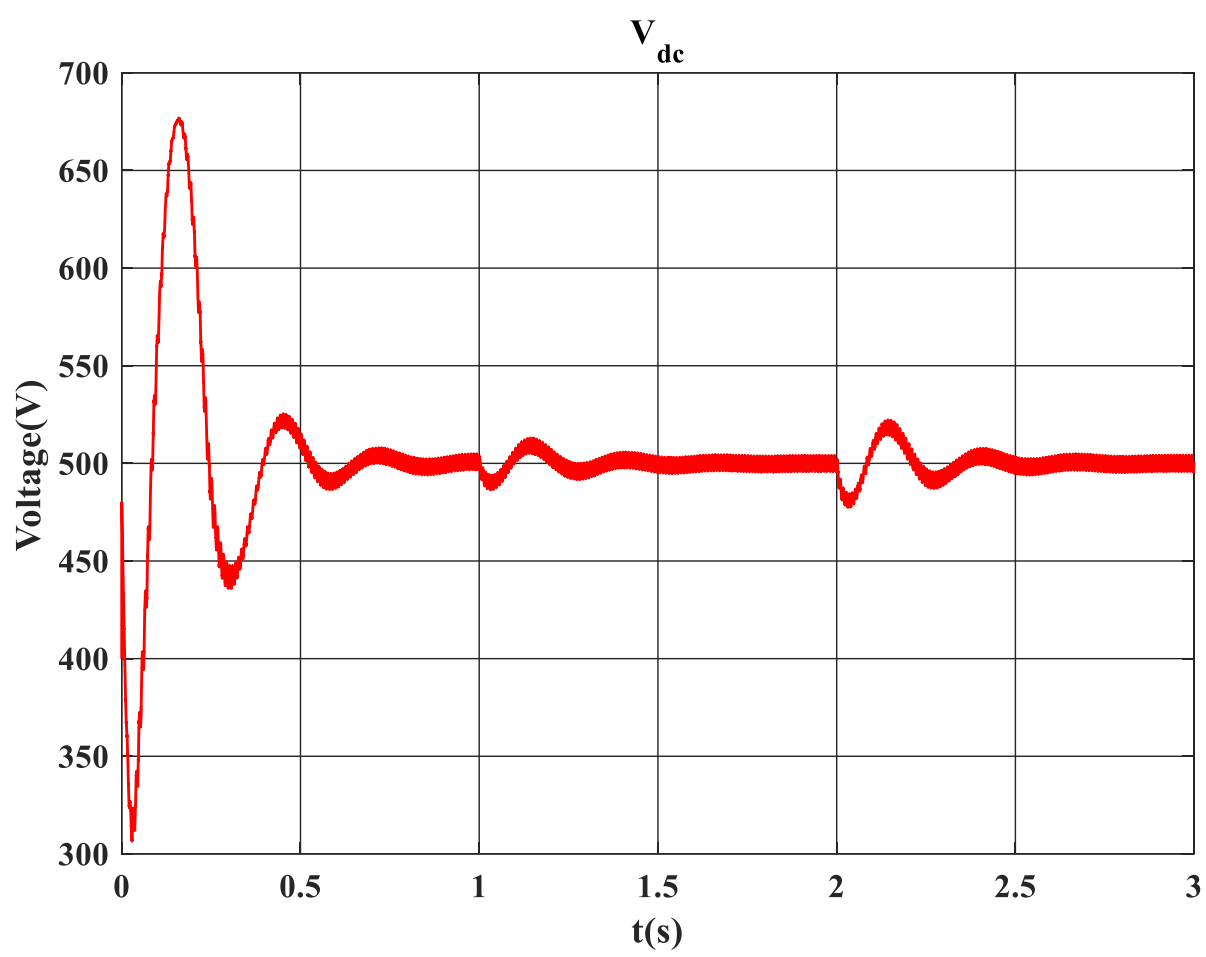

Figure 3.25(a) DC bus bar voltage 


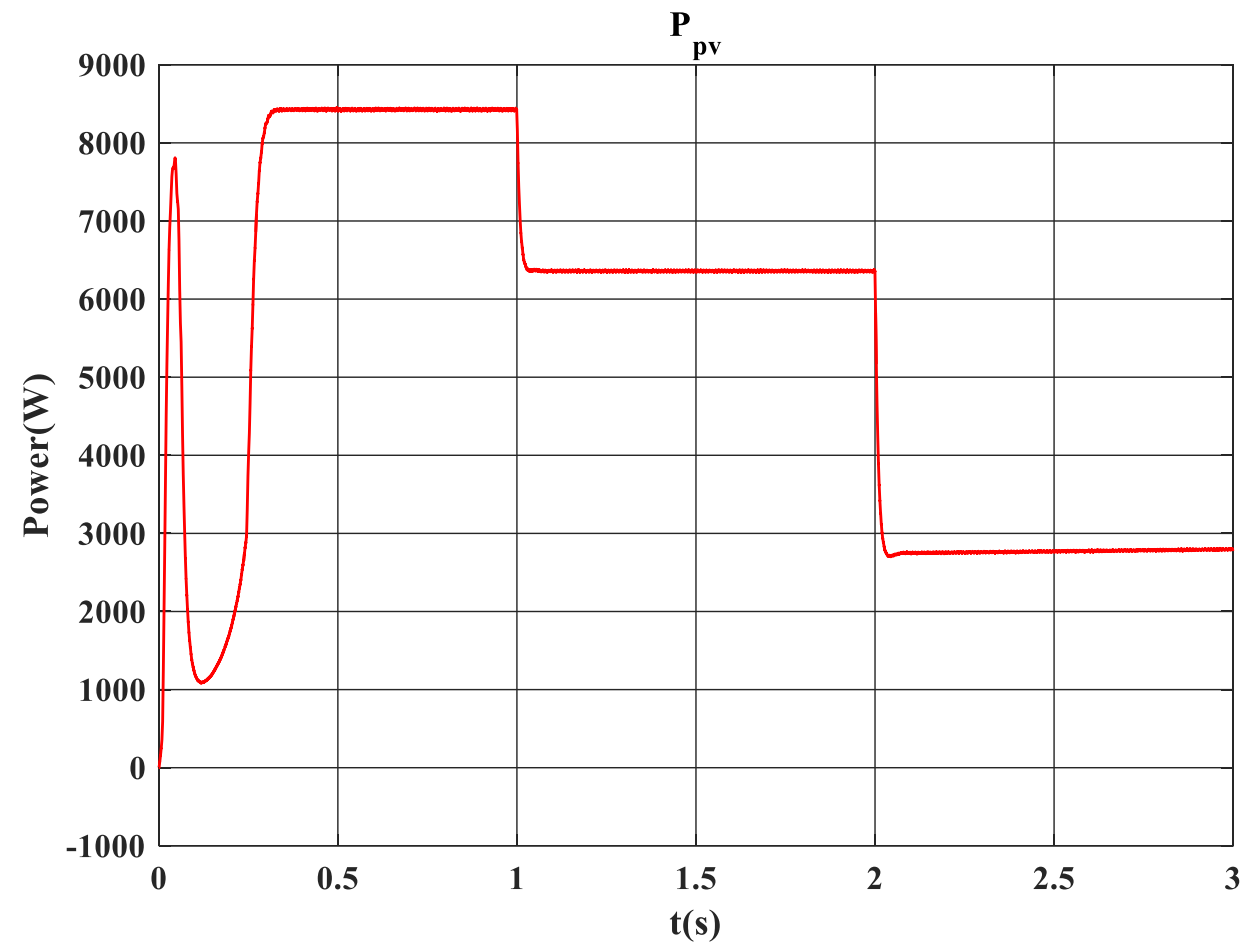

Figure 3.25(b) PV power output

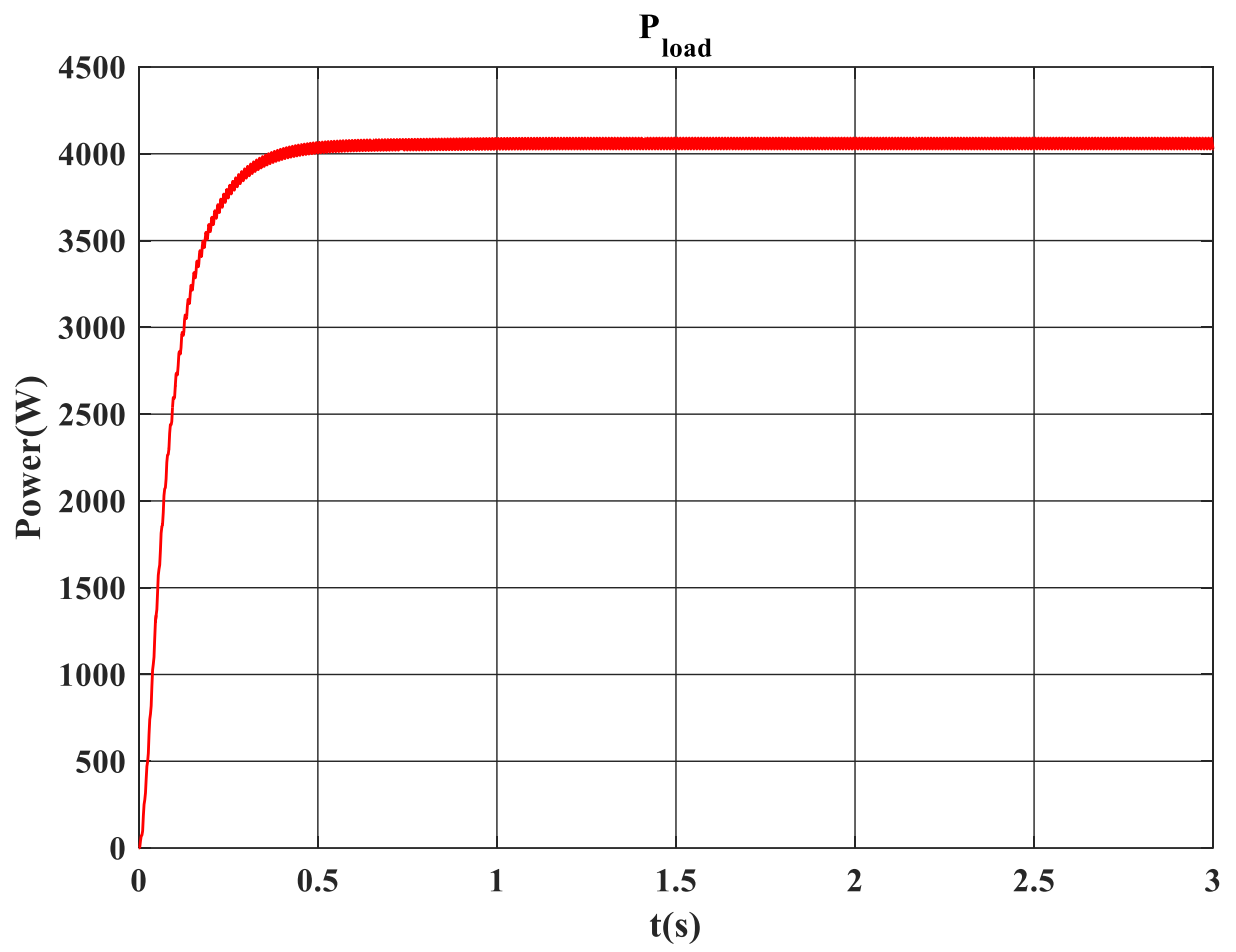

Figure 3.25(c) Power consumption of loads 


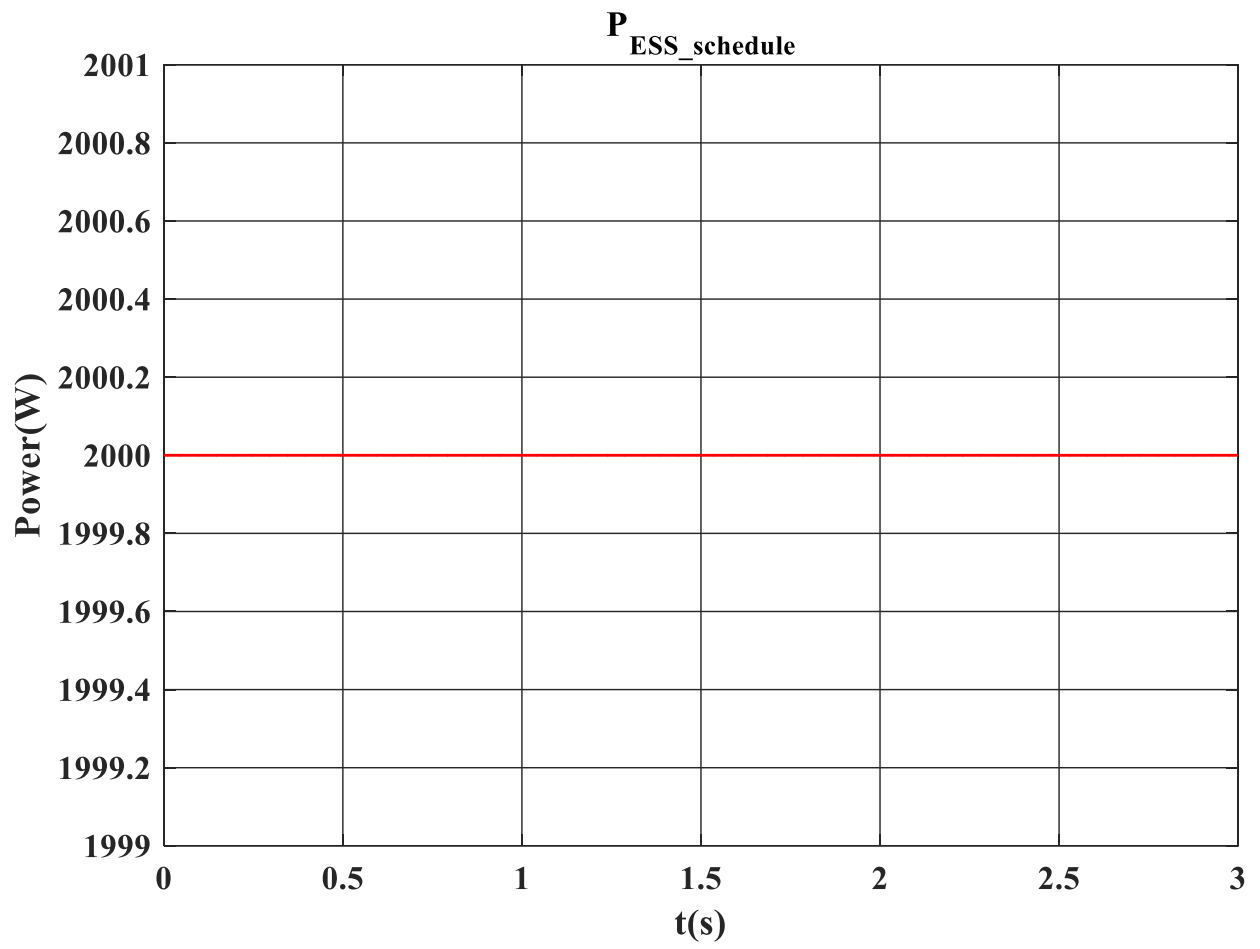

Figure 3.25(d) Optimal scheduled power command

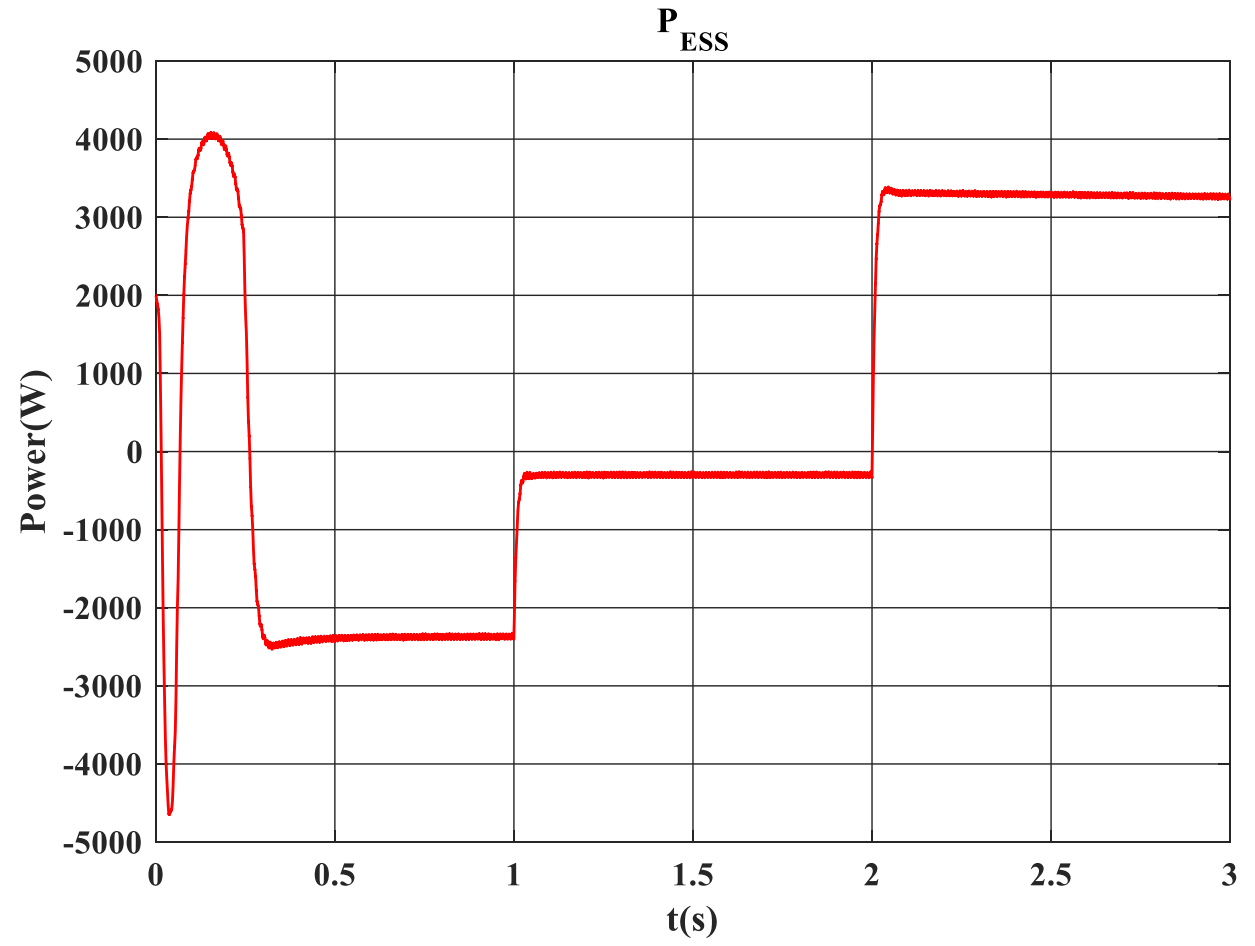

Figure 3.25(e) Power sum of scheduled power command and power fluctuation 


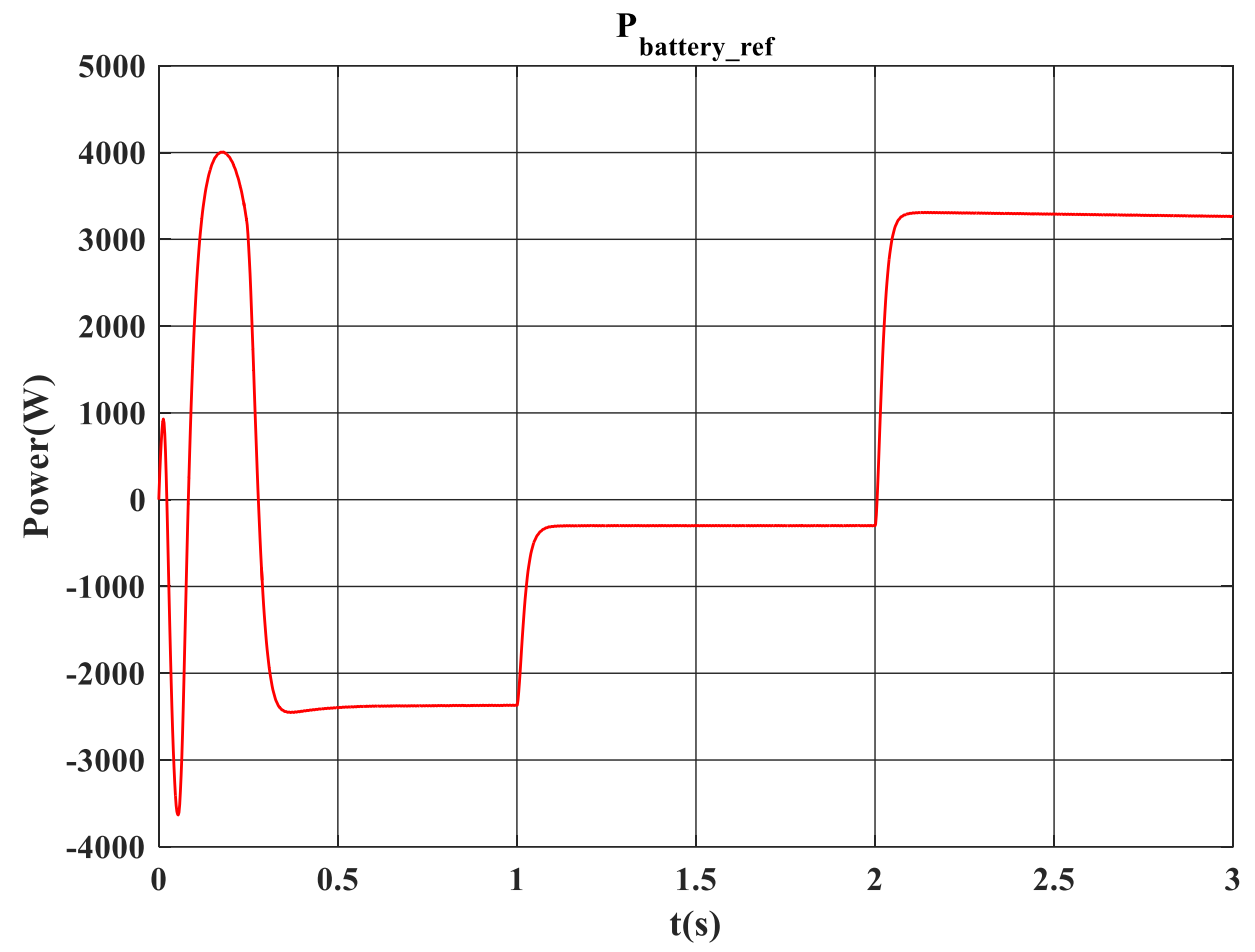

Figure 3.25(f) Low frequency power component of the power sum managed by battery

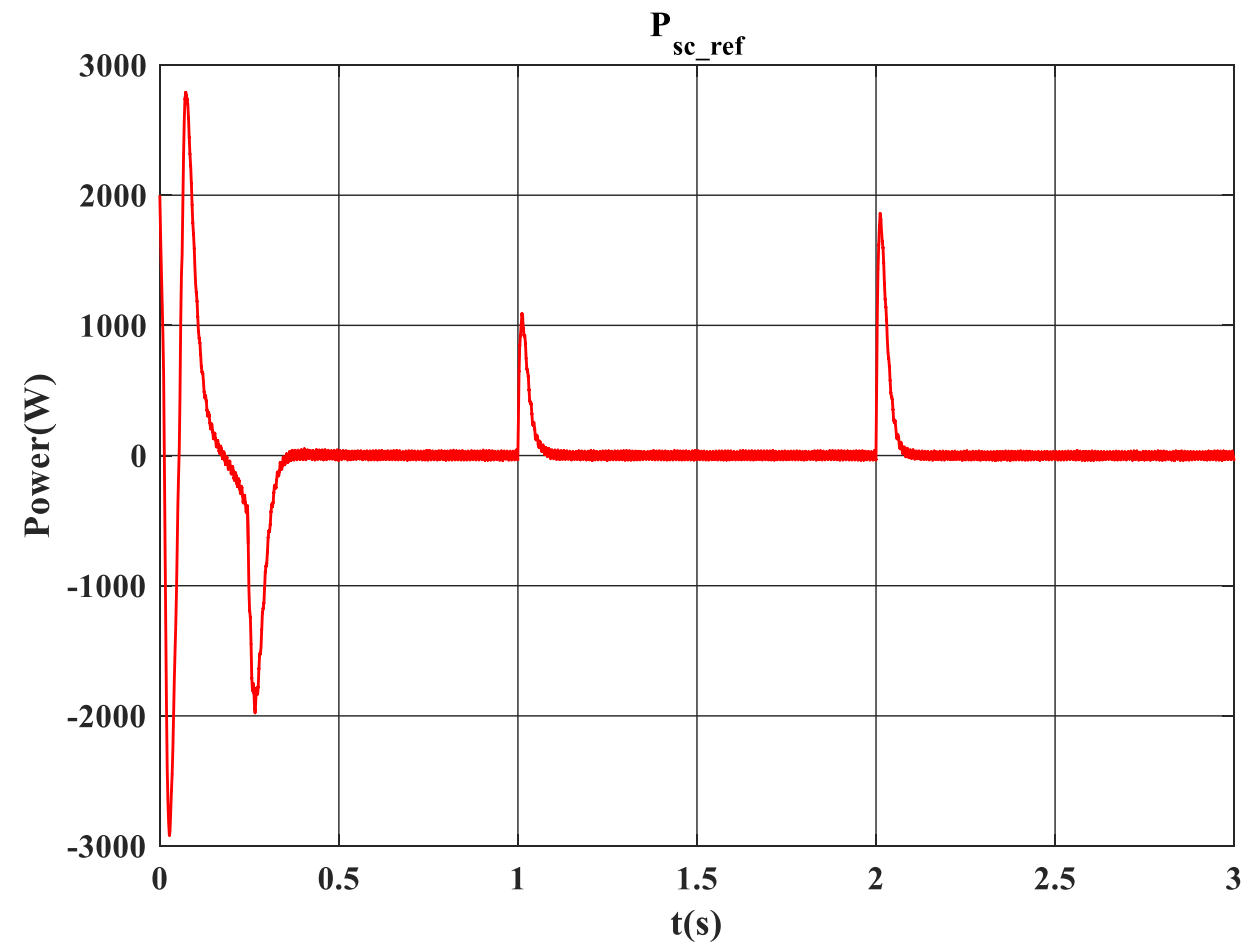

Figure 3.25(g) High frequency power component of the power sum managed by supercapacitor 


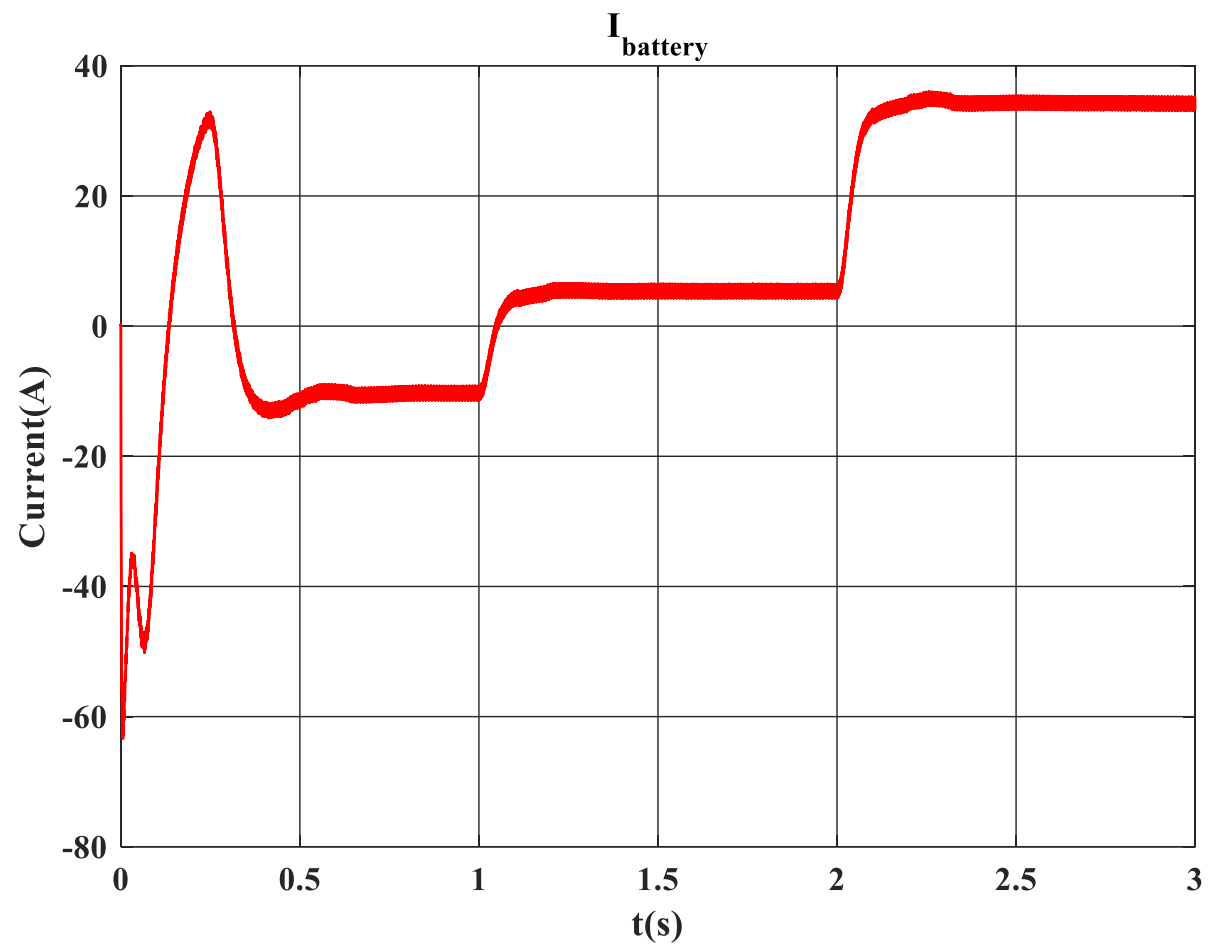

Figure 3.25(h) Battery charging/discharging current

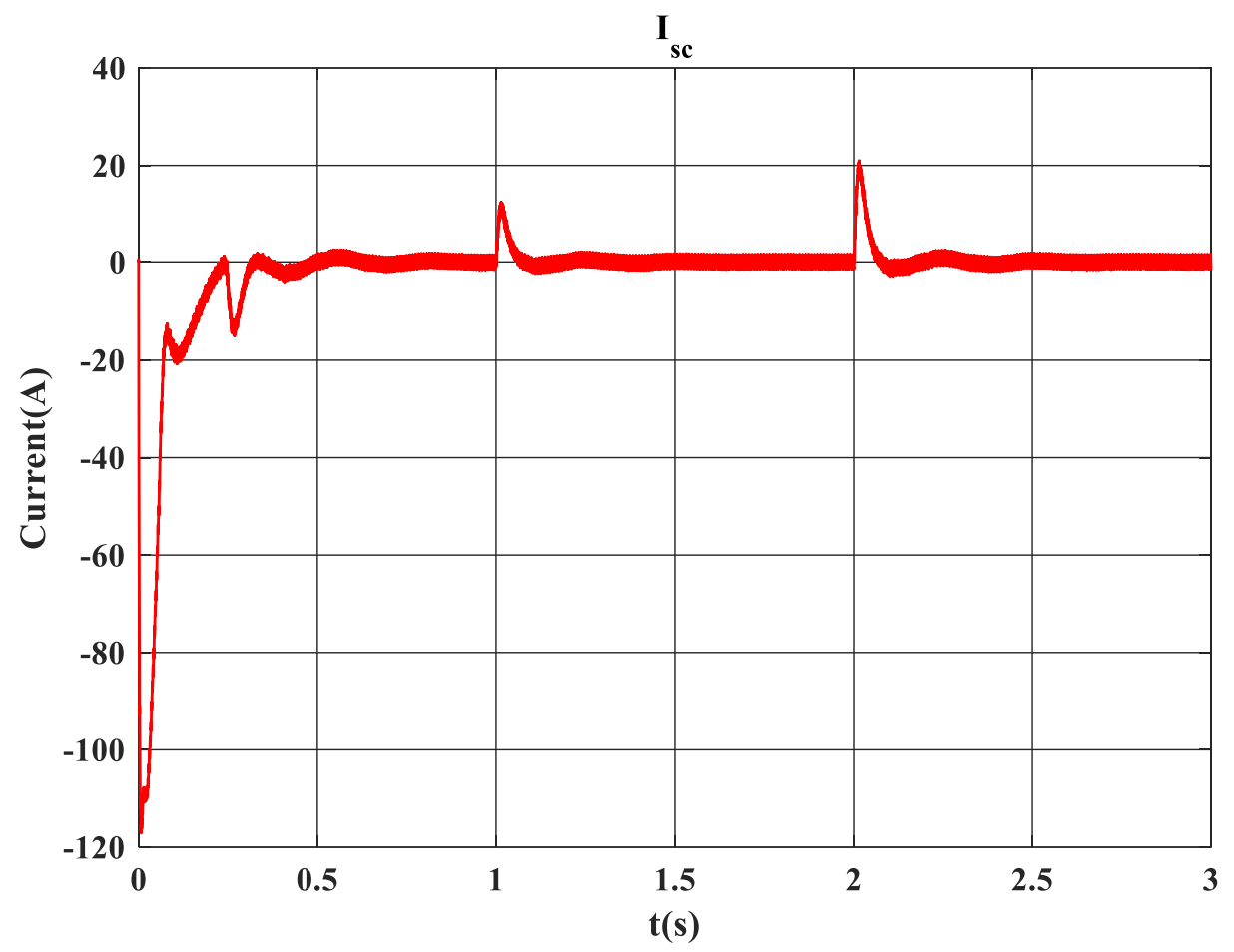

Figure 3.25(i) Supercapacitor charging/discharging current

Figure 3.25 Simulation results when changing $\boldsymbol{P}_{p v}$ 
From simulation analysis in Figure 3.25, simulation results match the required condition. DC bus bar voltage is stabilized around $500 \mathrm{~V}$ at steady state. Due to the change of $P_{p v}$ at $\mathrm{t}$ $=1 \mathrm{~s}$ and $\mathrm{t}=2 \mathrm{~s}$, the DC bus bar voltage fluctuates in transient state and goes back to steady state quickly, which shows the acceptable performance of transient response. The low frequency component of $P_{E S S}$ is managed by battery while the high frequency component of $P_{E S S}$ is managed by supercapacitor. The battery is charging at constant current before $\mathrm{t}$ $=1 \mathrm{~s}$ and discharging after $\mathrm{t}=1 \mathrm{~s}$. The supercapacitor is charging/discharging frequently in order to alleviate the high frequency component of power fluctuation. At $t=1 \mathrm{~s}$ and $t=2 \mathrm{~s}$, because of sudden change of $P_{P V}$, supercapacitor ensures the quick response of transient state, which compensates battery disadvantage.

3) $\quad P_{\text {ESS_schedule }}$ Changes

$P_{E S S_{-} s c h e d u l e}$ is set as $2 \mathrm{~kW}, 8 \mathrm{~kW}, 6 \mathrm{~kW}$ at $\mathrm{t}=0 \mathrm{~s}, 1 \mathrm{~s}, 2 \mathrm{~s} . P_{p v}$ and $P_{\text {load }}$ are kept unchanged. $P_{p v}=8.4 \mathrm{~kW}$ at $25^{\circ} \mathrm{C}, 1000 \mathrm{~W} / \mathrm{m}^{2} . P_{\text {load }}=4 \mathrm{~kW}$. Therefore, we should get:

$\Delta P=P_{\text {load }}-P_{p v}=4 \mathrm{~kW}-8.4 \mathrm{~kW}=-4.4 \mathrm{~kW}$

At $\mathrm{t}=0 \sim 1 \mathrm{~s}:$

$P_{E S S}=\left(P_{\text {load }}-P_{p v}\right)+P_{E S S_{-} s c h e d u l e}=-4.4 \mathrm{~kW}+2 \mathrm{~kW}=-2.4 \mathrm{~kW}$

At $\mathrm{t}=1 \sim 2 \mathrm{~s}:$

$P_{E S S}=\left(P_{\text {load }}-P_{p v}\right)+P_{E S S_{s} s c h e d u l e}=-4.4 \mathrm{~kW}+8 \mathrm{~kW}=3.6 \mathrm{~kW}$ 
At $\mathrm{t}=2 \sim 3 \mathrm{~s}:$

$P_{E S S}=\left(P_{\text {load }}-P_{p v}\right)+P_{E S S_{-} \text {schedule }}=-4.4 \mathrm{~kW}+6 \mathrm{~kW}=1.6 \mathrm{~kW} ;$

The simulation results are shown below:

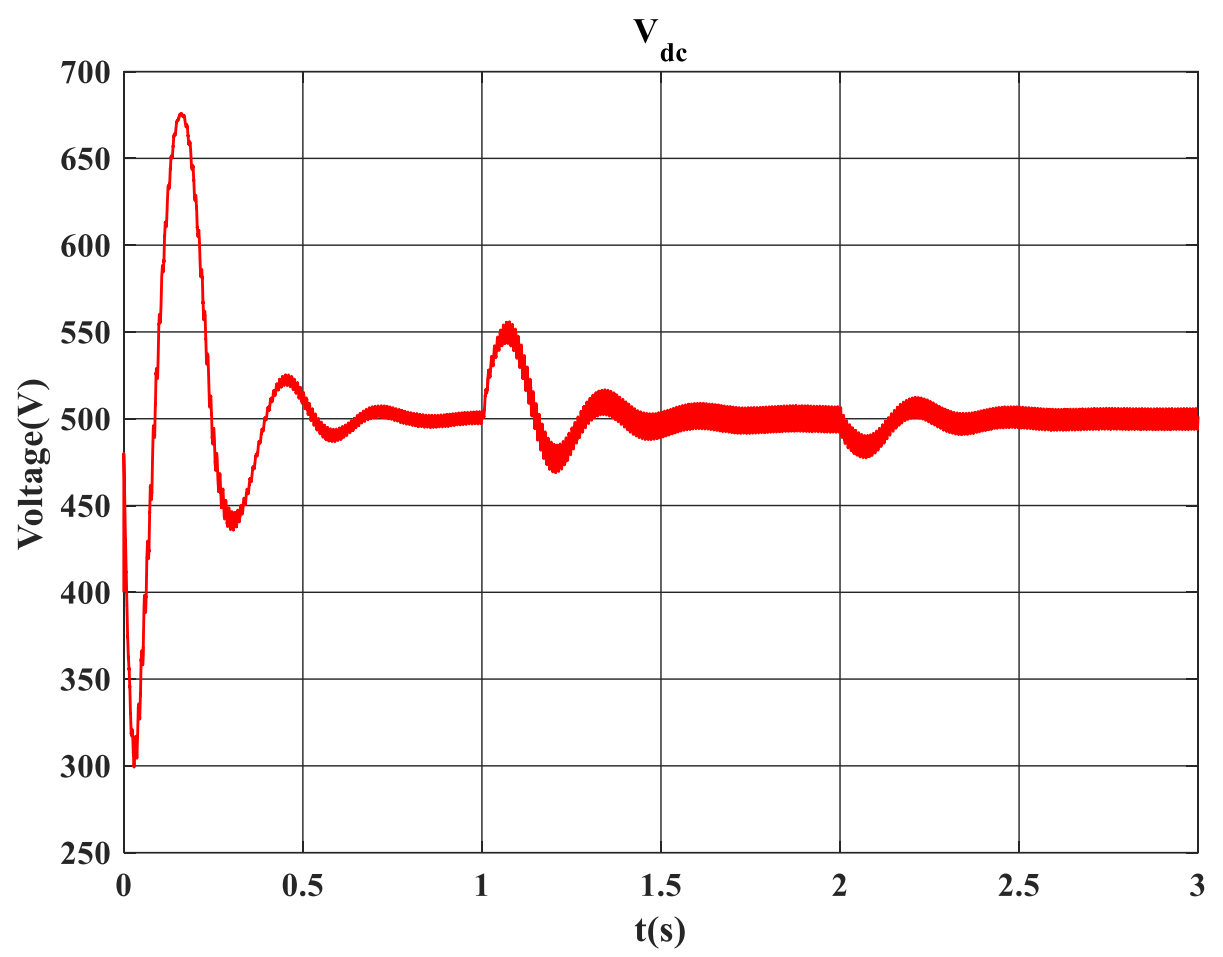

Figure 3.26(a) DC bus bar voltage 


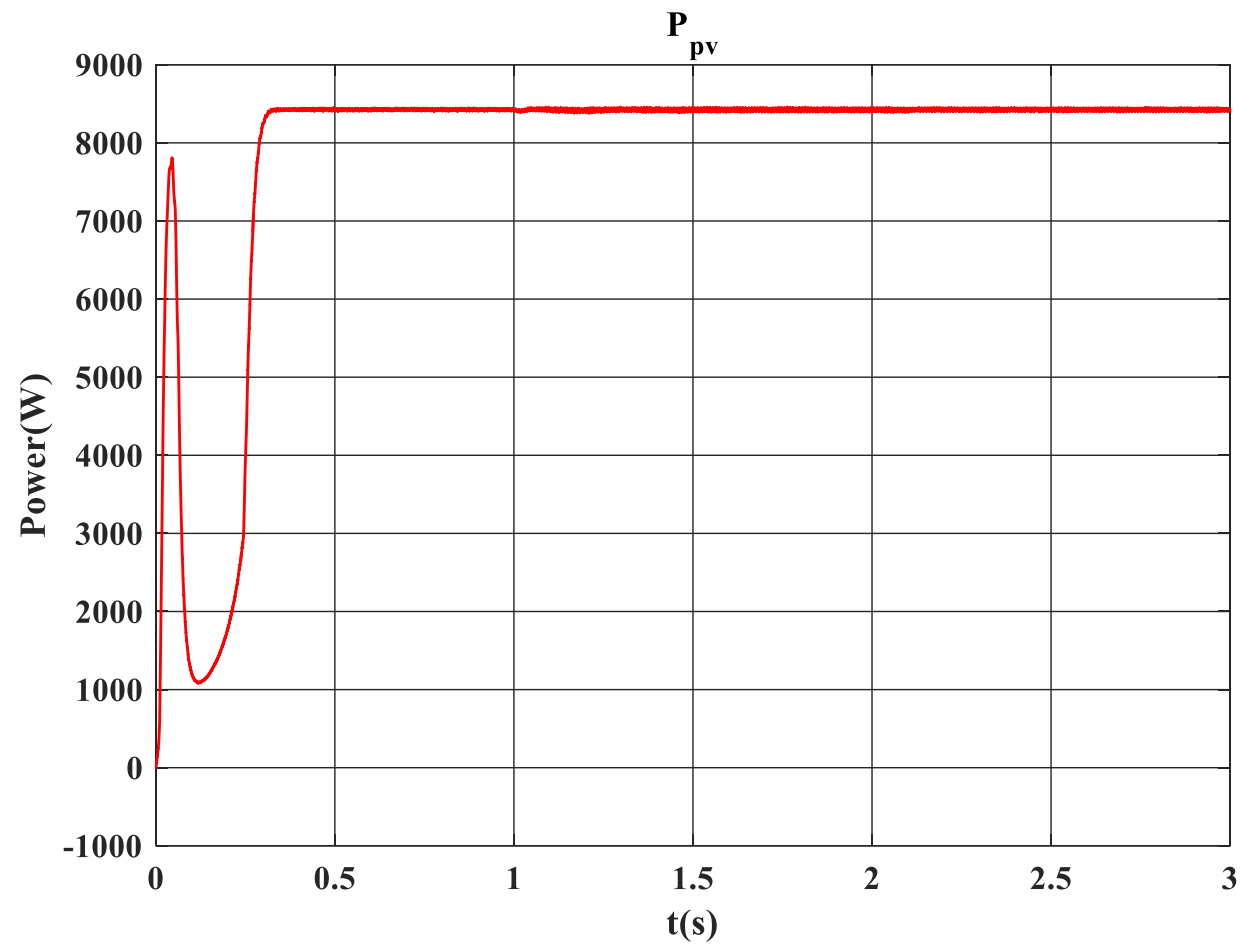

Figure 3.26(b) PV power output

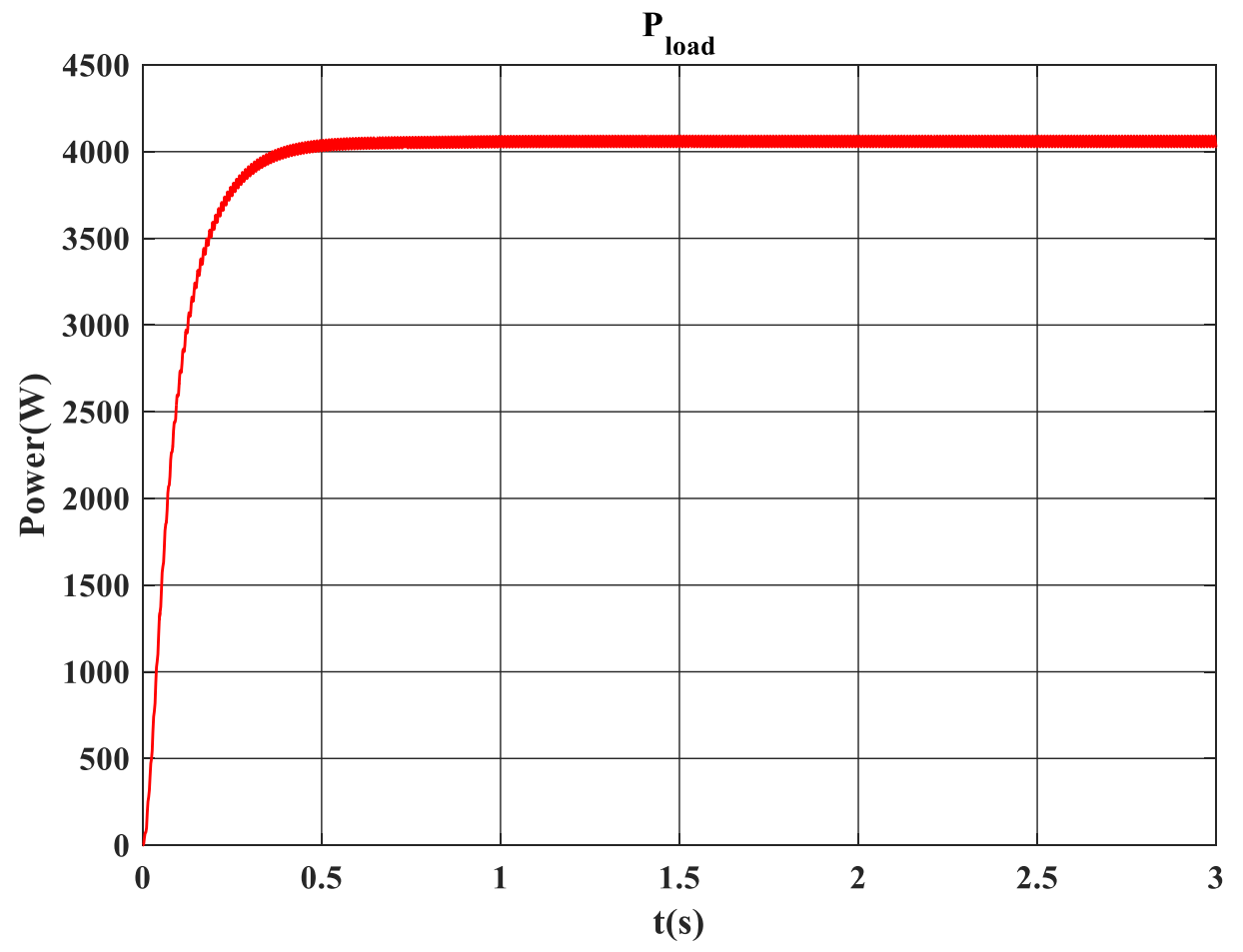

Figure 3.26(c) Power consumption of loads 


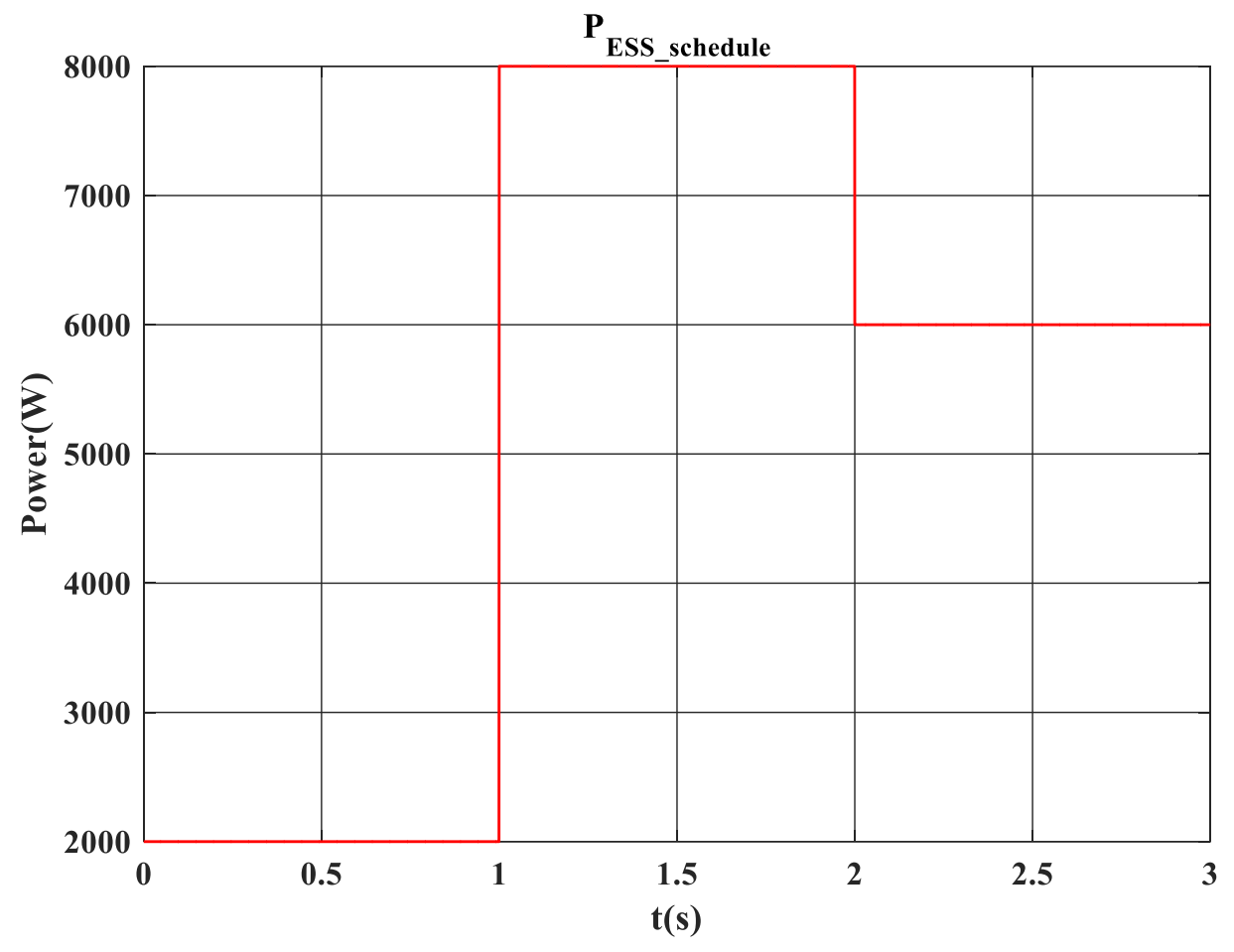

Figure 3.26(d) Optimal scheduled power command

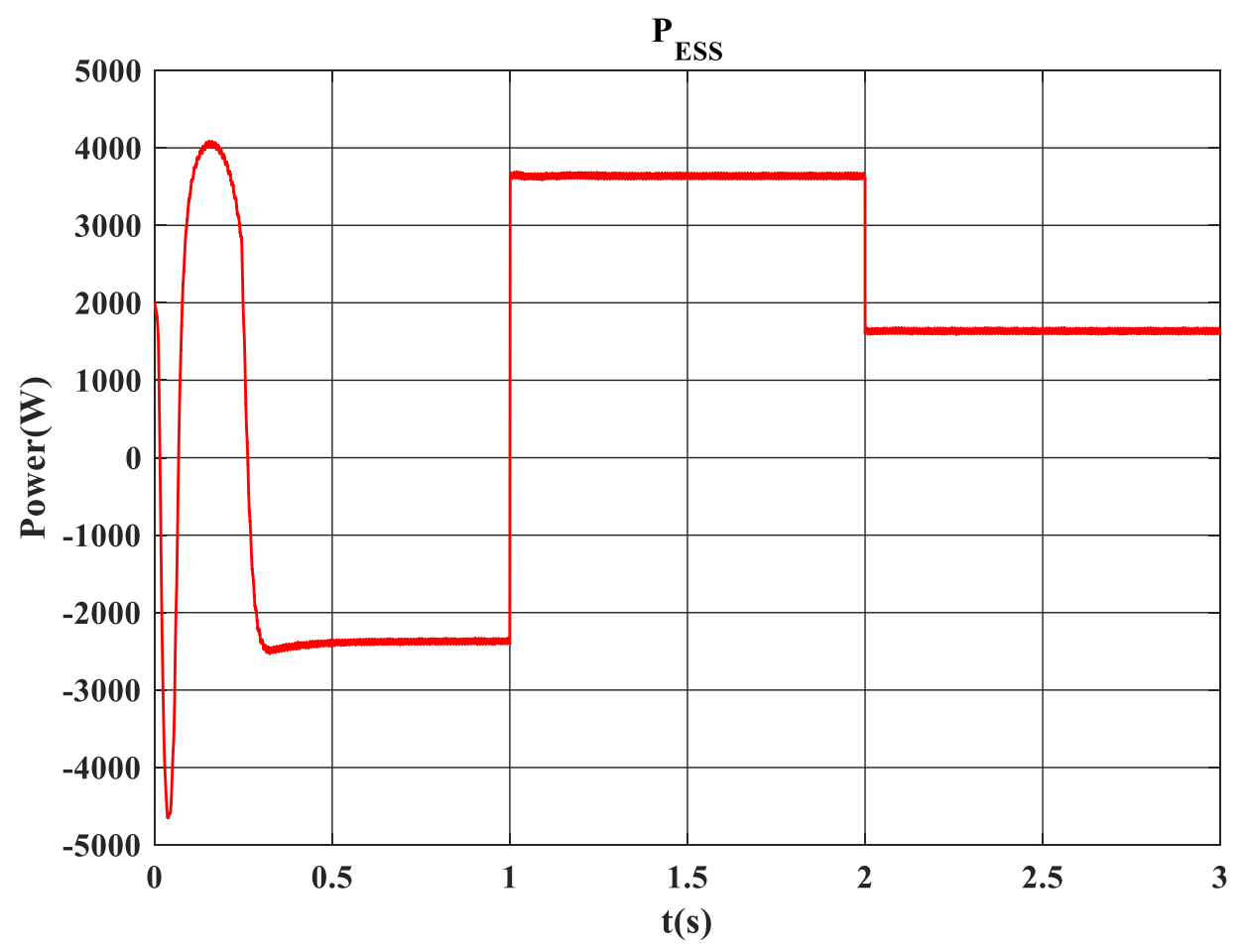

Figure 3.26(e) Power sum of scheduled power command and power fluctuation 


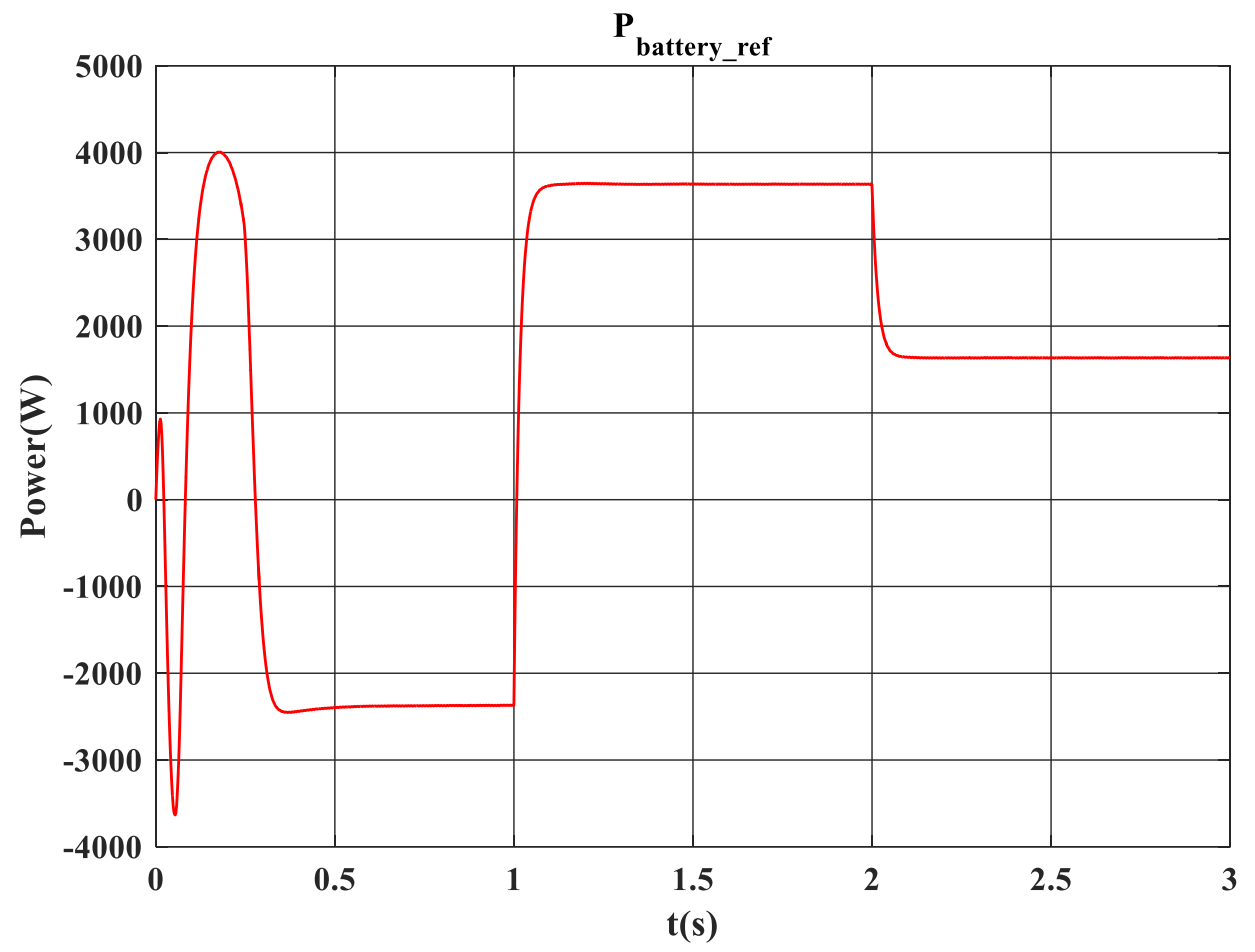

Figure 3.26(f) Low frequency power component of the power sum managed by battery

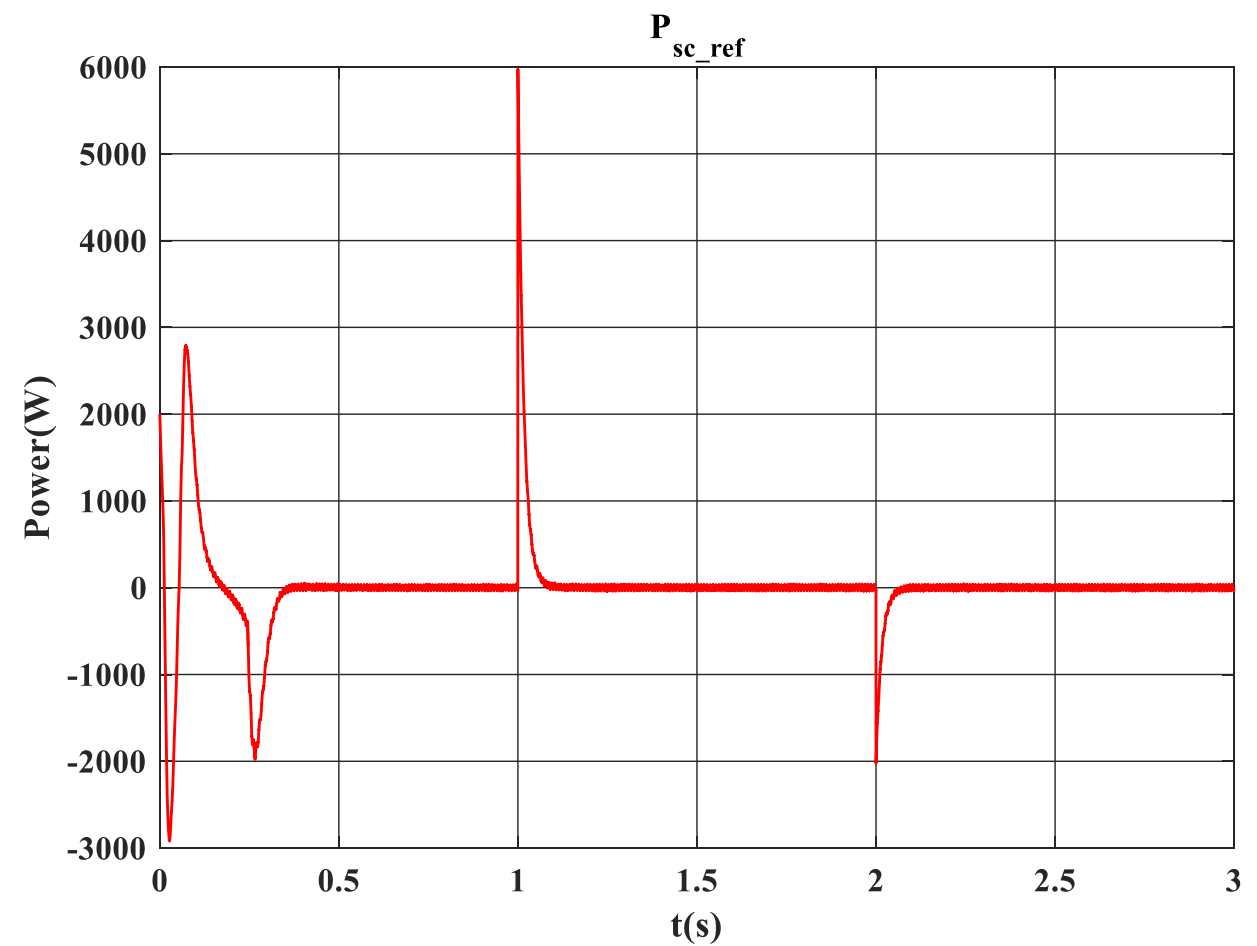

Figure 3.26(g) High frequency power component of the power sum managed by supercapacitor 


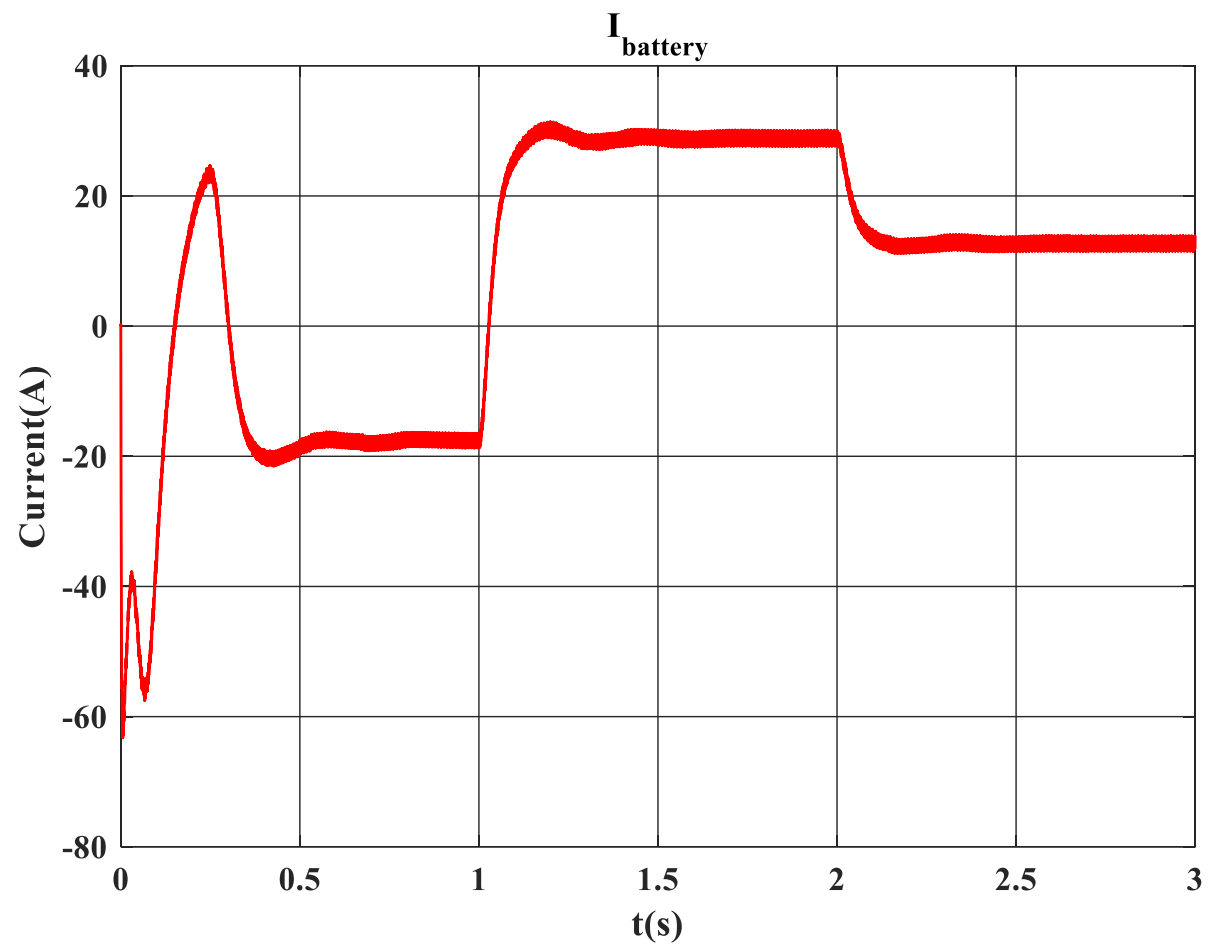

Figure 3.26(h) Battery charging/discharging current

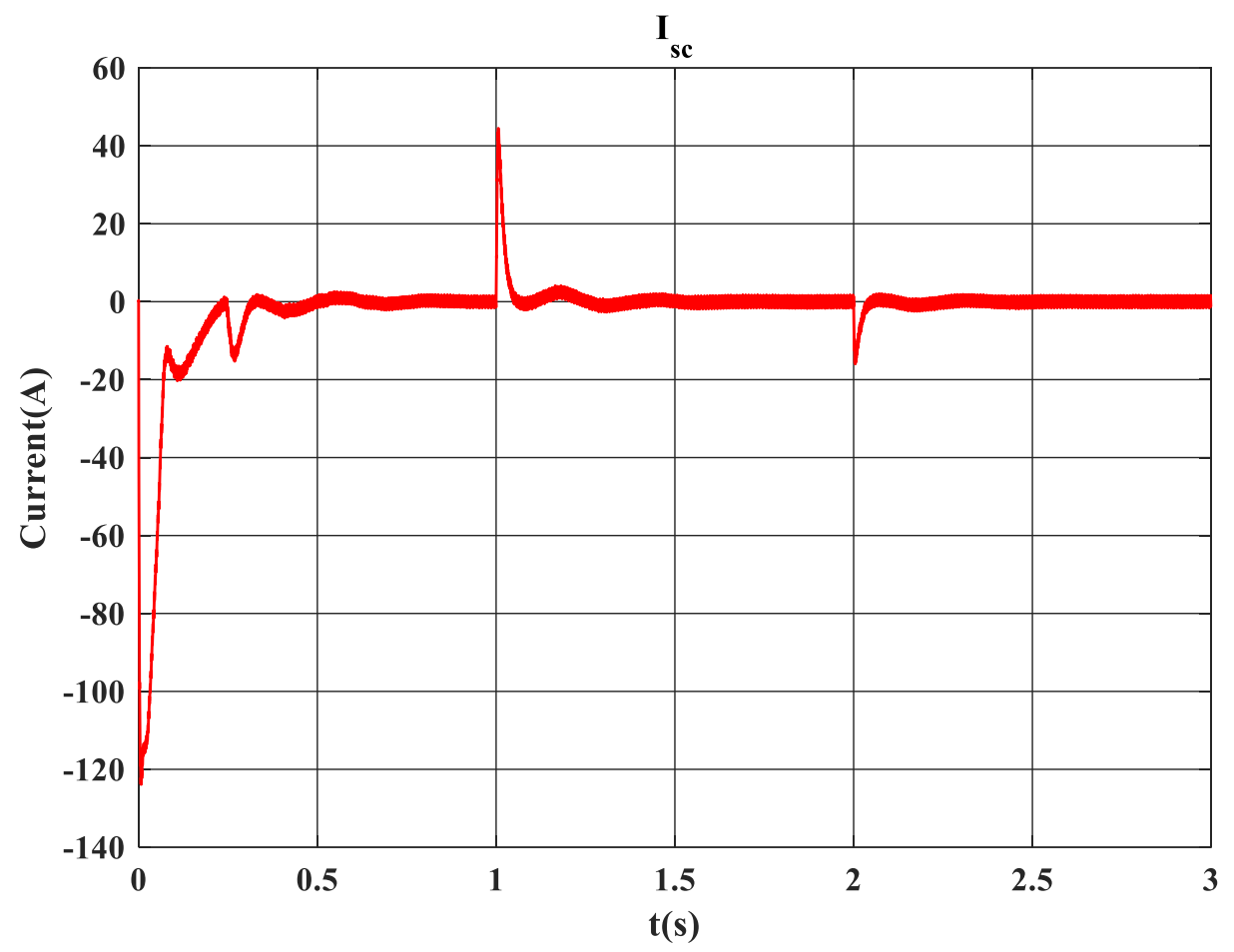

Figure 3.26(i) Supercapacitor charging/discharging current

Figure 3.26 Simulation results when changing PESS_schedule 
From simulation analysis in Figure 3.26, simulation results match the required condition. DC bus bar voltage is stabilized around $500 \mathrm{~V}$ at steady state. Due to the change of $P_{\text {ESS_schedule }}$ at $\mathrm{t}=1 \mathrm{~s}$ and $\mathrm{t}=2 \mathrm{~s}$, the DC bus bar voltage fluctuates in transient state and goes back to steady state quickly, which shows the acceptable performance of transient response. The low frequency component of $P_{E S S}$ is managed by battery while the high frequency component of $P_{E S S}$ is managed by supercapacitor. The battery is charging at constant current before $\mathrm{t}=1 \mathrm{~s}$ and discharging after $\mathrm{t}=1 \mathrm{~s}$. The supercapacitor is charging/ discharging frequently in order to alleviate the high frequency component of power fluctuation. At $\mathrm{t}=1 \mathrm{~s}$ and $\mathrm{t}=2 \mathrm{~s}$, because of sudden change of $P_{E S S_{-} s c h e d u l e}$, supercapacitor ensures the quick response of transient state, which compensate battery disadvantage.

\section{4) $\quad P_{\text {load }}$ Changes}

$P_{\text {load }}$ changes with the variation of residential loads. Resistors are used to represent residential loads. By modifying house loads values, $P_{\text {load }}$ changes. $P_{\text {load }}=0 \mathrm{~kW}, 4.8 \mathrm{~kW}$, $6.3 \mathrm{~kW}$ at $\mathrm{t}=0 \mathrm{~s}, \mathrm{t}=1.5 \mathrm{~s}, \mathrm{t}=2.5 \mathrm{~s} . P_{p v}=8.4 \mathrm{~kW}$ at $1000 \mathrm{~W} / \mathrm{m}^{2}, 25^{\circ} \mathrm{C} . P_{\text {EsS_schedule }}=3 \mathrm{~kW}$. A step signal is added for $P_{\text {battery_ref }}$ and $P_{s c_{-} r e f}$ in order to avoid the fluctuation of system starting process. Therefore, we should get:

At $\mathrm{t}=0 \sim 1.5 \mathrm{~s}:$

$\Delta P=P_{l o a d}-P_{p v}=0 \mathrm{~kW}-8.4 \mathrm{~kW}=-8.4 \mathrm{~kW}$

$P_{E S S}=\left(P_{l o a d}-P_{p v}\right)+P_{E S S_{-} s c h e d u l e}=(0 \mathrm{~kW}-8.4 \mathrm{~kW})+3 \mathrm{~kW}=-5.4 \mathrm{~kW}$

At $\mathrm{t}=1.5 \sim 2.5 \mathrm{~s}:$ 


$$
\begin{aligned}
& \Delta P=P_{\text {load }}-P_{p v}=4.8 \mathrm{~kW}-8.4 \mathrm{~kW}=-3.6 \mathrm{~kW} ; \\
& P_{E S S}=\left(P_{\text {load }}-P_{p v}\right)+P_{\text {ESS_schedule }}=(4.8 \mathrm{~kW}-8.4 \mathrm{~kW})+3 \mathrm{~kW}=-0.6 \mathrm{~kW} ;
\end{aligned}
$$

At $\mathrm{t}=2.5 \sim 3 \mathrm{~s}:$

$\Delta P=P_{\text {load }}-P_{p v}=6.3 \mathrm{~kW}-8.4 \mathrm{~kW}=-2.1 \mathrm{~kW} ;$

$P_{E S S}=\left(P_{\text {load }}-P_{p v}\right)+P_{E S S_{\_} s c h e d u l e}=(6.3 \mathrm{~kW}-8.4 \mathrm{~kW})+3 \mathrm{~kW}=0.9 \mathrm{~kW} ;$

The simulation results are shown below:

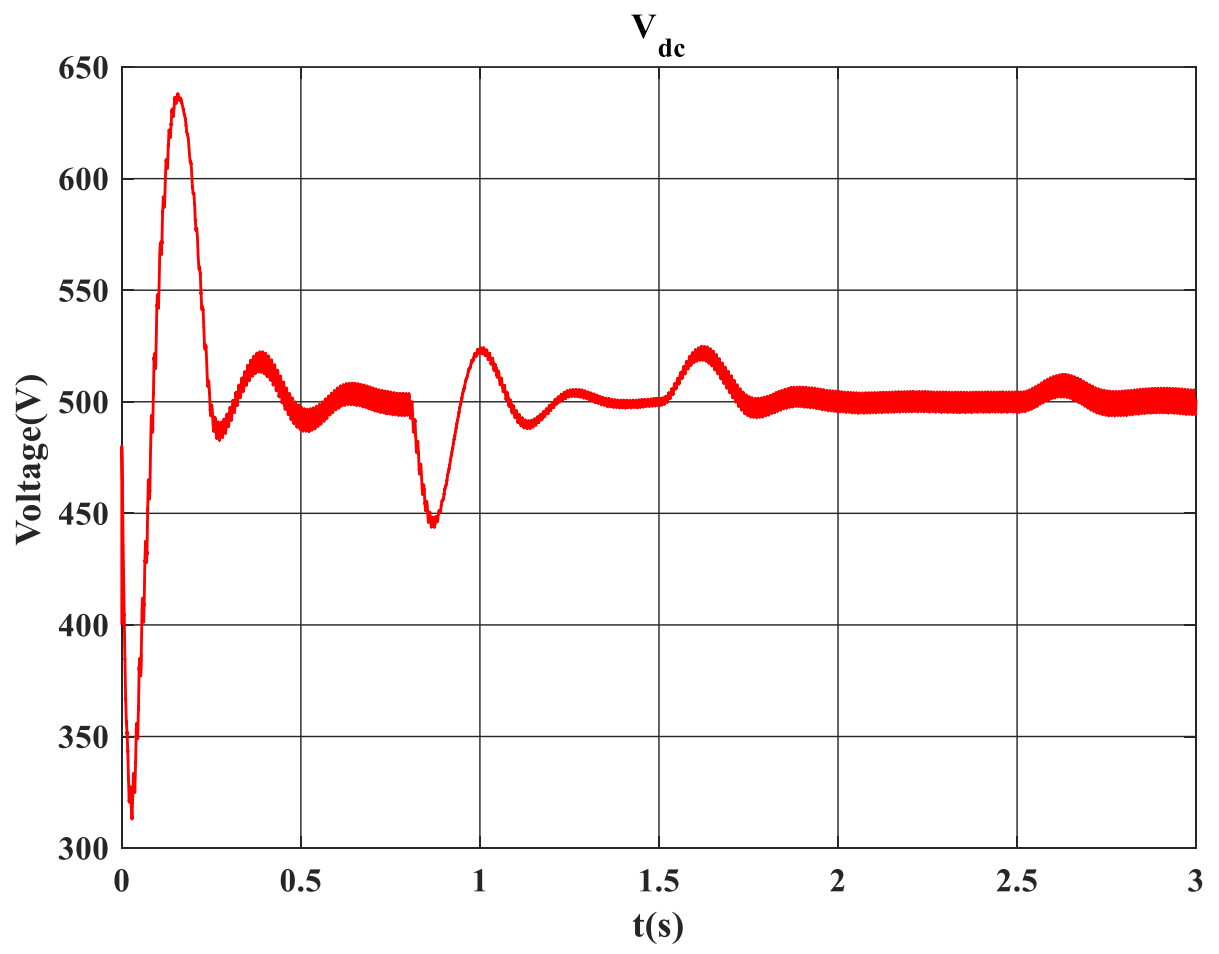

Figure 3.27(a) DC bus bar voltage 


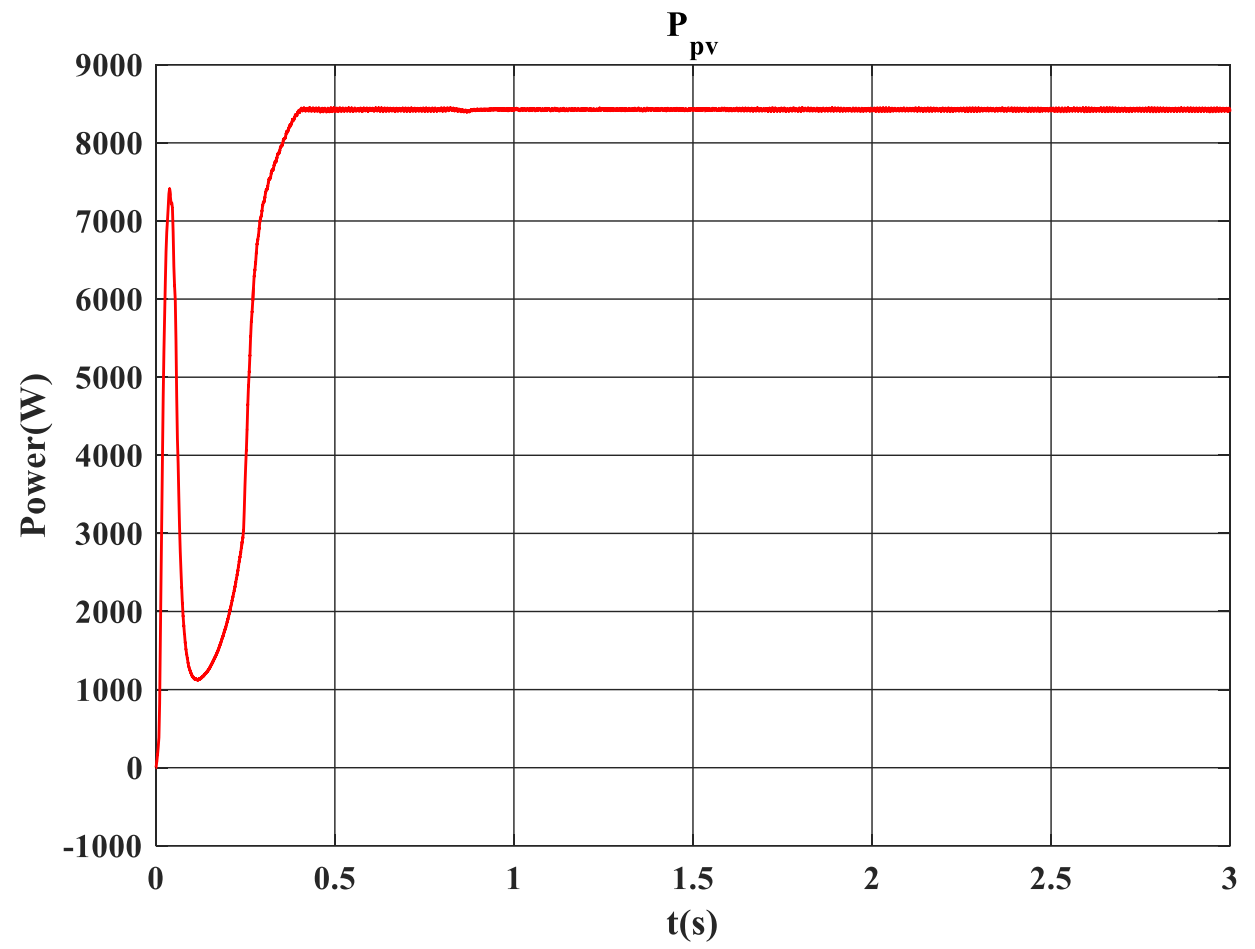

Figure 3.27(b) PV power output

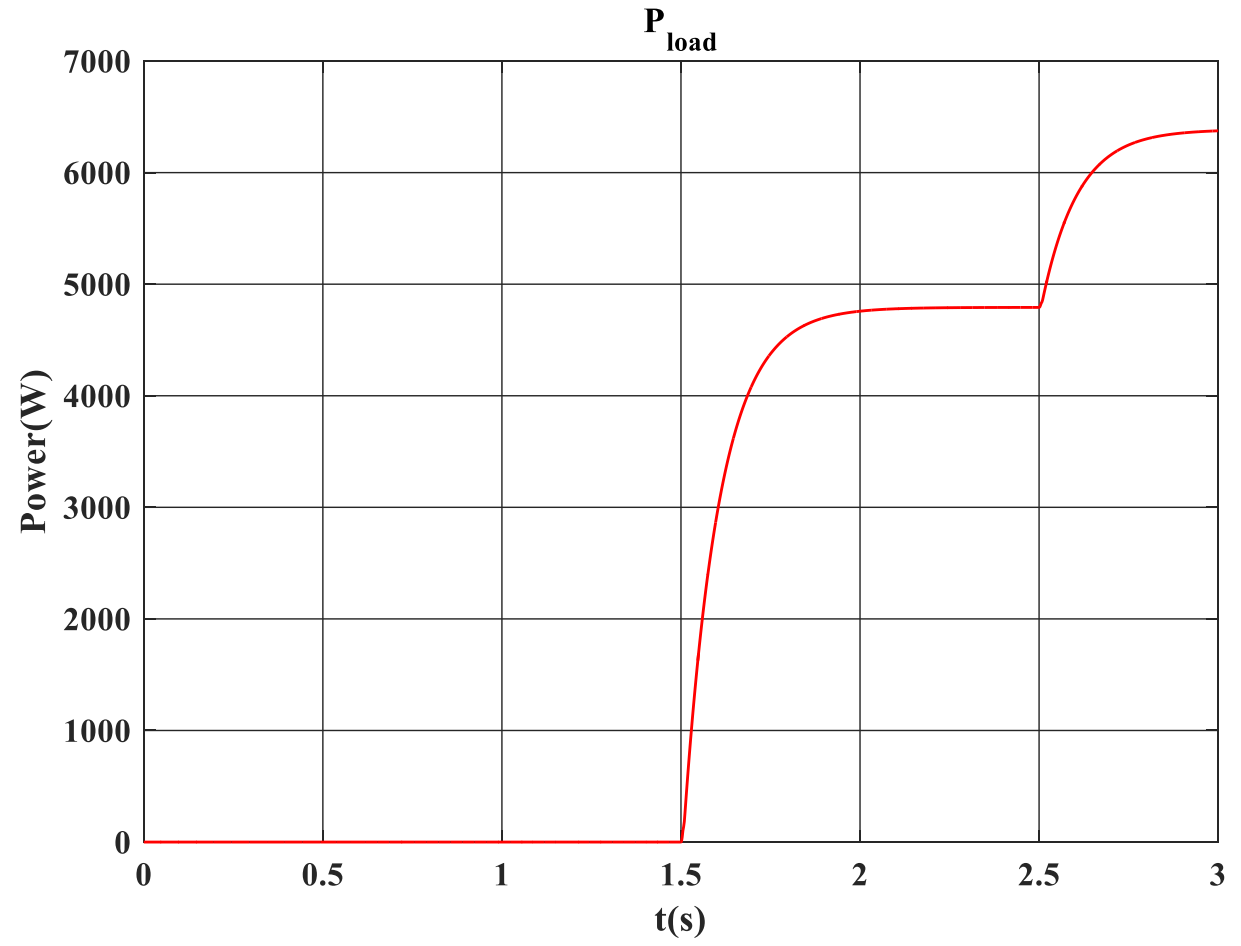

Figure 3.27(c) Power consumption of loads 


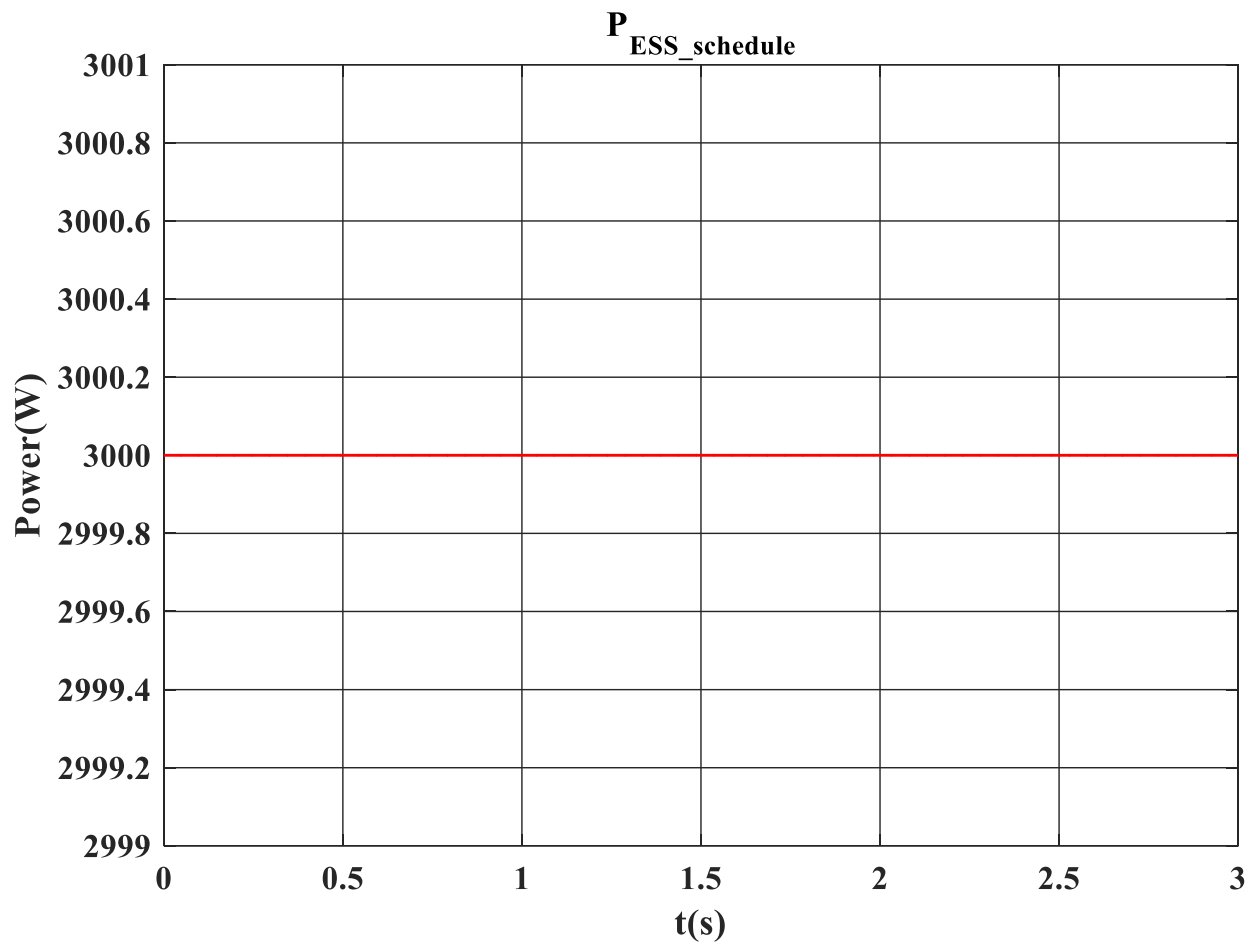

Figure 3.27(d) Optimal scheduled power command

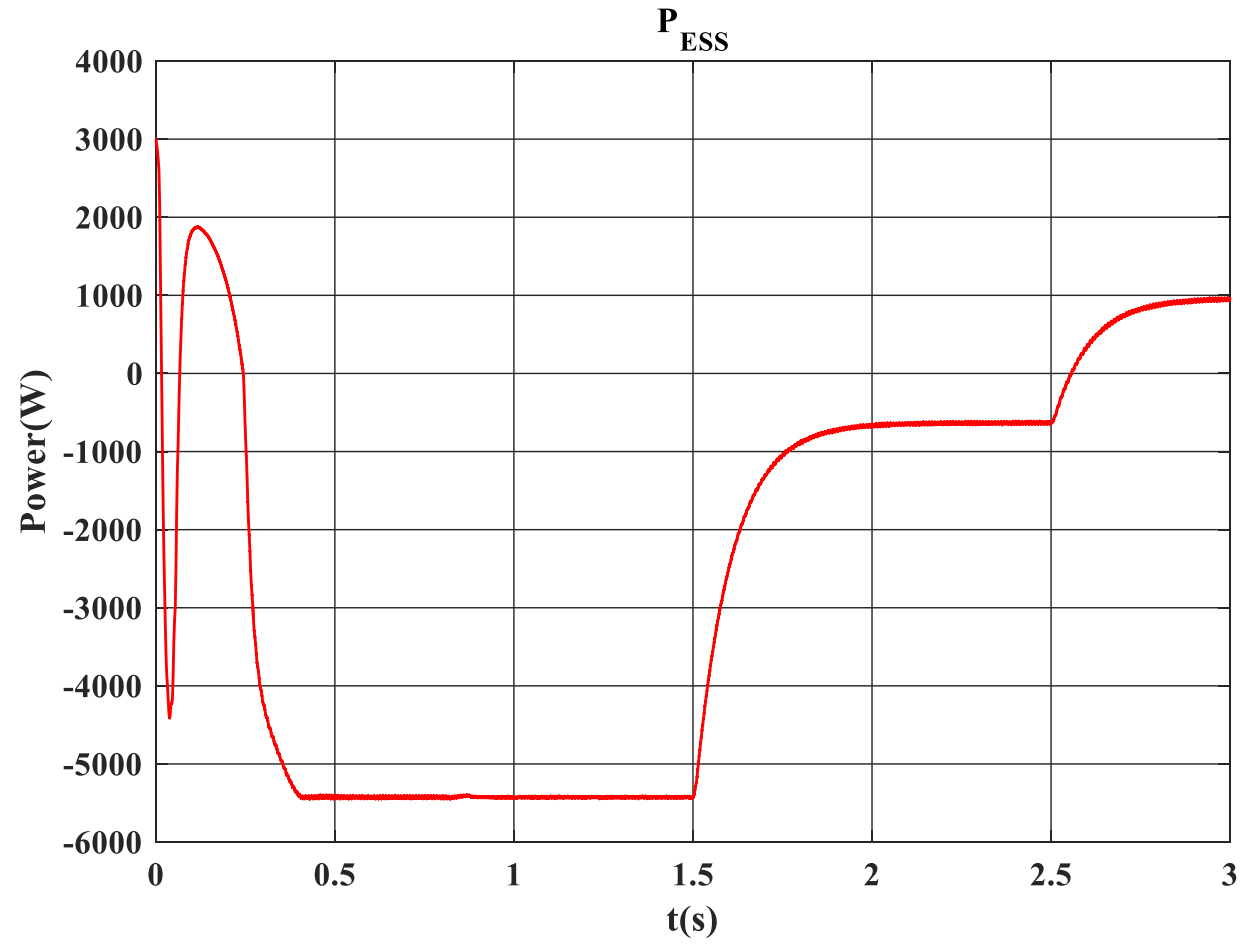

Figure 3.27(e) Power sum of scheduled power command and power fluctuation 


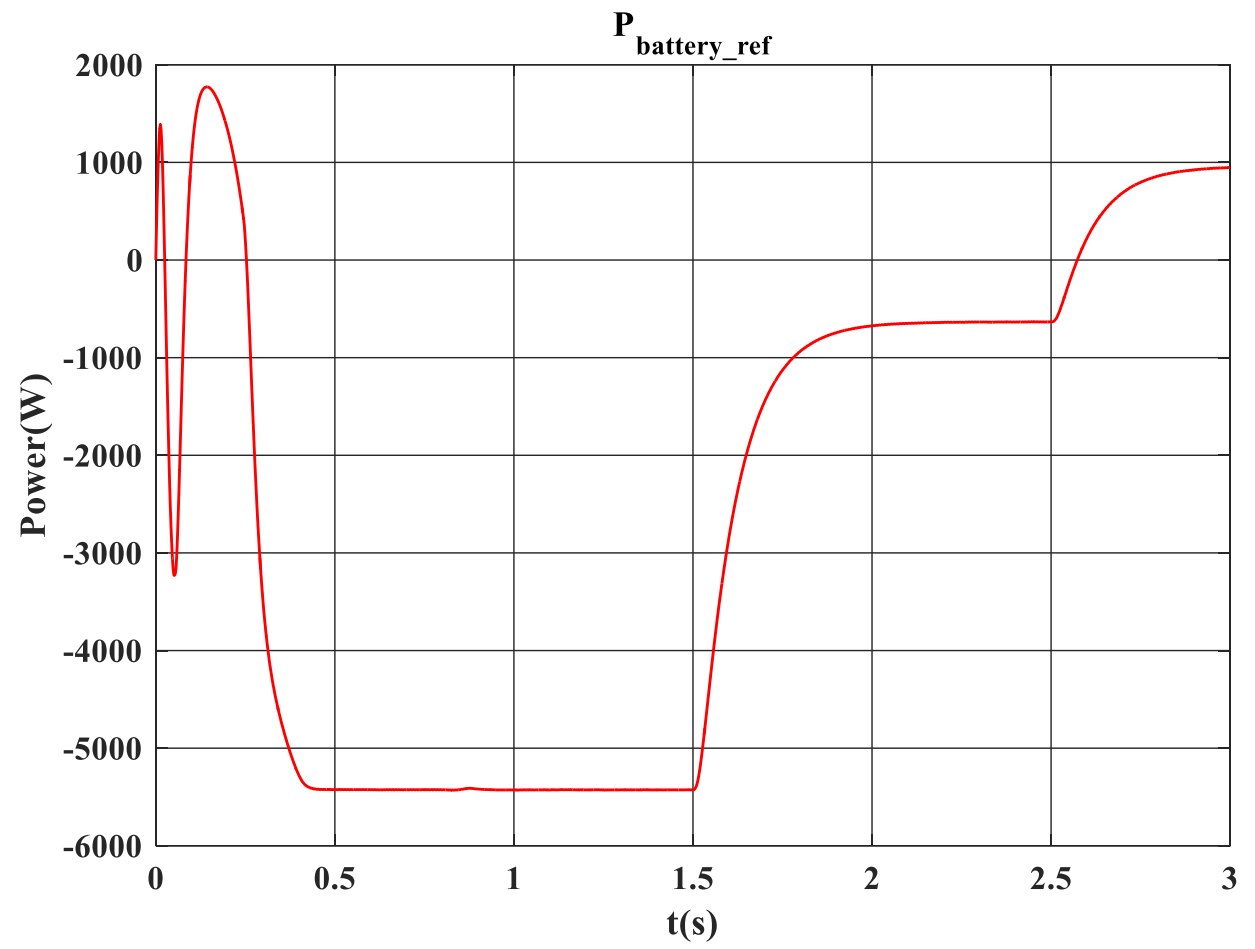

Figure 3.27(f) Low frequency power component of the power sum managed by battery

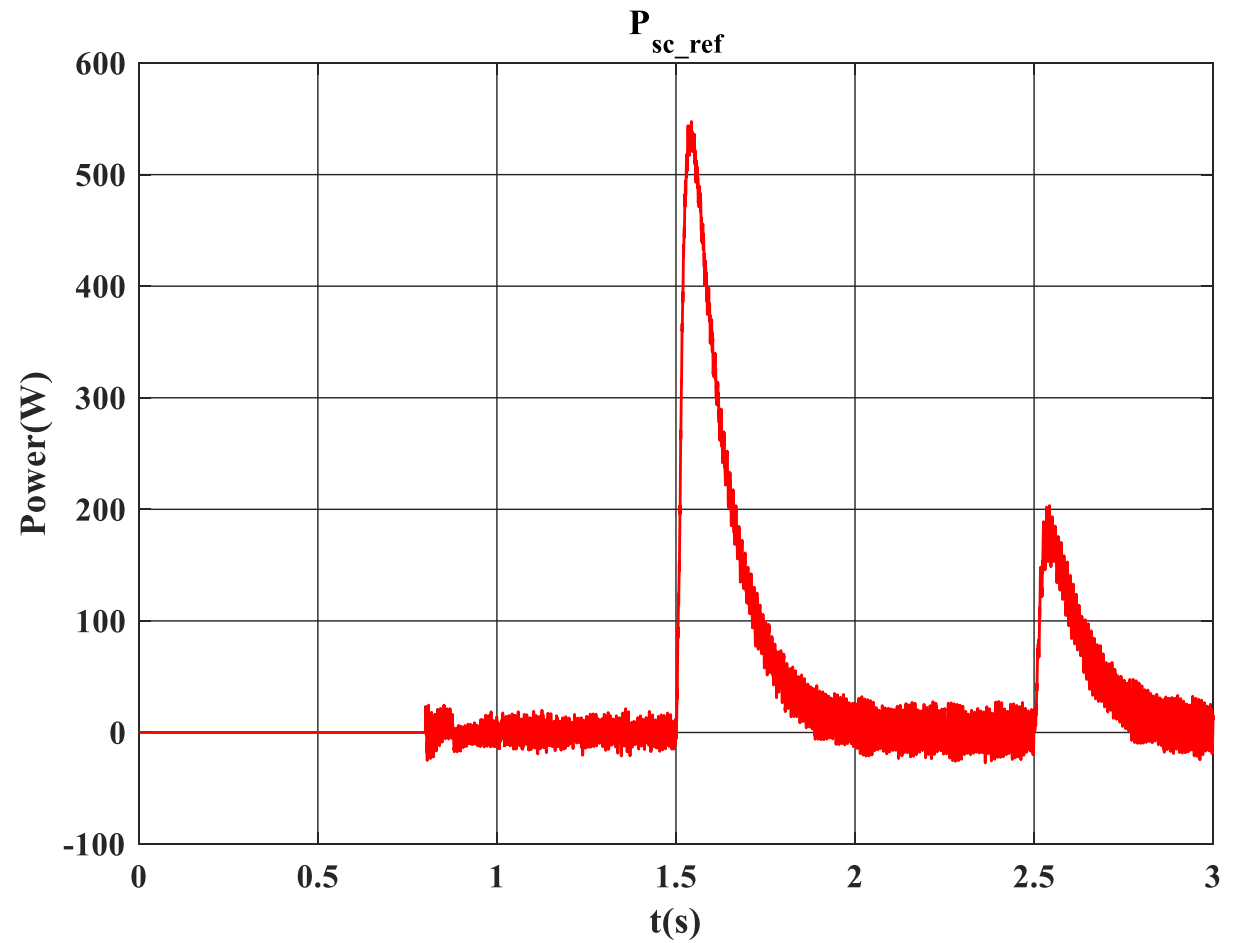

Figure 3.27(g) High frequency power component of the power sum managed by supercapacitor 


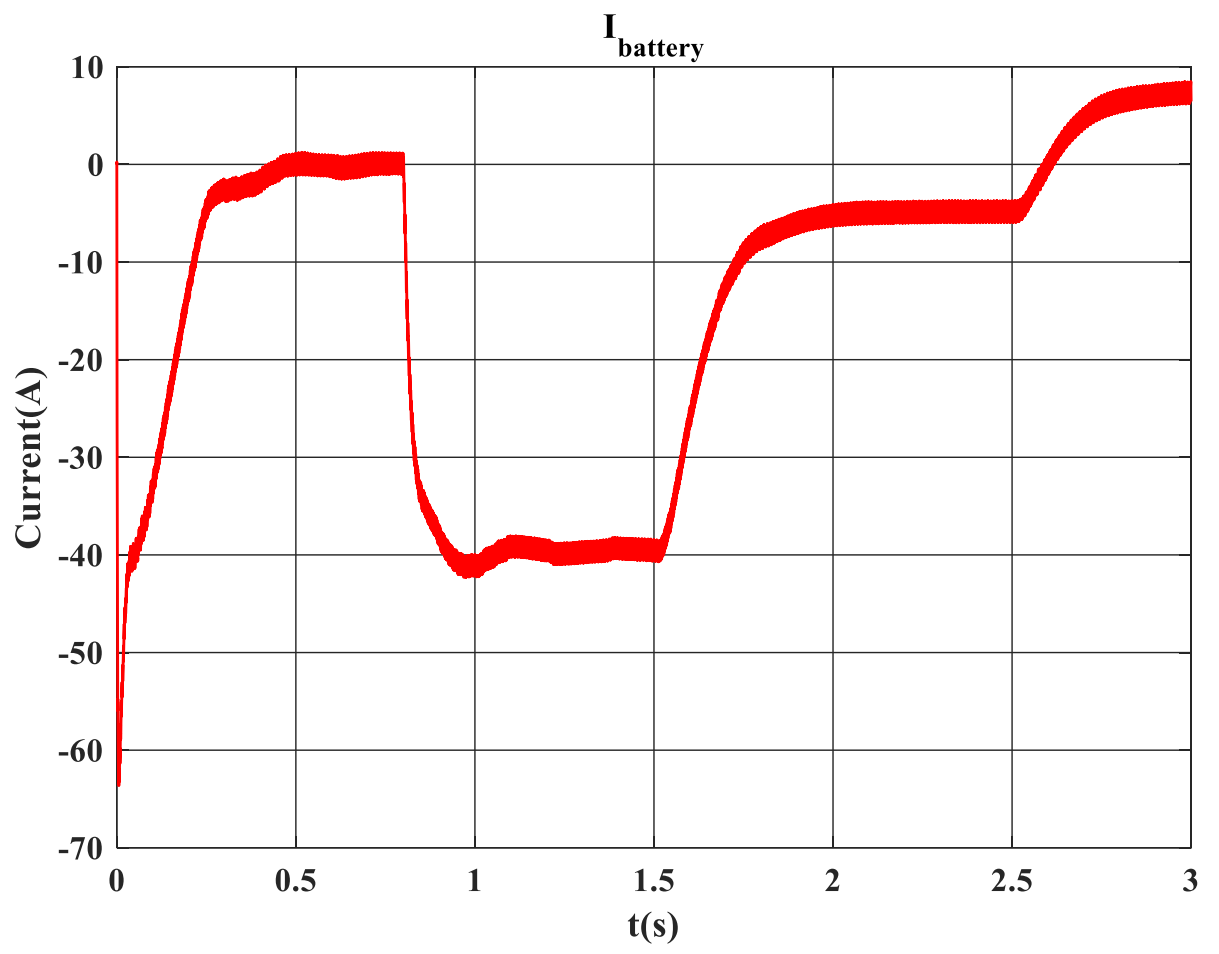

Figure 3.27(h) Battery charging/discharging current

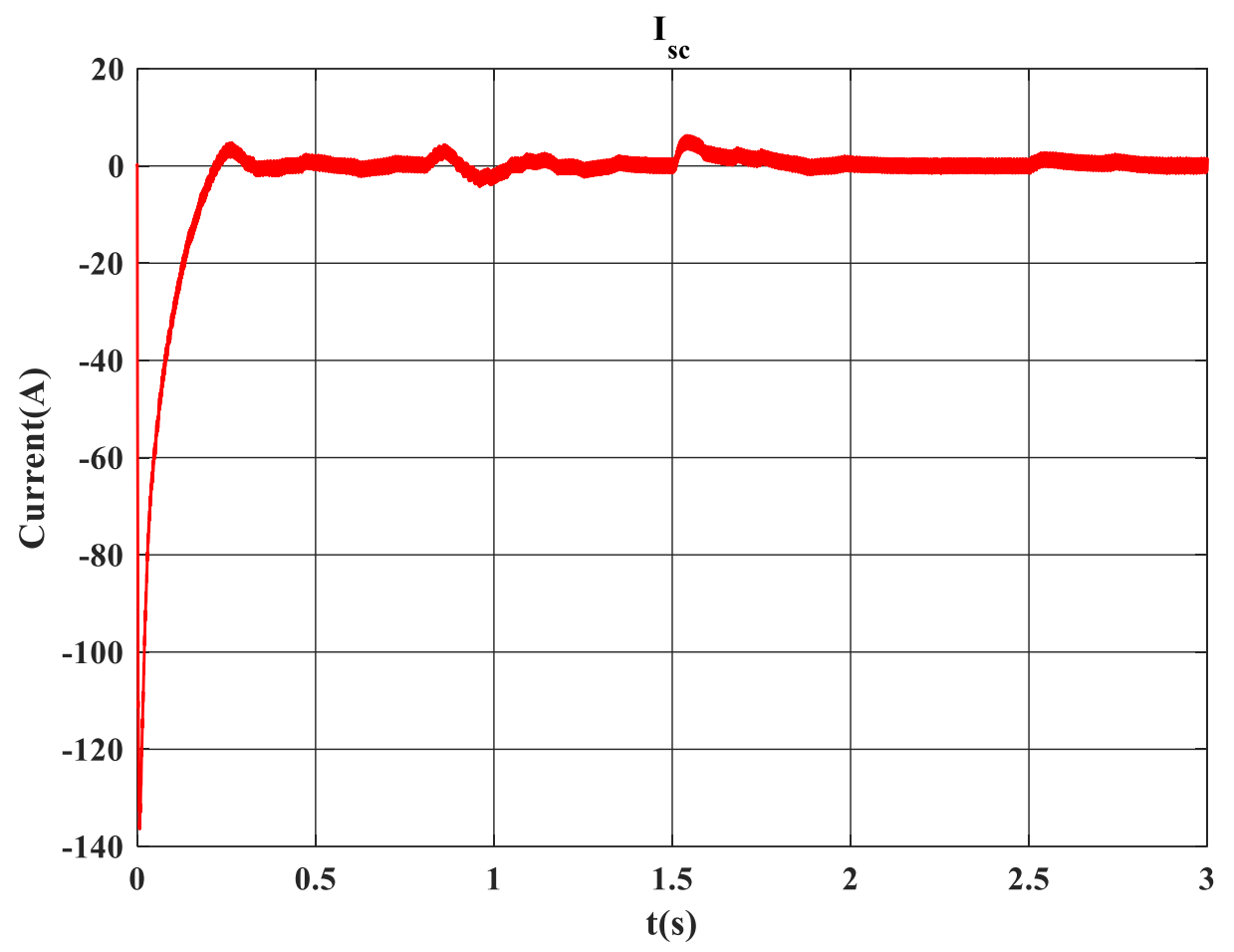

Figure 3.27(i) Supercapacitor charging/discharging current

Figure 3.27 Simulation results when changing $\boldsymbol{P}_{\text {load }}$ 
From simulation analysis in Figure 3.27, simulation results match the required condition. In order to avoide the fluctuation of system starting process, a step signal is added for $P_{\text {battery_ref }}$ and $P_{s c_{-} \text {ref. }}$. The step signal is activated at $\mathrm{t}=0.8 \mathrm{~s}$. Therefore, system fluctuation happens at $\mathrm{t}=0.8 \mathrm{~s}$, which can be seen in Figure 3.27. DC bus bar voltage is stabilized around $500 \mathrm{~V}$ at steady state. DC voltage fluctuates at $\mathrm{t}=0.8 \mathrm{~s}$ when the step signal is activated. Also, due to the change of $P_{\text {load }}$ at $\mathrm{t}=1.5 \mathrm{~s}$ and $\mathrm{t}=2.5 \mathrm{~s}$, the DC bus bar voltage fluctuates in transient state and goes back to steady state quickly, which shows the acceptable performance of transient response. The low frequency component of $P_{E S S}$ is managed by battery while the high frequency component of $P_{E S S}$ is managed by supercapacitor. The battery is charging at constant current before $t=2.5 \mathrm{~s}$ and discharging after $\mathrm{t}=2.5 \mathrm{~s}$. The supercapacitor is charging/discharging frequently in order to alleviate the high frequency component of power fluctuation. At $t=1.5 \mathrm{~s}$ and $t=2.5 \mathrm{~s}$, because of sudden change of $P_{\text {load }}$, supercapacitor ensures the quick response of transient state, which compensate battery disadvantage.

Power balance is satisfied in PV grid-connected household nano-grid system. Therefore, in this model, we have power balance equation:

$$
P_{p v}+P_{E S S}+P_{g r i d}=P_{l o a d}
$$

$P_{\text {grid }}$ is the exchanging power between PV nano-grid system and main power grid. Due to the existence of $P_{p v}, P_{E S S}, P_{\text {load }}, P_{\text {grid }}$ can be known from power balance equation. Therefore, we can assume that: 
$P_{\text {grid }}>0$, power is exchanged from main power grid to PV nano-grid system.

$P_{\text {grid }}<0$, power is exchanged from PV nano-grid system to main power grid.

The interaction between PV nano-grid system and main power grid can be analyzed by utilizing power balance equation. $P_{E S S}$ is the power command integrated with optimized power scheduled from EMS and power fluctuation, which determines charging or discharging. $P_{\text {grid }}$ can be known from power balance equation. When $P_{\text {grid }}<0$, power is sent from PV nano-grid system to main power grid. At this time, customer power demand on main power grid is very high such as in the morning so that main power grid is in power shortage situation. PV nano-grid system sends power to alleviate the high power demand on main power grid. Furthermore, electric price is high at this time due to high power demand time period. PV nano-grid system sells power to main power grid to achieve economic benefit. When $P_{\text {grid }}>0$, power is sent from main power grid to PV nano-grid system. At this time, customer power demand on main power grid is low such as at midnight so that main power grid is in power surplus situation. Electric price is lower at this time due to low power demand time period. Therefore, PV nano-grid system can buy power from power main grid to achieve economic benefit. In Figure 3.27, at $\mathrm{t}=2.5 \mathrm{~s} \sim 3 \mathrm{~s}$ in this simulation, $P_{E S S}$ is $0.9 \mathrm{~kW}$ as optimized power command that battery is discharging. $P_{\text {grid }}$, which is $-3 \mathrm{~kW}$, can be achieved by using power balance equation. Therefore, power is sent from PV nano-grid system to main power grid and PV nano-grid system achieves economic benefit. 


\subsection{Summary}

The chapter focuses on the model and analysis of PV grid-connected household nano-grid system. Based on the structure of PV nano-grid system, the control systems for PV DC/DC boost converter, the bi-directional DC/DC buck/boost converters in energy storage system and single phase full-bridge DC/AC inverter are proposed. MPPT is used for the control of PV DC/DC boost converter as a way to achieve the maximum power output of PV module. Energy storage system can be taken as the execution unit of upper EMS. The constant power control with the consideration of battery protection for the bi-directional DC/DC buck/boost converters of battery module and supercapacitor module is utilized. By using the frequency division, battery is responsible for managing the low frequency component of the sum of the scheduled power command and the power fluctuation of PV and residential loads while the supercapacitor is responsible for the high frequency component of the sum of the scheduled power command and the power fluctuation of PV and residential loads. The two energy storage devices are complementary in function. Single phase full-bridge $\mathrm{DC} / \mathrm{AC}$ inverter deploys the constant voltage control to maintain the voltage stability of DC bus bar. The model of PV grid-connected household nano-grid system is simulated in MATLAB/Simpower. The reasonable simulation results at various conditions can prove the correctness of control systems listed above. The model of PV grid-connected household nano-grid system is significant for proving the proposed EMS energy management strategy in this thesis, which builds for the foundation for the realization of upper EMS. Furthermore, in the future, more accurate load prediction method will be used in the proposed energy management strategy based on this PV nano-grid system model. In addition, this PV nano-grid system model can be used for the EMS based 
on Artificial Intelligence (AI) proposed in the future, which is contributive. 


\section{Chapter: Energy Management Strategy of EMS in PV Grid-}

\section{Connected Household Nano-grid System}

In this chapter, based on the PV prediction and load prediction data, a long-term (more than one day) optimal scheduling algorithm is proposed for the energy storage system in the nano-grid system, to better organize the charging/discharging action of the battery. The rolling optimization technique is used to generate hourly optimal scheduling decision. Moreover, a smoothing function is designed to alleviate the power fluctuation of the main grid in minutes level caused by real time PV and load variations. Figure 4.1 shows the schematic diagram of upper energy management strategy.

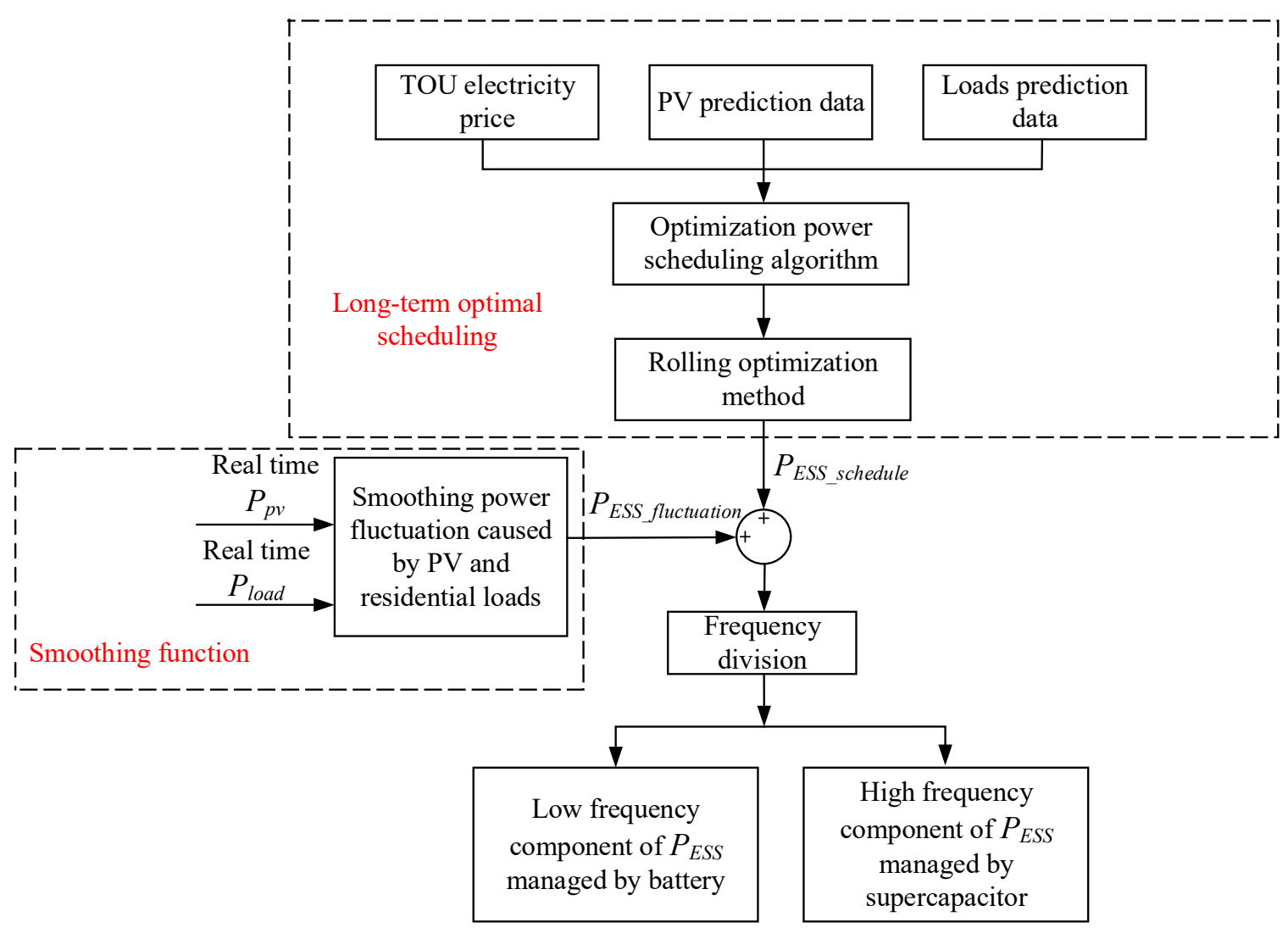

Figure 4.1 Schematic diagram of upper energy management strategy 


\subsection{Household Load Prediction}

Residential loads are inherently random. In the long-term optimal scheduling algorithm, the load prediction is based on the history data of the residential loads usage. The load prediction is based on the double exponential smoothing method for 24 hours prediction. In the double exponential smoothing method, the predicted value has a high fitting degree with its original time sequence. This method is relatively simple and effective on predicting non-straight linear trend curve.

The double exponential smoothing method is described as follows.

$$
S_{t}^{(1)}=a Y_{t}+(1-a) S_{t-1}^{(1)}
$$

$a$ is smoothing parameter, $Y_{t}$ is the observation, and $S_{t}^{(1)}$ is the smoothing value. Double exponential smoothing value is denoted as $S_{t}^{(2)}$, which is the smoothing value of single exponential smoothing value $S_{t}^{(1)}$. It can be written as:

$$
S_{t}^{(2)}=a S_{t}^{(1)}+(1-a) S_{t-1}^{(2)}
$$

The double exponential smoothing is mainly used on predicting linear-trend time sequence with variable parameters. Linear-trend time sequence with variable parameters can be expressed as:

$$
F_{t+T}=a_{t}+b_{t} T
$$

where, $a_{t}$ and $b_{t}$ are time-varying parameters, $T$ is the prediction period ahead of $t$, and $F_{t+T}$ is the forecast $T$ period ahead of $t$.

The variable parameters can be expressed as: 


$$
\left\{\begin{array}{c}
a_{t}=2 S_{t}^{(1)}-S_{t}^{(2)} \\
b_{t}=\frac{a}{1-a}\left(S_{t}^{(1)}-S_{t}^{(2)}\right)
\end{array}\right.
$$

Then we can take the variable parameters in (4.4) into (4.3), which can have the potential on predicting infinite time periods. If the prediction period is $T=1$, it can be expressed as:

$$
F_{t+1}=a_{t}+b_{t}=2 S_{t}^{(1)}-S_{t}^{(2)}+\frac{a}{1+a}\left(S_{t}^{(1)}-S_{t}^{(2)}\right)=\frac{2-a}{1-a} S_{t}^{(1)}-\frac{1}{1-a} S_{t}^{(2)}
$$

The value of smoothing factor $a$ determines the smoothing level and response time between prediction and actual situations.

In general, we can summarize the double exponential smoothing by equations:

$$
\begin{aligned}
& S_{t}^{(1)}=a Y_{t}+(1-a) S_{t-1}^{(1)} \\
& S_{t}^{(2)}=a S_{t}^{(1)}+(1-a) S_{t-1}^{(2)} \\
& \left\{\begin{array}{c}
a_{t}=2 S_{t}^{(1)}-S_{t}^{(2)} \\
b_{t}=\frac{a}{1-a}\left(S_{t}^{(1)}-S_{t}^{(2)}\right)
\end{array}\right. \\
& F_{t+T}=a_{t}+b_{t} T
\end{aligned}
$$

Where

- $Y$ = observation

- $S_{t}^{(1)}=$ single smoothing observation 
- $S_{t}^{(2)}=$ double smoothing observation

- $a$ = estimated level, smoothing parameter

- $\quad b \quad=$ estimated trend factor

- $F \quad=$ forecast $T$ periods ahead

- $t \quad=$ time period

- $T$ = periods ahead of $t$

Steps of conducting the algorithm for prediction are shown as follows.

(1) Compute mean value (the duration is 1 hour) from the original value;

(2) Select the same period of each day as the observation $Y(m, n) ; m$ means total days, and $n$ means total periods of one day. In this case, $m=30$ and $n=24$.

(3) Calculate each forecasting value $F(t+1, j)$ at $j$ hour for the day of $(t+1)$.

(4) Combine all forecasting value $F(t+1,:)$ as the curve of $(t+1)$ day. This curve has 24 points.

Table 1 Forecasting Values in $\mathbf{t}+1$ Days

\begin{tabular}{|l|l|l|l|l|}
\hline \multicolumn{1}{|c|}{$\begin{array}{l}\text { Period } \\
(\text { day })\end{array}$} & 1 & 2 & $\cdots$ & 24 \\
\hline 1 & $Y(1,1)$ & $Y(1,2)$ & $\cdots$ & $Y(1,24)$ \\
\hline 2 & $Y(2,1)$ & $Y(2,2)$ & $\cdots$ & $Y(2,24)$ \\
\hline$\cdots$ & $\cdots$ & $\cdots$ & $\cdots$ & $\cdots$ \\
\hline$t$ & $Y(t, 1)$ & $Y(t, 2)$ & $\cdots$ & $Y(t, 24)$ \\
\hline Forecasting & $F(t+1,1)$ & $F(t+1,2)$ & $\cdots$ & $F(t+1,24)$ \\
\hline
\end{tabular}


In the end, we can get:

$$
f(t+1)=[F(t+1,1), F(t+1,2), \ldots, F(t+1,24)]
$$

Figure 4.2 shows the load prediction result of August 2009 for a household loads based on [54].

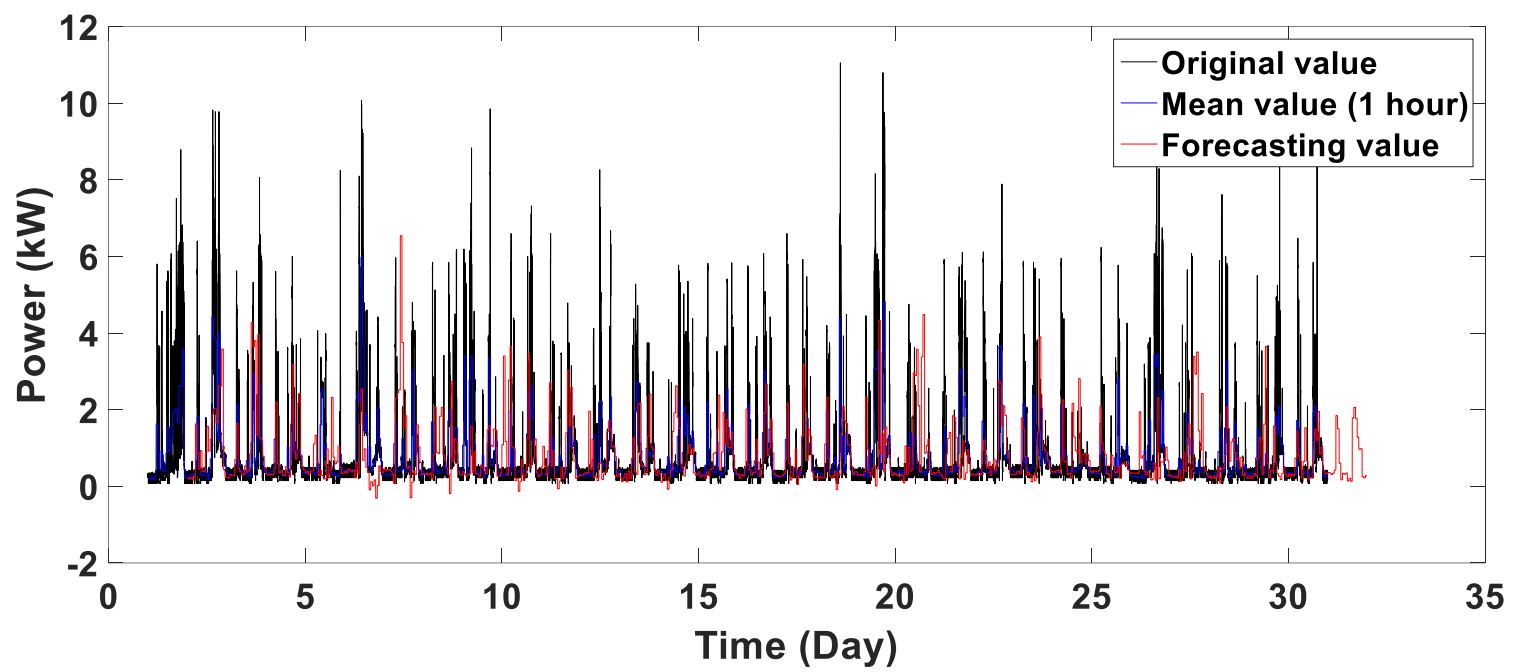

Figure 4.2(a) Load prediction result for Aug.2009

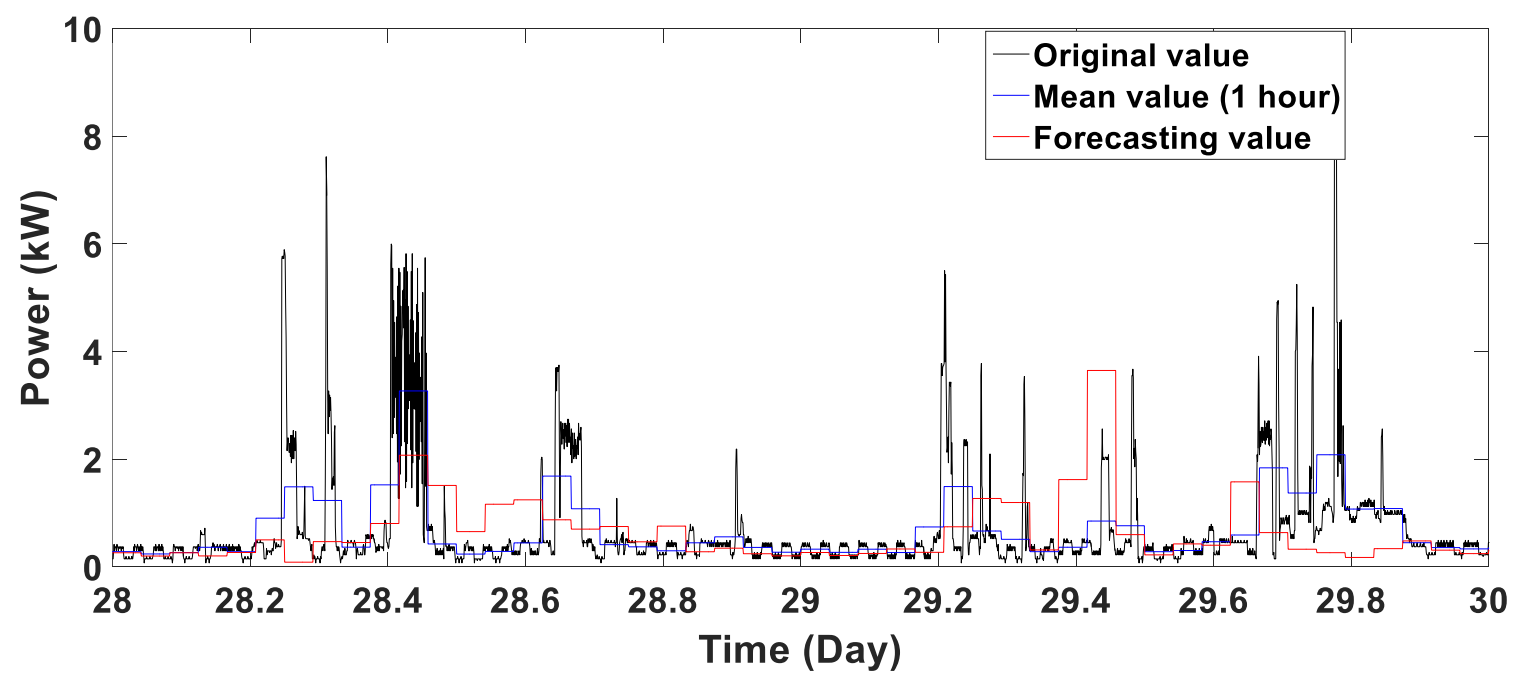

Figure 4.2(b) Load prediction result for two days in Aug.2009

Figure 4.2 Load prediction result 
From Figure 4.2, it can be seen that load prediction has error compared with real load data especially at load peak time.

\subsection{Long-Term Optimal Scheduling for Energy Storage System in PV Grid- Connected Household Nano-Grid System}

Based on the prediction data of PV power generation in 24 hours, load prediction data in 24 hours, ToU electricity pricing and battery SOC, the long-term optimal scheduling algorithm can determine the charging/discharging action for the battery in the energy storage system. In this thesis, the rolling optimization method is designed to solve the longterm optimal scheduling problem for the energy storage system. In the rolling optimization method, 24 hours are seen as a cycle and one hour is defined as a scheduling time span to realize optimal power scheduling, as shown in Figure 4.3. At each power scheduling point, which has one hour interval, the optimal powers are scheduled for 24 hours. However, only the optimized vector in first grid is used as other 23 optimized vectors are not accurate and abandoned. The adopted optimized vector shows the current operation state of PV nanogrid system. The optimization data window rolls one grid when the next scheduling point arrives after one hour. In Figure 4.3, the oblique data frame shows the adopted power command sequence. The dotted line grid shows the finished power scheduling command sequence. Therefore, with the power scheduling points going on, the data in optimization data window is updated when rolling every one hour. And the length of optimization data window keeps unchanged. Because the updating of PV and load prediction data is considered in rolling optimization method, the prediction error can be reduced. Optimal scheduled power command reserved at every one hour power scheduling time points can 
be achieved by using rolling optimization method.

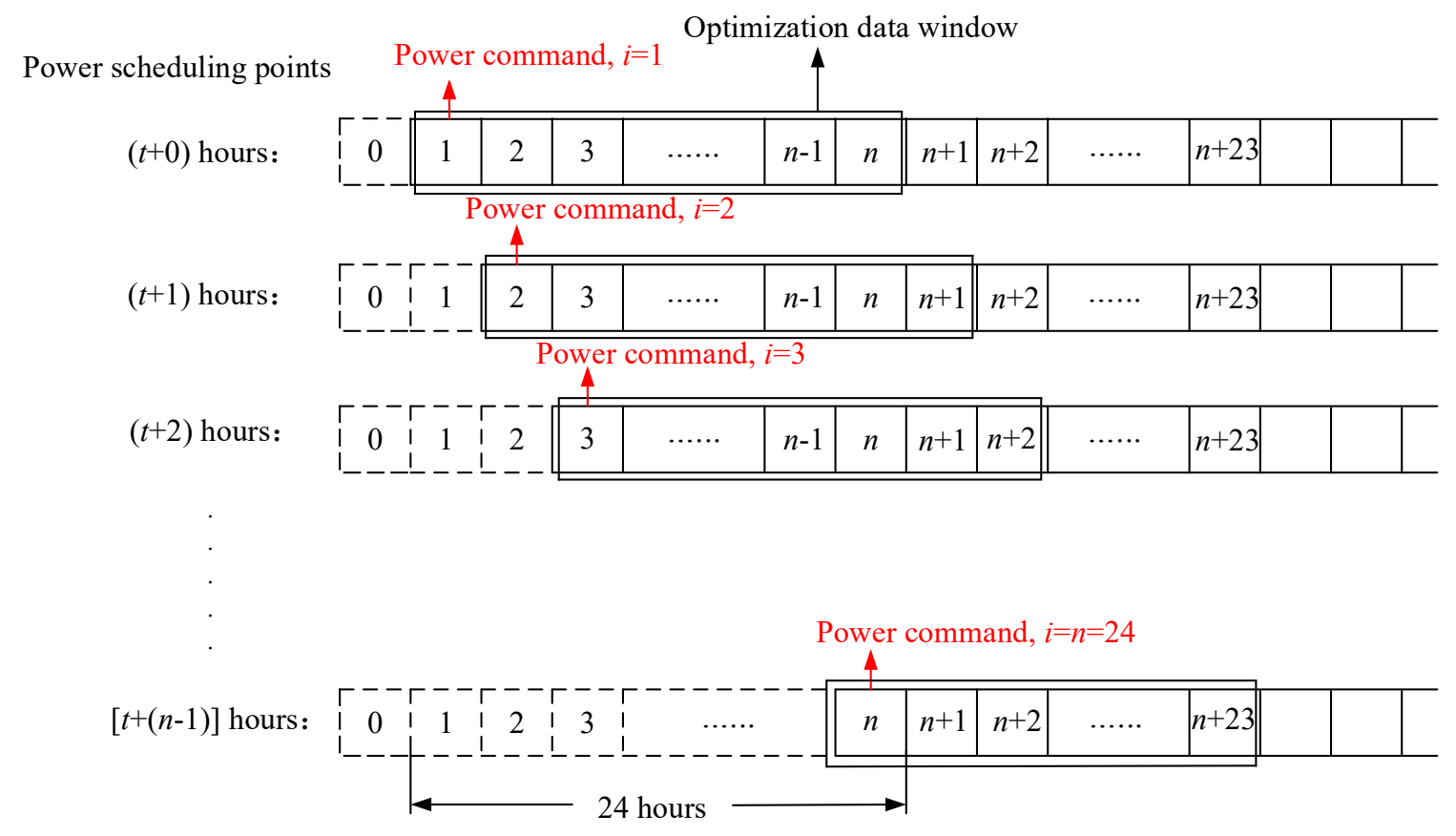

Figure 4.3 Rolling optimization method

The rolling optimization model is introduced as follows.

1) The setting of variables

$P_{\text {ESScharge }}\left(P_{e c}\right)$ : Battery charging power.

$P_{\text {ESSdischarge }}\left(P_{e d}\right)$ : Battery discharging power.

$P_{\text {GridIn }}\left(P_{g i}\right)$ : the exchanging power from main power grid to PV nano-grid system.

$P_{\text {Gridout }}\left(P_{\text {go }}\right)$ : the exchanging power from PV nano-grid system to main power grid.

$S O C$ : State of charge of battery.

$S_{E S S}\left(S_{e}\right)$ : State of energy storage system, 1 for charging; 0 for discharging.

$S_{\text {Grid }}\left(S_{g}\right)$ : State of PV nano-grid system, 1 for power in, 0 for power out. 
The seven variables above can be expressed as a vector:

$$
x(t)=\left[\begin{array}{c}
P_{e c}(t) \\
P_{e d}(t) \\
P_{g i}(t) \\
P_{g o}(t) \\
S O C(t) \\
S_{e}(t) \\
S_{g}(t)
\end{array}\right]_{7 \times 1}
$$

24 hours is the whole scheduling cycle. One hour is the scheduling time span, which schedules the optimized variables every one hour by rolling optimization. Optimization data window has $N=24$ vector groups, which corresponds to 24 grids. Every group has seven variables, which can be expressed as:

$$
X=\left[\begin{array}{c}
x\left(t_{1}\right) \\
x\left(t_{2}\right) \\
\cdots \\
x\left(t_{N}\right)
\end{array}\right]_{7 N \times 1}
$$

The battery charging or discharging power $P_{E S S}$ (At this time, $P_{E S S}=P_{E S S_{-} \text {schedule }}$ ) can be positive or negative. When $P_{E S S}>0$, battery is discharging. When $P_{E S S}<0$, battery is charging. The exchange of power between PV nano-grid system and main power grid is expressed as $P_{\text {grid. }}$ When $P_{\text {grid }}>0$ the exchanging power is from main power grid to PV nano-grid system. When $P_{\text {grid }}<0$ the exchanging power is from PV nano-grid system to main power grid. Therefore,

$$
\begin{aligned}
& P_{E S S}=P_{e d}-P_{e c} \\
& P_{\text {Grid }}=P_{g i}-P_{g o}
\end{aligned}
$$




\section{2) Objective function}

Objective function, which satisfies equality constraints and inequality constraints, is the minimized operational cost of PV nano-grid system. Equality constraints are the power balance of PV nano-grid system and cross-time battery capacity while inequality constraints are concentrating on the operating reliability of PV nano-grid system. Based on PV prediction data, residential load prediction data, ToU electricity price and battery SOC, the operating variables can be obtained by solving the mathematical model that is built from objective function and constraints. The operating variables include battery charging power, battery discharging power, the exchange of power from main power grid to PV nano-grid system, the exchanging power from PV nano-grid system to main power grid, SOC of battery, state of energy storage system and state of PV nano-grid system. The objective function is:

$$
\begin{aligned}
& \min \sum_{t=1}^{N}\left\{f_{\text {Cost.ESS }}(t)+f_{\text {Cost }}\left[P_{\text {Grid }}^{\text {In }}(t)\right]-f_{\text {Revenue }}\left[P_{\text {Grid }}^{\text {Out }}(t)\right]\right\} \\
& =\sum_{t=1}^{N}\left\{\left[k_{c} P_{e c}(t)+k_{d} P_{e d}(t)\right]+\left[k_{i}(t) P_{g i}(t)-k_{o}(t) P_{g o}(t)\right]\right\} \Delta T \\
& =\sum_{t=1}^{N} \Delta T\left[\begin{array}{lllllll}
k_{c} & k_{d} & k_{i}(t) & k_{o}(t) & 0 & 0 & 0
\end{array}\right] x \\
& =\sum_{t=1}^{N} f_{x} x=\left[\begin{array}{llll}
f_{x} & f_{x} & \cdots & f_{x}
\end{array}\right]_{(1,7 N)} X_{(7 N, 1)} \\
& =f X \\
& =f v a l
\end{aligned}
$$

In equation (4.12), fval is the minimized operational cost. $N=24$ is the total scheduling time spans. $f_{\text {Cost.ESS }}(t)$ is the operational cost of battery. $f_{\text {Cost }}\left[P_{\text {Grid }}^{I n}(t)\right]$ is the cost of 
buying electricity from main power grid. $f_{\text {Revenue }}\left[P_{\text {Grid }}^{\text {Out }}(t)\right]$ is benefit of selling electricity to main power grid. $\Delta T$ is the scheduling time span, which is the rolling time span. $k_{c}$ is battery charging price per $\mathrm{kWh} . k_{d}$ is the battery discharging price per $\mathrm{kWh} . k_{i}(t)$ is the buying electricity price per $\mathrm{kWh}$ from main power grid. $k_{o}(t)$ is the selling electricity price per kWh to main power grid.

\section{3) Equality constraints}

(1) Constraint of power balance of PV nano-grid system

The exchanging power between PV nano-grid system and main power grid, optimized power command for energy storage system charging or discharging, PV power generation and power consumption of residential loads are shown in the power balance equation below:

$$
\begin{aligned}
& P_{\text {grid }}+P_{E S S}=\left(P_{g i}-P_{g o}\right)+\left(P_{e d}-P_{e c}\right)=P_{l o a d}-P_{p v} \\
& \Rightarrow \quad\left[\begin{array}{lllllll}
-1 & 1 & 1 & -1 & 0 & 0 & 0
\end{array}\right]\left[\begin{array}{c}
P_{e c} \\
P_{e d} \\
P_{g i} \\
P_{g o} \\
S O C \\
S_{e} \\
S_{g}
\end{array}\right]=\left[P_{l o a d}-P_{p v}\right] \\
&\left.\Rightarrow \quad A_{\text {eq.power }}\right|_{(N, 7 N)} X_{7 N \times 1}=\left.b_{\text {eq.power }}\right|_{(N, 1)}
\end{aligned}
$$

In (4.13), $P_{l o a d}$ and $P_{p v}$ is based on PV prediction and load prediction.

(2) Constraint of cross-time battery capacity 
The battery capacity change during power scheduling time point $t$ and $t-1$ should be equal to the difference of battery charging and discharging capacity during $[t-1, t]$. This relationship can be expressed as following:

$$
\begin{aligned}
& {[\operatorname{SOC}(t)-\operatorname{SOC}(t-1)] \operatorname{Cap}=\Delta T\left(\eta_{c} P_{E S S}^{+}(t)-\frac{P_{E S}^{-}(t)}{\eta_{d}}\right) } \\
\Rightarrow \quad & \operatorname{Cap} \cdot \operatorname{SOC}(t-1)+\Delta T \eta_{c} P_{e c}(t)-\frac{\Delta T}{\eta_{d}} P_{e d}(t)-\operatorname{Cap} \cdot \operatorname{SOC}(t)=0
\end{aligned}
$$

In (4.14), Cap is the total battery capacity. $\eta_{c}$ is the battery charging efficiency. $\eta_{d}$ is the battery discharging efficiency. $\Delta T$ is scheduling time interval. (4.14) can be expressed as a vector:

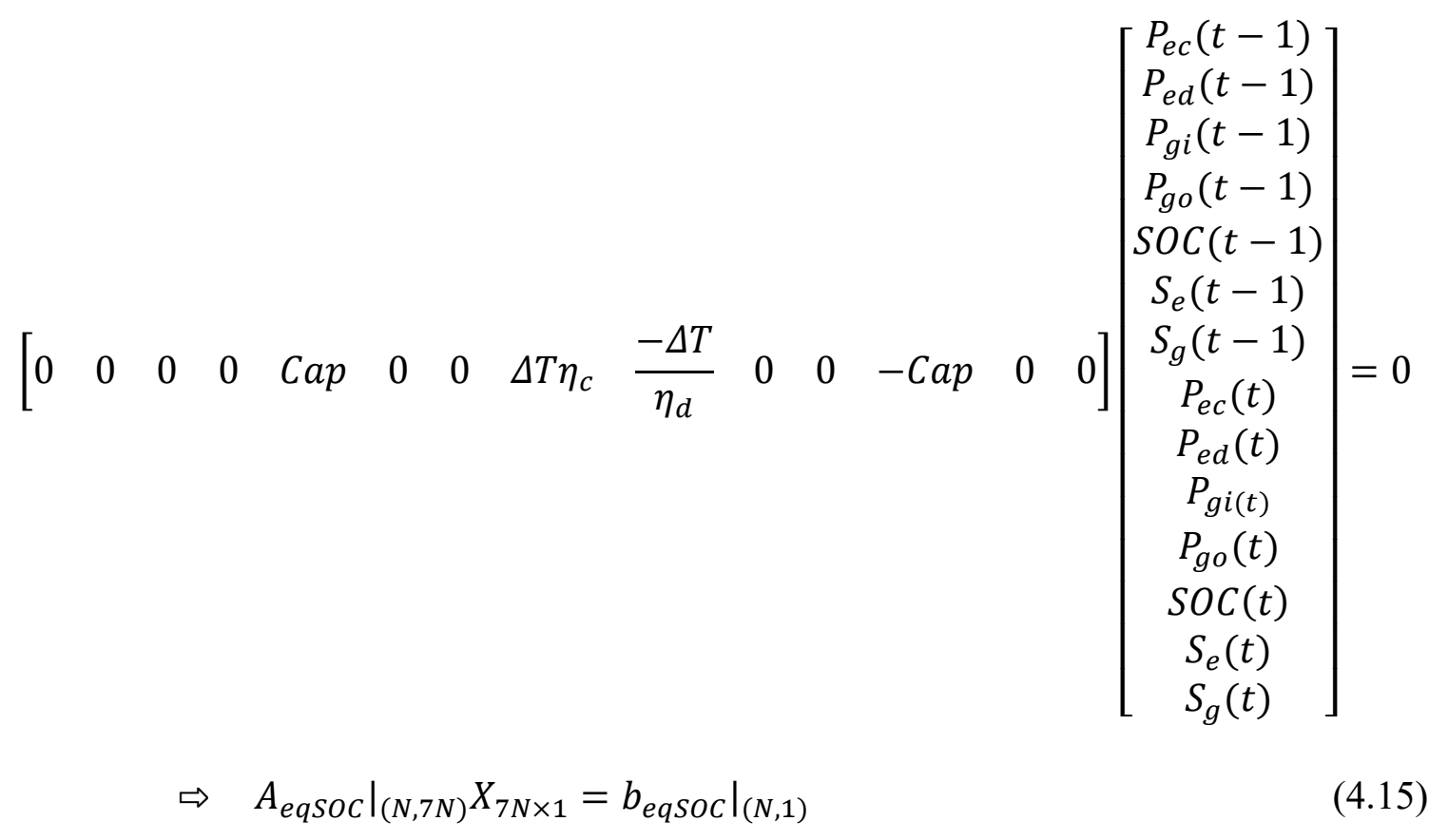

Therefore, two equality constraints above can be combined as:

$$
A_{e q} X=b_{e q} ; \text { where } A_{e q}=\left[\begin{array}{c}
A_{\text {eq.power }} \\
A_{\text {eqsoc }}
\end{array}\right]_{2 N \times 7 N} ; b_{\text {eq }}=\left[\begin{array}{c}
b_{\text {eq.power }} \\
b_{\text {eqsoc }}
\end{array}\right]_{2 N \times 1}
$$


4) Inequality constraints

(1) Constraint of battery SOC

$$
S O C_{\min } \leq S O C \leq S O C_{\max }
$$

$S O C_{\min }$ and $S O C_{\max }$ are the lower and upper limit of battery $S O C$.

(2) Constraint of battery charging and discharging power

$$
\begin{gathered}
P_{\text {ESSmin }} \leq P_{E S S} \leq P_{\text {ESSmax }} \\
\stackrel{\text { linearization }}{\longrightarrow}\left\{\begin{array}{c}
S_{e} P_{\text {ecmin }} \leq P_{\text {ec }} \leq S_{e} P_{\text {ecmax }} \\
\left(1-S_{e}\right) P_{\text {edmin }} \leq P_{\text {ed }} \leq\left(1-S_{e}\right) P_{\text {edmax }}
\end{array}\right.
\end{gathered}
$$

In (4.18), $P_{E S S m a x}$ and $P_{E S S m i n}$ are the maximum charging or discharging power and minimum charging or discharging power respectively. $P_{\text {ecmax }}$ and $P_{\text {ecmin }}$ are the maximum battery charging power and minimum battery charging power respectively. $P_{\text {edmax }}$ and $P_{\text {edmin }}$ are the maximum battery discharging power and minimum battery discharging power respectively. This inequality constraint can be expressed as:

$$
\begin{gathered}
\left\{\begin{array}{c}
-P_{e c}+P_{e c m i n} S_{e} \leq 0 \\
P_{e c}-P_{e c m a x} S_{e} \leq 0 \\
-P_{e d}-P_{e d m i n} S_{e} \leq-P_{e d m i n} \\
P_{e d}+P_{e d m a x} S_{e} \leq P_{e d m a x}
\end{array}\right. \\
\Rightarrow \quad\left[\begin{array}{ccccccc}
-1 & 0 & 0 & 0 & 0 & P_{e c m i n} & 0 \\
1 & 0 & 0 & 0 & 0 & -P_{e c m a x} & 0 \\
0 & -1 & 0 & 0 & 0 & -P_{e d m i n} & 0 \\
0 & 1 & 0 & 0 & 0 & P_{e d \max } & 0
\end{array}\right]\left[\begin{array}{c}
P_{e c} \\
P_{e d} \\
P_{g i} \\
P_{g o} \\
S O C \\
S_{e} \\
S_{g}
\end{array}\right] \leq\left[\begin{array}{c}
0 \\
0 \\
-P_{e d m i n} \\
P_{e d m a x}
\end{array}\right] \\
\Rightarrow \quad A_{P e} x \leq b_{P e}
\end{gathered}
$$


(3) Constraint of the exchanging power between PV nano-grid system and main power grid

$$
\begin{gathered}
P_{\text {Gridmin }} \leq P_{\text {Grid }} \leq P_{\text {Gridmax }} \\
\stackrel{S_{\text {inearization }}}{\longrightarrow}\left\{\begin{array}{c}
S_{g} P_{\text {gimin }} \leq P_{\text {gi }} \leq S_{g} P_{\text {gimax }} \\
\left(1-S_{g}\right) P_{\text {gomin }} \leq P_{\text {go }} \leq\left(1-S_{g}\right) P_{\text {gomax }}
\end{array}\right.
\end{gathered}
$$

In (4.20), $P_{\text {Gridmax }}$ and $P_{\text {Gridmin }}$ are the maximum exchanging power between PV nanogrid system and main power grid and minimum exchanging power between PV nano-grid system and main power grid respectively. $P_{\text {gimax }}$ and $P_{\text {gimin }}$ are the maximum exchanging power from main power grid to PV nano-grid system and the minimum exchanging power from main power grid to PV nano-grid system respectively. $P_{\text {gomax }}$ and $P_{\text {gomin }}$ are the maximum exchanging power from PV nano-grid system to main power grid and the minimum exchanging power from PV nano-grid system to main power grid respectively. This inequality can be expressed as:

$$
\begin{gathered}
\left\{\begin{array}{c}
-P_{g i}+P_{\text {gimin }} S_{g} \leq 0 \\
P_{\text {gi }}-P_{\text {gimax }} S_{g} \leq 0 \\
-P_{g o}-P_{\text {gomin }} S_{g} \leq-P_{\text {gomin }} \\
P_{\text {go }}+P_{\text {gomax }} S_{g} \leq P_{\text {gomax }}
\end{array}\right. \\
\Rightarrow \quad\left[\begin{array}{ccccccc}
0 & 0 & -1 & 0 & 0 & 0 & P_{\text {gimin }} \\
0 & 0 & 1 & 0 & 0 & 0 & -P_{\text {gimax }} \\
0 & 0 & 0 & -1 & 0 & 0 & -P_{\text {gomin }} \\
0 & 0 & 0 & 1 & 0 & 0 & P_{\text {gomax }}
\end{array}\right]\left[\begin{array}{c}
P_{e c} \\
P_{e d} \\
P_{g i} \\
P_{g o} \\
S O C \\
S_{e} \\
S_{g}
\end{array}\right] \leq\left[\begin{array}{c}
0 \\
0 \\
-P_{\text {gomin }} \\
P_{\text {gomax }}
\end{array}\right] \\
\Rightarrow \quad A_{P g} x \leq b_{P g}
\end{gathered}
$$


Therefore, two inequality constraints can be combined as:

$$
A_{x} x \leq b_{x} ; \text { where } A_{x}=\left[\begin{array}{l}
A_{P e} \\
A_{P g}
\end{array}\right]_{8 \times 7} ; b_{x}=\left[\begin{array}{l}
b_{P e} \\
b_{P g}
\end{array}\right]_{8 \times 1}
$$

Then we can get:

$$
A X \leq b ; \text { where } A=\left[\begin{array}{c}
A_{x} \\
A_{x} \\
\cdots \\
A_{x}
\end{array}\right]_{8 N \times 7 N} ; b=\left[\begin{array}{c}
b_{x} \\
b_{x} \\
\cdots \\
b_{x}
\end{array}\right]_{8 N \times 1}
$$

(4) Bounds of variables

$$
\begin{aligned}
& {\left[\begin{array}{c}
P_{\text {ecmin }} \\
P_{\text {edmin }} \\
P_{\text {gimin }} \\
P_{\text {gomin }} \\
S O C_{\min } \\
0 \\
0
\end{array}\right] \leq\left[\begin{array}{c}
P_{e c} \\
P_{e d} \\
P_{g i} \\
P_{g o} \\
S O C \\
S_{e} \\
S_{g}
\end{array}\right] \leq\left[\begin{array}{c}
P_{\text {ecmax }} \\
P_{\text {edmax }} \\
P_{\text {gimax }} \\
P_{\text {gomax }} \\
S O C_{\max } \\
1 \\
1
\end{array}\right] \Rightarrow l b_{x} \leq x \leq u b_{x} } \\
\Rightarrow \quad l b & =\left[\begin{array}{c}
l b_{x} \\
l b_{x} \\
\cdots \\
l b_{x}
\end{array}\right]_{7 N \times 1} ; u b=\left[\begin{array}{c}
u b_{x} \\
u b_{x} \\
\cdots \\
u b_{x}
\end{array}\right]_{7 N \times 1}
\end{aligned}
$$

In (4.25), $l b$ is the lower bound of variables and $u b$ is the upper bound of variables.

Therefore, based on the analysis above, the optimized mathematical model built above can solve linear optimization problem with multiple variables and multiple constraints. The model can be summarized as:

$$
\begin{aligned}
{[X, f v a l]=} & \operatorname{intlinProg}\left(f, \operatorname{intcon}, A, b, A_{e q}, b_{e q}, l b, u b\right) \\
& \text { Objective: } f v a l=\min (f X) \\
& \text { Inequality constraints: } A X \leq b \\
& \text { Equality constraints: } A_{e q} X=b_{e q} \\
& \text { Variable bonds: } l b \leq X \leq u b
\end{aligned}
$$


The optimization mathematical model above can be solved based on MATLAB software. In every scheduling time span, the optimization variable vector can be achieved. But only the current optimization power scheduling command, which is in the first grid of the optimization data window, is sent to the battery. Then when reaching the next power scheduling time point, the process above is repeated. Figure 4.4 shows a flow chart of longterm energy management strategy utilizing rolling optimization in 24 hours.

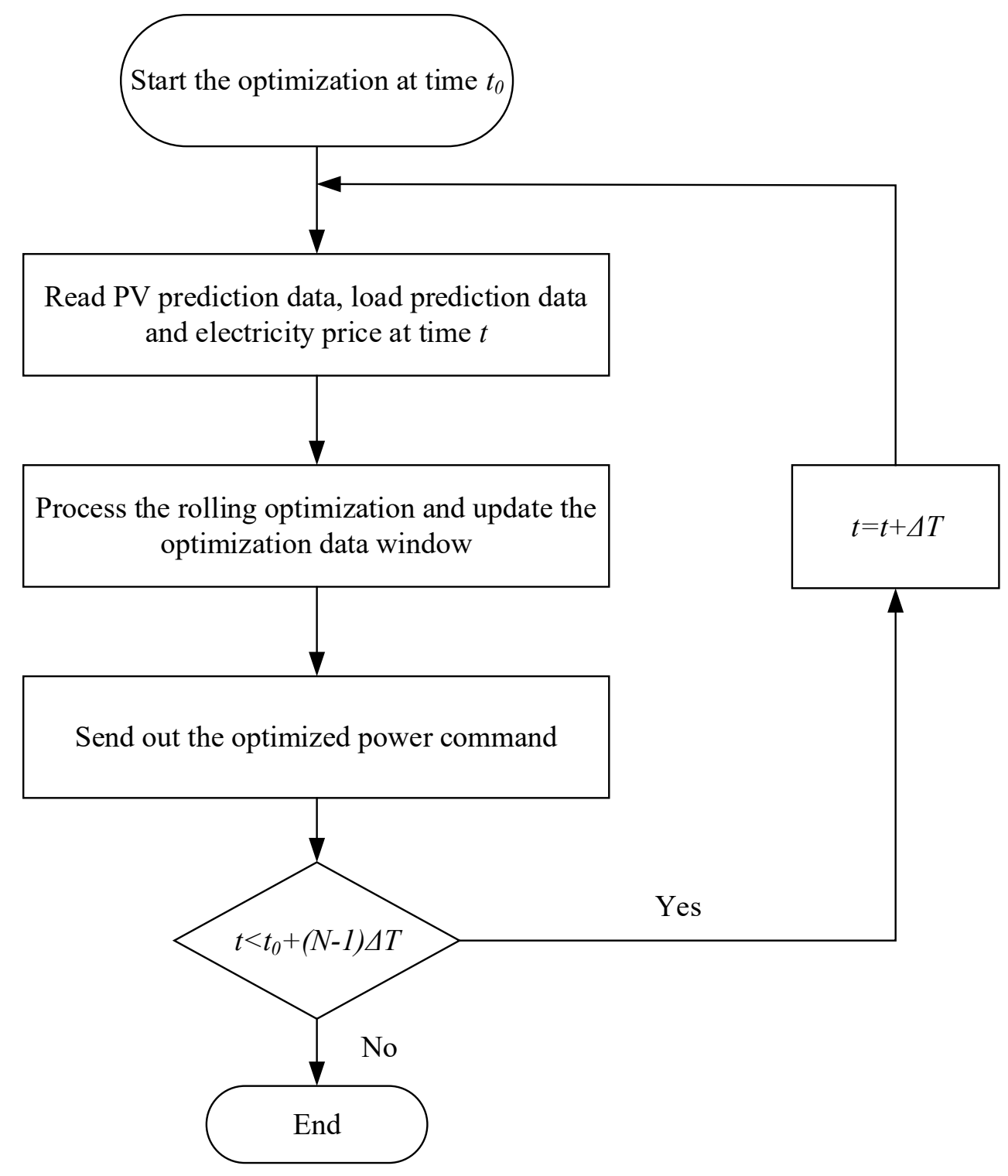

Figure 4.4 Flow chart of long-term optimal scheduling utilizing rolling optimization in 24 hours 


\subsection{Smoothing the Power Fluctuation of the Main Grid Caused by PV and Loads}

The long-term optimal scheduling for energy storage system is based on the prediction of PV power, loads and ToU price. Due to the intermittency of PV generation and residential loads, the power fluctuation of PV and residential loads in minutes level is hard to predict. When the power fluctuation range of PV and residential loads in minutes level is within $5 \%$ of the exchanging power, the main power grid can adjust it by itself. The operation of main power grid will not be influenced. However, when the power fluctuation range of PV and residential loads in minutes level is above $5 \%$ of the exchanging power, it can cause the fluctuation of voltage and frequency in main power grid, which adversely influences the operation of main power grid.

Therefore, a smoothing function is added in this work to smooth the power fluctuation of PV and residential loads in minutes level, as shown in Figure 4.5. The power fluctuation includes the low frequency power component and high frequency power component. The low frequency power component, which is in minutes level, is managed by battery while the high frequency power component, which is in seconds level, is managed by supercapacitor. As shown in Figure 4.5, the difference between the real-time PV power generation and power consumption of residential loads is sent into low pass filter and $P_{\text {ESS_fluctuation }}$ is obtained. Then, the $P_{\text {ESS_fluctuation }}$ is added to the optimal scheduled power $P_{E S S_{-} s c h e d u l e}$ and the adjusted scheduling signal called $P_{E S S}$ is generated and sent to the battery and supercapacitor in the energy storage system respectively. 


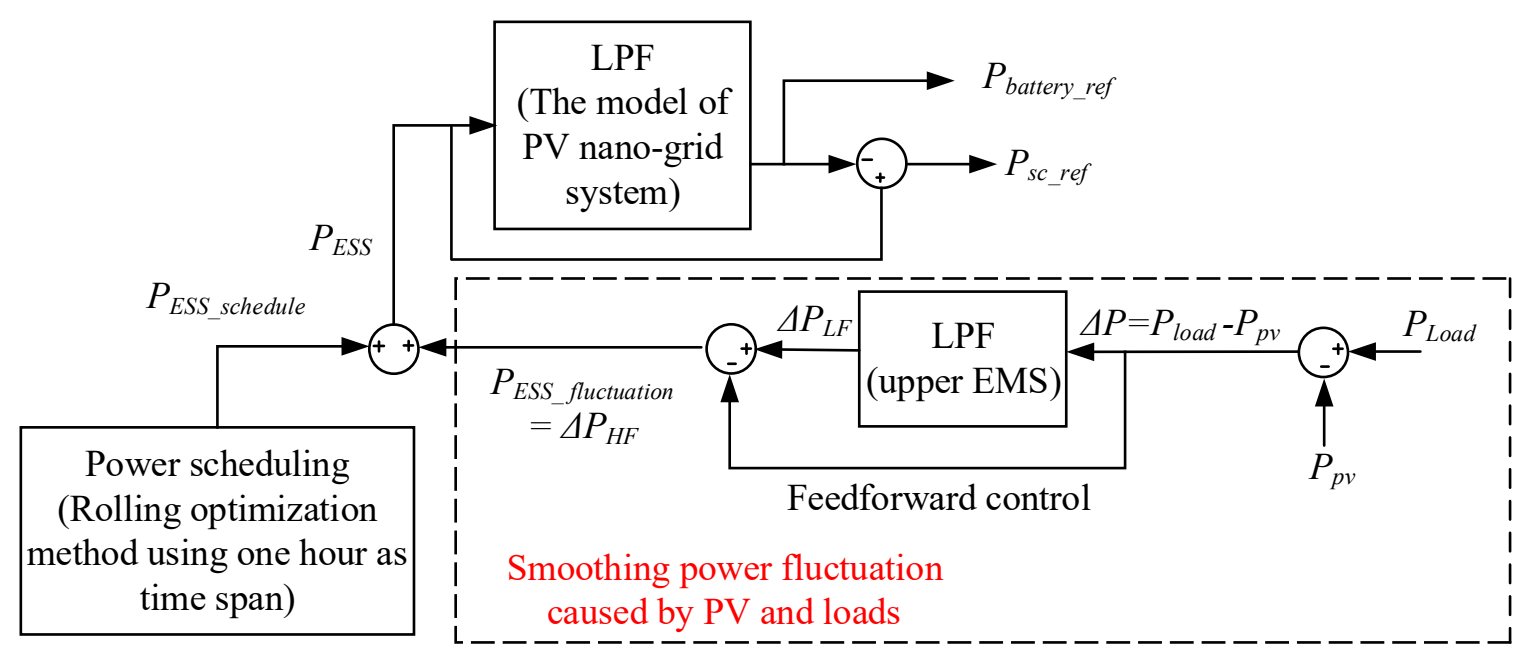

Figure 4.5 Smoothing power fluctuation of PV and loads

\subsection{Simulation Studies}

In this section, the energy management strategy presented previously is evaluated by the nano-grid system shown in Figure 4.6. The proposed energy management strategy of EMS has been proven based on the simulations in MATLAB/Simpower.

\subsubsection{System Parameters}

The system parameters of the PV nano-grid system shown in Figure 4.6 are listed in Table 2. The parameters of the battery are given in Table 3 . Table 4 shows ToU electricity price in Ottawa [55]. Table 5 shows the price of selling electricity from PV nano-grid system to main power grid. PV data is obtained from National Renewable Energy Laboratory (NREL) [56]. Residential loads data is historically gathered from 12 houses located in Ottawa, Canada [54]. 


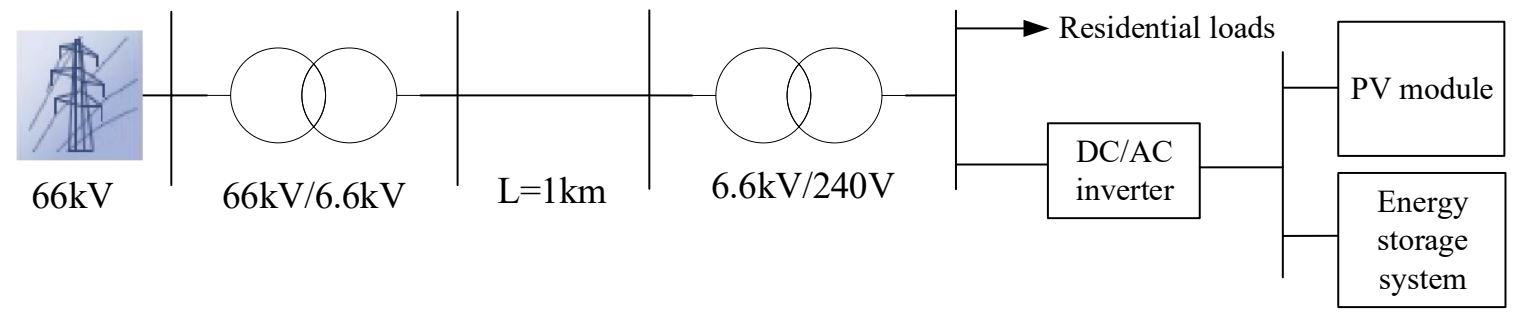

Figure 4.6 Overall system structure

Table 2 PV Nano-Grid System Operation Parameters

\begin{tabular}{|c|c|c|}
\hline Unit name & Parameters & Value \\
\hline Tie-line & $P_{\text {Gridmax }}$ & $15 \mathrm{~kW}$ \\
& $P_{\text {Gridmin }}$ & $0 \mathrm{~kW}$ \\
\hline Battery & $P_{\text {ESSmax }}$ & $3 \mathrm{~kW}$ \\
& $P_{\text {ESSmin }}$ & $0 \mathrm{~kW}$ \\
\hline
\end{tabular}

In Table 2, for the tie-line power, $P_{\text {Gridmax }}$ shows the maximum exchanging power between PV nano-grid and main power grid. $P_{\text {Gridmin }}$ shows the minimum exchange of power between PV nano-grid and main power grid. For the battery, $P_{\text {ESSmax }}$ shows the maximum battery charging/discharging power. $P_{\text {ESSmin }}$ shows the minimum battery charging/discharging power.

Table 3 Battery Parameters

\begin{tabular}{|c|c|c|}
\hline Parameters name & Parameters & Value \\
\hline SOC & $S O C_{\min }$ & 0.1 \\
& $S O C_{\max }$ & 0.9 \\
\hline Battery operational cost & $k_{c}$ & $0.01 \$ / \mathrm{kWh}$ \\
& $k_{d}$ & $0.01 \$ / \mathrm{kWh}$ \\
\hline Battery charging and & $\eta_{c}$ & 0.98 \\
discharging efficiency & $\eta_{d}$ & 0.98 \\
\hline Battery capacity & $C a p$ & $10.2 \mathrm{kWh}$ \\
& & \\
\hline
\end{tabular}


In Table3, for SOC, $S O C_{\max }$ is the maximum battery SOC value. $S O C_{\min }$ is the minimum battery SOC value. For the battery operational cost, $k_{c}$ is battery charging price per $\mathrm{kWh}$. $k_{d}$ is the battery discharging price per $\mathrm{kWh}$. For the battery charging and discharging efficiency, $\eta_{c}$ and $\eta_{d}$ are the battery charging efficiency and battery discharging efficiency respectively. Cap is the battery capacity.

Table 4 ToU Electricity Pricing for Winter Period (November 1 to April 30) Weekdays

\begin{tabular}{|c|c|c|}
\hline Time period & Electricity price & Time division \\
\hline Off-peak & $k_{i}=0.065 \$ / \mathrm{kWh}$ & $7 \mathrm{pm} \sim 7 \mathrm{am}$ \\
& & $11 \mathrm{am} \sim 5 \mathrm{pm}$ \\
\hline Mid-peak & $k_{i}=0.095 \$ / \mathrm{kWh}$ & $7 \mathrm{am} \sim 11 \mathrm{am}$ \\
& & $5 \mathrm{pm} \sim 7 \mathrm{pm}$ \\
\hline On-peak & $k_{i}=0.132 \$ / \mathrm{kWh}$ & \\
\hline
\end{tabular}

In Table $4, k_{i}$ is the buying electricity price per $\mathrm{kWh}$ from main power grid at different time division.

Table 5 Electricity Price of Selling Electricity to Main Power Grid

\begin{tabular}{|c|c|c|}
\hline Time period & Electricity price & Time division \\
\hline Off-peak & $k_{o}=0.065 \times 0.5 \$ / \mathrm{kWh}$ & $7 \mathrm{pm} \sim 7 \mathrm{am}$ \\
\hline Mid-peak & $k_{o}=0.095 \times 0.5 \$ / \mathrm{kWh}$ & $11 \mathrm{am} \sim 5 \mathrm{pm}$ \\
\hline On-peak & $k_{o}=0.132 \times 0.5 \$ / \mathrm{kWh}$ & $7 \mathrm{am} \sim 11 \mathrm{am}$ \\
& & $5 \mathrm{pm} \sim 7 \mathrm{pm}$ \\
\hline
\end{tabular}

In Table $5, k_{o}$ is the selling electricity price per $\mathrm{kWh}$ to main power grid at different time division. 
For the simulation results from Figure 4.7 to Figure 4.10, PV power output data is the measured historical data obtained from NREL, which is shown as green curve. Loads power consumption data is the measured historical data gathered from 12 houses located in Ottawa, Canada, which is shown as dark blue line. Dotted dark blue line shows load prediction value, which is the produced data. Battery charging/discharging power is shown as black curve, which is the produced data. The exchange of power between PV nano-grid and main power grid is shown as red curve, which is the produced data. The low frequency power component caused by PV and loads is shown as light blue curve, which is the produced data.

\subsubsection{Comparison of Simulation Results by Using Load Historical Data and Load Prediction Data}

The EMS simulation results applied with load prediction data generated by the method introduced in this Chapter and load historical data are shown in Figure 4.7. By comparing Figure 4.7(a) and Figure 4.7(b), the long-term optimal power scheduling applied with load prediction data is not reasonable due to the inaccurate load prediction data, which can be seen from battery charging/discharging curve. In Figure 4.7(a), at 17:00 18:00, the scheduled battery discharging power is not reasonable by using load prediction data as the battery discharges power to main power grid instead of storing to satisfy the high demand of residential loads at evening. Consequently, the battery would not be able to discharge enough power to satisfy the high demand of loads and power thus needs to be bought from main power grid to ensure the demand of loads at evening. In fact, the power consumption at 17:00 18:00 is very small and there is no need for the battery to discharge a lot of power. 
In Figure 4.7(b), the scheduled battery discharging power is reasonable by using load historical data. Battery discharges little power at 17:00 18:00 and store more power to satisfy the high demand of loads at evening. In summary, the inaccurate load prediction data leads to unreasonable long-term optimal power scheduling. Consequently, there will be less operational benefit of PV nano-grid system and more fluctuation of the exchanging power. Therefore, in the latter simulation studies, load historical data are used instead of load prediction data. In the future, more accurate prediction methods are to be investigated.

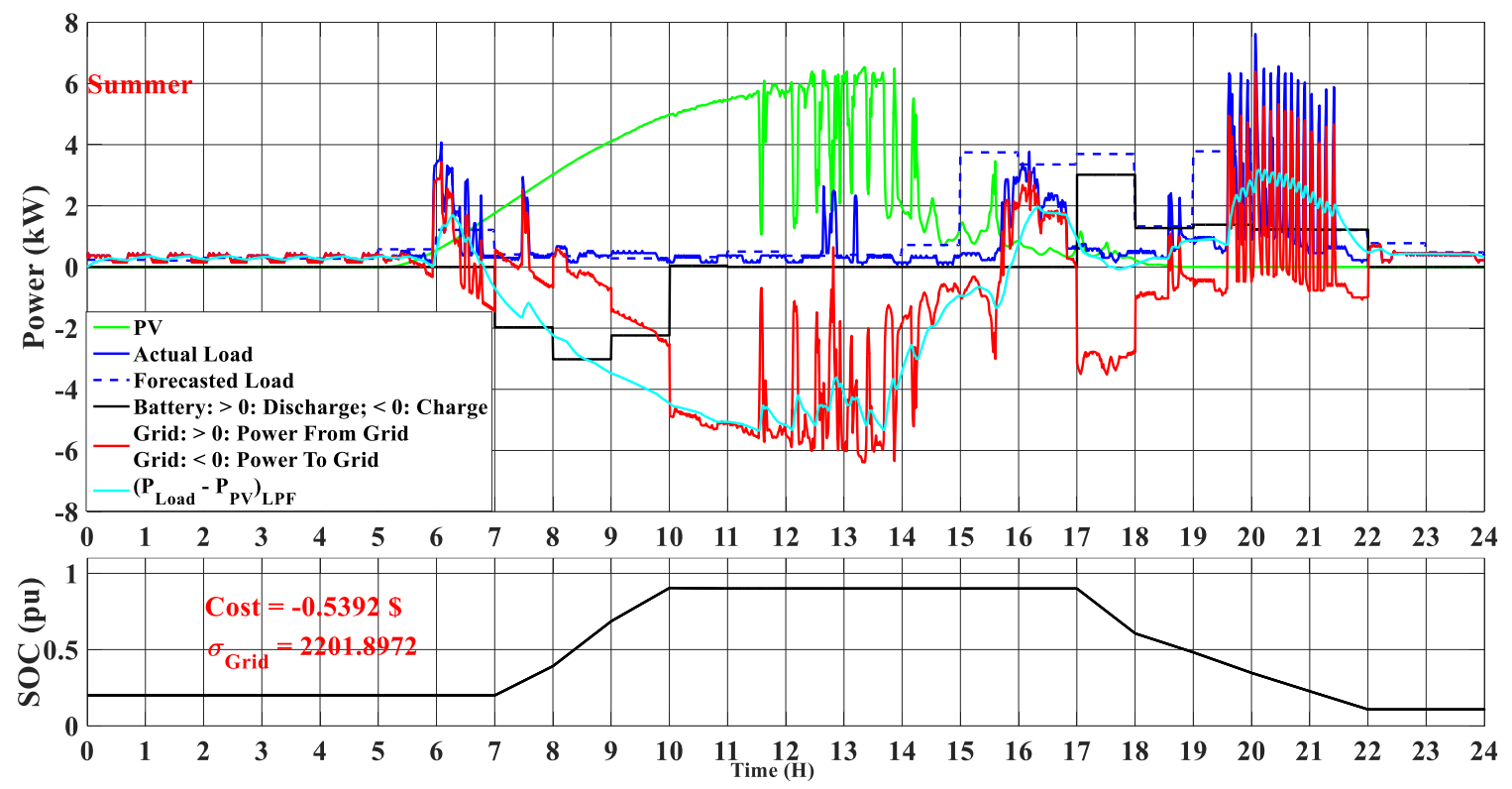

Figure 4.7(a) Simulation using load prediction data 


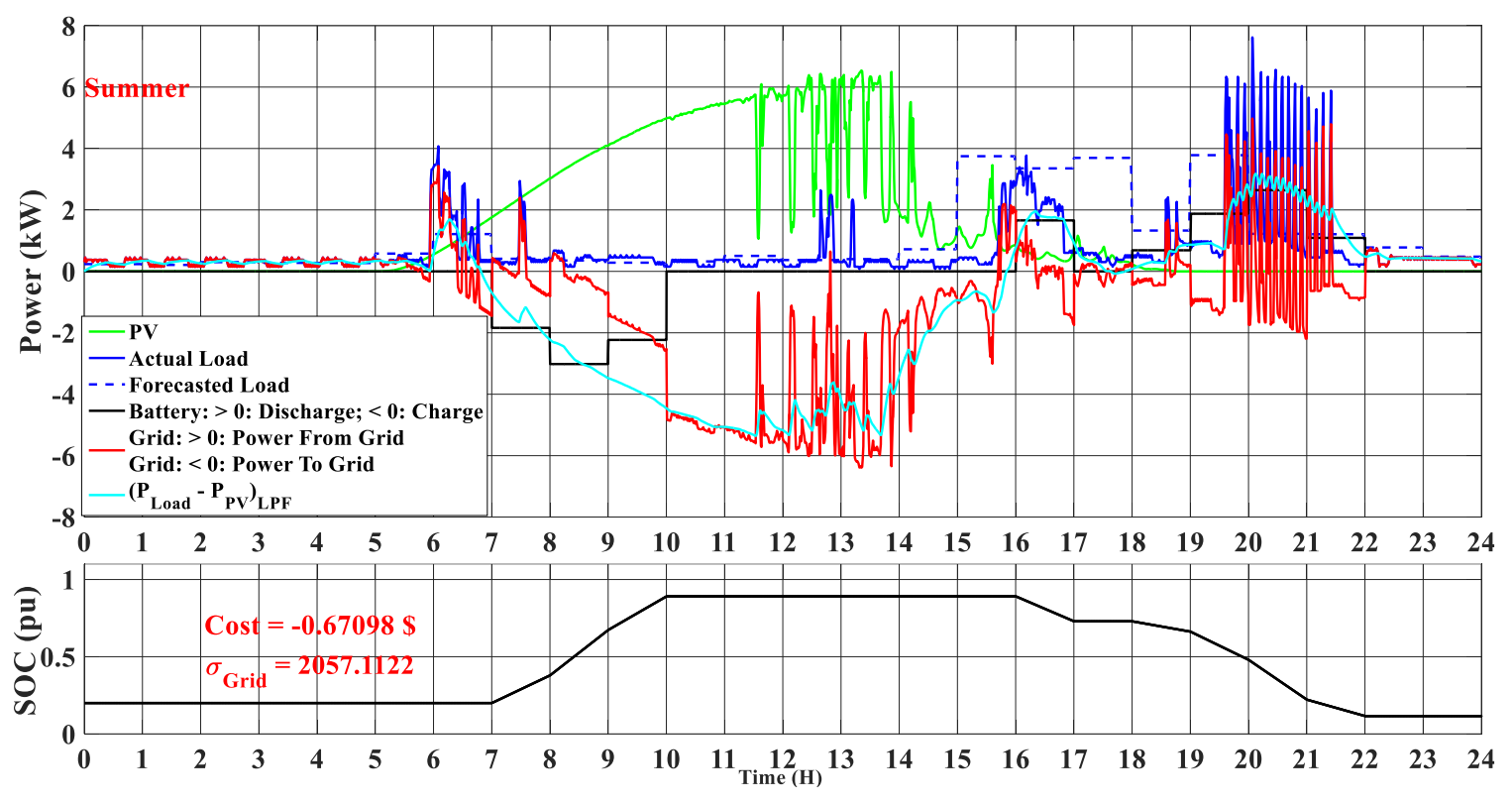

Figure 4.7(b) Simulation using load historical data

Figure 4.7 Simulation comparison between using load prediction data and load historical data

\subsubsection{Simulation Results and Analysis}

1) Analysis of the Smoothing Function in terms of PV Power and Load Intermittent

Fluctuation

As we discussed previously, the long-term optimal scheduling algorithm can schedule the charging/discharging of the battery in energy storage module every one hour by using the rolling optimization method. Furthermore, the smoothing function is added to smooth the effect of the power fluctuation of PV and residential loads on the power exchanging between the PV nano-grid system and main power grid. PV and load data on a typical cloud moving day is used to verify the effectiveness of the smoothing function designed in this thesis. Figure 4.8(a) shows the result of the long-term optimal power scheduling without the smoothing function, while Figure 4.8(b) shows the results of the long-term optimal power scheduling with the smoothing function. It can be seen from the figures the PV 
power is intermittent and fluctuating due to this cloud moving. Power consumption of residential loads has two on-peaks. First on-peak is around 7:00 8:00 and second on-peak is around 17:00 21:00.

As shown in Figure 4.8(a), the exchanging power between PV nano-grid system and main power grid is severely fluctuated resulting from the power fluctuation of PV and residential loads. On the other hand, as shown in Figure 4.8(b), it is observed that the exchange of power between PV nano-grid system and main power grid is smoothed when the smoothing function is added. The battery is used to smooth the power fluctuation of PV and residential loads by constantly charging/discharging. The battery does not only take action by following the optimal power command but also smooth the power fluctuation in PV nanogrid system. By comparing the two SOC curves in Figure 4.8(a) and Figure 4.8(b), the battery charges/discharges more frequently when the smoothing function is added, to smooth the effect caused by the power fluctuation in PV nano-grid system.

Energy storage module in the model of PV nano-grid system executes frequency division for the power command from upper EMS. Supercapacitor plays the role of managing the power fluctuation in the seconds level. Battery is managing the power fluctuation in minutes level. As a result, the battery can avoid frequently charging/discharging. 


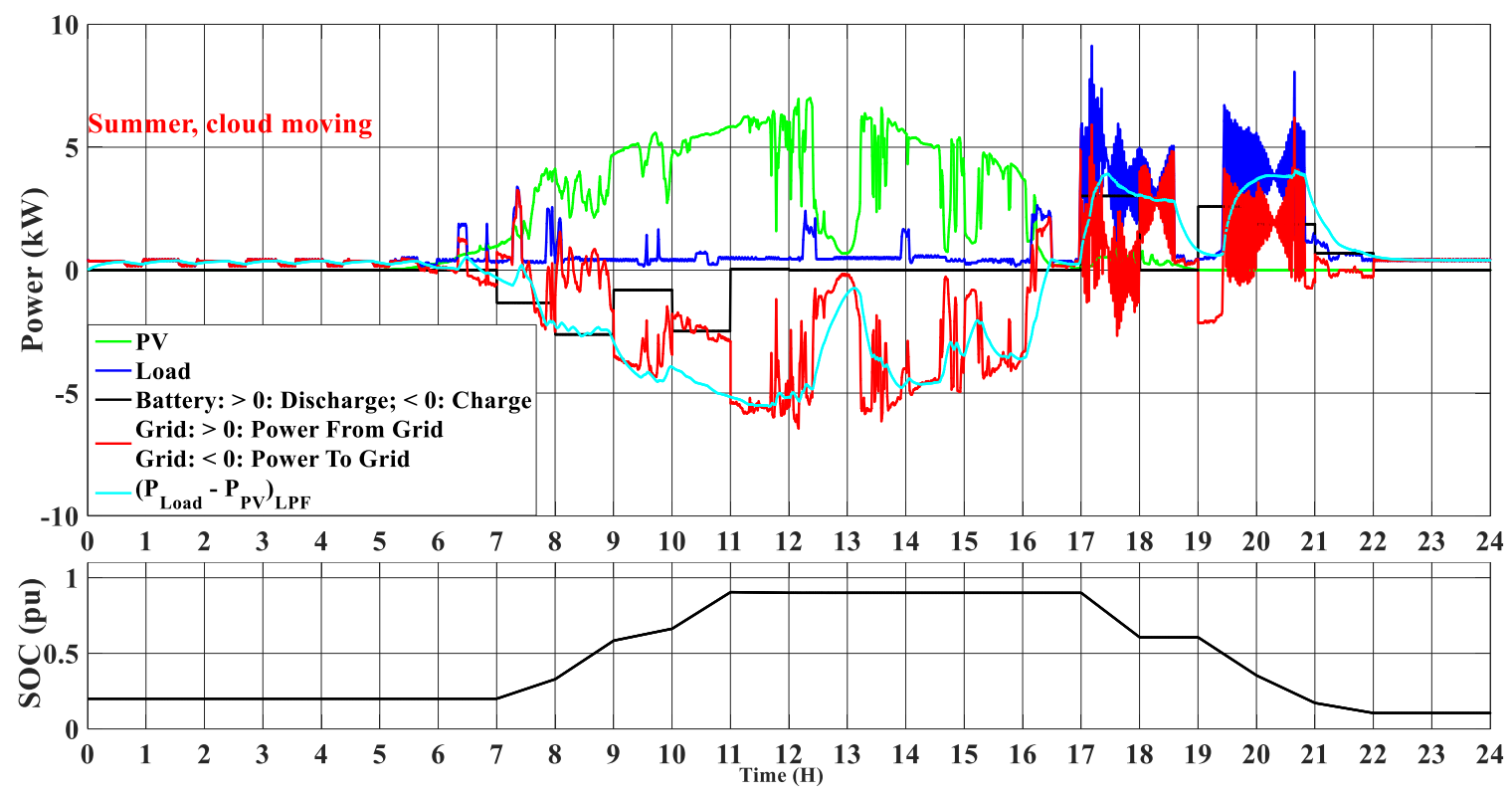

Figure 4.8(a) long-term optimal power scheduling

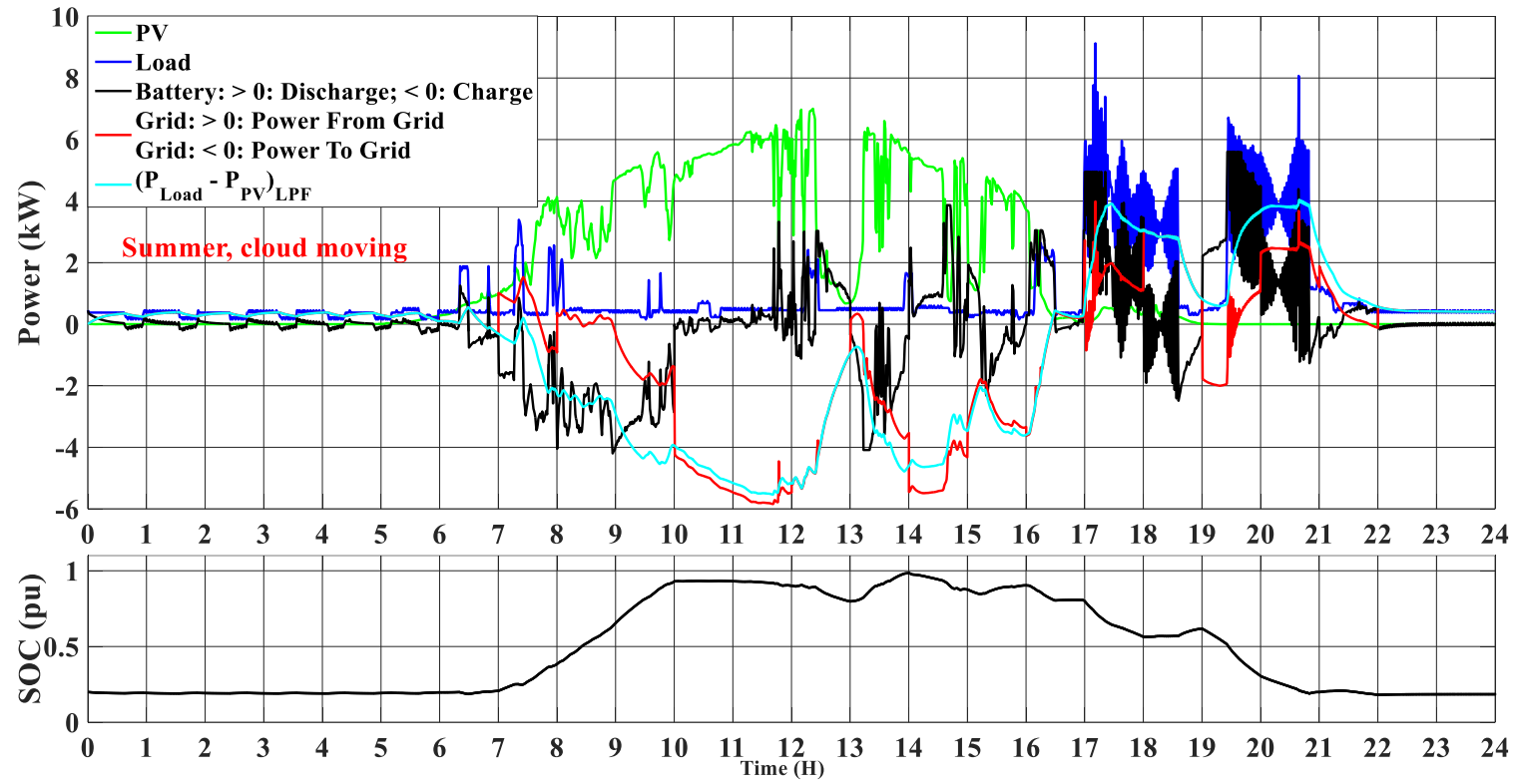

Figure 4.8(b) Combination of long-term optimal power scheduling with the smoothing function

Figure 4.8 Performance comparison

2) Analysis of Different Seasons

Figure 4.9 shows the results of EMS in different seasons, based on historical load data and 
PV power output.

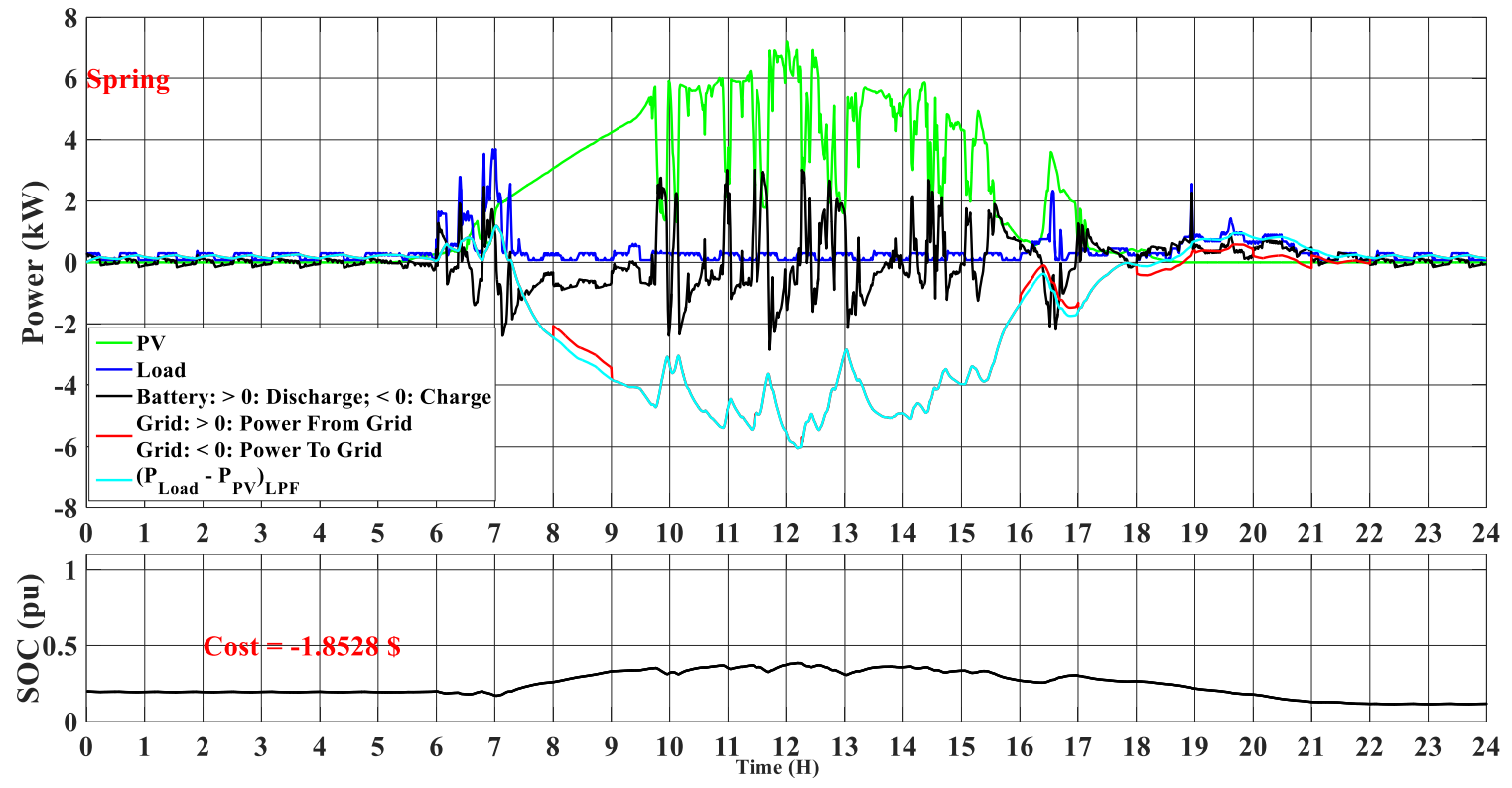

Figure 4.9(a) Spring

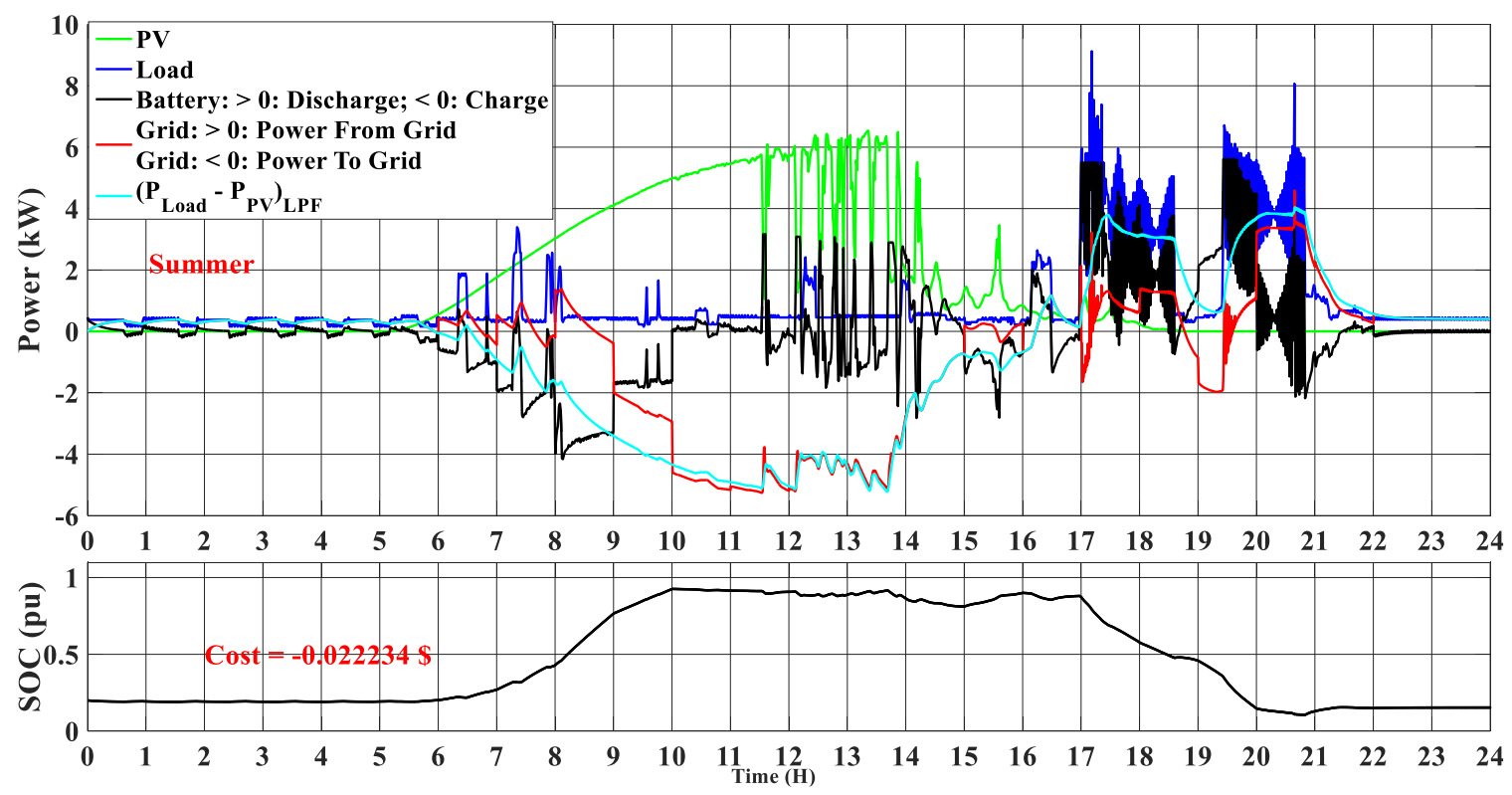

Figure 4.9(b) Summer 


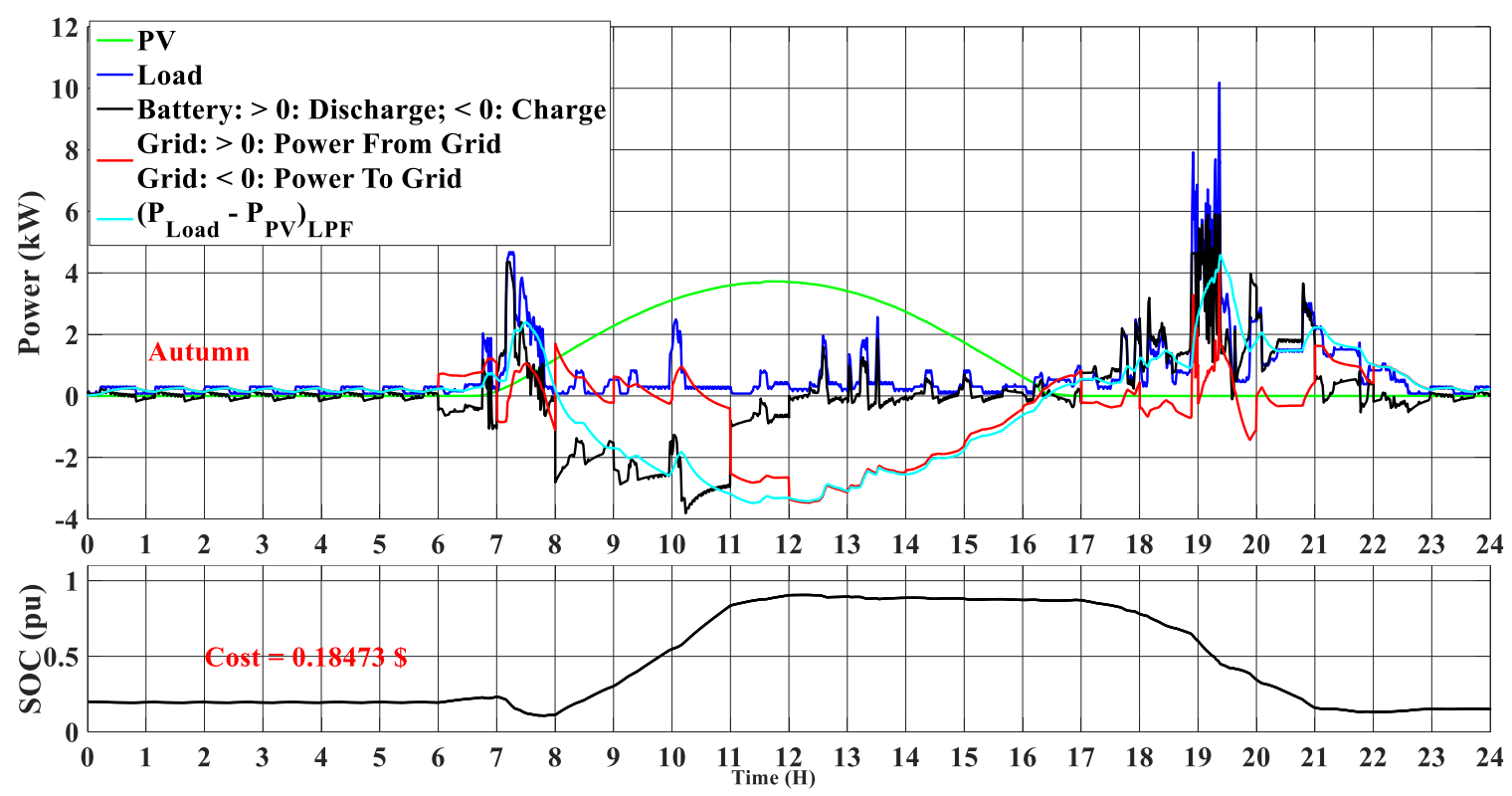

Figure 4.9(c) Autumn

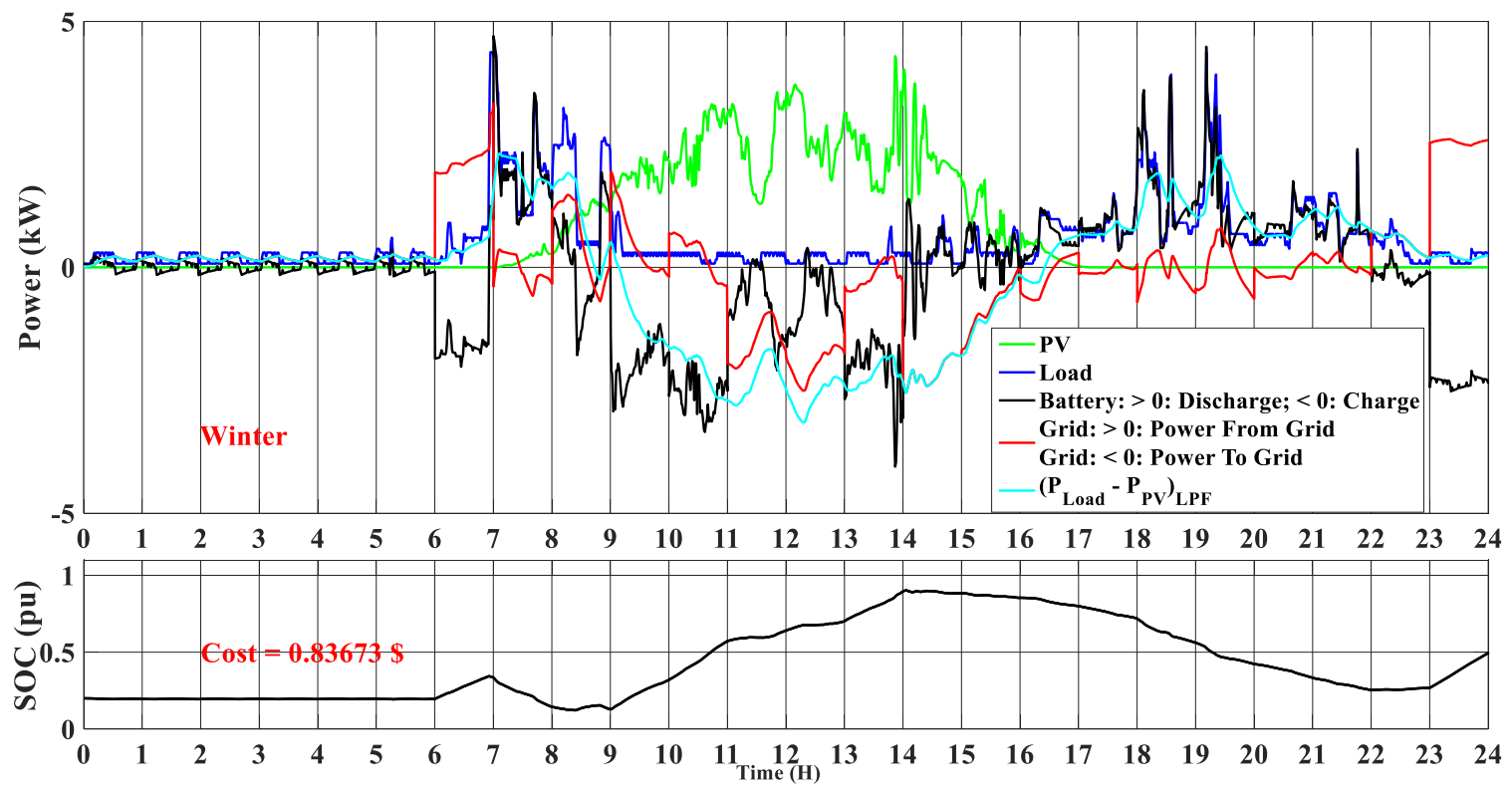

Figure 4.9(d) Winter

Figure 4.9 EMS simulation results of different seasons

As shown in Figure 4.9, the maximum power output of PV in spring and summer is above $6 \mathrm{~kW}$ while the maximum power output in autumn and winter is around $4 \mathrm{~kW}$. For 
residential loads, there are two on-peaks. The first on-peak is in the morning, around 6:00 8:00. The second on-peak is in the evening, around 17:00 21:00. Off-peak is at midnight, which is 22:00 6:00. There is almost no electricity usage demand at this offpeak time.

It can be noted from the battery charging/discharging and SOC curves shown in Figure 4.9, the battery is always charging when the PV power generation is high and electricity demand is low, around 8:00 17:00. SOC keeps increasing. However, when PV power output fluctuates due to weather conditions, the battery alternately charges/discharges to smooth the power fluctuation on the exchanging power between the nano-grid and the main grid. Battery is discharging when there are insufficient PV power generation and high electricity usage demand, around 6:00 8:00 and 17:00 21:00. SOC keeps decreasing. This achieves the peak load shifting for main power grid.

When the demand of residential loads is high, battery can discharge power to satisfy the power demand of residential loads. However, only battery discharging is not enough to satisfy the power demand of residential loads. Thus, power need to be bought from main power grid. When electricity usage demand decreases, the battery discharging can satisfy the power demand of residential loads. If there is still surplus, the power is sold to main power grid as it can be seen in Figure 4.9(b) around 19:00 in summer. Therefore, economic benefit can be made by satisfying the power demand of residential loads.

In terms of economic benefits, PV power output is relatively sufficient around 9:00 16:00 
and power demand of residential loads can be satisfied. Correspondingly, the battery charges to store power and sell back to main power grid. In two on-peaks of electricity usage demand, which are 6:00 8:00 and 17:00 21:00pm, PV power output is insufficient and the battery discharging is not enough to satisfy the power demand of residential loads. Therefore, power needs to be bought from main power grid. As shown in Figure 4.9(d), PV power generation is not very large but electricity usage demand is relatively high in winter. Consequently, it can be indicated that the operational cost of PV nano-grid system in winter is the largest among four seasons, which is $0.83673 \$$ in a day. As it is seen in Figure 4.9(a), PV power generation is large and electricity usage demand is relatively low when it is in spring. It can be observed that the operational cost of PV nano-grid system in spring is the smallest among four seasons, which is $-1.8528 \$$ in a day. In another word, the nano-grid achieves economic benefit in spring.

Due to the utilization of rolling optimization method, PV and load data in the second day can influence the optimization results of the first day. For example, as shown in Figure 4.9(d), the battery is charging ahead at 23:00 24:00 which is low electricity price period. It shows that the rolling optimization method predicts the high electricity usage demand in the second day and then the battery can charge ahead in midnight in order to satisfy the power demand of residential loads in the second day.

\section{3) Analysis of Different Weathers}

In order to analyze the EMS results in different weathers, four typical different weather conditions in summer are simulated. Figure 4.10 shows the EMS simulation results in days 
of four typical weathers in summer. Figure 4.10(a) (d) shows respectively, a sunny day, a cloud moving day, a sunny to cloudy day and a rainy to cloudy day.

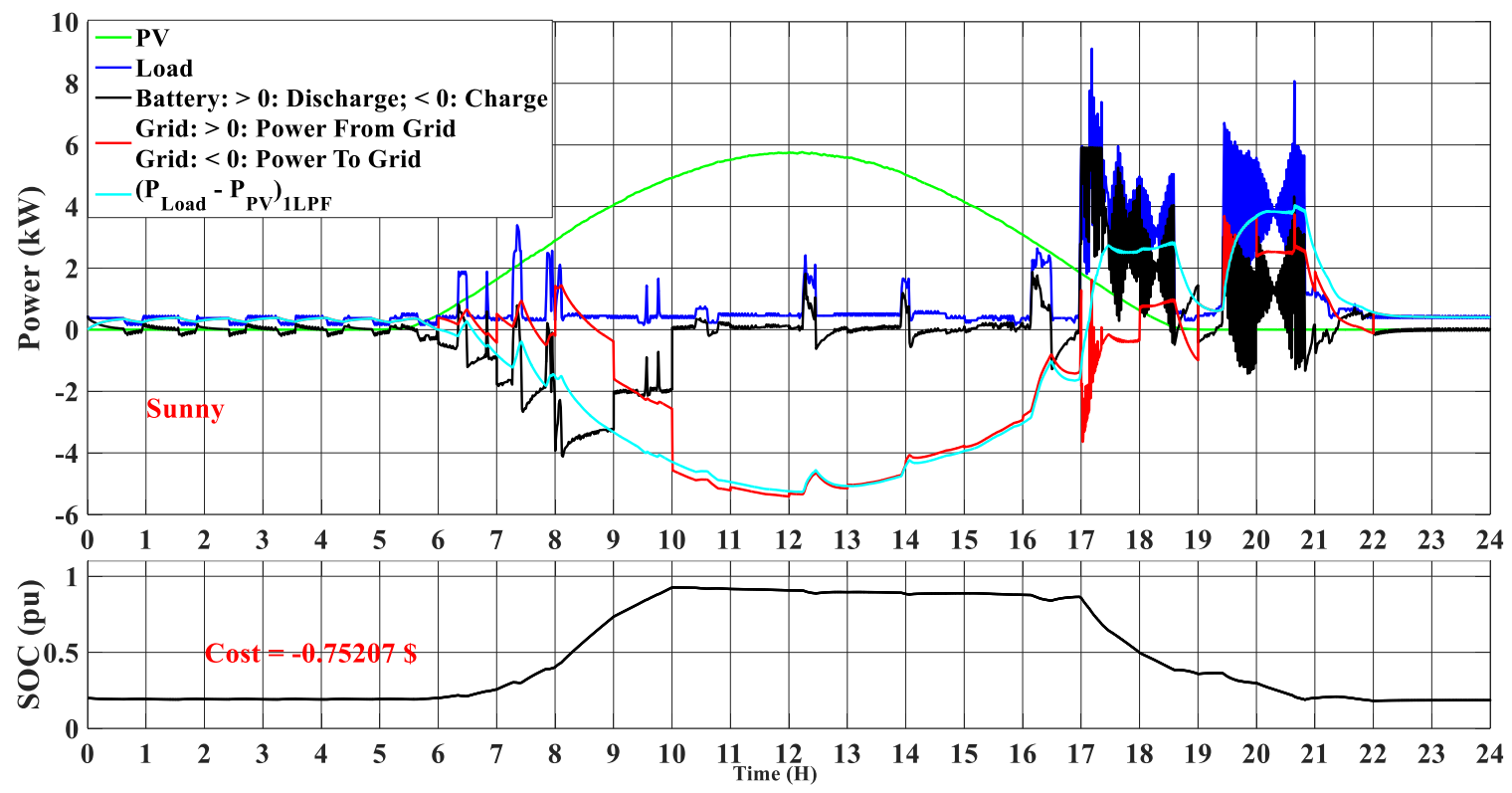

Figure 4.10(a) Sunny day

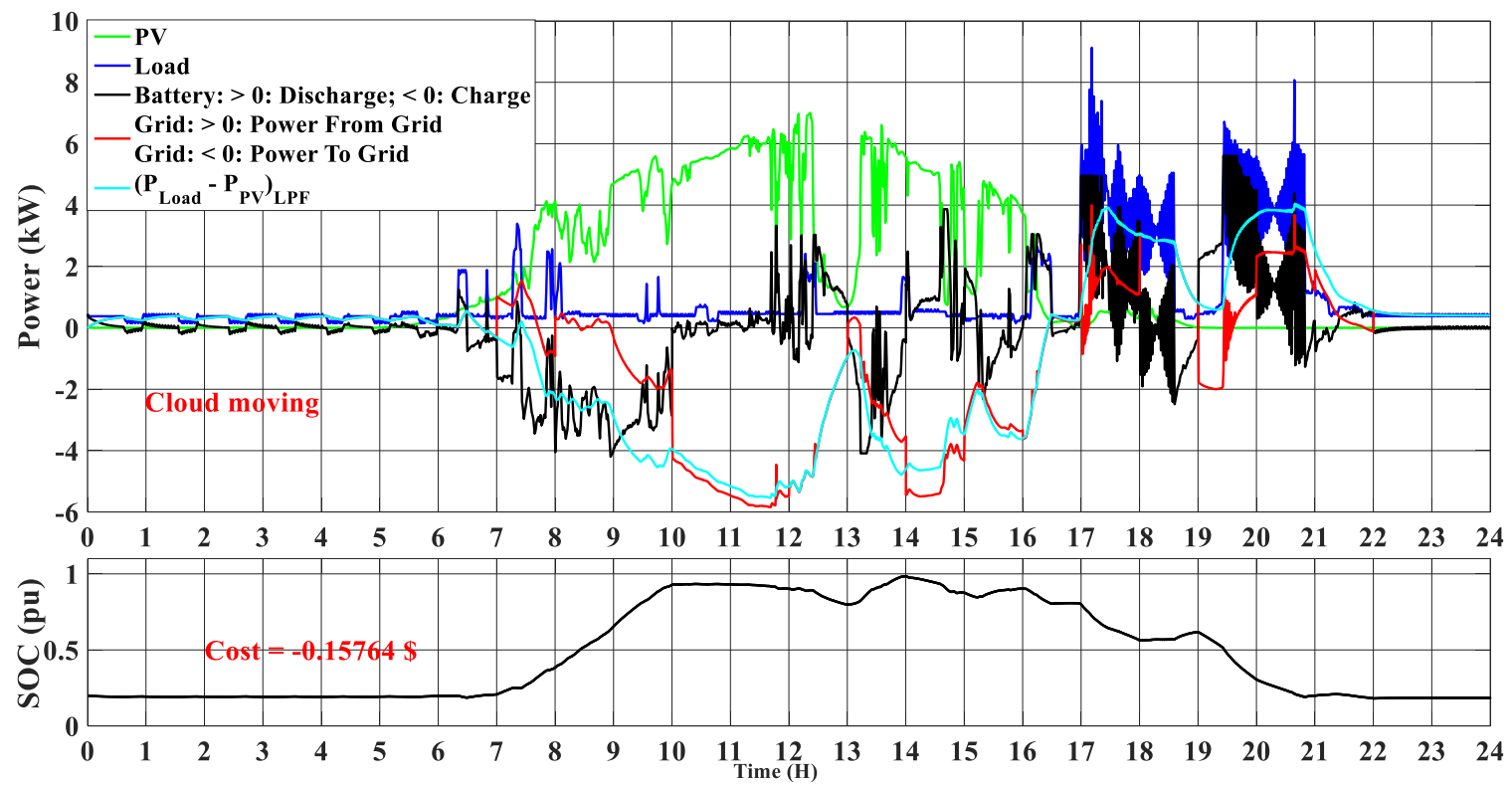

Figure 4.10(b) Cloud moving day 


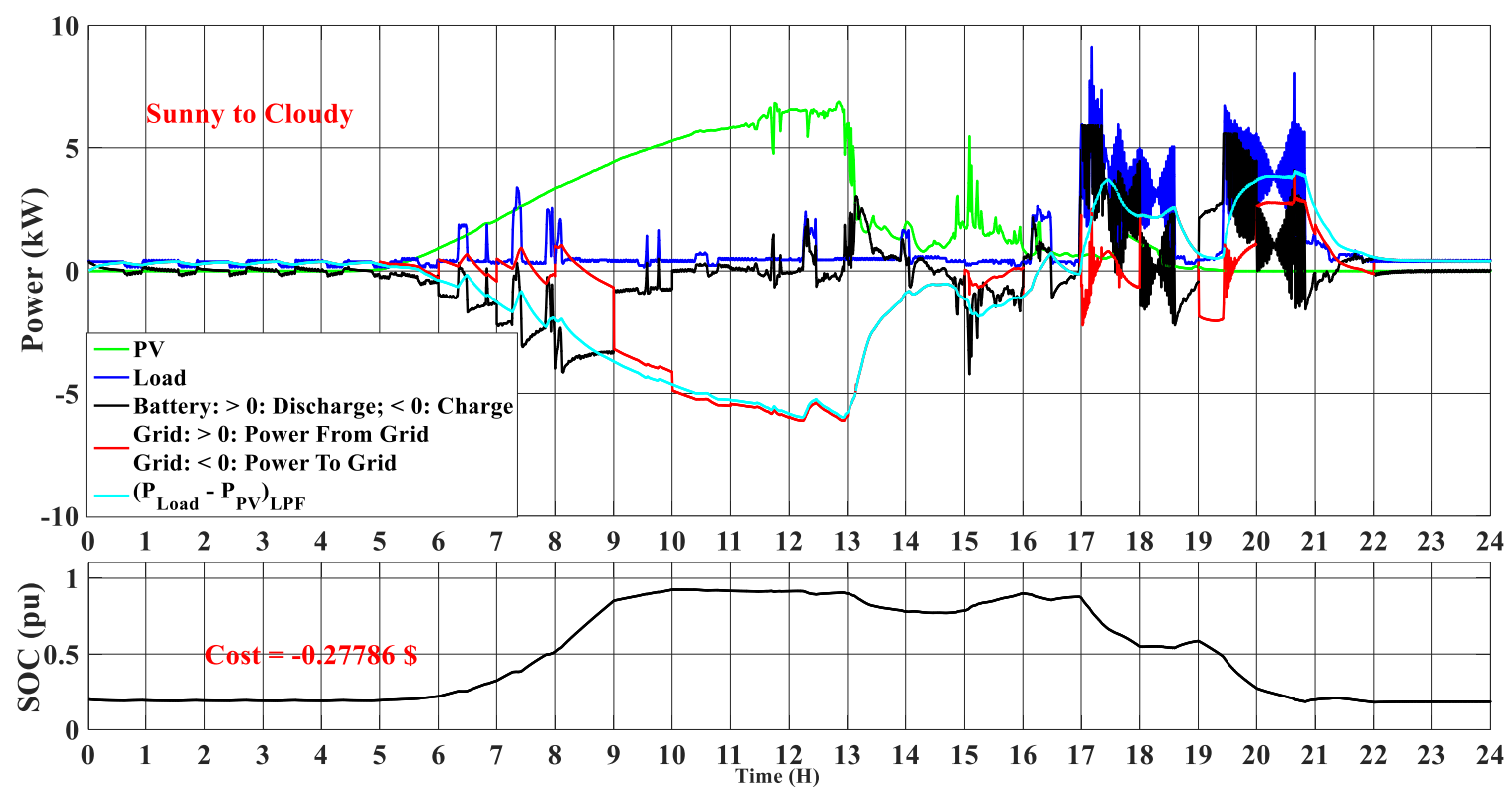

Figure 4.10(c) Sunny to Cloudy day

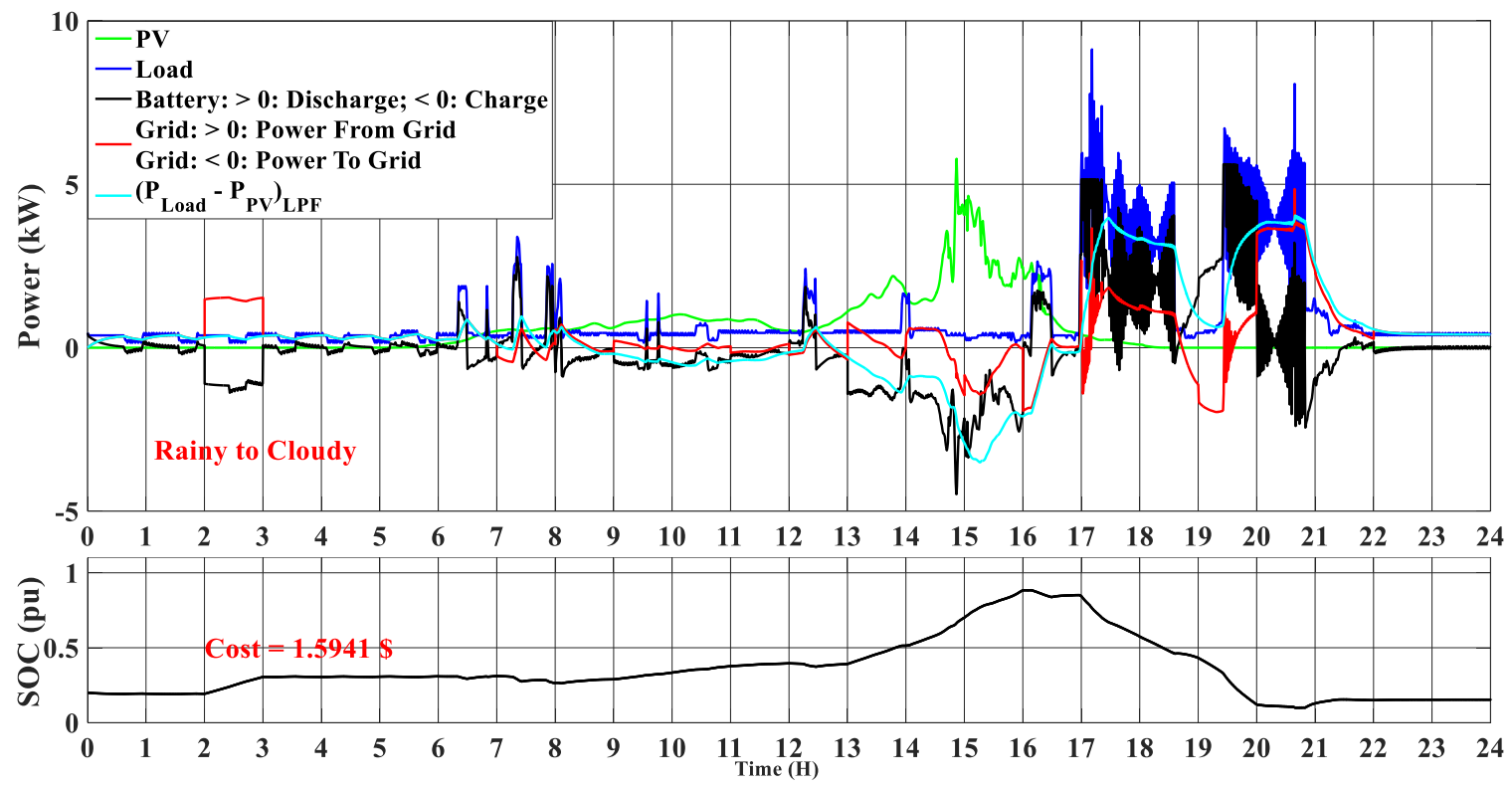

Figure 4.10(d) Rainy to Cloudy day

Figure 4.10 EMS simulation results of four typical weathers

According to Figure 4.10, the level of PV fluctuation and intermittency is different in different weather conditions. This can influence the frequency of battery 
charging/discharging and the smoothing level of the exchanging power. For example, as shown in Figure 4.10(b), PV power fluctuation in cloud moving day is more dramatical compared with other three weather conditions. Therefore, battery charging/discharging is more frequent, which can smooth the power fluctuation of exchanging power in minutes level. For Figure 4.10(c), the power fluctuation of PV is mild before 12:00 due to the sunny weather and battery charging/discharging is thus not frequent. Power fluctuation of exchanging power in minutes level is not very intensive before applying smoothing function. However, the power fluctuation of PV is becoming dramatical after 12:00 due to cloudy weather condition. Battery discharges/charges more frequently than the case in sunny weather after 12:00 shown in Figure 4.10(c).

As shown in Figure 4.10(d), due to the rainy weather before 12:00, there is almost no PV power output. The battery charging/discharging power is very small and the exchanging power is also very small. When the weather changes from rainy to cloudy condition, PV power output increases. Consequently, the battery begins to charge and power is sold to main power grid for achieving economic benefit.

In terms of economic benefit, it is observed from Figure 4.10(a) that the most economic benefit has been achieved at sunny weather compared with other three weathers due to the sufficient and steady PV power generation. The corresponding operational cost of PV nano-grid system is $-0.75207 \$$. As it is shown in Figure 4.10(d), the least economic benefit has been made at rainy to cloudy weather among all four weathers due to the least PV power output. The corresponding operational cost of PV nano-grid system is $1.5941 \$$. 


\subsection{Summary}

This chapter describes the long-term optimal scheduling algorithm for the energy storage system in the PV grid-connected household nano-grid system. For the load prediction, the double exponential smoothing method is used. The rolling optimization method is applied for optimally scheduling the charging/discharging action of the battery in the energy storage system. As the intermittency of PV power output and residential loads, the power fluctuation of the main grid is consequently caused when the PV nano-grid is connected with the grid. A power fluctuation smoothing function is also introduced in this chapter. Simulations prove the proposed methodology based on MATLAB/Simpower. 


\section{Chapter: Conclusions and Future Work}

\subsection{Conclusions}

In this thesis, the scheduling scheme is designed to optimally discharge/charge the energy storage system in a PV grid-connected household nano-grid system. For achieving this objective, the following tasks have been accomplished in the research.

1) The model of PV grid-connected household nano-grid system has been modeled, including PV module, the DC/DC boost converter, battery, supercapacitor and the bi-directional $\mathrm{DC} / \mathrm{DC}$ busk/boost converters, $\mathrm{DC} / \mathrm{AC}$ inverter and related controllers.

2) The long-term optimal scheduling algorithm is designed, which can realize the optimal power scheduling in 24 hours with the utilization of rolling optimization method. A Smoothing function can relieve the power fluctuation of exchanging power between the PV nano-grid and the main grid in minutes level. A load prediction method based on double exponential smoothing method is used. Simulation results of the PV grid-connected household nano-grid under different conditions verify the proposed energy management strategy that can realize the operation with the minimum operational cost and smooth the power fluctuation of the exchanging power between PV grid-connected household nano-grid system and main power grid.

3) Simulation results that the smallest operational cost of the PV nano-grid is achieved 
in spring, while the largest operation cost is achieved in winter. In the end, the PV nano-grid under four different typical weather conditions in summer are investigated including sunny, cloud moving, sunny to cloudy, and rainy to cloudy. The results show that the smallest operation cost of the nano-grid is made in the sunny day, while the largest operational cost is made under a rainy to cloudy weather condition.

The proposed EMS energy management strategy focuses on PV grid-connected household nano-grid system which is single phase grid connection with main power grid in this thesis. For the contribution of the proposed energy management strategy in this thesis, the longterm optimal scheduling achieves the economic operation for PV nano-grid system by optimal battery charging/discharging based on the simulation results of different seasons and different weathers in Figure 4.9 and Figure 4.10. From the simulation result in Figure 4.9 and Figure 4.10, peak load shifting can be successfully achieved so that economic benefit can be made on condition that the power demand of loads is satisfied. Electricity usage of main power grid can be relieved. The simulation results of four different seasons and four different weather conditions in Figure 4.9 and Figure 4.10 show the rationality of the proposed energy management strategy. The feasibility of the proposed energy management strategy can be proven. Furthermore, the proposed smoothing function can smooth the power fluctuation on the exchange of power between PV nano-grid and main power grid to maintain the reliable operation of main power grid based on the simulation comparison in Figure 4.8. From Figure 4.8(b), it can be observed that the exchange of power has been smoothed. Therefore, the economic operation for PV nano-grid and the 
smoothing of the exchanging power between PV nano-grid and main power grid can be achieved at the same time by implementing the proposed energy management strategies in this thesis.

\subsection{Future Work}

In the future research, the following problems need to be considered:

1) The long-term optimal scheduling is based on the PV and residential loads historical data to realize the rolling optimization method in this thesis. To predict PV power, it is necessary to build PV power output probability model and prediction model which are both required for an accurate prediction. To predict the load, the double exponential smoothing method cannot satisfy the high accuracy requirement of predicting residential loads. More accurate load prediction methods should be explored.

2) For the smoothing function, the low pass filter using in closed loop control can be replaced with the MPC. The MPC can realize the real-time modification for the predicted model. The power fluctuation of $\mathrm{PV}$ and residential loads in minutes level can be smoothed. Main power grid will not be influenced by the dramatic fluctuating exchanging power between PV nano-grid system and main power grid. However, with the utilization of low pass filter, time delay will be caused. MPC can effectively solve this problem. 
3) The EMS in the PV nano-grid system is only focused on grid-connected operation mode in this thesis. Off-grid operation mode and the smoothing transition between grid-connected and off-grid operation mode are not considered, which needs to be investigated in the future. 


\section{References}

[1] L. Xu and D. Chen, "Control and Operation of a DC Microgrid With Variable Generation and Energy Storage," IEEE Transactions on Power Delivery, vol. 26, no. 4, pp. $2513-2522,2011$.

[2] K. Wu, S. Shih and X. Kong, "Economic asset management of microgrids," in Region 10 Conference, TENCON 2017 - 2017 IEEE, Penang, Malaysia, 2017.

[3] A. Malkawi and L. A. C. Lopes, "Control of the power electronics interface of a PV source in a smart residential DC nanogrid," in 2016 IEEE Canadian Conference on Electrical and Computer Engineering (CCECE), Vancouver, BC, 2016, pp. 1-4, Vancouver, BC, Canada, 2016.

[4] D. Herman, "Investigation of the technical and economic feasibility of micro-gridbased power systems," Electric Power Research Institute, Palo Alto, CA, 2001.

[5] Y. Huang, S. Mao and R. M. Nelms, "Adaptive electricity scheduling in microgrids," in INFOCOM, 2013 Proceedings IEEE, Turin, Italy, 2013.

[6] K. Rahbar, C. C. Chai and R. Zhang, "Energy Cooperation Optimization in Microgrids With Renewable Energy Integration," IEEE Transactions on Smart Grid, vol. 9, no. 2, pp. 1482 - 1493, 2016.

[7] B. Young, N. Ertugrul and H. G. Chew, "Overview of optimal energy management for nanogrids (end-users with renewables and storage)," in Power Engineering Conference (AUPEC), 2016 Australasian Universities, Brisbane, QLD, Australia, 2016. 
[8] M. Rezwan Khan and E. D. Brown, "DC nanogrids: A low cost PV based solution for livelihood enhancement for rural Bangladesh," in Developments in Renewable Energy Technology (ICDRET), 2014 3rd International Conference on the, Dhaka, Bangladesh, 2014.

[9] "IDCL(Infrastructure Development Company Limited) website," Infrastructure Development Company Limited, [Online]. Available: www.idcol.org. [Accessed 12 August 2017].

[10] N. Gudi, L. Wang, V. Devabhaktuni and S. S. S. R. Depuru, "A demand-side management simulation platform incorporating optimal management of distributed renewable resources," in Power Systems Conference and Exposition (PSCE), 2011 IEEE/PES, Phoenix, AZ, USA, 2011.

[11] I. Atzeni, L. G. Ordóñez, G. Scutari, D. P. Palomar and J. R. Fonollosa, "DemandSide Management via Distributed Energy Generation and Storage Optimization," IEEE Transactions on Smart Grid, vol. 4, no. 2, pp. 866 - 876, 2012.

[12] J. Byun, I. Hong and S. Park, "Intelligent cloud home energy management system using household appliance priority based scheduling based on prediction of renewable energy capability," IEEE Transactions on Consumer Electronics, vol. 58, no. $4,2012$.

[13] Z. Chen, L. Wu and Y. Fu, "Real-Time Price-Based Demand Response Management for Residential Appliances via Stochastic Optimization and Robust Optimization," IEEE Transactions on Smart Grid, vol. 3, no. 4, pp. 1822 - 1831, 2012.

[14] N. Liu, Q. Chen, J. Liu, X. Liu, P. Li, J. Lei and J. Zhang, "A Heuristic Operation 
Strategy for Commercial Building Microgrids Containing EVs and PV System," IEEE Transactions on Industrial Electronics, vol. 62, no. 4, pp. 2560 - 2570, 2014.

[15] Adminstration, U.S. Energy Information, "Annual Energy Outlook 2013," Annual Energy Outlook 2013, Washington, DC, 2013.

[16] K. S. Cetin, P. C. Tabares-Velasco and A. Novoselac, "Appliance daily energy use in new residential buildings: Use profiles and variation in time-of-use," Energy and Buildings, vol. 84, pp. 716-726, 2014.

[17] Adminstration, U.S. Energy Information, "Residential Energy Consumption Survey (RECS)," U.S. Energy Information Administration, 2009. [Online]. Available: https://www.eia.gov/consumption/residential/data/2009/. [Accessed 18 September 2017].

[18] S. Teleke, L. Oehlerking and M. Hong, "Nanogrids with energy storage for future electricity grids," in T\&D Conference and Exposition, 2014 IEEE PES, Chicago, IL, USA, 2014.

[19] W. Su and J. Wang, "Energy Management Systems in Microgrid Operations," The Electricity Journal, vol. 25, no. 8, pp. 45-60, 2012.

[20] J. Jimeno, J. Auduaga, J. Oyarzabal and A. Muro, "Architecture of a microgrid energy management system," European Transactions on Electrical Power, vol. 21, no. 2, pp. 1142-1158, 2011.

[21] F. Katiraei, R. Iravani, N. Hatziargyriou and A. Dimeas, "Micro-grids management," IEEE Power and Energy Magazine, 2008.

[22] A. G. Tsikalakis and N. D. Hatziargyriou, "Centralized control for optimizing 
microgrids operation," in Power and Energy Society General Meeting, 2011 IEEE, Detroit, MI, USA, USA, 2011.

[23] The SGMM Team, "SGMM Model Definition," Software Engineering Institute, Carnegie Mellon University, Pittsburgh, PA, USA, 2011.

[24] A. Werth, N. Kitamura and K. Tanaka, "Conceptual Study for Open Energy Systems: Distributed Energy Network Using Interconnected DC Nanogrids," IEEE Transactions on Smart Grid, vol. 6, no. 4, pp. 1621-1630, 2015.

[25] N. A. Lidula and A. D. Rajapakse, "Microgrids research: A review of experimental microgrids and test systems," Renewable and Sustainable Energy Reviews, vol. 15, no. 1, pp. 186-202, 2011.

[26] R. H. Lasseter, "CERTS Microgrid Laboratory Test Bed," IEEE Transactions on Power Delivery, vol. 26, no. 1, pp. 325-332, 2010.

[27] R. Bayindir, E. Bekiroglu, E. Hossain and E. Kabalci, "Microgrid facility at European union," in Renewable Energy Research and Application (ICRERA), 2014 International Conference on, Milwaukee, WI, USA, 2014.

[28] M. Barnes, A. Dimeas, A. Engler, C. Fitzer, N. Hatziargyriou and C. Jones, "Microgrid laboratory facilities," in Future Power Systems, 2005 International Conference on, Amsterdam, Netherlands, 2005.

[29] S. Cobben, "Bronsbergen: The first Micro-grid in the Netherlands," in Proceedings of the Kythnos 2008 Symposium on Microgrids, Loutra, Kythnos Island, Greece, 2008.

[30] Y. Kojima, M. Koshio, S. Nakamura, H. Maejima, Y. Fujioka and T. Goda,, "A 
Demonstration Project in Hachinohe: Microgrid with Private Distribution Line," in System of Systems Engineering, 2007. SoSE '07. IEEE International Conference on, San Antonio, TX, USA, 2007.

[31] E. J. Coster, J. A. Myrzik, B. Kruimer and W. L. Kling, "Integration Issues of Distributed Generation in Distribution Grids," Proceedings of the IEEE, vol. 99, no. 1, pp. 28-39, 2011.

[32] E. Perez, H. Beltran, N. Aparicio and P. Rodriguez, "Predictive Power Control for PV Plants With Energy Storage," IEEE Transactions on Sustainable Energy, vol. 4, no. 2, pp. 482-490, 2013.

[33] M. Moghimi, D. Leskarac, C. Bennett, J. Lu and S. Stegen, "Rule-based Energy Management System in an Experimental Microgrid with the Presence of Time of Use Tariffs," MATEC Web of Conferences, vol. 70, 2016.

[34] D. S. Kirschen, "Demand-side view of electricity markets," IEEE Transactions on Power Systems, vol. 18, no. 2, pp. 520-527, 2003.

[35] A. I. Dounis and C. Caraiscos, "Advanced control systems engineering for energy and comfort management in a building environment-A review," Renewable and Sustainable Energy Reviews, vol. 13, no. 6-7, pp. 1246-1261, 2009.

[36] Z. Darabi and M. Ferdowsi, "Aggregated Impact of Plug-in Hybrid Electric Vehicles on Electricity Demand Profile," IEEE Transactions on Sustainable Energy, vol. 2, no. 4, pp. 501-508, 2011.

[37] N. Lu, "An Evaluation of the HVAC Load Potential for Providing Load Balancing Service," IEEE Transactions on Smart Grid, vol. 3, no. 3, pp. 1263-1270, 2012. 
[38] Y. H. Lin and M. S. Tsai, "An Advanced Home Energy Management System Facilitated by Nonintrusive Load Monitoring With Automated Multiobjective Power Scheduling," IEEE Transactions on Smart Grid, vol. 6, no. 4, pp. 1839-1851, 2015.

[39] J. Wang, R. Ran and Y. Zhou, "A Short-Term Photovoltaic Power Prediction Model Based on an FOS-ELM Algorithm," applied sciences, vol. 7, no. 4, 2017.

[40] Z. Zhao, W. C. Lee, Y. Shin and K. B. Song, "An Optimal Power Scheduling Method for Demand Response in Home Energy Management System," IEEE Transactions on Smart Grid, vol. 4, no. 3, pp. 1391-1400, 2013.

[41] Q. Jiang, M. Xue and G. Geng, "Energy Management of Microgrid in GridConnected and Stand-Alone Modes," IEEE Transactions on Power Systems, vol. 28, no. 3, pp. 3380-3389, 2013.

[42] X. Li, G. Geng and Q. Jiang, "A hierarchical energy management strategy for gridconnected microgrid," in PES General Meeting | Conference \& Exposition, 2014 IEEE, National Harbor, MD, USA, 2014.

[43] A. Anvari-Moghaddam, H. Monsef and A. Rahimi-Kian, "Optimal Smart Home Energy Management Considering Energy Saving and a Comfortable Lifestyle," IEEE Transactions on Smart Grid, vol. 6, no. 1, pp. 324-332, 2015.

[44] A. Chaouachi, R. M. Kamel, R. Andoulsi and K. Nagasaka, "Multiobjective Intelligent Energy Management for a Microgrid," IEEE Transactions on Industrial Electronics, vol. 60, no. 4, pp. 1688-1699, 2013.

[45] F. A. Mohamed and H. N. Koivo, "Online management genetic algorithms of microgrid for residential application," Energy Conversion and Management, vol. 64, 
pp. 562-568, 2012.

[46] A. K. Basu, A. Bhattacharya, S. Chowdhury and S. P. Chowdhury, "Planned Scheduling for Economic Power Sharing in a CHP-Based Micro-Grid," IEEE Transactions on Power Systems, vol. 27, no. 1, pp. 30-38, 2012.

[47] P. Harsha and M. Dahleh, "Optimal Management and Sizing of Energy Storage Under Dynamic Pricing for the Efficient Integration of Renewable Energy," IEEE Transactions on Power Systems, vol. 30, no. 3, pp. 1164-1181, 2015.

[48] E. Matallanas, M. Castillo-Cagigal, A. Gutiérrez, F. Monasterio-Huelin, E. Caamaño-Martín, D. Masa and J. Jiménez-Leube, "Neural network controller for Active Demand-Side Management with PV energy in the residential sector," Applied Energy, vol. 91, no. 1, pp. 90-97, 2012.

[49] K. Rahbar, J. Xu and R. Zhang, "Real-Time Energy Storage Management for Renewable Integration in Microgrid: An Off-Line Optimization Approach," IEEE Transactions on Smart Grid, vol. 6, no. 1, pp. 124-134, 2015.

[50] Y. Zong, D. Kullmann, A. Thavlov, O. Gehrke and H. Bindner, "Application of model predictive control for active load management in a distributed power system with high wind penetration," IEEE Trans. Smart Grid, vol. 3, no. 2, pp. 1055-1062, 2012.

[51] J. D. Foster, A. M. Berry, A. Boland and H. Waterer, "Comparison of Mixed-Integer Programming and Genetic Algorithm Methods for Distributed Generation Planning," IEEE Transactions on Power Systems, vol. 29, no. 2, pp. 833-843, 2014.

[52] Y. Wang, X. Lin and M. Pedram, "Adaptive control for energy storage systems in 
households with photovoltaic modules," IEEE Transactions on Smart Grid 5.2, vol. 5, no. 2, pp. 992-1001, March 2014.

[53] "929-2000-IEEE Recommended Practice for Utility Interface of Photovoltaic(PV) Systems," IEEE Standard, 2000.

[54] N. Saldanha and I. Beausoleil-Morrison, "Measured end-use electric load profiles for 12 Canadian houses at high temporal resolution," Energy and Buildings, vol. 49, pp. 519-530, June 2012.

[55] H. Ottawa, "Accounts \& Billing > Residential > Rates and Conditions," Hydro Ottawa, [Online]. Available: https://hydroottawa.com/accounts-andbilling/residential/rates-and-conditions. [Accessed 1012 2017].

[56] National Renewable Energy Laboratory, [Online]. Available: https://www.nrel.gov/mide/srrl_bms/. [Accessed 08 October 2017]. 